\title{
089 @ist
}

\section{THE STATUS AND DISTRIBUTION OF FRESHWATER BIODIVERSITY IN MADAGASCAR AND THE INDIAN OCEAN ISLANDS HOTSPOT}

Edited by Laura Máiz-Tomé, Catherine Sayer and William Darwall IUCN Freshwater Biodiversity Unit, Global Species Programme

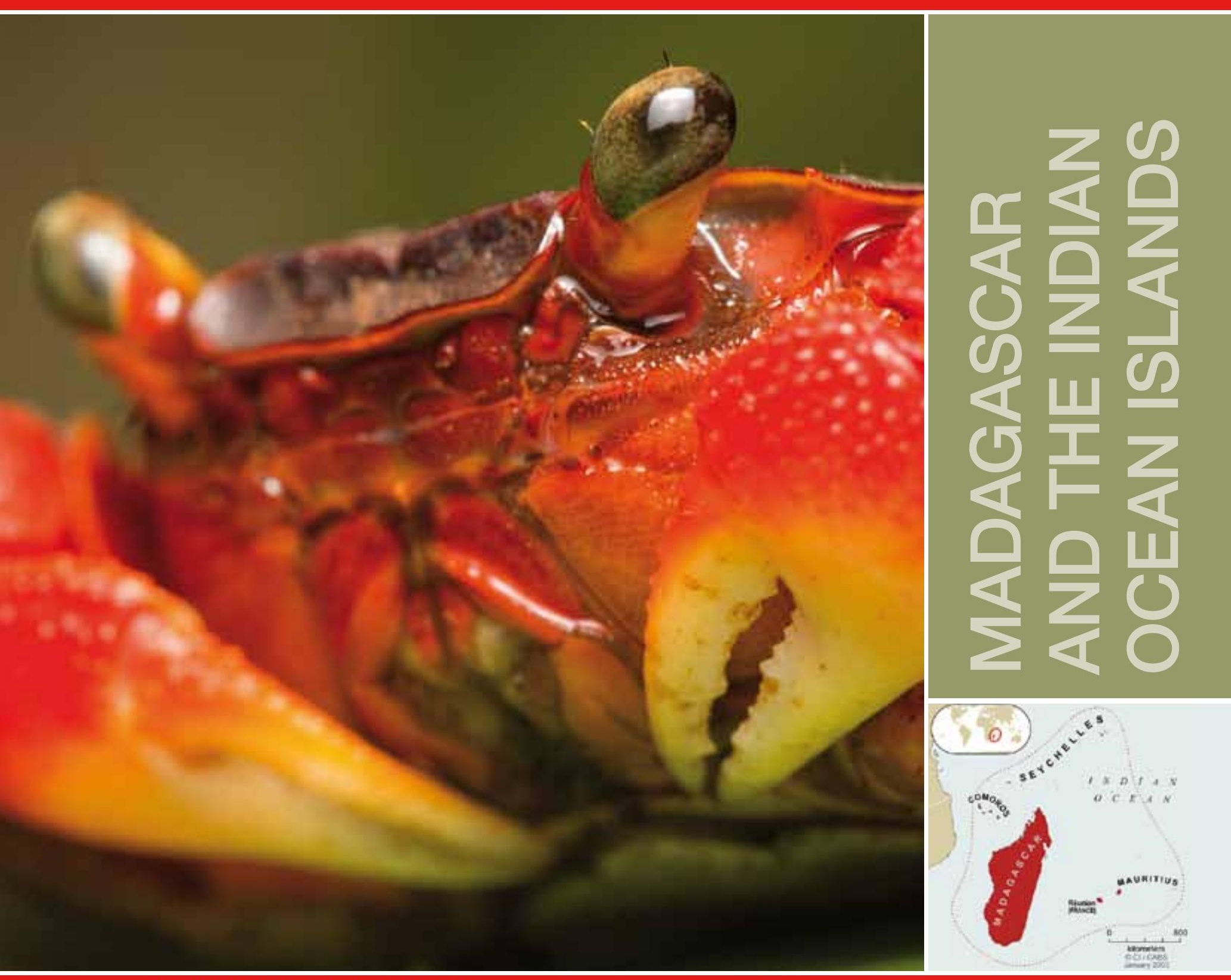

The IUCN Red List of Threatened Species ${ }^{\mathrm{TM}}$

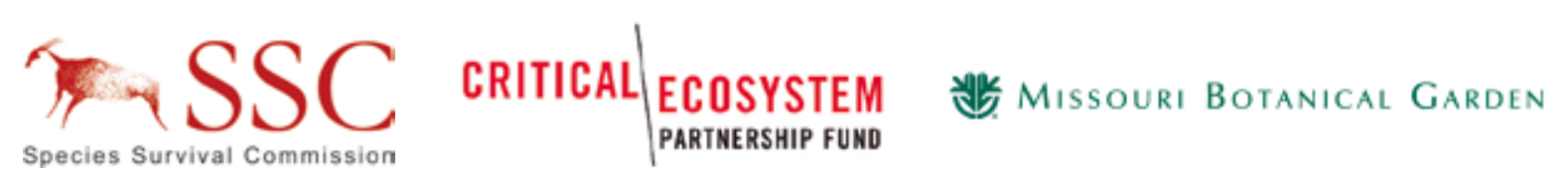





\section{THE STATUS AND DISTRIBUTION OF FRESHWATER BIODIVERSITY IN MADAGASCAR AND THE INDIAN OCEAN ISLANDS HOTSPOT}

Edited by Laura Máiz-Tomé, Catherine Sayer and William Darwall

IUCN Freshwater Biodiversity Unit, Global Species Programme 
The designation of geographical entities in this book, and the presentation of the material, do not imply the expression of any opinion whatsoever on the part of IUCN concerning the legal status of any country, territory, or area, or of its authorities, or concerning the delimitation of its frontiers or boundaries.

The views expressed in this publication do not necessarily reflect those of IUCN, or other participating organisations.

This publication has been made possible by funding from The Critical Ecosystem Partnership Fund.

Published by: $\quad$ IUCN Cambridge, UK in collaboration with IUCN Gland, Switzerland

Copyright: $\quad$ C 2018 IUCN, International Union for Conservation of Nature and Natural Resources

Reproduction of this publication for educational or other non-commercial purposes is authorised without prior written permission from the copyright holder provided the source is fully acknowledged.

Reproduction of this publication for resale or other commercial purposes is prohibited without prior written permission of the copyright holder.

Citation: $\quad$ Máiz-Tomé, L., Sayer, C. and Darwall, W. (eds) (2018). The status and distribution of freshwater biodiversity in Madagascar and the Indian Ocean islands hotspot. Gland, Switzerland: IUCN. viii+128pp.

ISBN:

978-2-8317-1881-1 (print version)

978-2-8317-1882-8 (PDF)

DOI:

10.2305/IUCN.CH.2018.RA.1.en

Cover photo:

Malagasya antongilensis. () Rob Schell Photography

All the photographs used in this publication remain the property of the original copyright holder (see individual captions for details). Photographs should not be reproduced or used in other contexts without written permission from the copyright holder.

Layout by: $\quad$ NatureBureau https://www.naturebureau.co.uk/

Printed by: $\quad$ Langham Press Ltd

The text of this book is printed on Cocoon FSC 50\% Recycled Silk $115 \mathrm{gsm}$.

Available from:

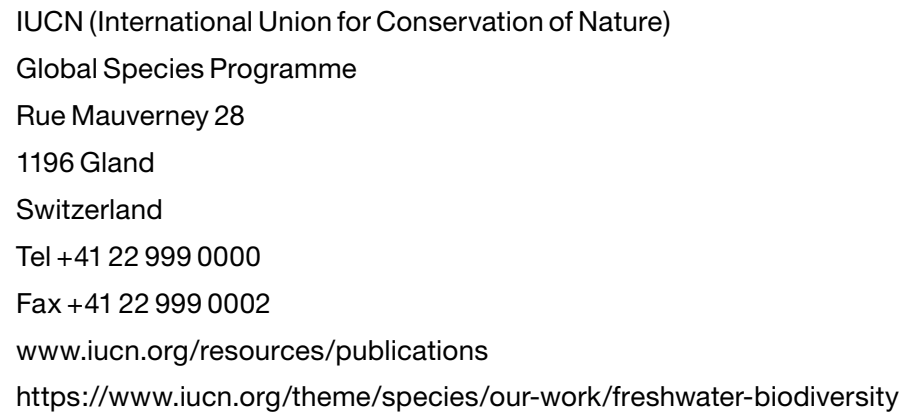

If you have any questions regarding the data and outputs presented in this report, please contact the IUCN Freshwater Biodiversity Unit (Freshwater.Biodiversity@iucn.org). 


\section{Contents}

Acknowledgements ....................................................

Executive summary .................................................... vi

Chapter 1 Madagascar and the Indian Ocean islands biodiversity hotspot

1.1 Situation analysis

1.1.1 The value of freshwater wetlands and their biodiversity.

1.1.2 Main threats to freshwater species......................1

1.2 Objectives of this study ..........................................

1.3 Project components...................................................... 3

1.4 Freshwater species as indicators ................................ 3

1.5 Madagascar freshwater ecoregions............................ 3

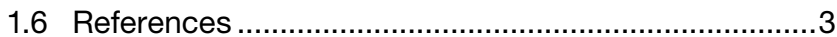

Chapter 2 Red List assessment methodology.............. 7

2.1 Selection of priority taxa........................................... 7

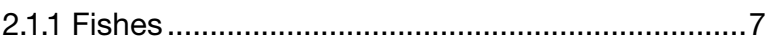

2.1.2 Molluscs............................................................. 7

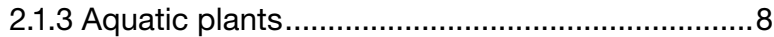

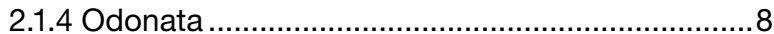

2.1.5 Decapods (crabs, crayfishes and shrimps) .........8

2.2 Data collection and quality control............................. 8

2.3 Species mapping ...................................................... 8

2.4 Assessment of species threatened status ...................9

2.5 References ................................................................ 10

\section{PART 1 SPECIES OF IMPORTANCE FOR CONSERVATION}

\section{Chapter 3 The status and distribution of freshwater fishes}

3.1 Overview of the ichthyofauna of Madagascar and the Indian Ocean islands hotspot.

3.2 Patterns of overall species richness

3.3 Conservation status

3.3.1 Threatened species

3.3.2 Data Deficient species.

3.3.3 Red List Index....

3.4 Main threats

3.5 Conservation recommendations

3.6 Research actions

3.7 Species in the spotlight

3.8 References.

Annex 3.1 Red List status of freshwater fishes
Chapter 4 The status and distribution of freshwater molluscs

4.1 Overview of freshwater molluscs of Madagascar and the Indian Ocean islands hotspot ......................29

4.2 Patterns of overall species richness.......................... 31

4.3 Conservation status ....................................................33

4.3.1 Threatened species...........................................34

4.3.2 Data Deficient species.......................................36

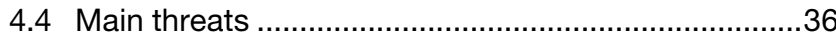

4.5 Conservation recommendations ...............................37

4.6 Research actions ....................................................39

4.7 Species in the spotlight ........................................38

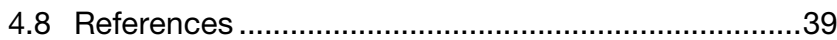

Annex 4.1 Red List status of freshwater molluscs ............. 41

Chapter 5 The status and distribution of freshwater decapod crustaceans

5.1 Overview of freshwater decapods of Madagascar and the Indian Ocean islands hotspot .......................42

5.2 Patterns of overall species richness .........................42

5.2.1 Freshwater crabs.............................................. 42

5.2.2 Freshwater crayfish.......................................... 45

5.2.3 Freshwater shrimps ........................................ 47

5.3 Conservation status ................................................. 47

5.3.1 Threatened species.......................................... 47

5.3.2 Data Deficient species.......................................49

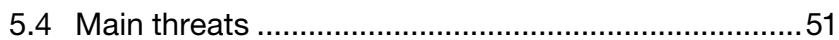

5.5 Conservation recommendations ................................53

5.6 Research actions .....................................................54

5.7 Species in the spotlight .............................................

5.8 References ............................................................55

Annex 5.1 Red List Status of freshwater crabs...................58 Annex 5.2 Red List Status of freshwater crayfish...............58 Annex 5.3 Red List Status of freshwater shrimps...............58

\section{Chapter 6 The status and distribution of} aquatic plants ..............................................................59

6.1 Overview of aquatic plants of Madagascar................59

6.2 Patterns of overall species richness..........................60

6.3 Conservation status ....................................................61

6.3.1 Threatened species...........................................63

6.3.2 Data Deficient species.......................................64

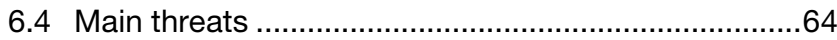

6.5 Conservation recommendations ..............................68

6.6 Research actions ..................................................68

6.7 References ........................................................69 
Annex 6.1 Family name inconsistencies between the IUCN Red List website and the APG IV system relevant for the Madagascar aquatic plant dataset .....71

Annex 6.2 Fern families that include aquatic species for Madagascar......

Annex 6.3 Seed-plant families that comprise only aquatic species in Madagascar. . .71

Annex 6.4 Seed-plant families comprising aquatic and terrestrial species in Madagascar

Annex 6.5 Number of species in lentic habitats in Madagascar... .72

Annex 6.6 Summary of Red List assessment results.........72

Annex 6.7 Red List status of Madagascar aquatic plants .73

Chapter 7 The status and distribution of Odonata ......75

7.1 Overview of the Odonata of Madagascar and the Indian Ocean islands hotspot. . .75

7.2 Patterns of overall species richness .........................76

7.3 Conservation status.................................................. 78

7.3.1 Threatened species ........................................ 78

7.3.2 Data Deficient species ...................................... 79

7.4 Main threats ....................................................... 79

7.5 Conservation recommendations ...............................83

7.6 Research actions .................................................. 84

7.7 Species in the spotlight ..........................................84

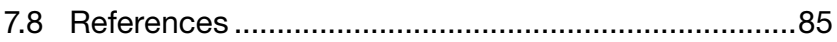

Annex 7.1 Red List status of Odonata ...............................87

Chapter 8 Synthesis for all taxa ................................ 89

8.1 Introduction ............................................................. 89

8.2 Freshwater biodiversity across Madagascar and the Indian Ocean islands hotspot.....................................89

8.2.1 Patterns of species richness.............................89

8.2.2 Threatened species .......................................... 91

8.2.3 Data Deficient species......................................91

8.3 Main threats ...............................................................94

8.4 Conservation priorities and recommendations .........95 8.4.1 Integrated River Basin Management (IRBM) ....95

8.4.2 Securing environmental flows ............................95

8.4.3 Site protection...................................................96

8.4.4 Environmental Impact Assessments.................96

8.4.5 Enforcement of existing legislation and government awareness. .96

8.5 References 96

\section{PART 2 SITES OF IMPORTANCE FOR FRESHWATER SPECIES}

Chapter 9 Freshwater Key Biodiversity Areas

in Madagascar .............................................................98

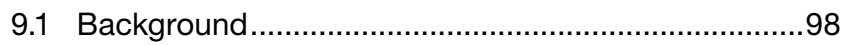

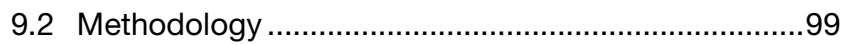

9.2.1 KBA criteria and thresholds ..............................99

9.2.2 Freshwater KBA delineation process ................99

9.3 Results.................................................................... 103

9.3.1 Freshwater KBA trigger species .....................103

9.3.2 Freshwater KBAs overview............................103

9.3.3 Current levels of protection .............................104

9.3.4 Newly delineated KBAs ...................................104

9.4 Site champions ..................................................... 106

9.5 Summary and recommendations............................106

9.6 Next steps ..........................................................108

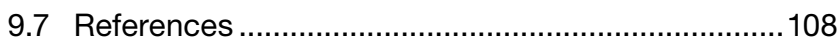

Annex 9.1 KBA trigger species......................................109

Annex 9.2 Site Champions - Madagascar....................... 113

Annex 9.3 Summary of the KBA Criteria and

Thresholds (IUCN 2016) 114

\section{Chapter 10 A critical sites network for freshwater}

biodiversity in Madagascar....................................... 115

10.1 Introduction .............................................................. 115

10.1.1 Systematic conservation planning ................. 115

10.2 Methods ..................................................................... 116

10.2.1 Marxan......................................................... 116

10.2.2 Conservation features.................................... 116

10.2.3 Planning units............................................... 116

10.2 .4 Connectivity .............................................. 117

10.2.5 Locking in existing management units.......... 117

10.2.6 Conservation features versus planning units......................................................... 118

10.2.7 Conservation features targets ....................... 118

10.2.8 Marxan set up .............................................. 118

10.3 Results................................................................... 118

10.3.1 Summary of scenarios run............................. 118

10.3.2 Scenario C - Optimal network considering

current land use and potential management ............ 122

10.4 Caveats................................................................. 127

10.5 Conclusions ......................................................... 127

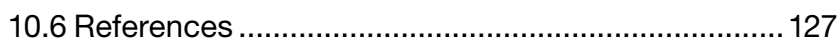




\section{Acknowledgements}

\begin{abstract}
Donor
IUCN would like to thank the Critical Ecosystems Partnership Fund for providing the financial support for this project. In particular we are grateful for the support provided by Pierre Carret and Antonia Cermak-Terzian throughout the project. The Critical Ecosystem Partnership Fund is a joint initiative of l'Agence Française de Développement, Conservation International, the European Union, the Global Environment Facility, the Government of Japan, the MacArthur Foundation and the World Bank. A fundamental goal is to ensure civil society is engaged in biodiversity conservation.
\end{abstract}

\section{Project Partner}

IUCN Species Programme, through its Freshwater Biodiversity Unit, led this project in close collaboration with Missouri Botanical Garden - Madagascar.

\section{Logistics}

We have, throughout the project, also been provided logistical support from non-project partners, and would like to give our thanks to the California Academy of Sciences Biodiversity Centre in Antananarivo for hosting the Red List review and KBA delineation workshops.

\section{Report contributors}

The editors thank the authors and contributors to this report and those others who have commented on the various states of the manuscript. We sincerely thank the reviewers, Ian Harrison and John Watkin, for their constructive comments and helpful suggestions.

\section{IUCN Specialist Groups}

The project has worked closely with the IUCN Species Survival Commission Specialist Group network which often provided the necessary species expertise for completing the Red List assessments. We would like to thank the Freshwater Fish Specialist Group; Dragonfly Specialist Group; Mollusc Specialist Group; Madagascar Plants Specialist Group and; Freshwater Crab and Crayfish Specialist Group in particular.
IUCN Publications Officer and Editorial Board We thank Sarina Van der Ploeg, IUCN's Publications officer, and the members of the IUCN Editorial Board for their review and contribution to the publication of this report.

\section{Finances}

The finances of the project have been diligently managed by Amy Burden and Mickael Chevalier.

\section{Red List species assessors, evaluators and workshop participants}

Assessment of species risk of extinction (IUCN Red List Categories and Criteria) and subsequent identification of Key Biodiversity Areas relies on the willingness of dedicated experts to contribute and pool their collective knowledge. Without their enthusiastic commitment to biodiversity conservation, this work would not be possible. We would therefore like to acknowledge the committed work of the experts who participated in the Red List review and KBA delineation workshops held in Antananarivo in July 2016 and January 2017 and contributed with their input to the production of this project, including: Adolphe Lehavana; Andriamihajarivo Tefy; Angelo Solofoniaina; Aristide Andrianarimisa; Botovao A. Ramiandrisoa; Brian Zimmerman; Christian H. Ranaivoson; Cyrille Maharombaka; Dimby Razafinimpahana; Dirk Van Damme; Estelle Razafindranaivo; Félicien Randrianandrianina; Frank Köehler; Harison Andriambelo; Harison H. Randrianasolo; Herilisy Ranarijaona; Herizo Andrianandrasana; Hery Lisy Ranarijaona; Hiarinirina Randrianizahana; Jean R. Rasoloniaina; Jeanne Rasamy Razanabolana; Jenny Rasoloson; John Sparks; Julia P.G. Jones; Juliette Velosoa; Juliot Ramamonjisoa; Kai Schutte; Klaas-Douwe B. Dijkstra; Liva Ramiandrarivo; Luciano Andriamaro; Lucienne Wilmé; Mampionona Randrianirina; Nadiah Manjato; Neil Cumberlidge; Nivo Rakotonirina; Njaka Ravelomanana; Parany Liliane; Patrick Ranirason; Peter Phillipson; Pierre Carret; Rado Andriamasimanana; Ranto Rakotoaridera; Richard E. Lewis; Rivolala Andriamparany; Roger de Lily; Rokiman Letsara; Sahoby I. Randriamahaleo; Sammy DeGrave; Simon Rafanomezantsoa; Sylvie Andriambololonera; Tahiana Andriaharimalala; Tsilavina Ravelomanana and Volatiana Rahanitriniaina. 


\section{Executive summary}

The inland waters of Madagascar and the Indian Ocean islands hotspot support a high diversity of aquatic species with high levels of endemism. Many of these species provide direct (e.g. fisheries) and indirect (e.g. water purification) benefits to people, supporting local economies and livelihoods across the hotspot. Freshwater ecosystems are, however, globally undervalued in terms of the biodiversity they support and the services they provide to people. This lack of concern for the conservation and sustainable use of inland wetlands has led to alarming rates of freshwater habitat loss and degradation. This report presents the most up-to-date information on the conservation status and distributions of freshwater species in inland waters in Madagascar and the Indian Ocean islands and the reasons behind their declining status. Important sites for conserving this biodiversity are also identified.

Six hundred and fifty-three species of freshwater fishes, molluscs, decapods, odonates (dragonflies and damselflies) and aquatic plants were assessed against the IUCN Red List Categories and Criteria. This represents the most comprehensive assessment yet of freshwater biodiversity at the species level for the hotspot. This assessment aims to address the lack of readily available information on freshwater species which has led to their inadequate representation in development and environmental planning. The full data set, including all species distribution maps, is available on the DVD accompanying this report and through the IUCN Red List website (www.iucnredlist.org).

Forty-three percent of all extant species assessed are threatened with extinction, assuming all species assessed as Data Deficient are as equally threatened as those with sufficient data for an assessment to be made. This level of threat is very high in comparison to the pan-African freshwater biodiversity assessment conducted in 2011 where twenty-one percent of species were assessed as threatened. The major drivers of threat are related to habitat loss and degradation, primarily caused by unsustainable agricultural practices such as the slash and burn approach and drainage of wetlands. The high dependency of local communities upon open access natural resources such as wood, medicinal plants and artisanal fisheries has led to biological resource use being the second most important threat, including over-fishing and deforestation. Overabstraction of water for rice cultivation and the construction of dams both modify hydrological landscapes, affecting water flows, water temperature, oxygen content and sediment loading of rivers and streams, in some cases also blocking important migration routes for native species. Human settlements are increasing alongside many freshwater systems in Madagascar with accompanying increased levels of water pollution from urban, agricultural, forestry and livestock farming effluents. Mining activities are also a current and growing threat, followed by invasive alien species which have a considerable impact on some indigenous species through predation and competition for resources. Finally, these threats are compounded through the increasing effects of climate change.

The impacts of these types of threat tend to spread rapidly throughout freshwater ecosystems. Future conservation efforts must therefore take greater account of upstream, downstream and lateral connectivity within water catchments. It is recommended that conservation efforts focus on the protection of upper catchments and the provision of adequate environmental flows. In addition, integrated river basin management and systematic conservation planning approaches are needed.

Another priority is to reduce the high proportion (23\%) of species assessed as Data Deficient due to insufficient information on their conservation status and distributions. This current lack of information represents a significant bottleneck in progress towards the effective management and conservation of the hotspots freshwater biodiversity.

Freshwater ecosystems throughout Madagascar are poorly represented within the existing protected areas system (SAPM), which is largely designated for the protection of terrestrial ecosystems and species. It is therefore important to identify those sites of importance for their freshwater species. Major centres of freshwater species richness are found in the upper reaches of the eastern coastal catchments, eastern wet lowland rainforests and the northwestern tropical and subtropical floodplain river and wetland complexes. A network of 23 freshwater Key Biodiversity Areas (KBAs - areas contributing significantly to the global persistence of biodiversity) was delineated and confirmed by national and international experts. These KBAs support 80 globally threatened (Critically Endangered, Endangered or Vulnerable) and 62 geographically restricted range freshwater species. Of these KBAs, 10 also meet the criteria for Alliance for Zero Extinction (AZE) sites.

The involvement of local communities and national stakeholders is critical to successful conservation of freshwater sites so assuring sustainable livelihoods and services as 
provided by functioning wetland ecosystems. Thirty-four potential Site Champions have been identified as individuals and organizations best placed to raise awareness and to help implement the required actions to safeguard these globally important sites. The full data set, including KBA boundary maps, is available on the DVD accompanying this report and will also be shortly available online through the World Database for Key Biodiversity Areas, managed by Birdlife International on behalf of the KBA partnership (http:// www.keybiodiversityareas.org/home).

From a policy perspective, the information presented in this report will help support implementation of Multilateral Environmental Agreements in Madagascar, such as the Ramsar Convention and the Convention on Biological Diversity, guiding conservation planning and prioritysetting at national level. In addition, this new information will help efforts to achieve targets of the UN Sustainable Development Goals (SDGs), such as Target 6.6 for protecting and restoring water-related ecosystems; Target 6.5 on implementing integrated water resources management at all levels; Target 15.1 for conservation, restoration and sustainable use of terrestrial and inland freshwater ecosystems and their services; and Target 15.5 focused on urgent and significant action to reduce the degradation of natural habitats, halt the loss of biodiversity and, by 2020, protect and prevent the extinction of threatened species.

The IUCN Red List is one of the most authoritative global standards supporting policy and action to conserve species. We hope the analysis presented in this report, based on an assessment of species Red List status, will provide new information to help guide conservation actions and development planning to safeguard the diversity of freshwater life within Madagascar and the Indian Ocean islands hotspot. Periodic update of IUCN Red List species assessments and monitoring of KBAs sites will enable calculation of a Red List Index of change in freshwater species extinction risk over time, so helping to inform managers on the conservation effectiveness of any management interventions. 


\section{Key messages}

- The inland waters of Madagascar and the Indian Ocean islands hotspot support a high diversity of aquatic species with high levels of endemism. Many of these species provide direct (e.g. fisheries) and indirect (e.g. water purification) benefits to people supporting local livelihoods and economies across the hotspot.

- Current levels of threat to freshwater species in the hotspot are higher than in mainland Africa, with $43 \%$ of species threatened with extinction. Data made available through this project must be integrated within the decision making processes for the conservation and future development of inland water resources.

- Species information remains very limited for many freshwater species in the hotspot - $23 \%$ of the species were assessed as Data Deficient (DD). There is an urgent need for collaborative field research and monitoring. Given the high levels of threat across the hotspot it is reasonable to expect that further research and sampling might reveal many of these DD species to also be threatened.

- Freshwater biodiversity is underrepresented within existing Protected Areas in Madagascar. Protected areas are a potentially powerful tool for conservation. However, they often are delineated primarily for terrestrial species such that they fail to include targeted management for the many restricted range and threatened species living in freshwater habitats.

- The 23 Freshwater Key Biodiversity Areas identified here represent a new data set to inform strategies for improved representation of freshwater biodiversity within the National Protected Areas Network and other site protection measures.

- The involvement of local communities and national stakeholders is critical to successful conservation of freshwater sites so assuring sustainable livelihoods and services as provided by functioning wetland ecosystems.

- Management of water resources must take account of the requirements of freshwater biodiversity. The implementation of Integrated River Basin Management and Environmental Flows methodologies is crucial to maintain the quality, quantity and timing of water flows required to sustain healthy freshwater ecosystems.

- Environmental Impact Assessments should expressly require reference to the species data sets made available through the IUCN Red List.

- Building capacity within government bodies (national to local) for better compliance and enforcement of existing legislation, including for management of resource exploitation (e.g. fisheries), water extraction and pollution is essential to the long-term survival of freshwater species and local livelihoods that depend on them.

- The political will and action of Madagascar and the other Indian Ocean island governments is essential to guarantee the long-term survival of freshwater-dependent species and livelihoods. 


\title{
Background: Madagascar and the Indian Ocean islands biodiversity hotspot
}

\author{
Laura Máiz-Tomé', William Darwall1

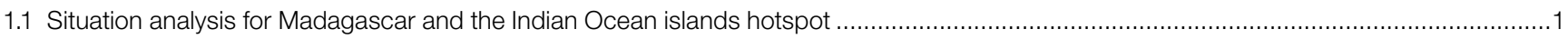

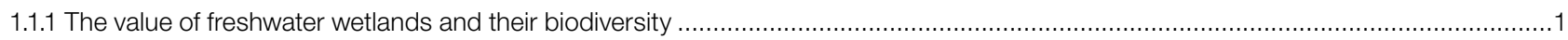

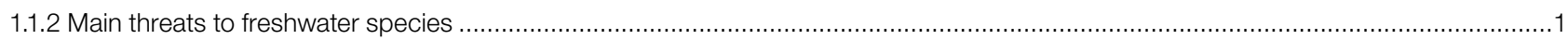

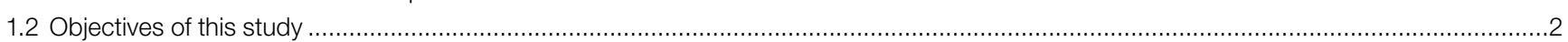

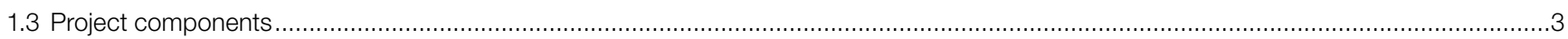

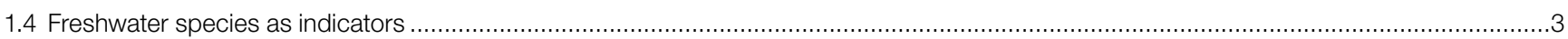

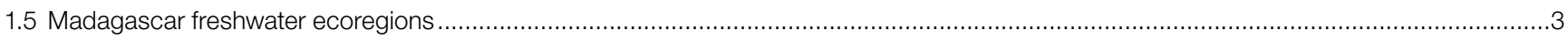

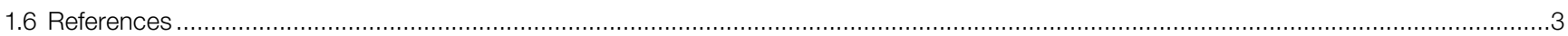

\subsection{Situation analysis for Madagascar and the Indian Ocean islands hotspot}

The Madagascar and Indian Ocean islands hotspot includes the nation of Madagascar and the neighbouring islands and archipelagos of Mauritius, the Comoros (including Mayotte), the Seychelles, La Réunion and the Scattered Islands of the Western Indian Ocean (Iles Eparses). While the different islands of the hotspot share specific biogeographical features, the countries constitute a heterogeneous whole in terms of demography and socioeconomics, related to their political context (Conservation International 2014). Réunion and Mayotte, French departments included in the European Union, have a level of development similar to the Organisation for Economic Co-operation and Development (OECD) countries. Seychelles and Mauritius can be considered as emerging economies, while Madagascar and Comoros are categorised by the United Nations as among the world's least developed countries (UNDP 2016).

The land area of the hotspot is estimated to be $600,461 \mathrm{~km}^{2}$ and it is characterised by a diverse and distinctive flora and fauna, with a very high rate of endemism not only at the species but also the genus and family levels (e.g. the Madagascar flora alone comprises about 10,000 endemic species) (Conservation International 2014). Madagascar covers 95\% of the land area and supports $98 \%$ of the population of the hotspot. While human well-being and economic development rely heavily on ecosystems, the environment of the hotspot is under increasing threat due to anthropogenic pressures caused by population growth and climate change.

\subsubsection{The value of freshwater wetlands and their biodiversity}

Madagascar's wetlands (lakes, lagoons, marshes, mangroves, rivers and streams, bays, estuaries and deltas) are extensive, with more than $300 \mathrm{~km}$ of rivers and streams, and about $2,000 \mathrm{~km}^{2}$ of lakes, divided across 256 catchments (Conservation International 2014). These habitats have always provided water, food, materials and services such as water purification essential to local communities since ancient times. However, this situation changed during the first part of the last century when population growth led to the loss and degradation of wetlands following public health initiatives for their desiccation, the expansion of urban areas along river courses and the conversion of wetlands into agricultural landscapes (Gardner et al. 2015; Lammers et al. 2015).

\subsubsection{Main threats to freshwater species}

The Ramsar Convention on Wetlands entered into force in 1999 and since then, Madagascar has designated 20 sites as Wetlands of International Importance (Ramsar Sites), covering a surface area of 20,949.11 km² (http://www.ramsar. $\mathrm{org} /$ wetland/madagascar). However, lowland wetlands continue to decline, both in area and quality as a result of drainage for expansion of rice agriculture, siltation caused by high rates of soil erosion from deforested land, and urbanisation activities threatening the already degraded and often fragmented freshwater ecosystems. A recent study based on aerial photograph analysis, revealed a dramatic 
loss of approximately $60 \%$ of wetlands and $37 \%$ of riparian forests in the latter half of the 20th century (Kull 2012).

In terms of energy production, hydropower generates approximately $70 \%$ of the electricity in Madagascar. A recent assessment and mapping of the hydropower potential of Madagascar (2014-2017), carried out by the Ministry of Energy in close collaboration with the World Bank, delivered a spatial database of more than 400 hydropower sites amongst which approximately 350 sites have a power capacity in the range of 1-20 MW for a total of 1,350 MW (SHER 2017). These new potential hydropower sites may have significant consequences for freshwater ecosystems and their associated biodiversity, affecting water regimes and hydrological connectivity.

The mining sector is also of growing importance with two large-scale operations posing further potential threats to freshwater biodiversity: Rio Tinto's mineral sands operations near Fort Dauphin on the south-eastern tip of Madagascar (Seagle 2011), and Ambatovy'a nickel and cobalt mining operation in the east (Dickinson \& Berner 2010).

Although Madagascar is well endowed with both extractive and renewable natural resources, the agricultural sector is the main contributor to the national economy. Production of rice, the staple food, accounts for $70 \%$ of the total agricultural production and it is essential to meet subsistence needs, followed by livestock, fisheries and forestry activities (Breuil et al. 2014). Traditional 'paddy' rice is grown in paddy fields in the low-lying valleys, while 'tavy' rice is grown on upland areas, neighbouring indigenous forests, as an insurance against the loss of the low-land crops (GRiSP 2013). Tavy rice cultivation is based on the slash and burn approach. Usually, after one or two cycles, the soil is completely depleted of nutrients and the land is colonised by scrub vegetation or alien grasses. This new vegetation growing on the hill slopes is often insufficient to anchor soils, causing high rates of soil erosion (Styger et al. 2007).

Deforestation in upper catchments, and conversion of wetland areas for rice production, have led to the loss and degradation of many wetland areas. Increased sedimentation and pollution, and unsustainable agricultural practices such as seen in the slash and burn approach, have major impacts on freshwater ecosystems so threatening the provision of services such as fisheries and clean drinking water with consequences for all sectors.

Madagascar's development has been hindered by repeated political crises since the country's independence in 1960. The latest crisis followed the unconstitutional change of regime in 2009 , and lasted close to five years. It left the economy severely crippled and led to a sharp rise in poverty levels with more than $77 \%$ of the population living below the poverty line (UNDP 2016). This situation has led to a high dependency upon open access natural resources such as wood, medicinal plants and artisanal fisheries. The national economy is also vulnerable in the face of climatic shocks such as droughts, cyclones and flooding that affect the country every year. These events provoke considerable damage in key economic sectors such as agriculture production, fisheries and water resources, and the effects are unequally distributed with poor, rural populations being the most affected (WAVES 2015; USAID 2016).

\subsection{Objectives of this study}

Freshwater ecosystems are globally undervalued in terms of the biodiversity they support and the services they provide to people, and tropical wetlands are particularly threatened and under-researched (Bamford et al. 2017). This lack of concern for the conservation and sustainable use of wetlands has led to the loss of almost $75 \%$ of the world's freshwater wetland habitats during the last century (Davidson 2014). Populations of freshwater species are declining at almost double the rate of other terrestrial or marine species (WWF Living Planet 2016), and around one in three of the freshwater species assessed for the IUCN Red List are classified as being threatened with extinction.

A strong indication for the poor status of the freshwater species comes from the IUCN assessment of the status of Madagascar's freshwater fish in 2017 conducted as part of this project, in which $60 \%$ of the endemic species, for which sufficient data were available, were assessed as threatened. Given the high reliance upon inland fisheries by the rural poor the ongoing loss and degradation of inland wetlands is of major concern.

Protected areas represent a potentially powerful tool for conservation of the habitats these species and local livelihoods depend upon. Terrestrial wetlands are, however, underrepresented in the protected areas system of Madagascar and have received little conservation or research attention (Bamford et al. 2017; Conservation International 2014), as they have for the rest of continental Africa (Darwall et al. 2011). Regional-scale assessments of the coverage and effectiveness of protected areas have shown that freshwater habitats are not only under-protected, but that protected areas are also ineffective for conserving these habitats and their species (CBD 2014).

The Promise of Sydney (IUCN 2014b) acknowledged that "Freshwaters are often only incidentally included as part of protected areas, or as borders to protected areas, without representative support for their management 
and conservation", and recommended that: "Countries give careful attention to ensuring that protected areas are identified and managed to conserve species and ecological processes across the biomes of land, freshwater, and marine".

The objective of this report is therefore to improve the conservation of freshwater biodiversity throughout the hotspot, in particular through improved representation within protected areas designed for conservation of freshwater species. The data on selected taxon groups broadly representing freshwater biodiversity presented in recognised and respected formats such as the IUCN Red List and Key Biodiversity Areas, provide important tools to: a) raise awareness of freshwater species and sites in need of protection; and b) inform decision making in relation to conservation and development planning to better represent the future of inland wetlands and the services they provide for Madagascar's rural poor in particular.

\subsection{Project components}

1) IUCN Red List Assessments: National and international species experts drafted species Red List assessments for freshwater fishes (145 spp.; 58\% endemic); molluscs (66 spp.; 59\% endemic); crayfish (7 spp.; 100\% endemic); crabs (20 spp.; 100\% endemic); odonates (201 spp.; 75\% endemic); shrimps (45 spp.; 64\% endemic); and selected species of aquatic plants (170 spp.; 100\% endemic). Species previously assessed for the Red List have been reassessed to provide an up to date comprehensive assessment and, in the case of fishes, a Red List Index providing insight into trends in status (IUCN 2014a).

2) Freshwater Key Biodiversity Areas (KBAs): Information generated through component 1 was employed to identify those river/lake sub-catchments that meet the KBA criteria (IUCN 2016).

3) Dissemination/awareness raising: Project results are widely disseminated through this report, policy briefs, the IUCN Red List, the Key Biodiversity Areas Database, and the Integrated Biodiversity Assessment Tool (IBAT). Training has been provided in accessing information through each of these tools. There was a public launch of results.

\subsection{Freshwater species as indicators}

There is an increasing need to integrate biodiversity information as a factor of relevance within new planning processes and improve its availability to decision-makers.
By combining the taxonomic groups assessed in this study a wide range of trophic levels are represented, all of which play diverse ecological roles and therefore are thought to provide a useful indication of the overall status of the associated wetland ecosystems (Darwall et al. 2008).

\subsection{Madagascar freshwater ecoregions}

Brief descriptions of Madagascar Freshwater Ecoregions (Figure 1.1), obtained from the online Freshwater Ecoregions of the World (FEOW 2015) are presented below. This biogeographic classification scheme has been used in the different chapters to describe the distribution of freshwater species across Madagascar.

\subsection{References}

Bamford, A.J., Razafindrajao, F., Young R.P., et al. 2017. Profound and pervasive degradation of Madagascar's freshwater wetlands and links with biodiversity. PLoS ONE 12(8): e0182673. https://doi.org/10.1371/journal.

Breuil, C. and Grima, D. 2014. Baseline Report Madagascar. SmartFish Programme of the Indian Ocean Commission, Fisheries Management FAO component, Ebene, Mauritius.

CBD. 2014. Global Biodiversity Outlook 4. Montréal. Available at: https://www.cbd.int/gbo4/

Conservation International. 2014. Ecosystem profile: Madagascar and Indian Ocean Islands. Critical Ecosystem Partnership Fund. Final Version: December 2014.

Darwall, W.R.T., Holland, R.A., Smith, K.G., et al. 2011. Implications of bias in conservation research and investment for freshwater species. Conservation Letters 4: 474-482. https://doi.org/10.1111/j.1755263X.2011.00202.x

Darwall, W., Smith, K., Allen, D., et al. 2008. Freshwater biodiversity - a hidden resource under threat. In: J.-C. Vié, C. Hilton-Taylor and S.N. Stuart (eds.). The 2008 Review of The IUCN Red List of Threatened Species. IUCN, Gland, Switzerland.

Davidson, N.C. 2014. How much wetland has the world lost? Long-term and recent trends in global wetland area. Marine and Freshwater Research 65: 934-941. https:// doi.org/10.1071/MF14173

Dickinson, S. and Berner, P.O. 2010. Ambatovy project: Mining in a challenging biodiversity setting in Madagascar. In: Goodman, S.M. and Mass, V. (eds.). Biodiversity, exploration, and conservation of the natural habitats associated with the Ambatovy project. Malagasy Nature 3: 2-13.

FEOW. 2015. Freshwater Ecoregions of the World. Available online at: http://www.feow.org/ 


\section{Madagascar Freshwater Ecoregions (FEOW 2015)}

Western Madagascar is characterised by xeric freshwater ecosystems defined by little permanent surface water and a relative abundance of springs, and endorheic (closed) basins. In contrast to the extremely wet eastern forests, Western Madagascar is considerably drier. Western rivers are long, generally slow flowing, and subject to seasonal fluctuations in water level and flow. Distinctive freshwater habitats within this region include tsingy or karst formations characterised by fissures, subterranean streams, sinkholes, and caverns produced by erosion. Lac Itasy, located in the western central highlands, once supported a diverse assemblage of native fishes, although exotics have almost entirely replaced the native species.

North-Western Madagascar is characterised by tropical and subtropical floodplain rivers and wetland complexes. This ecoregion includes all westward flowing drainages from the northern tip of Madagascar (near Antsiranana) including the Mahavavy du Sud drainage basin located to the south-west of Mahajunga. The satellite island of Nosy Be is also part of this ecoregion. The North-Western basins, especially those draining the Tsaratanana Massif, receive more annual rainfall and are more diverse geomorphologically and biologically than the drier drainages of eastern Madagascar and Southern Madagascar. The rivers and floodplain lakes of this ecoregion support rich and highly endemic freshwater fish faunas.

The Eastern Highlands of Madagascar comprise a long strip of land extending from the north to the south of Madagascar defined by the upper reaches of the eastern coastal drainages above about $200 \mathrm{~m}$ elevation. Rivers in this ecoregion are generally small to moderate in size, with a rocky substrate, and swift currents. Drainages are steep in their upper reaches, with numerous sections of rapids and cascades interspersed with flatter stretches of more moderate flows. These coastal rivers are short and terminate on a narrow coastal plain over a contracted continental shelf. In addition to freshwater fishes, this ecoregion supports extremely high richness and endemism among aquatic frogs. About 130 aquatic frog species are described from the ecoregion with nearly $65 \%$ being endemic.

Southern Madagascar has a relatively depleted aquatic fauna due to its aridity. Much of the region is essentially devoid of rivers or surface water. Vegetation is referred to as 'spiny desert', and members of the endemic family Didiereaceae dominate the landscape.

The Eastern Lowlands of Madagascar are characterised by tropical and subtropical coastal rivers with moderate to slow flows and frequently turbid waters which often meander and terminate in chains of brackish lagoons. The lower reaches of eastern drainages have a more diverse ichthyofauna than headwater regions. In terms of endemic taxa, these lower elevation communities are primarily rich in Bedotia and are also home to six species of crayfish in the endemic genus Astacoides. Frogs are also abundant in this ecoregion with about half of the 70 species found here being endemic. Several wetlands and forested streams along the coast are also important sites for waterbirds.

Gardner, R.C., Barchiesi, S., Beltrame, C., et al. 2015. State of the World's Wetlands and their Services to People: A compilation of recent analyses. Ramsar Briefing Note no.

7. Gland, Switzerland: Ramsar Convention Secretariat.

Available at: http://www.ramsar.org/sites/default/files/ documents/library/bn7e_0.pdf

GRiSP (Global Rice Science Partnership). 2013. Rice almanac, 4th edition. Los Baños (Philippines): International Rice Research Institute.

IUCN. 2014a. Red List assessment of Madagascar's Freshwater

Fishes. IUCN, Gland Switzerland and Cambridge, UK.

IUCN. 2014b. World Parks Congress: The Promise of Sydney.

Available at: https://www.iucn.org/theme/protectedareas/about/promise-sydney

IUCN. 2016. A Global Standard for the Identification of Key Biodiversity Areas, Version 1.0. First Edition. Gland, Switzerland: IUCN.

Kull, C.A. 2012. Air photo evidence of land cover change in the highlands: wetlands and grasslands give way to crops and woodlots. Madagascar Conservation and Development. 7:(3) 144-152.
Lammers, L.P., Richter, T., Waeber, O.P., et al. 2015. Lake Alaotra wetlands: how long can Madagascar's most important rice and fish production region withstand the anthropogenic pressure? Madagascar Conservation and Development. 3 No.3S. https://doi.org/10.4314/mcd. v10i3.4

Madagascar Small Hydro GIS Atlas 2017. Available at: https:// energydata.info/dataset/madagscar-small-hydro-gisatlas-2017

Seagle, C. 2011. The mining-conservation nexus: Rio Tinto, development gifts and contested compensation in Madagascar. The Land Deal Politics Initiative. LDPI Working Paper.

SHER. 2017. Hydropower Atlas of Madagascar. Available at: http://www.sher.be/en/page/successful-delivery-of-thehydropower-atlas-of-madagascar.

Styger, E., Rakotondramasy, H.M., Pfeffer, J.M., et al. 2007. Influence of slash-and-burn farming practices on fallow succession and land degradation in the rainforest region of Madagascar. Agriculture, Ecosystems and Environment 119(3-4): 257-269. 
UNDP. 2016. Human Development Report: Madagascar. Available online at: http://hdr.undp.org/sites/all/themes/ hdr_theme/country-notes/MDG.pdf

USAID. 2016. Climate Change Risk Profile: Madagascar Fact Sheet. Available at: http://pdf.usaid.gov/pdf_docs/ pa00mtz8.pdf

WAVES. 2015. Madagascar Country Report 2015: Priority Policy Linkages and Work Plan. WAVES Madagascar
National Steering Committee. Available at: http://www. wavespartnership.org/sites/waves/files/images/ Country\%20Report\%20Madagascar.pdf

WWF. 2016. Living Planet Report: Risk and resilience in a new era. WWF International, Gland, Switzerland. Available at: http://wwf.panda.org/about_our_earth/all_publications/ Ipr_2016/ 
Figure 1.1 Freshwater Ecoregions of Madagascar created from FEOW online database.

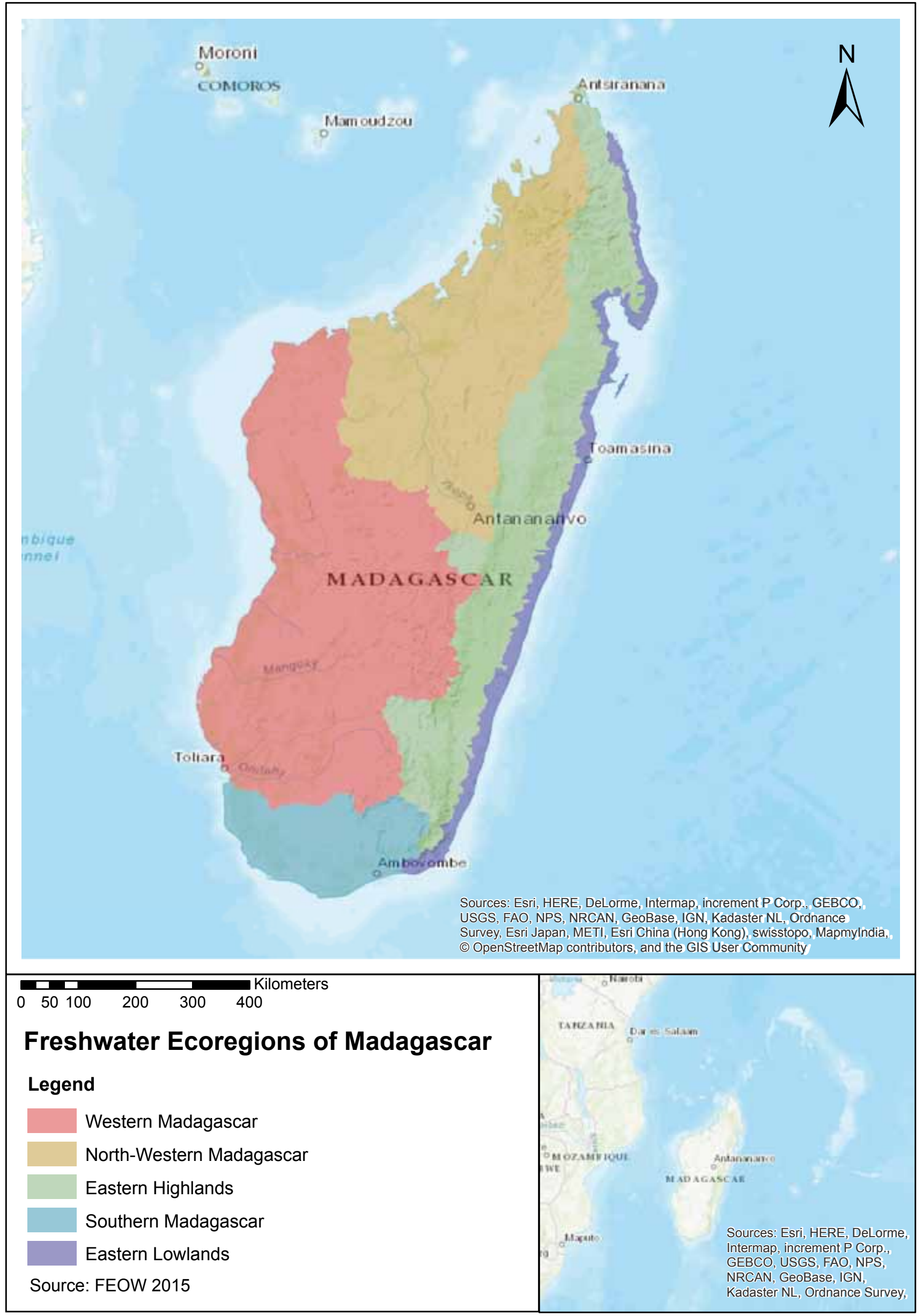




\title{
Chapter 2
}

\section{Red List assessment methodology}

\author{
Laura Máiz-Tomé1, William Darwall ${ }^{1}$

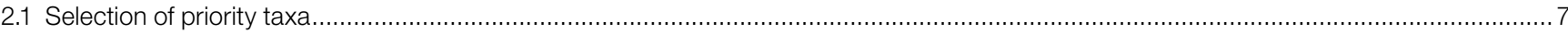

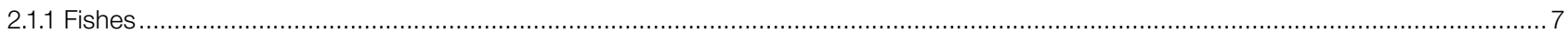

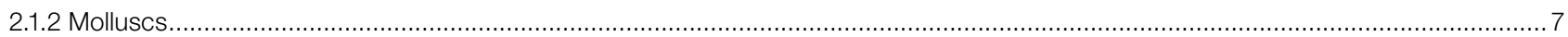

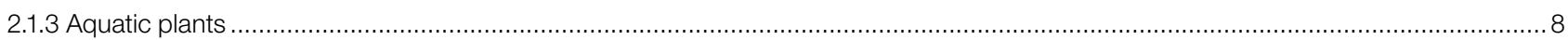

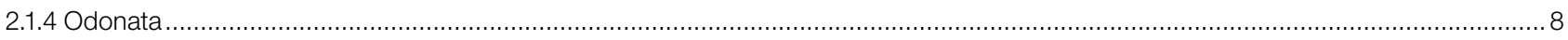

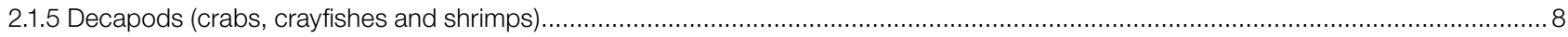

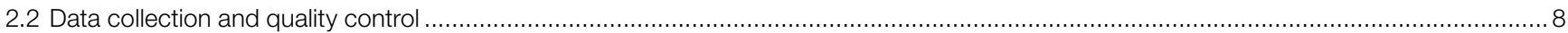

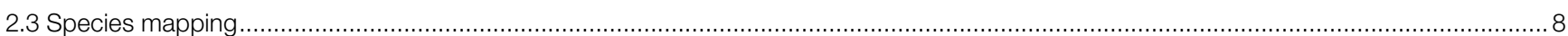

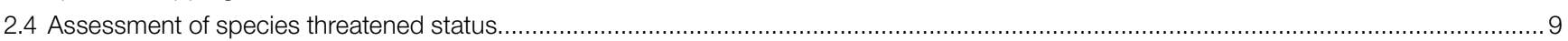

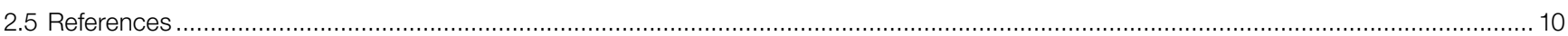

\subsection{Selection of priority taxa}

In the majority of cases, large-scale biodiversity assessments have focused on a limited range of taxonomic groups, most often including those groups that provide obvious benefits to humans through direct consumption, or the more charismatic groups, such as mammals and birds. In the case of freshwater systems it is the wetland birds, amphibians and fishes that have received most attention. It is, however, important that we take a more holistic approach by collating information to conserve those other components of the food web essential to the maintenance of healthy functioning wetland ecosystems, even if they are neither charismatic nor often noticed, especially for submerged species (Darwall et al. 2008).

Clearly, it is not practical to assess all species. Therefore, a number of priority taxonomic groups were selected to represent a range of trophic levels within the food webs that underlie and support wetland ecosystems. Priority groups were selected to include those taxa for which there was thought to be a reasonable level of pre-existing information. The taxonomic groups selected were: fishes; molluscs; odonates (dragonflies and damselflies); decapod crustaceans (crabs, shrimps and crayfishes); and aquatic plants.

Although fishes provide a clear benefit to the livelihoods of many people throughout Madagascar and the Indian Ocean islands hotspot, either as a source of income or as a valuable food supply (Breuil \& Grima 2014), benefits provided by the other taxa may be indirect and poorly appreciated but nonetheless also important. Given the wide range of trophic levels and ecological roles encompassed within these five taxonomic groups, it is proposed that information on their distributions and conservation status, when combined, will provide a useful indication for the overall status of the associated wetland ecosystems.

\subsubsection{Fishes}

Freshwater fishes provide an important source of food, nutrition, income and livelihoods for hundreds of millions of people around the world (FAO 2016). Global total capture from inland waters, although widely accepted to be an underestimate, in 2014 was of 11.9 million tonnes continuing a positive trend that has resulted in a $37 \%$ increase in the last decade (Breuil \& Grima 2014). For the purposes of this assessment freshwater fishes are defined as those species that spend all or a critical part of their life cycle in fresh waters, such as rivers and lakes. Of all freshwater fish species assessed in Madagascar and Indian Ocean islands $58 \%$ are endemic.

\subsubsection{Molluscs}

Freshwater molluscs are one of the most diverse and threatened groups of freshwater taxa (Seddon et al. 2011). They are mostly unobtrusive, and not considered as being charismatic creatures, so rarely attract the attention of the popular media. However, they are essential to the maintenance of wetland ecosystems, primarily due to 
their control of water quality and nutrient balance through filter-feeding, algal-grazing, and to a lesser degree, as a food source for other species (Bogan 2008). There are an estimated 5,000 freshwater mollusc species for which valid descriptions exist, in addition to a possible additional 10,000 undescribed taxa. Under this project, the conservation status of 66 freshwater mollusc species was assessed.

\subsubsection{Aquatic plants}

Aquatic plants are defined here as those physiologically and morphologically bound to water (a hydrophite) or essentially terrestrial plants whose photosynthetically active parts tolerate long periods submerged or floating (a helophyte). Aquatic plants are building blocks of wetland ecosystems, providing food, oxygen and habitats for many other species. They are a hugely important natural resource providing direct benefits to human communities (Darwall et al. 2009). Numerous aquatic plants are highly valued for their nutritious, medicinal, cultural, structural or biological properties (Cook 1996). They are also key species supporting wetland ecosystem services such as water filtration and nutrient recycling. For this project, the conservation status of aquatic vascular plant species endemic to Madagascar, as recorded in the Madagascar Catalogue (MBG 2017), including representatives from 44 selected plant families were assessed. The selection of species was based on the criterion that the taxonomy is relatively reliable and stable.

\subsubsection{Odonata}

Larvae of almost all of the 5,680 species of the insect order Odonata (dragonflies and damselflies) are dependent on freshwater habitats (Kalkman et al. 2008). The habitat selection of adult dragonflies strongly depends on the terrestrial vegetation type and their larvae develop in water where they play a critical role with regards to water quality, nutrient cycling, and aquatic habitat structure. A full array of ecological types is represented within this group which, as such, has been widely used as an indicator for wetland quality. A total of 151 endemic species and 50 nonendemic species of dragonflies were assessed under this project. This baseline dataset on the status and distribution of Odonata will facilitate the development of long-term monitoring schemes for the hotspot.

\subsubsection{Decapods (crabs, crayfishes and shrimps)}

Freshwater decapods are amongst the most important invertebrates inhabiting inland waters playing a critical role in the trophic web. Decapods are preyed upon by a variety of species including fishes and birds and they also act as secondary predators themselves, consuming phytoplankton, benthic algae, and macrobenthos, contributing in this way to the dynamics of nutrient recycling and the maintenance of healthy freshwater ecosystems (Reynods et al. 2013). Freshwater decapods are also of high economic value for local livelihoods (Jenkins et al. 2011). This project has assessed all currently known decapod species of freshwater crabs (Potamonautidae), crayfish (Parastacidae) and freshwater shrimps (Atyidae and Palaemonidae) from Madagascar and the Indian Ocean islands hotspot, most of which are endemic (Cumberlidge et al. 2017).

\subsection{Data collection and quality control}

The biodiversity assessment required sourcing and collating the best information on all known, described species within the priority taxonomic groups. As the primary source for this information, the best regional and international experts for these taxa were first identified through consultation with the relevant IUCN Species Survival Commission (SSC) Specialist Groups and Missouri Botanical Garden staff in Madagascar. These experts collated the relevant information within the IUCN Species Information Service database (https://sis.iucnsis.org) and applied the IUCN Red List Categories and Criteria (IUCN 2012), to assess the species risk of extinction in the wild. Species range distributions were also mapped (see below). All information was then peer reviewed at a workshop held in Antananarivo in July 2016 where each species assessment was evaluated by at least two independent experts to ensure that the information presented for each Red List assessment was both complete and correct and that the Red List Category and Criteria assigned to each species were supported by the information provided.

\subsection{Species mapping}

Using ArcMap software (Esri 2015) all species distributions were mapped to river and lake sub-basins as delineated by HydroBASINS Level 08 (Lehner \& Grill 2013) a global standardised hydrological framework that delineates catchments at 12 resolutions and includes information on network hydrological connectivity. Where spatial data were of sufficiently high detail species were mapped to smaller sub-catchments (HydroBASINS Level 12). River basins were selected as the spatial unit for mapping and analysing species distributions as it is generally accepted that the river/lake basin or catchment is the most appropriate management unit for inland waters.

Where data were available, point localities (the latitude and longitude for a species collection record) were used to identify which sub-basins are known to contain the species. 
To determine whether a species should be assigned to one of the three threatened categories, there are five criteria with quantitative thresholds (Figure 2.3), reflecting biological indicators of populations threatened with extinction.

For a detailed explanation of the categories and of the criteria that must be met for a species to qualify under each category, please refer to The IUCN Red List Categories and Criteria: Version 3.1 (IUCN 2012).

Red List assessments are published online on the IUCN Red List website (www.iucnredlist.org).

Reporting the proportion of species in a taxonomic grouping that are threatened requires a standardised approach as some species have so little information available that they can only be assessed as Data Deficient (DD). The reported percentage of threatened species for each group is presented as a best estimate within a range of possible values bounded by lower and upper estimates:

- Lower estimate $=\%$ threatened extant species if all DD species are not threatened, i.e. $(\mathrm{CR}+\mathrm{EN}+\mathrm{VU}) /$ (total assessed-EX)

- Best estimate $=\%$ threatened extant species if DD species are equally threatened as data sufficient species, i.e. $(C R+E N+V U) /($ total assessed - EX - DD)

- Upper estimate $=\%$ threatened extant species if all DD species are threatened, i.e. $(\mathrm{CR}+\mathrm{EN}+\mathrm{VU}+\mathrm{DD}) /$ (total assessed-EX)

\subsection{References}

Bogan, A. 2008. Global diversity of freshwater mussels (Mollusca, Bivalvia) in freshwater. Hydrobiologia 595: 139-147. https://doi.org/10.1007/s10750-007-9011-7

Breuil, C. and Grima, D. 2014. Baseline Report Madagascar. SmartFish Programme of the Indian Ocean Commission, Fisheries Management FAO component, Ebene, Mauritius.

Cook, C.D.K. 1996. Aquatic Plant Book (2nd revised edition). SPB Academic Publishing. Amsterdam/New York.

Cumberlidge, N., Rasamy Razanabolana, J. and Ranaivoson, C.H. 2017. Updated extinction risk assessments of Madagascar's freshwater decapod crustaceans reveal fewer threatened species but more Data Deficient species. Malagasy Nature 12: 32-41.

Darwall, W., Smith, K., Allen, D. et al. 2008. Freshwater biodiversity - a hidden resource under threat. In: Vié, J.-C.,
Hilton-Taylor, C. and Stuart, S.N. (eds.). The 2008 Review of The IUCN Red List of Threatened Species. IUCN, Gland, Switzerland.

Darwall, W.R.T., Smith, K.G., Tweddle, D. and Skelton, P. (eds.). (2009). The Status and Distribution of Freshwater Biodiversity in Southern Africa. Gland, Switzerland: IUCN and Grahamstown, South Africa: SAIAB. viii+120pp.

Environmental Systems Research Institute (ESRI). 2015. ArcGIS Release 10.3.1 Redlands, CA.

FAO. 2016. The State of World Fisheries and Aquaculture 2016. Contributing to food security and nutrition for all. Rome.

IUCN Standards and Petitions Subcommittee. 2017. Guidelines for Using the IUCN Red List Categories and Criteria. Version 13. Prepared by the Standards and Petitions Subcommittee. Available at: http://www.iucnredlist.org/ documents/RedListGuidelines.pdf

IUCN. 2012. IUCN Red List Categories and Criteria: Version 3.1. Second edition. Gland, Switzerland and Cambridge, UK: IUCN. iv+32pp.

Jenkins, R.K.B., Keane, A., Rakotoarivelo, A.R., et al. 2011. Analysis of patterns of bushmeat consumption reveals extensive exploitation of protected species in eastern Madagascar. PLoS ONE 6: e27570. https://doi.org/10.1371/ journal.pone.0027570

Kalkman, V.J., Clausnitzer, V., Dijkstra, K.D.B., et al. 2008. Global diversity of dragonflies (Odonata) in freshwater. Hydrobiologia 595(1): 351-363. https://doi.org/10.1007/ s10750-007-9029-x

Lehner, B. and Grill, G. 2013. Global river hydrography and network routing: baseline data and new approaches to study the world's large river systems. Hydrological Processes 27(15): 2171-2186. Data is available at www. hydrosheds.org https://doi.org/10.1002/hyp.9740

Missouri Botanic Gardens. 2017. Catalogue of the Plants of Madagascar. Available at: http://www.tropicos.org/ projectwebportal.aspx?pagename=ProtectedAreas\&pr ojectid $=17$

Reynolds, J., Souty-Grosset, C., and Richardson, A. 2013. Ecological Roles of Crayfish in Freshwater and Terrestrial Habitats. Freshwater Crayfish 19(2): 197-218.

Seddon, M., Appleton, C., Van Damme, D. et al. 2011. Chapter 4. Freshwater molluscs of Africa: Diversity, Distribution and Conservation. In: Darwall, W.R.T., Smith, K.G., Allen, D.J., et al. (eds.). 2011. The Diversity of Life in African Freshwaters: Under Water, Under Threat. An analysis of the status and distribution of freshwater species throughout mainland Africa. Cambridge, United Kingdom and Gland, Switzerland: IUCN. xiii+347pp+4pp cover. 
Figure 2.3 Summary of the five criteria (A-E) used to evaluate if a species belongs in an IUCN Red List threatened category: Critically Endangered, Endangered or Vulnerable.

\section{SUMMARY OF THE FIVE CRITERIA (A-E) USED TO EVALUATE IF A TAXON BELONGS IN AN IUCN RED LIST THREATENED CATEGORY (CRITICALLY ENDANGERED, ENDANGERED OR VULNERABLE). ${ }^{1}$}

A. Population size reduction. Population reduction (measured over the longer of 10 years or 3 generations) based on any of A1 to A4

A1

A2, A3 \& A4

A1 Population reduction observed, estimated, inferred, or suspected in the past where the causes of the reduction are clearly reversible AND understood AND have ceased.

A2 Population reduction observed, estimated, inferred, or suspected in the past where the causes of reduction may not have ceased OR may not be understood OR may not be reversible.

A3 Population reduction projected, inferred or suspected to be met in the future (up to a maximum of 100 years) [(a) cannot be used for A3].

A4 An observed, estimated, inferred, projected or suspected population reduction where the time period must include both the past and the future (up to a max. of 100 years in future), and where the causes of reduction may not have ceased OR may not be understood OR may not be reversible.

\begin{tabular}{|c|c|}
\hline Endangered & Vulnerable \\
\hline$\geq 70 \%$ & $\geq 50 \%$ \\
\hline$\geq 50 \%$ & $\geq 30 \%$ \\
\hline
\end{tabular}

(a) direct observation [except A3]

(b) an index of abundance appropriate to the taxon

(c) a decline in area of occupancy (AOO), extent of occurrence (EOO) and/or habitat quality

based on any of the following:

(d) actual or potential levels of exploitation

(e) effects of introduced taxa, hybridization, pathogens, pollutants, competitors or parasites.

B. Geographic range in the form of either B1 (extent of occurrence) AND/OR B2 (area of occupancy)

\begin{tabular}{|l|c|c|c|}
\hline & Critically Endangered & Endangered & Vulnerable \\
\hline B1. Extent of occurrence (EOO) & $<100 \mathrm{~km}^{2}$ & $<5,000 \mathrm{~km}^{2}$ & $<20,000 \mathrm{~km}^{2}$ \\
\hline B2. Area of occupancy (AOO) & $<10 \mathrm{~km}^{2}$ & $<500 \mathrm{~km}^{2}$ & $<2,000 \mathrm{~km}^{2}$ \\
\hline AND
\end{tabular}

AND at least 2 of the following 3 conditions:
(a) Severely fragmented OR Number of locations
$=1$
$\leq 5$
$\leq 10$

(b) Continuing decline observed, estimated, inferred or projected in any of: (i) extent of occurrence; (ii) area of occupancy; (iii) area, extent and/or quality of habitat; (iv) number of locations or subpopulations; (v) number of mature individuals

(c) Extreme fluctuations in any of: (i) extent of occurrence; (ii) area of occupancy; (iii) number of locations or subpopulations; (iv) number of mature individuals

\section{Small population size and decline}

\section{Number of mature individuals}

\begin{tabular}{c|} 
Critically Endangered \\
\hline$<250$ \\
\hline
\end{tabular}

AND at least one of $\mathrm{C} 1$ or $\mathrm{C} 2$

C1. An observed, estimated or projected continuing decline of at least (up to a max. of 100 years in future):

\section{$25 \%$ in 3 years or}

1 generation (whichever is longer)

\section{$20 \%$ in 5 years or \\ 2 generations} (whichever is longer)
Vulnerable

$<10,000$

C2. An observed, estimated, projected or inferred continuing decline AND at least 1 of the following 3 conditions:

(a) (i) Number of mature individuals in each subpopulation (ii) $\%$ of mature individuals in one subpopulation =

$\leq 50$

90-100\% $\leq 250$

95-100\%
$10 \%$ in 10 years or

3 generations (whichever is longer)

(b) Extreme fluctuations in the number of mature individuals

\section{Very small or restricted population}

\section{Number of mature individuals}

D2. Only applies to the VU category

Restricted area of occupancy or number of locations with a plausible future threat that could drive the taxon to $C R$ or EX in a very short time.

\begin{tabular}{|c|c|c|}
\hline Critically Endangered & Endangered & Vulnerable \\
\hline$<50$ & $<250$ & D1. $\quad<1,000$ \\
\hline- & - & \begin{tabular}{c} 
D2. $\begin{array}{c}\text { typically: } \\
\text { AOO }<20 \mathrm{~km}^{2} \text { or } \\
\text { number of locations } \leq 5\end{array}$ \\
\hline
\end{tabular} \\
\hline
\end{tabular}

$\leq 1,000$

$100 \%$

E. Quantitative Analysis

Indicating the probability of extinction in the wild to be:

\begin{tabular}{|c|c|c|}
\hline Critically Endangered & Endangered & Vulnerable \\
\hline $\begin{array}{c}\geq 50 \% \text { in } 10 \text { years or } 3 \\
\text { generations, whichever } \\
\text { is longer (100 years } \\
\text { max.) }\end{array}$ & $\begin{array}{c}\geq 20 \% \text { in } 20 \text { years or } 5 \\
\text { generations, whichever } \\
\text { is longer (100 years } \\
\text { max.) }\end{array}$ & $\geq 10 \%$ in 100 years \\
\hline
\end{tabular}

1 Use of this summary sheet requires full understanding of the IUCN Red List Categories and Criteria and Guidelines for Using the IUCN Red List Categories and Criteria. Please refer to both documents for explanations of terms and concepts used here. 


\section{SPECIES OF IMPORTANCE FOR CONSERVATION}

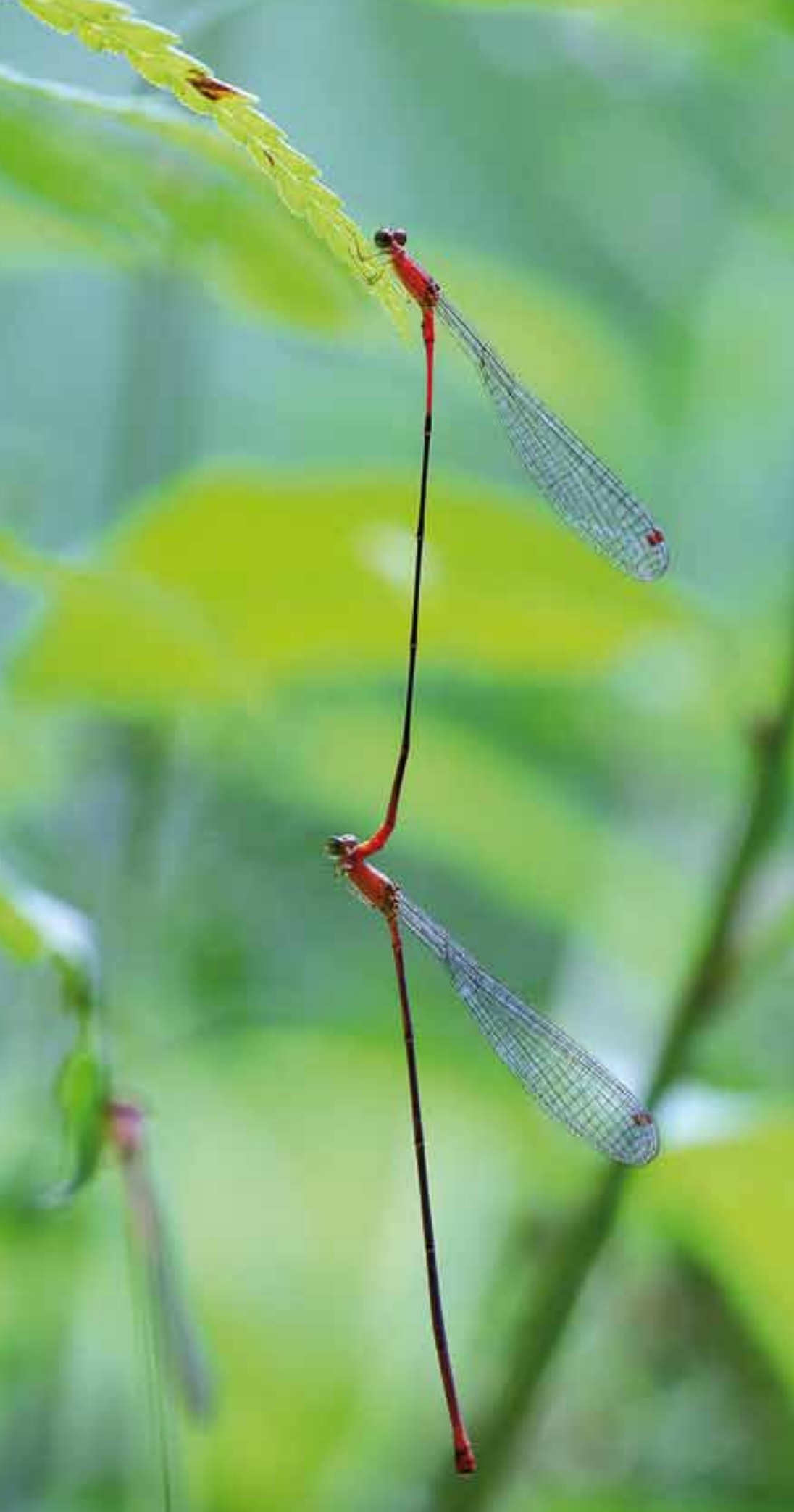

Teinobasis alluaudi. (C) Erland R. Nielsen 


\section{Chapter 3}

\section{The status and distribution of freshwater fishes}

\section{Tsilavina Ravelomanana1, Laura Máiz-Tomé2, William Darwall², Catherine Sayer², John Sparks ${ }^{3}$}

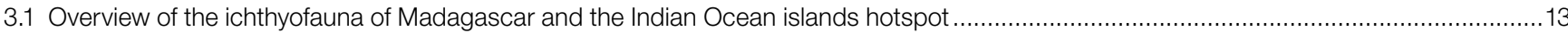

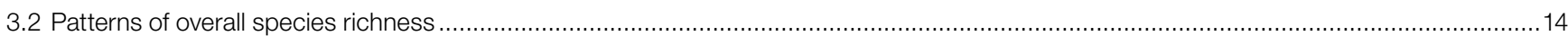

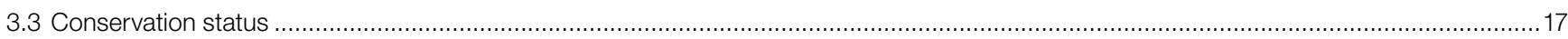

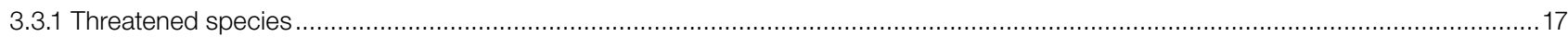

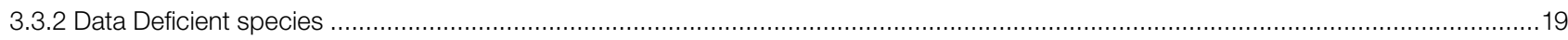

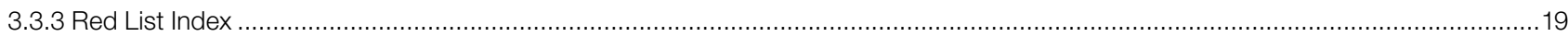

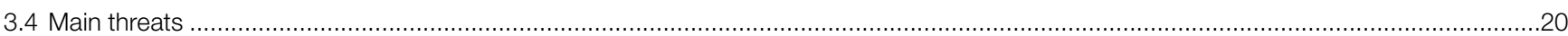

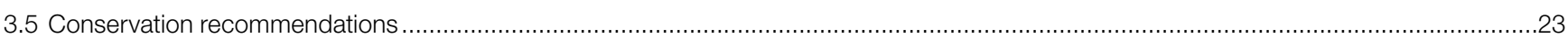

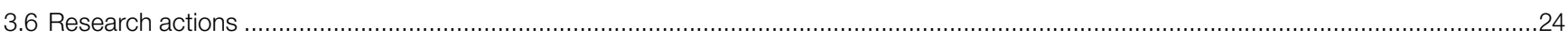

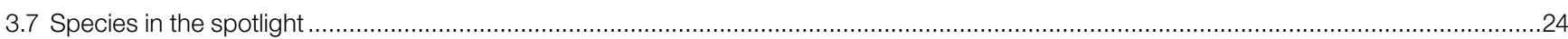

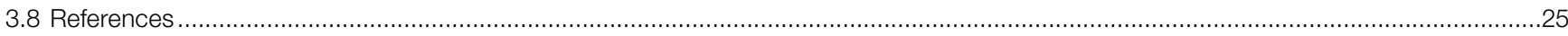

Annex 3.1 Red List status of Madagascar and the Indian Ocean islands hotspot freshwater fishes ............................................................27

\subsection{Overview of the ichthyofauna of Madagascar and the Indian Ocean islands hotspot}

Based on data from extensive aquatic and ichthyofaunal surveys conducted throughout Madagascar, Sparks \& Stiassny (2003) subdivided Madagascar into five freshwater ecoregions, comprising North-Western basins, Western basins, Southern basins, the Eastern Highlands, and the Eastern Lowlands (Figure 1.1 Chapter 1). The North-Western basins support species rich and highly endemic freshwater fish faunas (Sparks \& Stiassny 2003; Sparks 2005). A recent review found that 71 native freshwater fish species have been recorded from North-Western rivers and lakes (Sparks \& Stiassny 2003). This ecoregion is the most speciesrich Malagasy ecoregion for freshwater fishes, and also contains the highest number of endemics (26 spp.) (Sparks \& Stiassny 2003; 2008). The small crater lakes on Nosy Be remain relatively undisturbed and are home to a number of Malagasy endemics, including members of the cichlid genera Ptychochromis and Paratilapia (Sparks 2005). Many of the larger lakes within this region, such as lakes Kinkony, Andrapongy, and Ravelobe, once supported diverse and highly endemic fish faunas that are now dominated by nonnative species due to the combined pressures of habitat degradation, overfishing, and the introduction of exotic species (Sparks, pers. obs.).
Western rivers flow into the Mozambique Channel and they are generally much longer and more slow-flowing than eastern rivers. The longest river in the west is the Mangoky, which is $821 \mathrm{~km}$ long, whereas the Mangoro is the longest in the east at $300 \mathrm{~km}$ long (Aldegheri 1972). Many of western Madagascar's smaller river basins are dry from April to November, experiencing considerable seasonal fluctuations in water level and flow (Aldegheri 1972). On the highlands, the rivers pass through a series of calm stretches and rapids, while in the sedimentary zone the profile is more regular with a much lower average gradient. Tidal influence is significant in the lower reaches of these watercourses (Kiener \& Richard-Vindard 1972). For the western basins, 49 freshwater fish species, including eight endemics, have been recorded (Sparks \& Stiassny 2003; 2008). The larger and relatively undisturbed rivers in western Madagascar (e.g. those adjacent to the Parc National de Isalo) historically supported extremely rare and localised freshwater fish assemblages, including members of the endemic genera Ptychochromoides, Ptychochromis and Ancharius ( Ng \& Sparks 2005; Sparks 2005). Fish communities in this ecoregion contain numerous intrusive freshwater and marine species, many of which migrate far inland (Kiener 1963). It has been hypothesised that the pattern of seasonal desiccation may account for the depauperate assemblages of freshwater fishes inhabiting western basins and the relative dominance of marine species (Brenon 1972). 
Madagascar's Southern ecoregion receives only about $50 \mathrm{~mm}$ of rainfall per month (Donque 1972) and the rivers are wide, shallow, and subject to extreme seasonality in flow (Sparks 2005). Only 10 fish species are known from this ecoregion, including three endemics (Sparks \& Stiassny 2003; Sparks \& Chakrabarty 2012). Distinctive habitats include vast karst systems and plateaus comprising numerous limestone caves, located both to the north and south of the Onilahy River. These caves and sinkholes are home to a small radiation of endemic blind cave eleotrids (Typhleotris spp.) (Sparks \& Chakrabarty 2012; Chakrabarty et al. 2012).

Eastern rivers drain into the Indian Ocean and exhibit a much accentuated, steep profile: from time to time they have calm reaches, are not very wide, and are interspersed with rapids and waterfalls. The major rivers in this ecoregion are the Bemarivo, Lokoho, Maningory, Rianila, Mangoro, Mananjary, and Mananara (Aldegheri 1972). Lake Alaotra, the largest lake on the island in surface area, is located here and empties into the Maningory River (Sparks 2005). The rivers are generally small to moderate in size, rocky in substrate, and swift in current (Sparks 2005). Fifty-one species (some awaiting formal description) of freshwater fishes, including 22 that are endemic, are known to inhabit the rivers and streams of Madagascar's Eastern Highlands (Sparks \& Stiassny 2003; 2008). Mostly intact native fish communities can still be found in the upper to middle reaches of many eastern rivers, including the Nosivolo, Ankavanana, and Mananara. Exotic species, and increased habitat degradation, become more abundant as one moves downstream into the lower reaches of many eastern basins (Sparks 2005).

The Eastern Lowlands ecoregion is characterised by narrow coastal plains. Rivers here often meander and terminate in chains of brackish lagoons (Aldegheri 1972). Lowland Pandanus and palm swamps, as well as numerous estuarine habitats along the eastern coast, continue to support isolated native fish faunas (Sparks 2005). Sparks \& Stiassny (2003; 2008) inventoried 69 fish species, 22 that are endemic, from the Eastern Lowlands ecoregion. The lower reaches of eastern drainages support higher abundance and diversity of ichthyofauna than headwater regions. In terms of endemic taxa, these lower elevation communities are primarily rich in Bedotia, but members of the endemic cichlid genera Paretroplus, Paratilapia, and Ptychochromis are also present.

Steep, fast-flowing rivers and streams are relatively abundant on the Mascarene Islands - the group of islands in the Indian Ocean east of Madagascar consisting of Mauritius, Réunion and Rodrigues. Several of these rivers are marked by waterfalls. Mangroves occur along the coast near river mouths and estuaries. On Mauritius, small areas of mangrove are present at various locations (Institute of Marine Sciences et al. 1998). On the island of Mauritius, the Grand River South East $(34 \mathrm{~km})$ is the longest river, followed by Rivière du Poste (23 km), Grand River North West (22 km), Rivière La Chaux $(22 \mathrm{~km})$, and Rivière des Créoles $(20 \mathrm{~km})$ (Abell \& Brown 2015). In addition to numerous man-made reservoirs, Mauritius has two natural crater lakes, Grand Bassin and Bassin Blanc. Rodrigues and Réunion are similarly endowed with high-gradient rivers (Abell \& Brown 2005). About 35 species of fish use Mascarene freshwater habitats, and many move between fresh, brackish, and marine waters. Gobies (Gobiidae) dominate the freshwater fish fauna of these islands. Other fish families with freshwater species represented in this ecoregion include Anguillidae, Kuhliidae, and Eleotridae. In the Seychelles only 27 native species that enter freshwater habitats are known.

Inland fishery resources in Madagascar are mostly based on lacustrine fisheries, which cover a total surface area of close to $1,500 \mathrm{~km}^{2}$. The main water bodies include the lakes of Kinkony (139 km²), Anketraka, Ihotry $\left(97 \mathrm{~km}^{2}\right)$ and Tsimanampetsostsa in the western part of the country, Lake Alaotra $\left(220 \mathrm{~km}^{2}\right)$ in the east, and Lake Itasy in the Eastern Highlands ecoregion (Breuil et al. 2014).

\subsection{Patterns of overall species richness}

Madagascar's freshwater ichthyofauna exhibits a high level of endemism, a result of the island's long-term isolation from other Gondwanan landmasses (Sparks \& Smith 2004a). The origins of Madagascar's extant vertebrate fauna have perplexed biologists and have been dubbed "one of the greatest unsolved mysteries of natural history". Given a near complete absence of fossil evidence of Cretaceous age, paleontologists argue that Madagascar's extant and recently extinct vertebrate faunas, including freshwater fishes, owe their origins to Cenozoic colonisation via trans-oceanic dispersal. However, recovered phylogenetic patterns for all freshwater fish groups demonstrate that Madagascar's freshwater fishes owe their origin to the Mesozoic break up of Gondwana, not Cenozoic oceanic dispersal (Sparks \& Smith 2004a; Chakrabarty et al. 2012). Only a single sister-group relationship (Pantanodon) is recovered between a Malagasy and African lineage (between landmasses isolated for ca. 165 Myr by, at most, $430 \mathrm{~km}$ ). In addition, the sister taxa to all other Malagasy freshwater fish clades are present on Gondwanan landmasses separated from Madagascar by thousands of kilometers of open ocean since the Early Cenozoic (e.g. India/ Sri Lanka, Australia, Seychelles) (Sparks \& Smith 2005a).

Madagascar freshwater habitats are also home to numerous euryhaline and marine species. These species can ascend quite far up river courses and their dispersal to higher 
elevations is limited by important ecological barriers such as rapids and waterfalls. Freshwater fish species are quite rare at high elevations, due both to barriers to upstream dispersal and lack of productivity (food sources) in these habitats. Only fish species capable of breaching these obstacles can reach high altitudes, and include members of Anguillidae (freshwater eels) and Gobiiformes (eleotrids and gobies) as well as other related families.

Although the list is not exhaustive, about 273 fish species occur in Madagascan and Mascarene freshwater habitats (Daget et al. 1986; DeRham 1996; Raminosoa et al. 2002; Sparks \& Stiassny 2003; 2008; Froese \& Pauly 2017). Thirtyeight of these represent introduced fish species.

For Madagascar, there currently are 183 native freshwater fishes species inventoried (Froese \& Pauly 2017), of which 106 are endemic to the island (Figure 3.1). However, it is worth noting that numerous new endemic freshwater species remain to be formally described, including several bedotiid rainbow fishes and cichlids (Sparks \& Stiassny 2003 ; 2008). Non-described endemics have not been assessed under this project.

According to Froese \& Pauly (2017), of the Mascarene islands, Mauritius has the highest number of native fish species that enter freshwater habitats (45), followed by Réunion (42), and the two islands share many native species in common. For Comoros, 30 native freshwater fish species are reported. In the Seychelles islands, there are only 27 native freshwater fishes, two of which are endemic:
Pachypanchax playifairii and Parioglossus multiradiatus (Figure 3.1). Rodrigues has a depauperate freshwater fish fauna comprising only 10 native species.

In Madagascar, $13 \%$ of the overall fish species are introduced/exotic species. These species have not been assessed as part of this project. However, from an abundance perspective, exotic species now comprise the vast majority of individuals collected throughout most of the island's freshwater systems. It is now extremely rare to find localities where fish assemblages are not overwhelmingly dominated by exotics (Sparks \& Stiassny 2003; 2008). In general, these isolated locations comprised of primarily native/endemic species are in intact forest or small isolated floodplain lakes that have remained relatively pristine.

There are currently no known endemic fish species reported from Comoros, Réunion or Rodrigues. The level of endemism for freshwater fishes in Madagascar is high due to the islands long-term isolation from other Gondwanan landmasses, and there are many drainage basins with exceptional local endemism. For Cichlidae and Bedotiidae, almost every system has its own endemic species. In Madagascar, the two richest regions in terms of native fish diversity and endemism are the north-western basins and eastern lowlands (Sparks \& Stiassny 2003 ; 2008). In contrast, some areas are completely devoid of fishes, often coinciding with the mountainous areas such as Ankaratra or the top of the Tsaratanana massif. However, for the Bongolava, Makay, and Lambosina regions, the absence of recorded fishes is probably due to lack of effective surveying and sampling (Figure 3.2).

Figure 3.1 Percentage of native, endemic and introduced freshwater fish species in the Indian Ocean islands hotspot including non-described species (Froese \& Pauly 2017; Sparks \& Stiassny 2008).
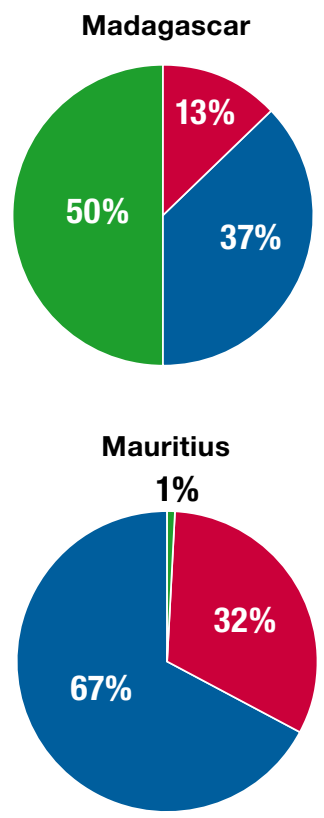
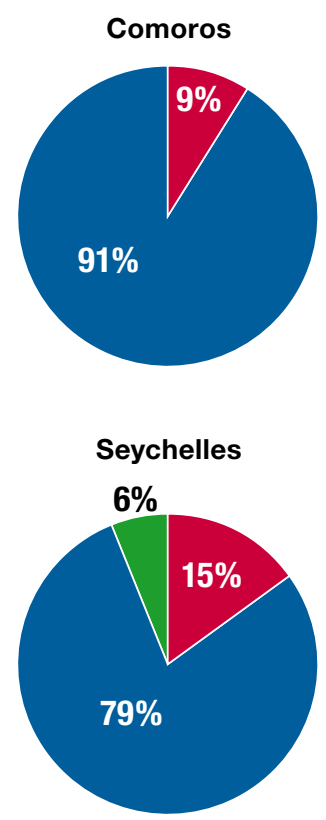
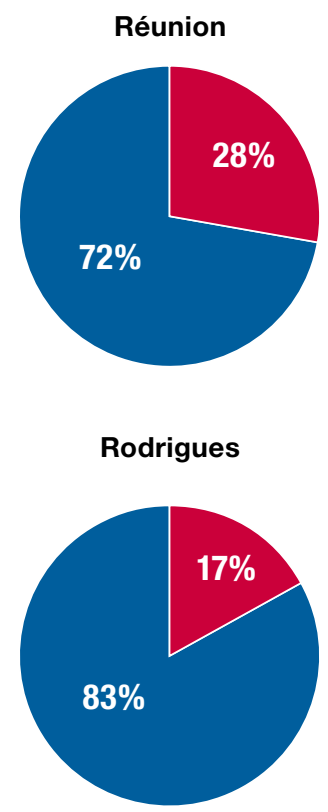

Legend: Endemic $\quad$ Native $\quad$ Introduced 


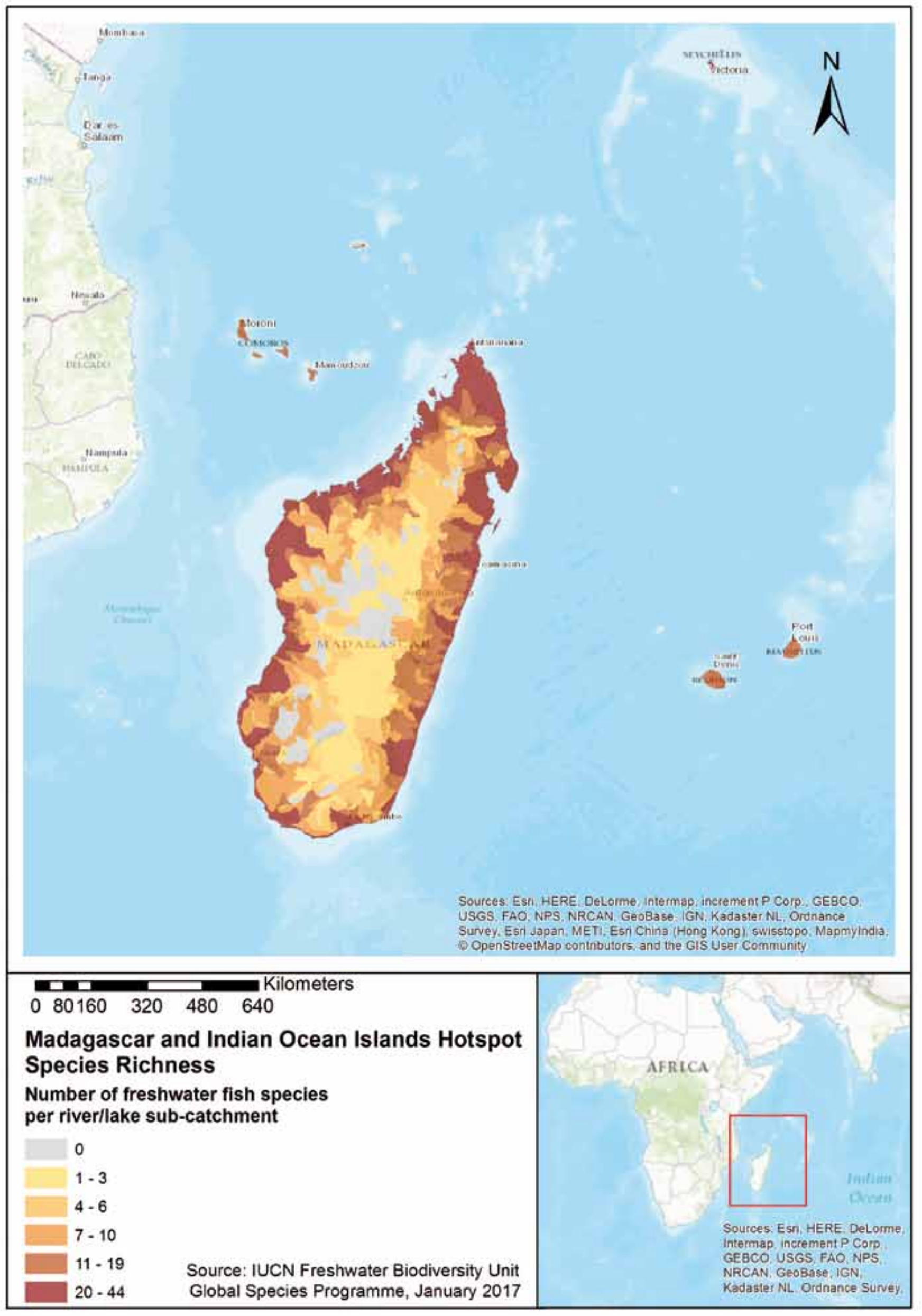




\subsection{Conservation status}

The conservation status of $\mathbf{1 4 5}$ freshwater fish species from Madagascar and Indian Ocean islands hotspot was assessed using the IUCN Red List Categories and Criteria Version 3.1 (IUCN 2012). The results of the assessments are summarised in the table below and the list of species can be found in Annex 3.1. Approximately $58 \%$ of all freshwater fish species assessed are endemic.

Overall, 50 freshwater fish species - representing about 34\% of all freshwater fish species assessed in the hotspot, are threatened with extinction. Assuming that all Data Deficient (DD) species are threatened in the same proportion as those species for which enough information was available, the percentage of threatened fish species increases to $43 \%$. If we consider only Madagascar island endemics, this number rises to $78 \%$ - assuming that the DD endemic species are threatened in the same proportion. These figures highlight the severity of threat to the endemic freshwater fishes in the hotspot. Two species are reported as Extinct (EX) (Ptychochromis onilahy and Pantanodon madagascariensis), although this is probably an underestimate of the true numbers as recent surveys have failed to locate a number of once relatively common species, including the endemic

Table 3.1 The number of freshwater fish species and number of endemic fish species in each Red List Category for the entire hotspot.

\begin{tabular}{|l|l|c|c|}
\hline \multirow{2}{*}{ IUCN Red List Categories } & $\begin{array}{c}\text { Total no. } \\
\text { species }\end{array}$ & $\begin{array}{c}\text { No. endemic } \\
\text { species }\end{array}$ \\
\hline \multirow{3}{*}{$\begin{array}{l}\text { Threatened } \\
\text { categories }\end{array}$} & Critically Endangered (CR) & 14 & 14 \\
\cline { 2 - 4 } & Endangered (EN) & 30 & 30 \\
\cline { 2 - 4 } & Vulnerable (VU) & 6 & 6 \\
\hline \multirow{3}{*}{$\begin{array}{l}\text { Other } \\
\text { Categories }\end{array}$} & Near Threatened (NT) & 2 & 1 \\
\cline { 2 - 4 } & Least Concern (LC) & 64 & 13 \\
\cline { 2 - 4 } & Data Deficient (DD) & 27 & 18 \\
\cline { 2 - 4 } & Extinct (EX) & 2 & 2 \\
\hline \multicolumn{2}{|l|}{ Total number of species assessed } & $\mathbf{1 4 5}$ & $\mathbf{8 4}$ \\
\hline
\end{tabular}

cichlids Paretroplus maculatus and Ptychochromis insolitus (Sparks, pers. obs.).

\subsubsection{Threatened species}

The threatened freshwater fish species are largely concentrated in the North-Western ecoregion of Madagascar (e.g. Galoka and Sambirano regions, Anjingo and Sofia river basins) and in south-eastern drainages, including the Mananara, Mananjary, and Mangoro rivers (Figure 3.4). The North-Western ecoregion harbours the most diverse freshwater ichthyofauna (Sparks \& Stiassny 2003; 2008), including several threatened endemic species, and is home to a radiation of endemic cichlids of the genus Paretroplus, all of which are highly threatened and rapidly declining in numbers. Many Malagasy fishes are locally endemic; their distribution being restricted to a single river basin or/and with an estimated Extent of Occurrence (EOO) of less than $20,000 \mathrm{~km}^{2}$. For example, Ptychochromis inornatus and Arius uncinatus are confined to the Anjingo/ Ankofia basins, Rheocles vatosoa is only known from the upper reaches of the Lokoho basin, and Katria katria and Oxylapia polli are confined to more or less pristine stretches of the Nosivolo River (IUCN 2017). Most of these species are assessed at least as Vulnerable (VU).

Data were lacking for some species and it was not possible, for example, to estimate the levels of decline for several species. Researchers have, however, reported that endemic species are no longer found in many sampling sites (Kiener 1959; 1966; De Rham 1996; DeRham \& Nourrisat 2002; Sparks 2008; Sparks \& Stiassny 2003; 2008; Zimmerman 2014). The Sofia basin provides a good example of this situation. This area holds at least seven locally endemic species: Ptychochromis insolitus, Paretroplus nourrisati, Paretroplus gynmopreopercularis, Paretroplus menarambo, Rheocles derhami, Arius festinus and Sauvagella robusta (Stiassny \& Rodriguez 2001; Ng

Figure 3.3 The proportion (\%) of freshwater fish species in each IUCN Red List Category in Madagascar and the Indian Ocean islands hotspot.

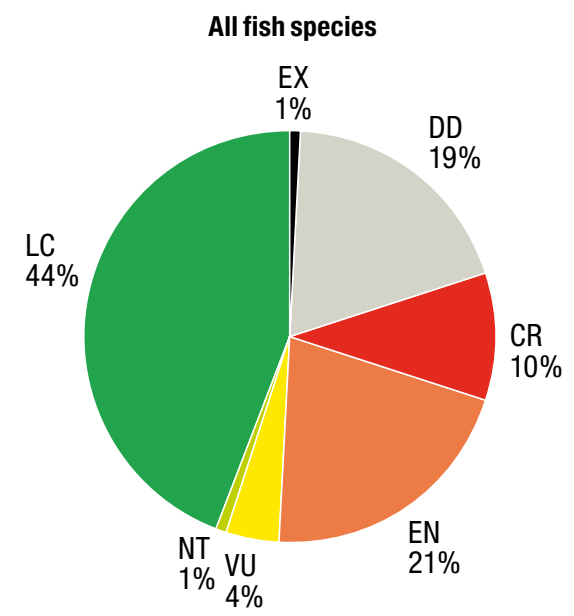

Endemic fish species

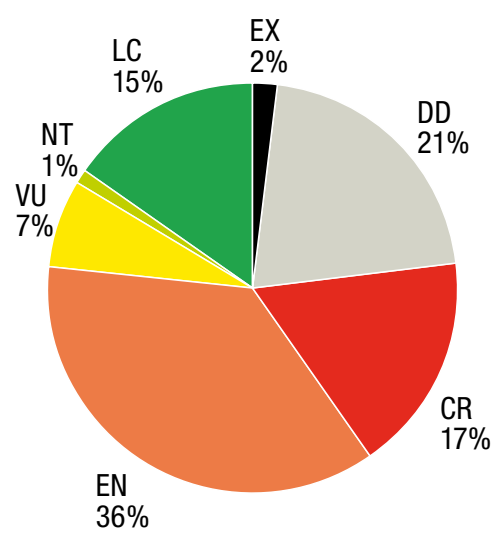


Figure 3.4 Numbers of freshwater species that are threatened within each sub-catchment across Madagascar and the Indian Ocean islands hotspot.

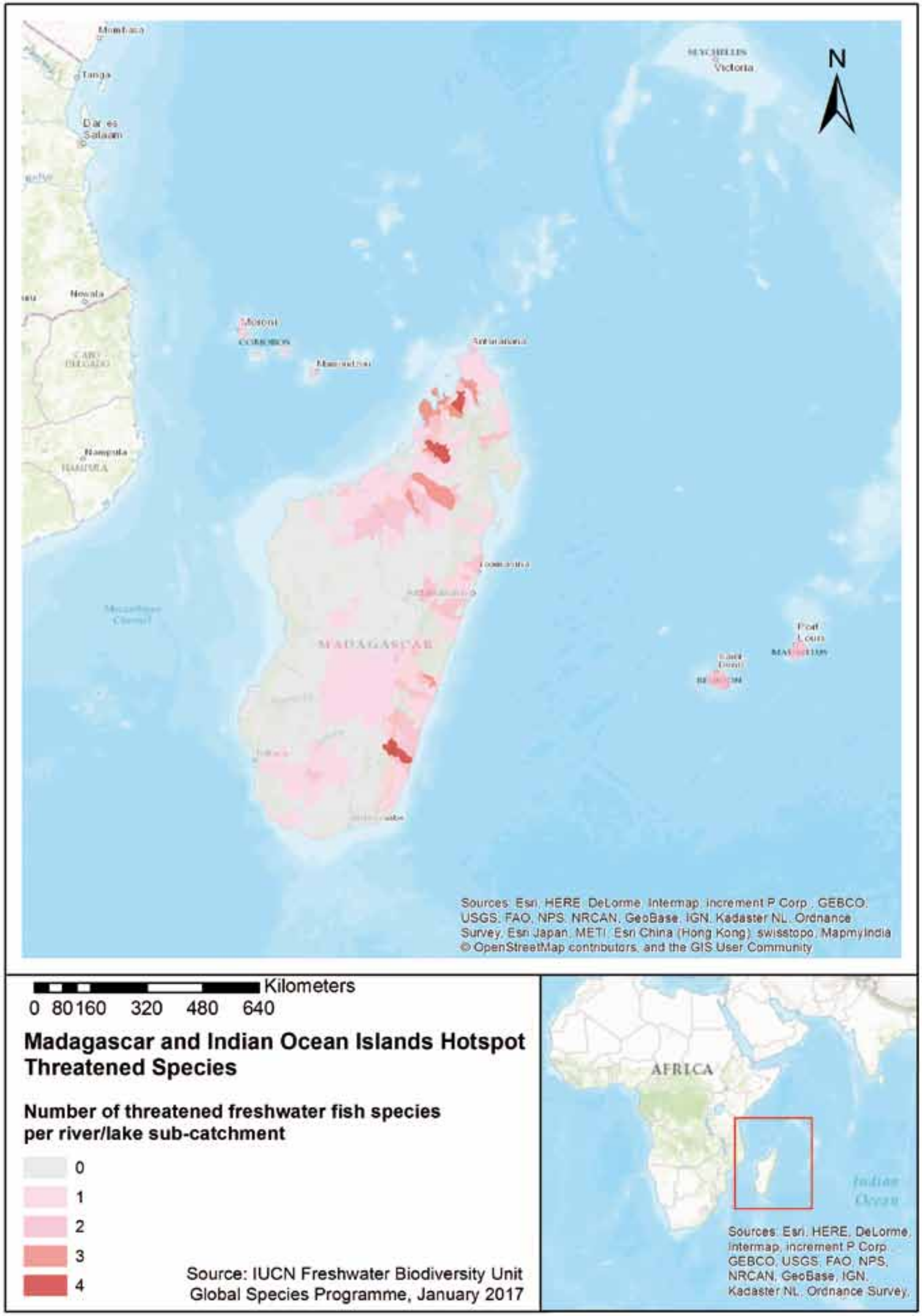


\& Sparks 2003; Stiassny \& Sparks 2006; Sparks 2008; Andriafidison et al. 2011). The majority of the aquatic habitats within the Sofia basin are now severely degraded and the system is dominated by exotic species. The landscape is covered with burnt trees, and burning continues unabated within the river basin. Similar deforestation and burning practices have severely impacted most of the river and lake basins throughout Madagascar (Zimmerman 2014). An important portion of the Mangarahara and Amboaboa river basins providing suitable habitat for the seven endemic species listed above is now completely desiccated due to the construction of a dam upstream and drought conditions in recent decades (DeRham \& Nourrisat 2002), or has very little flowing water seasonally (Zimmerman 2014). This has had devastating environmental consequences, including the severe decline and probable extinction of several endemic fish species. As a result, the distribution of some of these endemic species (i.e. Paretroplus nourrisati, Paretroplus gynmopreopercularis, Rheocles derhami, Arius festinus and Sauvagella robusta) is now restricted to the upper reaches of the Amboaboa River, a small tributary of the Sofia, where the habitat remains more intact with more consistent water flow (Mcdiarmid 2014). Others of these species are restricted to Lake Tseny, which is somewhat isolated, is under only limited fishing pressure, and still harbours multiple endemic cichlids, including Paretroplus gynmopreopercularis, Paretroplus menarambo and Paretroplus lamenabe (Andriafidison et al. 2011; Sparks, pers. obs.).

Another species-rich habitat comprises the Betsiboka River drainage and its satellite lakes in north-western Madagascar. However, overfishing and invasive species such as Channa maculata and Xiphophorus helleri are posing severe threats to endemic species. Lake Ravelobe which up until the turn of the century supported healthy populations of at least three endemic cichlids, Paratilapia polleni, Paretroplus kieneri, and Paretroplus maculatus, is now covered entirely by water hyacinth and only introduced tilapias were caught there in recent surveys (Sparks 2011b). Recent survey efforts throughout the Betsiboka river drainage have failed to locate any remaining populations of Paretroplus maculatus (Sparks 2011; Sparks, pers. obs.). The swift habitat decline in Lake Ravelobe and the consequent disappearance of the lake's native species is currently being witnessed throughout Madagascar's other freshwater ecosystems and does not bode well for the island's endemic freshwater fishes.

\subsubsection{Data Deficient species}

Species assessed as Data Deficient (DD) are those for which their status remains uncertain due to poor knowledge, such as regarding their taxonomic status, distribution, or population status. This lack of basic information means it is often impossible to make a reliable assessment of the extinction risk for a species. Many endemic Malagasy freshwater fish species are, for example, only known from one or a few specimens from a single collection site. Twentyseven species are ranked as DD for the hotspot (Figure 3.5). Much information is outdated and some species are only known from information presented in the original description (e.g. from the type locality). This represents $19 \%$ of all the assessed species and underscores the conclusion that a considerable amount of additional surveying and monitoring of Madagascar and Indian Ocean islands hotspot is required, particularly in western Madagascar, in the east around the Masoala and Makira national parks, and the area extending into the Mananara du Nord River to the south. South-Eastern Madagascar, particularly the highland regions, also remains poorly sampled for freshwater fishes (Martinez et al. 2015). Given the abundant threats to freshwater fish species and the high numbers of DD species found throughout the hotspot, it is reasonable to expect that further research and sampling might reveal evidence of extinction for some of these DD species.

\subsubsection{Red List Index}

The IUCN Red List Index (RLI) measures trends in the overall extinction risk of sets of species, as an indicator of trends in the status of biodiversity (Bubb et al. 2009). In this way, the RLI serves as an indicator to track progress towards the Sustainable Development Goals (SDGs), the Convention on Biological Diversity (CBD) Aichi Biodiversity Targets, and various multilateral environmental agreements such as the Ramsar Convention (Butchart et al. 2005; 2006; 2010; Tittensor et al. 2014; Visconti et al. 2015).

\section{Calculation}

To calculate the RLI, all species in a group must have been assessed against the IUCN Red List Categories and Criteria at least twice. The first Red List assessment of Madagascar's endemic freshwater fishes took place in 2004 (IUCN 2004). The second assessment conducted under this project in 2016 enabled calculation of the RLI for 69 endemic freshwater fish species from the hotspot. Endemic species assessed for the first time in 2016 (15 spp.) were excluded from the RLI calculation as it was not possible to compare them against previous assessments.

The RLI is calculated from the number of species in each Red List Category and the number changing Categories between assessments as a result of genuine improvement or deterioration in status (Bubb et al. 2009). Put simply, the number of species in each Red List Category is multiplied by the Category weight (which ranges from 0 for Least Concern, 1 for Near Threatened, 2 for Vulnerable, 3 for Endangered, 4 for Critically Endangered and 5 for Extinct in 
the Wild and Extinct). These products are summed, divided by the maximum possible product (the number of species multiplied by the maximum weight), and subtracted from one. This produces an index that ranges from 0 to 1 . An RLI value of 1.0 equates to all species being categorised as Least Concern, and hence that none are expected to go extinct in the near future. An RLI value of zero indicates that all species have gone Extinct (Bubb et al. 2009). Mathematically the calculation of the RLI can be expressed as (Butchart et al. 2007):

$$
R L I_{t}=1-\frac{\sum_{s} W_{c(t, s)}}{W_{\mathrm{EX}} \cdot N}
$$

\section{Results}

Ten endemic freshwater fishes experienced genuine deteriorations in their Red List status. For 2016, the RLI value for the endemic freshwater fishes of Madagascar was 0.5107. This value decreased by $10.62 \%$ ( 0.5714 to 0.5107$)$ over the period of 2004 to 2016 (Figure 3.6). The decreasing overall $\mathrm{RLI}$ for the endemic freshwater fishes presented in the graph below indicates the expected rate of extinctions for these species across the hotspot is increasing. The value of the RLI for endemic freshwater fishes is also notably lower than for the other groups shown, further confirming the very high risk to species wholly reliant on freshwater ecosystems.

Extinction is a key measure of biodiversity loss that has clear relevance to ecological processes and ecosystem function and has resonance with the public and decision-makers. When interpreting these results it is important to note the exclusion of non-endemic fish species in the analysis. Direct comparison of the freshwater fishes RLI with RLIs for the other species groups that also included non-endemics (birds, mammals, corals and amphibians) was possible as each species is weighted according to the proportion of its range within Madagascar. For example, all endemic species, with $100 \%$ of their range in Madagascar such as freshwater fishes, are given a weighting of "1", whereas a species with only $25 \%$ of its range in Madagascar would be given a weighting of " 0.25 ".

\subsection{Main threats}

The main threats to Madagascar's freshwater ecosystems are well described by Sparks \& Stiassny (2003; 2008), Sparks (2011a), and Beansted et al. (2003). The bottom line is that Madagascar's native freshwater fishes are in serious trouble. Narrow endemism and widespread habitat degradation are a dangerous combination. Throw in competition with an array of exotic species, and you have the ingredients for a catastrophic loss of biodiversity (Sparks \& Stiassny 2003; 2008; Sparks 2011a). Essentially, freshwater fishes are
Figure 3.6 IUCN Red List Index of species survival for Madagascar endemic freshwater fish species based on genuine changes in the number of species in each IUCN Red List Category over time (2004-2016). The graph also shows change in aggregate extinction risk across range-weighted taxonomic groups (birds, mammals, corals and amphibians) in Madagascar resulting from genuine improvements or deteriorations in the status of individual species (Birdlife International, unpublished data). An RLI value of 1.0 equates to all species being categorised as Least Concern, with no species expected to go extinct in the near future. An $\mathrm{RLI}$ value of zero indicates that all species have gone Extinct.

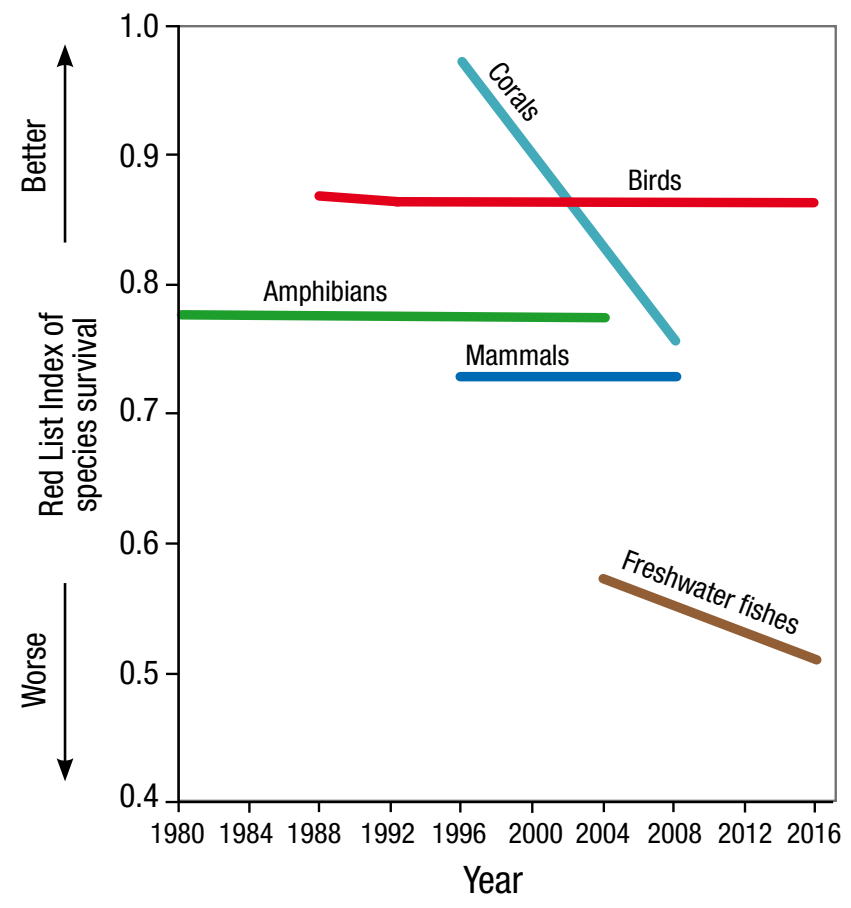

afforded little direct protection within the isolated patches of protected forest that remain throughout the country, given that most of these forest reserves exist at higher elevation, where there is little suitable habitat for fishes other than a few species of rheophilic gobioids (gobies and eleotrids). In addition it is difficult, if not impossible, to find a water catchment that has not been affected to some degree by deforestation and the negative effects of the resulting siltation persist downstream to the sea (Sparks 2011a). Over two and a half decades of ichthyofaunal survey work in Madagascar, we have witnessed the severe decline of aquatic habitats throughout Madagascar, with the result that nearly every species of endemic freshwater fish has exhibited drastically reduced range size and extreme reduction in abundance over this limited time period.

\section{Deforestation, habitat loss and sedimentation}

Widespread deforestation has led to increased sedimentation of river habitats, particularly spawning beds, and erosion of river banks and riparian habitat, leading to permanent alterations in water flow, quality and nutrient input. For example, the Sofia River drainage basin (Figure 3.7) is an important system for a number of endemic species found nowhere else, such as Critically Endangered species (CR) 
Figure 3.5 The distribution of Data Deficient freshwater fish species across Madagascar and the Indian Ocean islands hotspot. The map shows only those species with distribution information could be mapped.

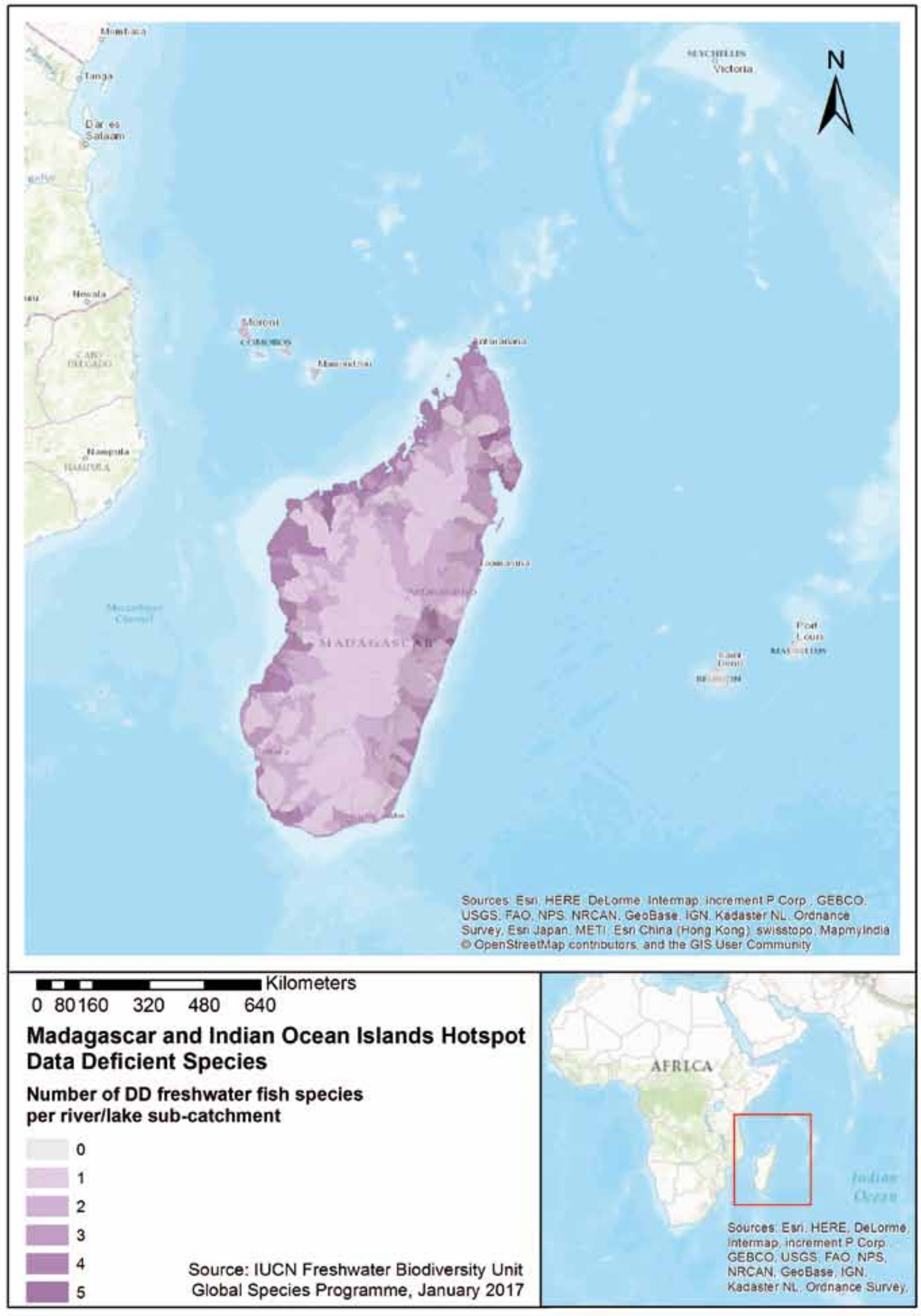


Rheocles derhami and Ptychochromis insolitus. However, due to a massive sedimentation load following extensive deforestation within the catchment, the river bed is now very shallow and sandy such that daytime water temperatures are now very high. Consequently, this type of habitat is no longer suitable for the majority of the endemic species that occur in the basin. Only exotic and some hardy native species can survive under these conditions. Sedimentation due to widespread deforestation now affects the majority of western rivers in Madagascar.

\section{Introduced invasive fish species}

Numerous non-native freshwater fish species have been introduced for fishery and aquaculture purposes in Madagascar, including the common carp (Cyprinus carpio), trouts (Salmo spp.), several species of tilapiines, largemouth (black) bass (Micropterus salmoïdes), the fibata (Ophiocephalus striatus), the Asian snakehead (Channa maculata), and the bonytongue Heterotis niloticus (Breuil et al. 2014). These species present a major threat to many of the endemic species through predation, disruption of nesting sites, and competition for resources. By far the worst offenders in terms of their negative impact on native fishes are the introduced tilapiines and Asian Snakehead (Channa maculata).

Despite its small size, the introduced species, Xiphophorus helleri (Figure 3.8), is considered a major predator of endemic fish eggs and larvae. Where it is found, small endemic species (Bedotiidae or Aplocheilidae) have disappeared entirely. It is the same situation with Channa maculata. The decline of Paratilapia throughout much of their once extensive range also coincides with the arrival of Channa around Antananarivo (Raminosoa 1987).

\section{Overfishing}

Overfishing is a major threat to many native freshwater fish species in Madagascar, and has led to the local extirpation of many of the larger, commercially important fishes (i.e. the

Figure 3.7 River Sofia heavily impacted by sedimentation. (C) Tsilavina Ravelomanana

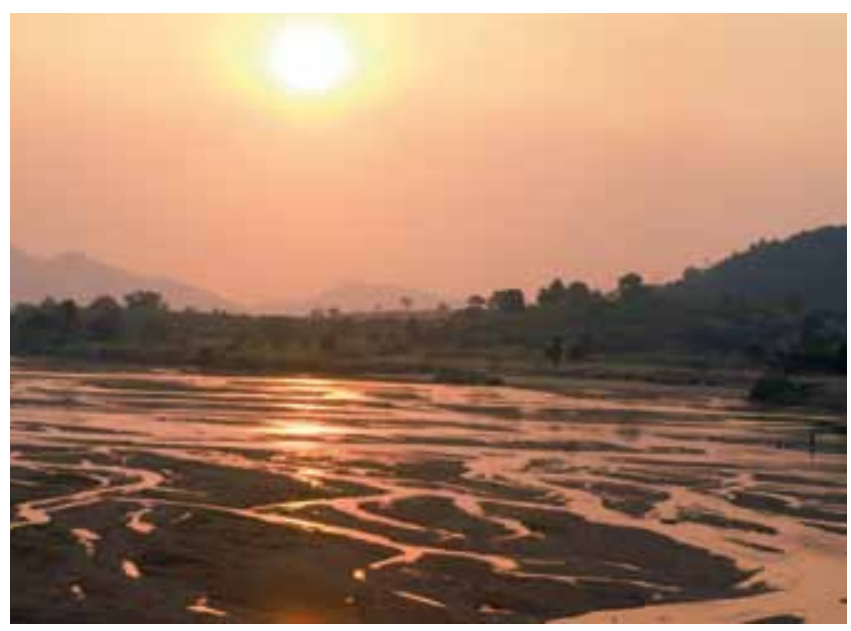

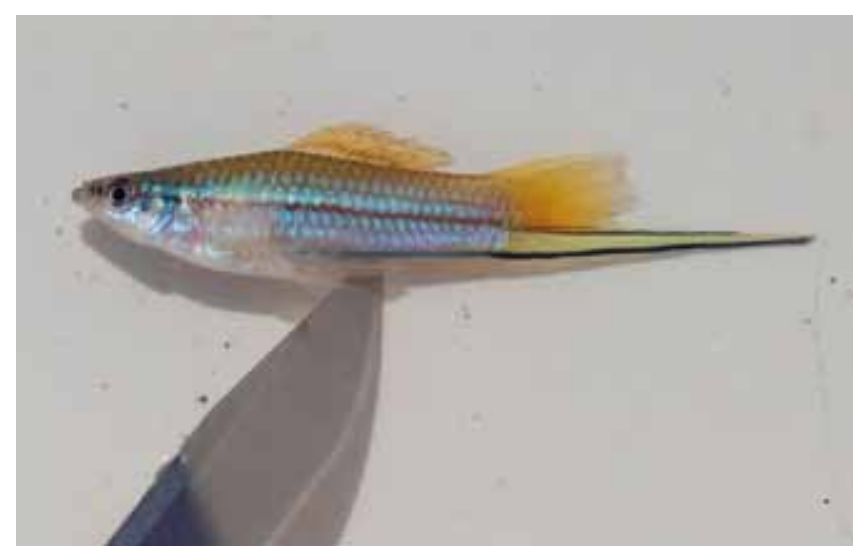

Figure 3.8 Introduced invasive alien species Xiphophorus helleri. () Tsilavina Ravelomanana

endemic cichlids). In many freshwater bodies, such as in the Andapa basin and Lake Kinkony, increased harvesting, including the use of small mesh gill nets, has led to changes in fish community structures and distributions, with an overall reduction in recruitment. Poorly managed fisheries, the use of small mesh nets (e.g. mosquito nets) and unselective fishing gear, fish poisons and explosives are commonly used in Madagascar (Figure 3.9). The administration responsible for regulating these kinds of fishing practices and managing the inland fishery sector is the Ministry of Fisheries and Fishery Resources (MFFR) Inland Fishery Section. However, there is a lack of sufficient human and financial capacity for implementation of standards to support management of inland fisheries, such as effective monitoring, control and surveillance (MCS) (Breuil et al. 2014).

\section{Mining}

Mining is widespread in Madagascar, including at both industrial and artisanal scales, and has been growing rapidly over the past decade (Figure 3.10; Filou 2016). In many locations, in addition to impacts at the mine site itself, and the impact of the associated drains and pipelines, there are negative impacts for extensive distances downstream from the mining site.

Figure 3.9 Fishers using small mesh mosquito net. (C) Tsilavina Ravelomanana

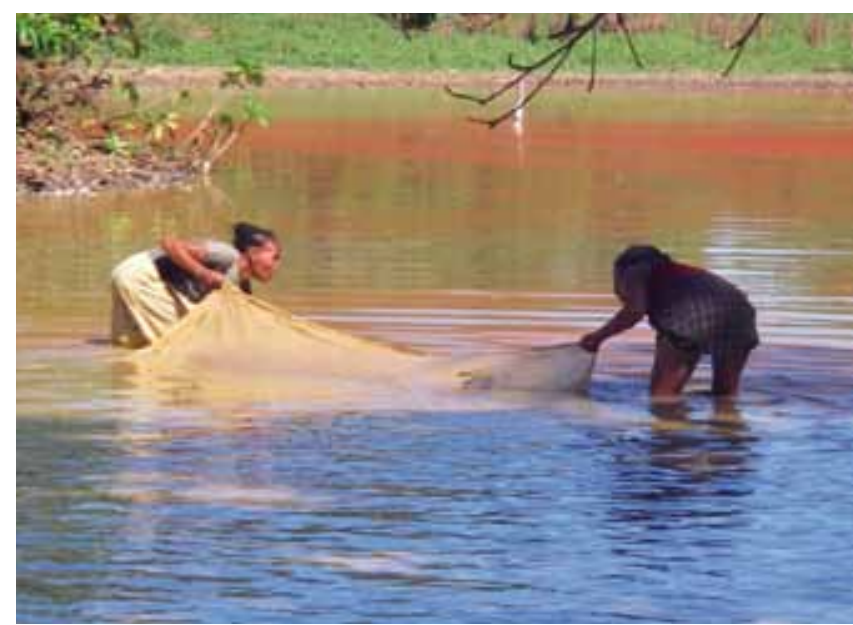




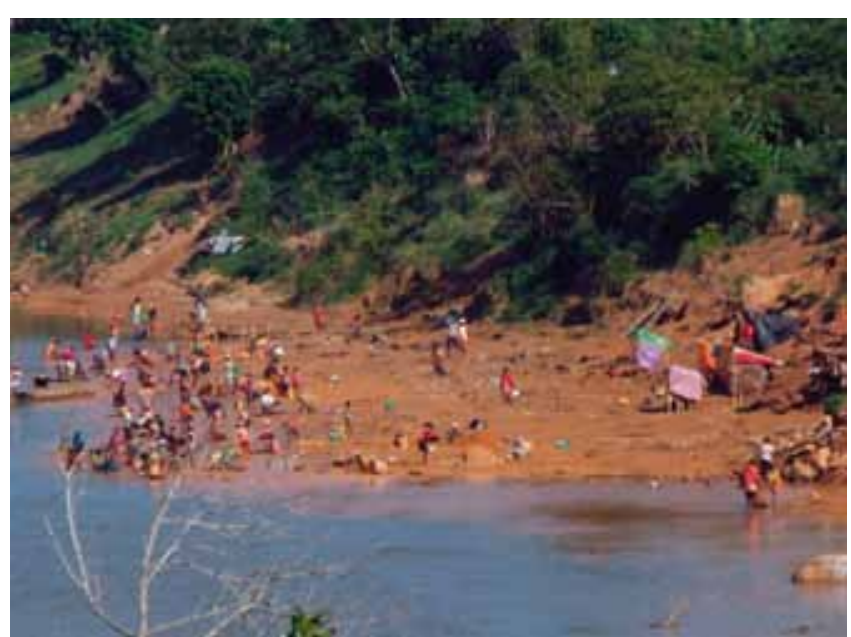

Figure 3.10 Small-scale artisanal gold mining on the Rianila River. (C) Tsilavina Ravelomanana

\section{Conversion of wetland habitats for farming}

Drainage and conversion of wetlands to cultivated land, primarily for rice cultivation or for aquaculture purposes, is severely degrading wetlands in many parts of Madagascar. A number of taxa (e.g. Pantanodon spp.) are dependent upon wetland habitats such as lowland coastal marshlands and the near entire loss of these habitats throughout Madagascar has had a clear negative impact on these extremely restricted range endemic taxa that require specialised habitats.

\section{Climate change and extreme events}

Climate change is becoming an increasing threat throughout the hotspot. A rise in surface water temperatures and increased frequency and intensity of extreme events such as cyclones, floods and periods of severe droughts, are causing increased sedimentation, reduced water quality and general habitat loss and degradation (Figure 3.11). The combination of these climatic events with the threats listed above, presents a severe threat to native freshwater fish populations.

Figure 3.11 Small tributary of Mangoky in Makay heavily impacted by the effects of drought and sedimentation. (C) Tsilavina Ravelomanana

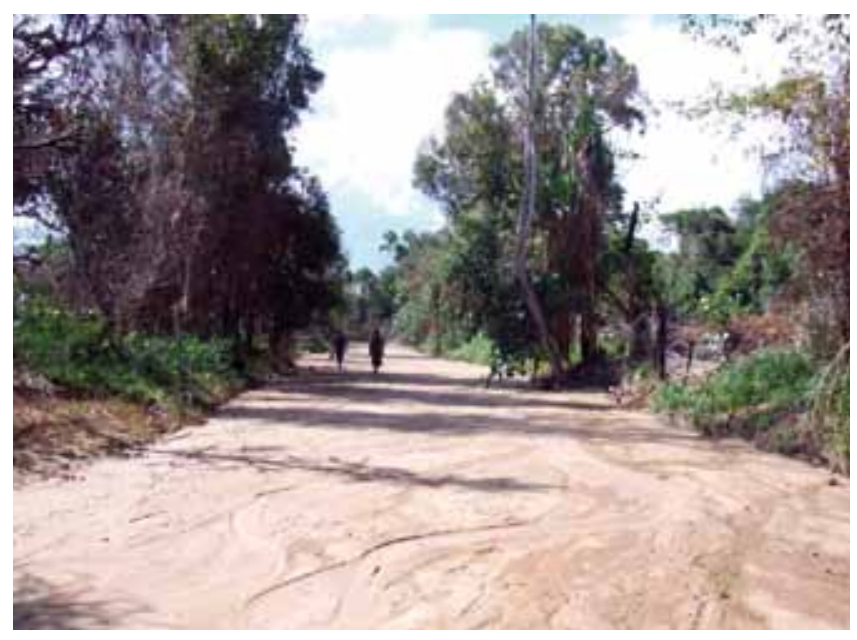

\subsection{Conservation recommendations}

The findings of this assessment confirm that the freshwater fishes of Madagascar and the Indian Ocean islands hotspot are highly threatened, and the situation is continuing to get worse. Freshwater ecosystems need to be better represented in the network of protected areas, included as legitimate conservation targets in national biodiversity strategies, and addressed within environmental impact assessments. The economic value of wetlands also needs to be determined and presented for consideration within development planning strategies.

Given the importance of inland fisheries to local economies in Madagascar, in-situ conservation should always be accompanied by plans for long-term sustainable use for many species.

Fisheries regulations need to be viewed as legitimate by stakeholders, in order to gain their support and compliance. Devolution of governance to indigenous and local communities, shared governance, and comanagement arrangements are a means to attain this legitimacy, and have contributed to successful fisheries management outcomes, especially in small-scale fisheries in other developing countries (Secretariat of the Convention on Biological Diversity 2014).

Maintenance of natural flow regimes (including quantity, quality and timing of water flows) is essential and the E-Flows Tool provides guidance on the methods to do this (Dyson et al. 2008). Where the modification of river flows is unavoidable in order to meet essential human requirements the E-Flows approach should be applied in order to minimise impacts.

Implementation of Invasive Alien Species (IAS) regulations, risk assessments and deliberate site and population specific management of IAS need to be put into practice (Kull et al. 2014). Actions both at catchment and site scale must be taken to minimise the introduction and movement of invasive species to catchments where they are not currently present.

\section{Short-term recommendations:}

- Encourage ex-situ breeding of threatened native fish species at aquaculture facilities in Madagascar.

- Expand the ex-situ conservation activities of the Species Survival Program (SSP) where aquariums across the world hold and breed endemic Malagasy species that are highly threatened in the wild (CR and EN species).

- Identify those areas that remain relatively pristine and that hold endemic species for potential protection through the national protected areas network and/or through private or Non-Governmental Organisations (NGO) efforts. 
- Refer to the freshwater Key Biodiversity Areas identified for fishes (see Chapter 9) for consideration within the existing and a future expanded national protected areas network.

- Focus management actions within existing protected areas to protect and sustainably manage those freshwater fish species identified to be present. This may require inclusion of management actions at the catchment scale and not just within the sites themselves.

- Identify new Ramsar sites for the conservation and wise use of freshwater fish species.

\section{Long-term recommendations:}

- Develop an information, education and communication programme to raise awareness of Malagasy freshwater fishes, their importance and the threats they face.
- Update Malagasy freshwater fishes species list in the Malagasy fisheries legislation.

- Include a greater focus on freshwater fish species in the countries National Biodiversity Strategy and Action Plans (NBSAPS) using the information presented here to guide proposed actions and to improve the basic information base and recommendations for freshwater fishes.

- Adopt Integrated River Basin Management approaches throughout, as recommended by CBD (Ramsar 2010).

\subsection{Research actions}

Information on the distribution and status of many freshwater species remains poor. We therefore recommend additional field surveys to provide up-to-date knowledge

\subsection{Species in the spotlight}

\section{Oxylapia polli (Kiener \& Maugé 1966)}

The Songatana (Oxylapia polli), an endemic ptychochromine cichlid (Sparks 2004; Sparks \& Smith $2004 a$ ), is only known from the rapids and rocky areas within the Nosivolo river, a tributary of the Mangoro river in the highlands of eastern Madagascar. This species is the most rheophilous Madagascan cichlid, exhibiting specialisations to a life in a swift flowing environment, including a dorsoventrally compressed body and welldeveloped, robust pelvic fins (De Rham \& Nourrisat 2002; Sparks 2008). The fish is rare and difficult to catch within its very limited range (De Rham 1999). However, the species is subject to high fishing pressure outside regulated areas. Although the Nosivolo River is now a protected area and a Ramsar site, its restricted range makes it particularly susceptible to habitat loss and degradation through siltation caused by deforestation. Therefore, it is assessed as Endangered and continued monitoring is recommended to evaluate the effectiveness of this protection.

Figure 3.12 Oxylapia polli (EN). ๑) Paul V. Loiselle

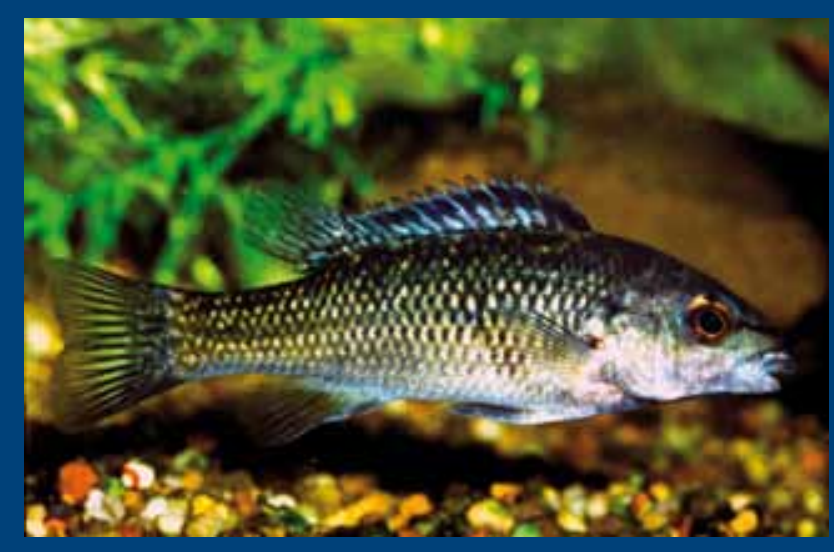

Rheocles vatosoa (Stiassny et al. 2002)

The Endangered species Rheocles vatosoa is locally endemic to the upper reaches of the Lokoho River in NorthEastern Madagascar. The species was formerly restricted to the streams that drain the slopes of the surrounding mountains of the Andapa basins (Stiassny et al. 2002). A recent survey of the Andapa basin by Ravelomanna and the Duke Lemur Center, however, shows that many populations within its former range are now extinct, including populations in the Marovato River at Ambodivohitra, the Andramonta River at Ambodihasina, and the Andrakata River at Andrakata village. Although the catchment of the streams in the Lokoho basin is protected by the Marojejy and Anjanaharibe Sud national parks, the species is threatened by ongoing deforestation, the use of small mesh mosquito nets in fishery activities and the presence of the exotic species Gambusia holbrooki, Xiphophorus hellerii and Channa maculata. The central part of the species' range has also been converted into extensive areas of rice fields where $R$. vatosoa is no longer present.

Figure 3.13 Male Rheocles vatosoa (EN). ( ) Paul V. Loiselle

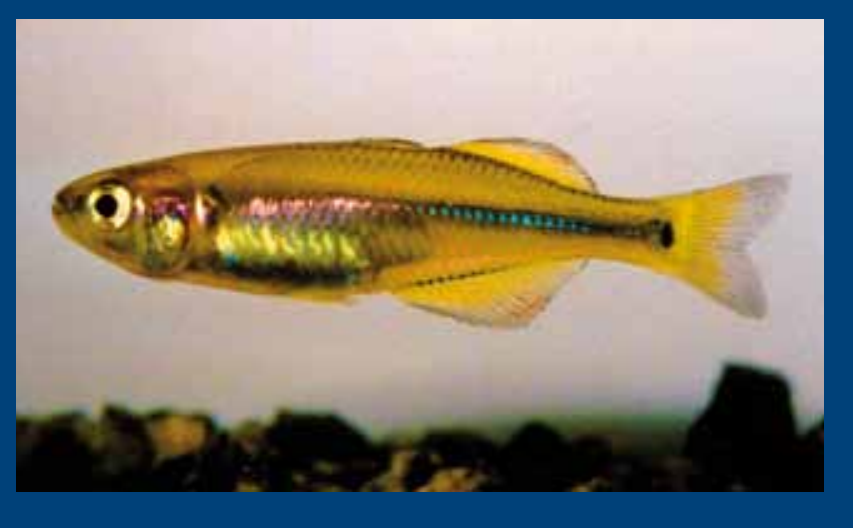


on the overall distribution of endemic freshwater species and their threats. This basic information on species is essential for informing decision-making on environmental development and conservation priorities throughout the hotspot. Many species have not been recorded for more than 100 years and only from limited field surveys - their continued existence and full distribution needs to be confirmed. We strongly recommend that fieldwork be conducted as a collaborative effort involving both national and international scientists to also build regional scientific capacity.

\subsection{References}

Abell, R.A. and Brown, A. 2005. Mascarenes. p. 272-275. In: Thieme, M.L., R.A. Abell, M.L.J. Stiassny, P. Skelton, B. Lehner, G.G. Teugels, E. Dinerstein, A.K. Toham, N. Burgess and D. Olson (eds.). Fresh-water Ecoregions of Africa and Madagascar: A Conservation Assessment. Island Press, Washington, DC. 431 p.

Aldegheri, M. 1972. Rivers and streams on Madagascar. In: Battistini, R., Richard-Vindard, G. Biogeography and ecology in Madagascar, 261-310. https://doi. org/10.1007/978-94-015-7159-3_8

Andriafidison, D., Jenkins, R.K.B., Loiselle, P.V., et al. 2011. Preliminary fish survey of Lac Tseny in north-western Madagascar. Madagascar Conservation and Development 6(2): 83-87.

Benstead, P.J., Douglas, M.M., Pringle, M.C. 2003. Relationships of stream invertebrate communities to deforestation in Eastern Madagascar. Ecological Applications 13(5): 1473-1490. https://doi.org/10.1890/02-5125

Brenon, P. 1972. The geology of Madagascar. In: R. Battistini and G. Richard-Vindard (ed.). Biogeography and ecology in Madagascar. pp. 27-86. The Hague, The Netherlands: DrW. Junk. https://doi.org/10.1007/978-94-015-7159-3_2

Breuil, C. and Grima, D. 2014. Baseline Report Madagascar. SmartFish Programme of the Indian Ocean Commission, Fisheries Management FAO component, Ebene, Mauritius.

Bubb, P.J., Butchart, S.H.M., Collen, B., et al. 2009. IUCN Red List Index - Guidance for National and Regional Use. Gland, Switzerland: IUCN.

Butchart, S.H.M., Walpole, M., Collen, B., et al. 2010. Global biodiversity: indicators of recent declines. Science 328: 1164-1168. Available from http://www.sciencemag.org/ content/328/5982/1164.short. https://doi.org/10.1126/ science. 1187512

Butchart, S.H.M., Stattersfield, A.J., Baillie, J., et al. 2005. Using Red List Indices to measure progress towards the 2010 target and beyond. Philosophical Transactions of the Royal Society of London B 360: 255-268. Downloaded from: http://rstb.royalsocietypublishing.org/ content/360/1454/255.full.
Butchart, S.H.M., Stattersfield, A.J. and Baillie, J. et al. 2006. Biodiversity indicators based on trends in conservation status: strengths of the IUCN Red List Index. Conservation Biology 20:579-581. Downloaded from: http://onlinelibrary.wiley.com/doi/10.1111/j.15231739.2006.00410.x/abstract

Chakrabarty, P., Davis, M.P. and Sparks, J.S. 2012. First reported case of a trans-oceanic sister-group relationship between obligate troglobites. PLOS ONE 7(8): e44083. https://doi.org/10.1371/journal.pone.0044083

Daget, J., Gosse, J.-P. and Thys van den Audenaerde, D.F.E. 1986. Check-list of the freshwater fishes of Africa. Cloffa volume 2.

De Rham, P.H. 1996. Poissons des eaux intérieures de Madagascar. In: Biogeographie de Madagascar. (ed.). W.R. Lourenco: pp423-440.

De Rham, P. and Nourissat, J.C. 2002. Les cichlidés endémiques de Madagascar. Association France Cichlid. Sagrafic, Barcelona, Spain.

De Rham, P. 1999. Oxylapia polli, the enigmatic cichlid of the Nosivolo River. The cichlid room companion. Cichlid Room Companion. Retrieved on January 31, 2018, from: https://www.cichlidae.com/article.php?id=126.

Dyson, M., Bergkamp, G. and Scanlon, J. 2008. Flow: The Essentials of Environmental Flows. IUCN, Gland, Switzerland and Cambridge, UK. xiv+118 pp. Ecological Indicators 45: pp456-464.

Donque, G. 1972. The climatology of Madagascar. In: R. Battistini and G. Richard-Vindard (eds.). Biogeography and ecology in Madagascar. pp. 87-144. The Hague, The Netherlands: Dr W. Junk. https://doi.org/10.1007/97894-015-7159-3_3

Filou, E. 2016. A million artisanal gold miners in Madagascar wait to come out of the shadows. The Guardian. Available at: https://www.theguardian.com/sustainablebusiness/2016/nov/15/gold-rush-madagascars-artisanalminers-could-benefit-from-global-downturn\#img-1

FishBase. 2017. List of Freshwater Fishes reported from Madagascar and the Mascarene Islands. Froese, R. and D. Pauly. (eds.). 2017. World Wide Web electronic publication. Downloaded from: www.fishbase.org (08/2017).

Ng, H.H. and Sparks, J.S. 2003. The ariid catfishes (Teleostei: Siluriformes: Ariidae) of Madagascar With the description of two new species. Occ. Pap. Mus. Zool., Univ. Michigan, 735: 1-21.

Ng, H.H. and Sparks, J.S. 2005. Revision of the endemic Malagasy catfish family Anchariidae (Teleostei: Siluriformes), with descriptions of a new genus and three new species. Ichthyological Exploration of Freshwaters, 16: 303-323.

IUCN. 2004. Assessment of the Threatened Status (2001 IUCN Red List Categories and Criteria) of the Endemic Freshwater Fishes of Madagascar. 
IUCN. 2012. IUCN Red List Categories and Criteria: Version 3.1. Second edition. Gland, Switzerland and Cambridge, UK: IUCN. iv+32pp.

IUCN, 2004. Assessment of the Threatened Status (2001 IUCN Red List Categories and Criteria) of the Endemic Freshwater Fishes of Madagascar.

IUCN. 2017. The IUCN Red List of Threatened Species. Version 2017-1. <http://www.iucnredlist.org>.

Kiener, A. 1959. Le "Marakely à Bosse " de Madagascar. Bulletin de Madagascar. 157: 1-12.

Kiener, A. 1963. Poissons, pêche et pisciculture à Madagascar : Poissons curieux, espèces d'aquarium et poissons fossiles. Place du poisson dans le folklore et dans l'art malgache. Publication C.T.F.T. 31-176.

Kiener, A. and Mauge, M. 1966. Contribution à l'étude systématique et écologique des poisons Cichlidés éndémiques de Madagascar. Mém. M.N.H.N. 40(2): 99pp.

Kiener, A. and Richard-Vindard, G. 1972. "Fishes of the continental waters of Madagascar" In: R. Battistini and G. Richard-Vindard (eds.). Biogeography and ecology in Madagascar. pp. 477-499. The Hague, The Netherlands: Dr W. Junk. https://doi.org/10.1007/978-94-015-71593_15

Kull, C., Tassin, J., and M. Carriere, S. 2014. Approaching invasive species in Madagascar. Madagascar Conservation and Development. 9:2. December 2014.

Martinez, C.M., Arroyave, J., and Sparks, J.S. 2015. A new species of Ptychochromis from southeastern Madagascar (Teleostei: Cichlidae). Zootaxa 4044(1): 079-092. https:// doi.org/10.11646/zootaxa.4044.1.4

Mcdiarmid, J. 2014. Toronto zoo expert helps give fish on brink of extinction another chance. The star news. GTA. Downloaded from: https://www.thestar.com/news/ gta/2014/01/27/toronto_zoo_expert_helps_give_fish_on_ brink_of_extinction_another_chance.html

Raminosoa, N.R., Loiselle, P.V., Rafomanana, G., et al. 2002. Poissons. In: Evaluation et Plans de Gestion pour la Conservation (CAMP) de la Faune de Madagascar: Lémuriens, Autres Mamofères, Reptiles et Amphiobiens, Poissons d'Eau Douce et Evaluation de la Viabilité des Populations et des Habitats de Hypogeomeys antimena (Vositse). Conservation Breeding Specialist Group (SSC/ IUCN), Apple Valley.

Ramsar Convention Secretariat. 2010. River basin management: Integrating wetland conservation and wise use into river basin management. Ramsar handbooks for the wise use of wetlands, 4th edition, vol. 9. Ramsar Convention Secretariat, Gland, Switzerland.

Secretariat of the Convention on Biological Diversity. 2014. Global Biodiversity Outlook 4. Montreal, 155 pages. Downloaded from: https://portals.iucn.org/library/sites/ library/files/documents/Bios-Cons-BD-GBO-4.pdf

Sparks, J.S. 2004. Molecular phylogeny and biogeography of the Malagasy and South Asian cichlid fishes (Teleostei:
Perciformes: Cichlidae). Molecular Phylogenetics and Evolution 30: 599-614. https://doi.org/10.1016/S10557903(03)00225-2

Sparks, J.S. and Smith, W.L. 2004a. Phylogeny and biogeography of cichlid fishes (Teleostei: Perciformes: Cichlidae). Cladistics 20: 501-517. https://doi.org/10.1111/ j.1096-0031.2004.00038.x

Sparks, J.S. and Smith, W.L. 2004b. Phylogeny and biogeography of the Malagasy and Australasian rainbowfishes (Teleostei: Melanotaenioidei): Gondwanan vicariance and evolution in freshwater. Molecular Phylogenetics and Evolution 33: 719-734. https://doi. org/10.1016/j.ympev.2004.07.002

Sparks, J.S. and Smith, W.L. 2005. Freshwater fishes, dispersal ability, and non-evidence: "Gondwana Life Rafts" to the rescue. Systematic Biology 53: 11-19.

Sparks, J.S. 2005. Madagascar Freshwater Ecoregions: Eastern lowlands. Pp 218-219, Eastern highlands. Pp. 252-254, Northwestern basins. Pp 307-308, Western basins, Pp 309, Southern basins Pp 343-344. In: M.L. Thieme, R. Abell, M.L.J. Stiassny, B. Lehner, P. Skelton, G. Teugals, E. Dinerstein, A. Kamdem Toham, N. Burgess, and D. Olson (eds.). Freshwater ecoregions of Africa and Madagascar. A conservation assessment. Island Press, Washington, DC.

Sparks, J.S. 2008. Phylogeny of the cichlid subfamily etroplinae and taxonomic revision of the malagasy cichlid genus Paretroplus (teleostei: cichlidae). Bull. Amer. Mus. Nat. His. 314: 151pp.

Sparks, J.S. 2011a. Changes in Madagascar's Rivers and Lakes. Scientist at work. New York Times. http:// scientistatwork.blogs.nytimes.com/2011/06/28/changesin-madagascars-rivers-and-lakes/

Sparks, J.S. 2011b. Returning upriver with very few fish. Scientist at work. New York Times. https://scientistatwork. blogs.nytimes.com/2011/07/13/returning-upriver-withvery-few-fish/\#more-12079

Sparks, J.S. and Chakrabarty, P. 2012. Revision of the Endemic Malagasy Cavefish Genus Typhleotris (Teleostei: Gobiiformes: Milyeringidae), with Discussion of its Phylogenetic Placement and Description of a New Species. Amer. Mus. Novitates. 3764, 28 pp.

Sparks, J.S. and Stiassny, M.L.J. 2003. Introduction to the freshwater fishes. In: Goodman, S.M. and Benstead, J.P. (eds.). The Natural History of Madagascar, University of Chicago Press.

Sparks, J.S. and Stiassny, M.L.J. 2008. Les poissons d'eaux douce. Pp. 283-309. In: S.M. Goodman (ed.) Paysages Naturels et Biodiversité de Madagascar. Publications Scientifiques Muséum national d'Histoire naturelle (MNHN), Paris.

Stiassny, M.L.J. and Rodriguez, D.M. 2001. Rheocles derhami, a new species of freshwater rainbowfish (Atherinomorpha: Bedotiidae) from the Ambomboa River 
in northeastern Madagascar. Ichthyol. Explor. Freshwat. 12(2): 97-104.

Stiassny, M.L.J., Rodriguez, D.M. and Loiselle, P.V. 2002. Rheocles vatosoa, a new species of freshwater rainbowfish (Atherinomorpha: Bedotiidae) from the Lokoho River basin in northeastern Madagascar. Cybium 261: 71-77.

Stiassny, M.L.J. and Sparks, J.S. 2006. Phylogeny and Taxonomic Revision of the Endemic Malagasy Genus Ptychochromis (Teleostei: Cichlidae), with the Description of Five New Species and a Diagnosis for Katria, New Genus. Amer. Mus. Novitates 3535, 55pp.

Tittensor, D.P., Walpole, M., Hill, S.L., et al. 2014. A mid-term analysis of progress towards international biodiversity targets. Science 346: 241-244. Available at: http://www. sciencemag.org/content/346/6206/241.short. https://doi. org/10.1126/science.1257484

Visconti, P., Bakkenes, M., Baisero, D., et al. 2015 Projecting global biodiversity indicators under future development scenarios. Conservation Letters doi: 10.1111/conl.12159. Downloaded from: http://onlinelibrary.wiley.com/ doi/10.1111/conl.12159/abstract. https://doi.org/10.1111/ conl.12159

Zimmerman, B. 2014. In search of the Mangarahara cichlid. Newsletter of the IUCN SSC/WI Freshwater Fish Specialist Group Issue 4: 17-22.

Annex 3.1 Red List status of Madagascar and the Indian 0cean islands hotspot freshwater fishes.

\begin{tabular}{|c|c|c|c|}
\hline Family & Genus and species & $\begin{array}{l}\text { IUCN Red } \\
\text { List } \\
\text { Category }\end{array}$ & $\begin{array}{c}\text { Endemic } \\
\text { to the } \\
\text { hotspot }\end{array}$ \\
\hline Poecilidae & $\begin{array}{l}\text { Pantanodon } \\
\text { madagascariensis }\end{array}$ & EX & Yes \\
\hline Cichlidae & Ptychochromis onilahy & EX & Yes \\
\hline Ariidae & Arius festinus & $\mathrm{CR}$ & Yes \\
\hline Ariidae & Arius uncinatus & $\mathrm{CR}$ & Yes \\
\hline Bedotiidae & Bedotia tricolor & CR & Yes \\
\hline Cichlidae & Paretroplus dambabe & $\mathrm{CR}$ & Yes \\
\hline Cichlidae & $\begin{array}{l}\text { Paretroplus } \\
\text { gymnopreopercularis }\end{array}$ & CR & Yes \\
\hline Cichlidae & Paretroplus maculatus & CR & Yes \\
\hline Cichlidae & Paretroplus menarambo & CR & Yes \\
\hline Cichlidae & Ptychochromis insolitus & CR & Yes \\
\hline Cichlidae & $\begin{array}{l}\text { Ptychochromoides } \\
\text { betsileanus }\end{array}$ & CR & Yes \\
\hline Cichlidae & Ptychochromoides itasy & $\mathrm{CR}$ & Yes \\
\hline Bedotiidae & Rheocles derhami & $\mathrm{CR}$ & Yes \\
\hline Bedotiidae & Rheocles lateralis & $\mathrm{CR}$ & Yes \\
\hline Eleotridae & Typhleotris mararybe & CR & Yes \\
\hline Eleotridae & Typhleotris pauliani & CR & Yes \\
\hline Anchariidae & Ancharius griseus & EN & Yes \\
\hline Bedotiidae & Bedotia albomarginata & EN & Yes \\
\hline Bedotiidae & Bedotia geayi & EN & Yes \\
\hline Bedotiidae & Bedotia leucopteron & EN & Yes \\
\hline Bedotiidae & Bedotia longianalis & EN & Yes \\
\hline Bedotiidae & Bedotia madagascariensis & EN & Yes \\
\hline Bedotiidae & Bedotia marojejy & EN & Yes \\
\hline Anchariidae & Gogo ornatus & EN & Yes \\
\hline Cichlidae & Katria katria & EN & Yes \\
\hline Cichlidae & Oxylapia polli & EN & Yes \\
\hline Aplocheilidae & Pachypanchax omalonota & EN & Yes \\
\hline Aplocheilidae & Pachypanchax patriciae & EN & Yes \\
\hline Aplocheilidae & Pachypanchax sakaramyi & EN & Yes \\
\hline Aplocheilidae & Pachypanchax sparksorum & EN & Yes \\
\hline Aplocheilidae & Pachypanchax varatraza & EN & Yes \\
\hline Cichlidae & Paretroplus lamenabe & EN & Yes \\
\hline Cichlidae & Paretroplus loisellei & EN & Yes \\
\hline Cichlidae & Paretroplus maromandia & EN & Yes \\
\hline
\end{tabular}

\begin{tabular}{|c|c|c|c|}
\hline Family & Genus and species & $\begin{array}{l}\text { IUCN Red } \\
\text { List } \\
\text { Category }\end{array}$ & $\begin{array}{c}\text { Endemic } \\
\text { to the } \\
\text { hotspot }\end{array}$ \\
\hline Cichlidae & Paretroplus nourissati & EN & Yes \\
\hline Cichlidae & Paretroplus tsimoly & EN & Yes \\
\hline Cichlidae & Ptychochromis inornatus & EN & Yes \\
\hline Cichlidae & Ptychochromis loisellei & EN & Yes \\
\hline Cichlidae & $\begin{array}{l}\text { Ptychochromis } \\
\text { oligacanthus }\end{array}$ & EN & Yes \\
\hline Cichlidae & $\begin{array}{l}\text { Ptychochromoides } \\
\text { vondrozo }\end{array}$ & EN & Yes \\
\hline Bedotiidae & Rheocles alaotrensis & EN & Yes \\
\hline Bedotiidae & Rheocles vatosoa & EN & Yes \\
\hline Bedotiidae & Rheocles wrightae & EN & Yes \\
\hline Clupeidae & Sauvagella robusta & EN & Yes \\
\hline Atherinidae & Teramulus waterloti & EN & Yes \\
\hline Eleotridae & $\begin{array}{l}\text { Typhleotris } \\
\text { madagascariensis }\end{array}$ & EN & Yes \\
\hline Bedotiidae & Bedotia masoala & VU & Yes \\
\hline Kuhliidae & Kuhlia sauvagii & VU & Yes \\
\hline Aplocheilidae & Pachypanchax arnoulti & VU & Yes \\
\hline Cichlidae & Paratilapia polleni & VU & Yes \\
\hline Cichlidae & Paretroplus damii & VU & Yes \\
\hline Cichlidae & Paretroplus kieneri & VU & Yes \\
\hline Bedotiidae & Bedotia alveyi & NT & Yes \\
\hline Gobiidae & Favonigobius reichei & NT & No \\
\hline Gobiidae & Acentrogobius therezieni & $\mathrm{DD}$ & Yes \\
\hline Mugilidae & Agonostomus catalai & DD & No \\
\hline Batrachoididae & Allenbatrachus meridionalis & $\mathrm{DD}$ & No \\
\hline Ambassidae & Ambassis fontoynonti & $\mathrm{DD}$ & Yes \\
\hline Ariidae & Arius africanus & $\mathrm{DD}$ & No \\
\hline Gobiidae & $\begin{array}{l}\text { Bathygobius } \\
\text { samberanoensis }\end{array}$ & $\mathrm{DD}$ & No \\
\hline Terapontidae & Datnia elongata & $\mathrm{DD}$ & No \\
\hline Eleotridae & Eleotris vomerodentata & $\mathrm{DD}$ & Yes \\
\hline Anchariidae & Gogo arcuatus & $\mathrm{DD}$ & Yes \\
\hline Anchariidae & Gogo atratus & DD & Yes \\
\hline Anchariidae & Gogo brevibarbis & $\mathrm{DD}$ & Yes \\
\hline Aplocheilidae & Pachypanchax playfairii & $\mathrm{DD}$ & Yes \\
\hline Eleotridae & Hypseleotris cyprinoides & $\mathrm{DD}$ & No \\
\hline
\end{tabular}


Annex 3.1 cont'd. Red List status of Madagascar and the Indian 0cean islands hotspot freshwater fishes.

\begin{tabular}{|c|c|c|c|c|c|c|c|}
\hline Family & Genus and species & $\begin{array}{l}\text { IUCN Red } \\
\text { List } \\
\text { Category }\end{array}$ & $\begin{array}{c}\text { Endemic } \\
\text { to the } \\
\text { hotspot }\end{array}$ & Family & Genus and species & $\begin{array}{l}\text { IUCN Red } \\
\text { List } \\
\text { Category }\end{array}$ & $\begin{array}{c}\text { Endemic } \\
\text { to the } \\
\text { hotspot }\end{array}$ \\
\hline Megalopidae & Megalops cyprinoides & $\mathrm{DD}$ & No & Gerreidae & Gerres filamentosus & $\mathrm{LC}$ & No \\
\hline Syngnathidae & Microphis fluviatilis & DD & No & Eleotridae & Giuris margaritacea & LC & No \\
\hline Gobiidae & Oligolepis acutipennis & $\mathrm{DD}$ & No & Gobiidae & Glossogobius ankaranensis & $\mathrm{LC}$ & Yes \\
\hline Cichlidae & Paratilapia bleekeri & $\mathrm{DD}$ & Yes & Gobiidae & Glossogobius callidus & $\mathrm{LC}$ & No \\
\hline Cichlidae & Paretroplus petiti & $\mathrm{DD}$ & Yes & Gobiidae & Glossogobius giuris & $\mathrm{LC}$ & No \\
\hline Cichlidae & Ptychochromis curvidens & DD & Yes & Kraemeriidae & Gobitrichinotus arnoulti & $\mathrm{LC}$ & Yes \\
\hline \multirow[t]{2}{*}{ Cichlidae } & \multirow{2}{*}{$\begin{array}{l}\text { Ptychochromis } \\
\text { ernestmagnusi }\end{array}$} & \multirow[t]{2}{*}{$\mathrm{DD}$} & \multirow[t]{2}{*}{ Yes } & Gobiidae & Gobius hypselosoma & $\mathrm{LC}$ & No \\
\hline & & & & Syngnathidae & Hippichthys cyanospilos & $\mathrm{LC}$ & No \\
\hline Cichlidae & Ptychochromis mainty & $\mathrm{DD}$ & Yes & Syngnathidae & Hippichthys spicifer & $\mathrm{LC}$ & No \\
\hline Cichlidae & Ptychochromis makira & $\mathrm{DD}$ & Yes & Gobiidae & Istigobius ornatus & $\mathrm{LC}$ & No \\
\hline Eleotridae & Ratsirakia legendrei & $\mathrm{DD}$ & Yes & Kuhliidae & Kuhlia rupestris & $\mathrm{LC}$ & No \\
\hline Bedotiidae & Rheocles pelligrini & $\mathrm{DD}$ & Yes & Leiognathidae & Leiognathus equulus & $\mathrm{LC}$ & No \\
\hline Bedotiidae & Rheocles sikorae & $\mathrm{DD}$ & Yes & Lutjanidae & Lutjanus argentimaculatus & $\mathrm{LC}$ & No \\
\hline Gobiidae & Sicyopterus punctissimus & $\mathrm{DD}$ & Yes & Lutjanidae & Lutjanus ehrenbergii & $\mathrm{LC}$ & No \\
\hline Clupeidae & Spratellomorpha bianalis & $\mathrm{DD}$ & Yes & \begin{tabular}{|l} 
Syngnathidae \\
\end{tabular} & Microphis brachyurus & $\mathrm{LC}$ & No \\
\hline Sparidae & Acanthopagrus berda & LC & No & Syngnathidae & Microphis leiaspis & $\mathrm{LC}$ & No \\
\hline Gobiidae & Acentrogobius audax & LC & No & Monodactylidae & Monodactylus argenteus & $\mathrm{LC}$ & No \\
\hline Anguillidae & Anguilla marmorata & LC & No & Monodactylidae & Monodactylus falciformis & $\mathrm{LC}$ & No \\
\hline Gobiidae & Acentrogobius nebulosus & LC & No & Mugilidae & Moolgarda perusii & $\mathrm{LC}$ & No \\
\hline Mugilidae & Agonostomus telfairii & $\mathrm{LC}$ & No & Mugilidae & Mugil cephalus & $\mathrm{LC}$ & No \\
\hline Ambassidae & Ambassis ambassis & LC & No & Eleotridae & Ophiocara porocephala & LC & Yes \\
\hline Ambassidae & Ambassis natalensis & $\mathrm{LC}$ & No & Mugilidae & Osteomugil engeli & $\mathrm{LC}$ & No \\
\hline Anchariidae & Ancharius fuscus & LC & Yes & Cichlidae & Paretroplus polyactis & $\mathrm{LC}$ & Yes \\
\hline Ariidae & Arius madagascariensis & LC & Yes & Pristigasteridae & Pellona ditchela & LC & No \\
\hline Atherinidae & Atherinomorus & LC & Yes & Ariidae & Plicofollis dussumieri & LC & No \\
\hline & duodecimalis & & & Gobiidae & Psammogobius biocellatus & $\mathrm{LC}$ & No \\
\hline Leiognathidae & Aurigequula fasciata & LC & No & Cichlidae & Ptychochromis grandidieri & $\mathrm{LC}$ & Yes \\
\hline Gobiidae & Awaous aeneofuscus & LC & No & Gobiidae & Redigobius balteatus & LC & No \\
\hline Gobiidae & Awaous macrorhynchus & LC & Yes & Gobiidae & Redigobius dewaali & LC & No \\
\hline Gobiidae & Bathygobius fuscus & LC & No & Clupeidae & Sauvagella & LC & Yes \\
\hline Eleotridae & Butis butis & LC & No & & madagascariensis & & \\
\hline Chanidae & Chanos chanos & LC & No & Scatophagidae & Scatophagus tetracanthus & LC & No \\
\hline Mugilidae & Chelon melinopterus & LC & No & Gobiidae & Sicyopterus franouxi & LC & Yes \\
\hline Mugilidae & Crenimugil crenilabis & $\mathrm{LC}$ & No & Gobiidae & Stenogobius polyzona & $\mathrm{LC}$ & No \\
\hline Eleotridae & Eleotris fusca & LC & No & Gobiidae & Taenioides gracilis & LC & No \\
\hline Eleotridae & Eleotris mauritiana & LC & No & Atherinidae & Teramulus kieneri & LC & Yes \\
\hline Eleotridae & Eleotris melanosoma & $\mathrm{LC}$ & No & Terapontidae & Terapon jarbua & $\mathrm{LC}$ & No \\
\hline Eleotridae & Eleotris pellegrini & LC & Yes & Mugilidae & Valamugil buchanani & $\mathrm{LC}$ & No \\
\hline Elopidae & Elops machnata & LC & No & Mugilidae & Valamugil robustus & LC & No \\
\hline \begin{tabular}{|l} 
Leiognathidae \\
\end{tabular} & Equulites leuciscus & LC & No & Ophichthidae & Yirrkala tenuis & LC & No \\
\hline
\end{tabular}




\section{Chapter 4}

\section{The status and distribution of freshwater molluscs}

\section{Dirk Van Damme, Frank Köehler², Luciano Andriamaro³, William Darwall ${ }^{4}$, Laura Máiz-Tomé ${ }^{4}$}

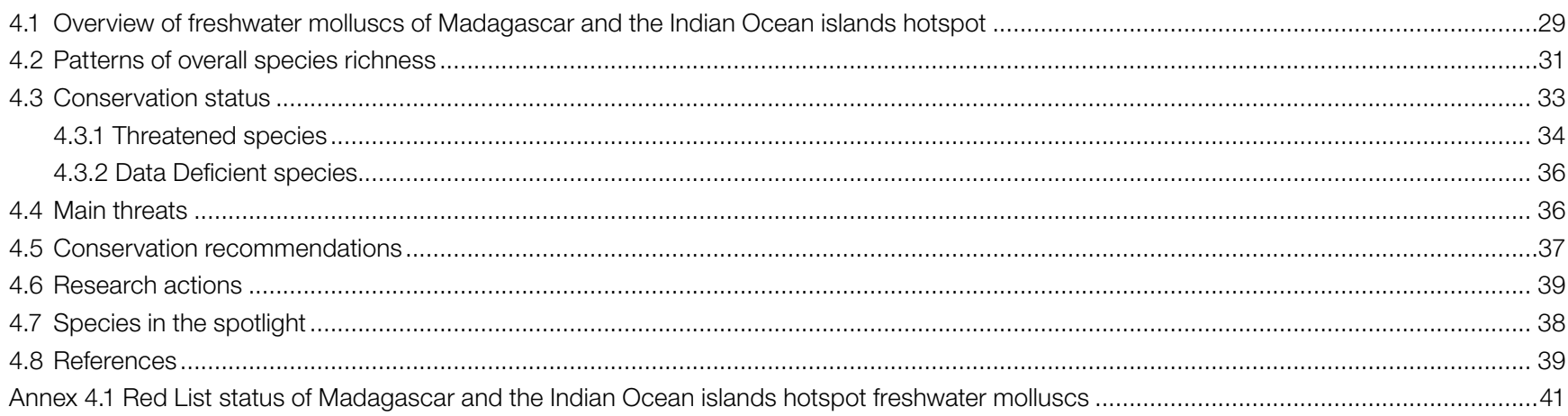

\subsection{Overview of freshwater molluscs of Madagascar and the Indian Ocean islands hotspot}

Freshwater molluscs (bivalves and gastropods) are found in a wide range of freshwater habitats, have varied life-history strategies and exhibit complex ecological interactions, all of which underscore their use as proxies for understanding our changing freshwater diversity (Seddon et al. 2011). In Madagascar and the surrounding Indian Ocean islands freshwater molluscs are represented by ten families of gastropod and four families of bivalves. On the islands (excluding Madagascar), the number of freshwater gastropod species is low and freshwater bivalves are missing altogether.

As part of this project only native species have been assessed and mapped for the IUCN Red List. In Madagascar, the only known introduced species is the Afrotropical Bellamya unicolor (Viviparidae). However, this species has been only recorded once and it could have been potentially misidentified. It is very likely that a number of other widespread Afrotropical planorbids have also been introduced, but further molecular studies are needed to confirm this. Compared to Madagascar, the number of introduced species on the Indian Ocean islands is considerably higher. Six species including the ampullariid Pomacea canaliculata from South America, the viviparid
Bellamya bengalensis from South-East Asia, the European lymnaeid Galba truncatula and the south Asian lymnaeid Austropeplea viridis, the potamiopsid Oncomelania hupensis from South-East Asia and the physid Physella acuta from North America now occur in the Mascarenes. These species thrive in man-made and disturbed habitats, such as rice paddies, and they can live in waters clogged by invasive aquatic plants such as so-called Nile cabbage (Pistia sp.). Therefore, their presence and dominance indicate an alteration of aquatic ecosystems and high levels of eutrophication. Since most of these species are intermediate hosts for highly dangerous trematodes (e.g. for Schistosoma), their population increase is triggering the use of non-selective molluscicides.

\section{Freshwater gastropods}

Freshwater gastropods represent about $85 \%$ of all freshwater molluscs in the hotspot, within three groups; neritimorphs, caenogastropods and eupulmonates (Table 4.1). Native nerithomorphs and caenogastropods are most diverse within the lakes and larger river systems, whereas freshwater eupulmonates are more often associated with smaller water-bodies, including artificial ones such as rice paddies and ditches, and many are tolerant of seasonal drying. In total 12 species of neritomorphs, 20 species of caenogastropods, and 20 species of eupulmonates are recognised.

4 Freshwater Biodiversity Unit, IUCN Global Species Programme, The David Attenborough Building, Pembroke Street, Cambridge CB2 3QZ, UK. 
Table 4.1 Diversity and endemism in freshwater mollusc families in Madagascar and the Indian 0cean islands hotspot.

\begin{tabular}{|c|c|c|c|c|c|}
\hline \multirow[t]{2}{*}{ Class } & \multirow[t]{2}{*}{ Order } & \multirow[t]{2}{*}{ Family } & \multicolumn{3}{|c|}{ Species } \\
\hline & & & $\begin{array}{l}\text { No. of } \\
\text { species }\end{array}$ & $\begin{array}{c}\text { No. of } \\
\text { endemic } \\
\text { species }\end{array}$ & $\begin{array}{c}\text { \% of } \\
\text { endemic } \\
\text { species }\end{array}$ \\
\hline \multirow{4}{*}{ 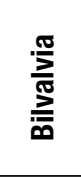 } & \multirow[t]{2}{*}{ Unionoida } & Etheriidae & 1 & 0 & 0 \\
\hline & & Incertae sedis & 3 & 1 & 3 \\
\hline & \multirow[t]{2}{*}{ Veneroida } & Cyrenidae & 1 & 1 & 3 \\
\hline & & Sphaeriidae & 9 & 3 & 9 \\
\hline \multirow{11}{*}{ 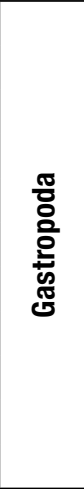 } & \multirow{8}{*}{ Prosobranchia } & Neritidae & 12 & $2-3$ & $6-9$ \\
\hline & & Ampullariidae & 2 & 2 & 6 \\
\hline & & Potamididae & 1 & 0 & 0 \\
\hline & & Assimineidae & 2 & $?$ & $?$ \\
\hline & & Pachychilidae & 6 & 6 & 18 \\
\hline & & Paludomidae & 4 & 4 & 12 \\
\hline & & Thiaridae & 5 & $0-1$ & $0-3$ \\
\hline & & \begin{tabular}{|l|} 
Potamididae \\
\end{tabular} & 1 & 0 & 0 \\
\hline & \multirow{3}{*}{ Pulmonata } & Ellobiidae & 5 & $0-2$ & $0-6$ \\
\hline & & Lymnaeidae & 2 & 1 & 3 \\
\hline & & Planorbidae & 13 & 9 & 27 \\
\hline Total & & & 66 & $30-50$ & $\sim 50$ \\
\hline
\end{tabular}

\section{Neritomorpha}

Neritidae: Many neritids are marine although some have adapted to brackish and freshwater habitats, but in Africa they do not penetrate far inland (Brown 1994). Twelve species belonging to five genera (Septaria, Neripteron, Neritina, Neritilia and Clithon) are known with most, possibly all, occurring on Madagascar. Of the other Indian Ocean islands, Mauritius and Réunion have the richest neritid fauna. The larvae of all species complete their ontogenetic development in marine environments. Therefore, neritids are found predominantly in the lower courses of rivers or river systems that flow into the sea.

\section{Caenogastropoda}

Ampullariidae: On Madagascar this Afro-Asian family is represented by one species of the genus Lanistes ( $L$. grasseti) and one species of the genus Pila ( $P$. cecillei). Both these species are endemic to Madagascar. This family is not represented on the other Indian Ocean islands. However, the South American Pomacea canaliculata has been introduced on Mauritius. Viviparidae: The Asian species Bellamya bengalensis has been introduced from India to Mauritius. There is also a doubtful record of the Afrotropical species $B$. unicolor from a single location on Madagascar (FischerPiette \& Vukadinovic 1973). Potamiopsidae: The southeastern Asian amphibious Oncomelania hupensis, a dangerous vector for flukes, has possibly been introduced on Mauritius (Andriamaro 2010). Assimineidae: This is a family of minute gastropods with just a few identified characters. Two species of the genus Assiminea ( $A$. parvula and $A$. hidalgoi) are found on the Indian Ocean islands, the first one also occurring on Madagascar. Originally considered as endemics, their identification requires confirmation, as they are also recorded from other parts of the Indo-Pacific region. Pachychilidae: Only one genus, previously named Melanatria and until recently considered to contain just two species (Brown 1994), occurs on Madagascar. Recently, however, this genus was renamed Madagasikara by Köhler \& Glaubrecht (2010), who also recognised a total of six species. All species are endemic to Madagascar, Nosy Be and Sainte Marie Island. Paludomidae: Two genera (Cleopatra and Paludomus) are known to occur in the hotspot. The first genus, Cleopatra, has an Afrotropical distribution and is only found on Madagascar within this hotspot, while the second, Plaudomus, also occurs in south Asia and the Seychelles (island of Mahé). The species $P$. ajanensis is endemic to the island of Mahé and it was erroneously reported from Somalia (Brown 1994). Thiaridae: Three genera (Mieniplotia, Thiara and Melanoides) occur on Madagascar and on many of the Indian Ocean islands. All are represented by species that are widely distributed in the Indian Ocean or are globally widespread (Melanoides tuberculata). Further research is needed to clarify the taxonomic status of M. psorica, which is either a Malagasy endemic species or, more likely, a slender form of $M$. tuberculata. Potamididae: Cerithidea decollata, a brackish water species that is widespread along Indo-Pacific coasts including eastern Africa and also occurs on Madagascar, Mauritius, Mayotte and Réunion.

\section{- Eupulmonata}

Ellobiidae: These are mainly amphibious species found in marine and brackish water habitats. Four genera (Laemodonta, Pedipes, Allochroa and Auriculastra) are present in Madagascar and the Indian Ocean islands, where only Pedipes affinis and Auriculastra subula are present. Three species are widespread in the Indo-Pacific. Two species (Laemodonta madagascariensis and L. livida) have only been recently discovered on a beach in Madagascar. It is unlikely that these two species would be restricted to the type locality and further investigation is necessary to delimit their real distribution. Lymnaeidae: Two genera are known from the hotspot. The neritiform genus Lantzia (L. carinata) is endemic to Réunion and restricted to the type locality. The genus Radix (Lymnaea) is represented by the widespread Afrotropical species $R$. natalensis. It occurs on Madagascar (formerly identified as a presumed endemic species, $L$. ovarum), Mauritius (formerly identified as a presumed endemic species, L. mauritiana), Anjouan, Réunion, Mayotte and Comoros. Radix natalensis has been introduced to the three last locations. The European, pollution resistant, Galba truncatula is also found on Réunion. Planorbidae: Fourteen species belonging to eight genera are represented, namely Ferrissia, Gyraulus, Africanogyrus, Ceratophallus, Lentorbis, Segmentorbis, Biomphalaria and Bulinus. Most are endemic to Madagascar and/or the Indian Ocean islands: Africanogyrus crassilabrum occurs on Madagascar, Comoros and Mayotte, $A$. starmuehlneri is confined to the 
Ankaratra Mountains on Madagascar and A. rodriguensis is only known from two locations on Rodrigues. Gyraulus mauritianus was originally restricted to Mauritius and Rodrigues, but has been introduced on other islands. Ferrissia modesta and Bulinus bavayi are widespread on Madagascar and occur on several islands, where they have probably also been introduced. Bulinus liratus and $B$. obtusispira are endemic to Madagascar and $B$. cernicus is endemic to Mauritius. This species also occurred on Réunion, where it was probably introduced and may have since become extinct. The other five species, namely Ceratophallus natalensis, Bulinis forskalii, Lentorbis junodi, Segmentorbis angustus and Biomphalaria pfeifferi have an Afrotropical distribution. Physidae: The North American species Physella acuta (previously referred to as Physa acuta) has been introduced to Réunion.

\section{Freshwater bivalves}

Freshwater bivalves represent approximately $15 \%$ of the freshwater mollusc fauna of Madagascar and the Indian Ocean islands hotspot. In total, we recognise 10 species (four genera, two families, one order) of bivalves in the hotspot (Table 4.1). Bivalves are divided into two globally distributed orders: Unionoida (otherwise known as freshwater mussels) and Veneroida (otherwise known as clams and pea-clams). All bivalves in the hotspot belong to the latter order (Graf \& Cummings 2011). They occupy a wide range of habitats, from brackish estuarine waters to interior lentic and lotic environments. Originally, four species of Unionoida were also described from Madagascar, two from Réunion and three from Mauritius. All the species described from the Mascarenes proved to have been collected elsewhere, two of the Malagasy ones are based on unidentifiable shell fragments and the remaining two have become extinct (Graf \& Cummings 2009).

\section{- Unionoida}

Etheriidae: The widespread Afrotropical monospecific genus Etheria (E. elliptica) has been collected in three river systems in north-west Madagascar but all material predates the 20th century. Enigmatic Unionoida (incertae sedis): From Madagascar three other unionoids were described. One, 'Unio madagascariensis', must be considered as a nomen dubium, because its author gives a summary description only without a figure and whereabouts of the type material are unknown. It was collected in one river basin at the east coast. Of 'Unio malgachensis' only an unidentifiable part of a juvenile shell $(12 \mathrm{~mm}$ ) remains. It is not known from where in Madagascar this shell comes and it is also a nomen dubium. Of the third species, no precise location is given, but some shells remain, collected at the end of the 19th century. Originally described as Unio geayi, Graf \& Cummings (2009) created a new genus, Germainaia, for it, stating that this species could as well belong to the
Holartic-Indo-Malaysian-Afrotropical family Unionidae as to the Australian-Neotropical family Hyriidae. However, in a later publication on the taxonomy of the recent and fossil Hyriidae (Graf et al. 2015) the species is not mentioned. The unionoid species described from Réunion and Mauritius have been introduced (from Philippines, South America, etc.) (Graf \& Cummings 2009).

\section{- Veneroida}

Cyrenidae: One species, the endemic Corbicula madagascariensis, is known from Madagascar (Glaubrecht et al. 2006). Once a widespread species, its distribution seems presently to be reduced to a dozen locations. Sphaeridae: Nine species belonging to three genera (Sphaerium, Pisidium and Eupera) are known from Madagascar but none are found on the Indian Ocean islands, except for the widespread Afrotropical Eupera ferruginea. Three species, Eupera degorteri, Pisidium johnsoni and $P$. betafoense are Malagasy endemics with a restricted distribution. The others have a wider Afrotropical or global distribution.

\subsection{Patterns of overall species richness}

Generally, freshwater molluscs find their highest levels of endemism and diversity in ancient lakes, large river basins and artesian basins (Seddon et al. 2011), and all of these habitats can be found in the hotspot. Due to its size, its diversified morphology and proximity to the African continent, Madagascar is the island with the highest species richness in freshwater molluscs within the hotspot. However, this species richness has clearly suffered due to periods of severe aridity that occurred in this region and southern Africa during the Quaternary (Burney 1996). This faunal decline is obvious in the freshwater mussels, a group that needs large limpid rivers and lakes and tends to be absent in Africa south of the equator in waters above 1,000 m (Mandahl-Barth 1984; Graf \& Cummings 2011). The absence of two caenogastropod families, Viviparidae and Bithyniidae, which are common on continental Africa, may also be linked to these dramatic Quaternary climate events. Apparently the larger freshwater bivalves never recovered fully and only survived in the lowland parts of a few river basins until human activities that caused land denudation and siltation, rendered them extinct around the turn of the 19th century.

The Malagasy regions with the highest species richness (12-17 species) are the central mountain range and some small coastal sub-catchments, mainly along the eastern lowlands (Figure 4.1). The high diversity in the central mountain range is due to the relatively lower impact on the natural habitats by humans, in comparison to that of the densely populated foothills and lowlands. The diversity is significantly increased by the presence of a larger number of 


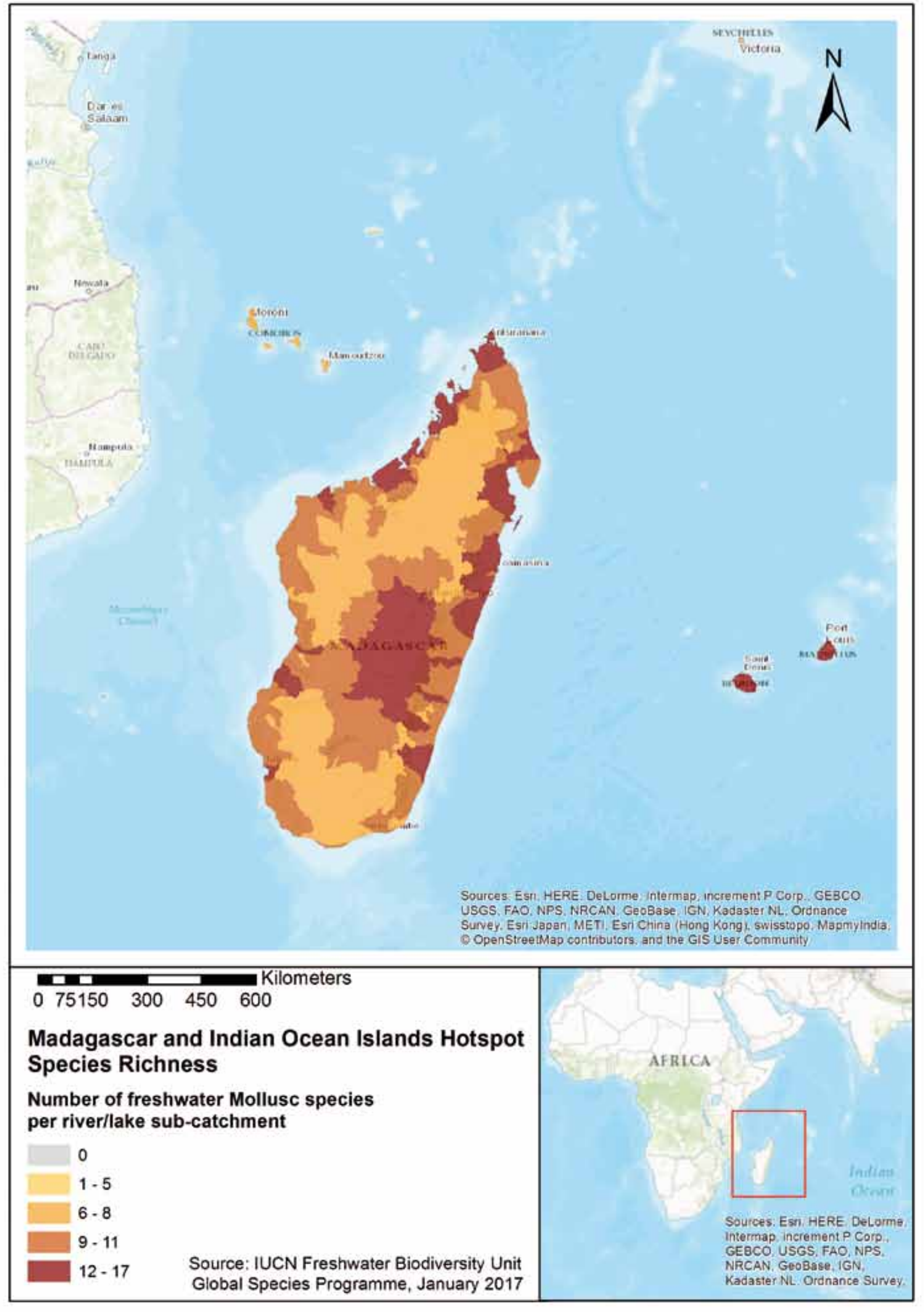


pulmonates (e.g. the endemic Africanogyrus starmuehlneri), many sphaeriids and the relict occurrence of species of the endemic caenogastropod genera Madagasikara and species such as Lanistes grasseti and Cleopatra grandidieri.

The high diversity in some coastal zones on Madagascar occurs in those regions with a strongly rugged relief, mainly on the eastern lowlands, and is due to the occurrence of some endemics such as Madagasikara species and a number of Indo-Pacific euryhaline neritid and ellobiid species that do not venture far from the sea.

The lowest diversity (6-8 species) is found in southern Madagascar and on the northern and central plateaus which have been turned into rice paddies and meadows. In these regions the malacofauna consists of opportunistic species which can survive seasonally suboptimal conditions (hypoxy, high temperatures, and droughts). Several of these are endemic (Pila cecillei, Bulinus liratus and B. obtusispira).

Species richness of the other Indian Ocean islands is directly related to their size: the Mascarene islands of Réunion and Mauritius have the highest diversity (12-17 species), the diversity on the Comoros and the larger islands of the Seychelles is already quite low (6-8 species) while on small islands such as Aldabra (Seychelles) only two species are known to occur.

The high diversity of freshwater molluscs on Réunion and Mauritius is mainly due to the presence of a significant amount of euryhaline assimineids, ellobiids, neritids, thiarids, paludomids and potamidids with an Indian Ocean or even Indo-Pacific distribution. Species richness of the obligatory freshwater species is rather low. Only a single widespread Afrotropical bivalve (Eupera ferruginea) has reached these islands. The obligatory freshwater gastropods are mainly widespread Afrotropical species or species that were probably introduced from Madagascar. Endemism is low and the amount of species introduced from South-East Asia and other parts of the world is comparatively high and a cause for concern.

Tropical freshwater molluscs have not yet received the same level of attention as European and North American faunas, and as taxonomic reviews continue, especially those using molecular systematics, the number of known species may well increase, as has happened in studies of some genera already.

\subsection{Conservation status}

The conservation status of $\mathbf{6 6}$ freshwater mollusc species was assessed by applying the IUCN Red List Categories and Criteria: Version 3.1 on a global scale (IUCN 2012). At least $24 \%$ of these species are considered to be threatened, with at least $4 \%$ of the total species assessed being Critically Endangered (CR), 14\% Endangered (EN) and 6\% Vulnerable (VU) (Figures 4.2 and 4.3, Table 4.2 and Annex 4.1). Assuming that all Data Deficient (DD) species are threatened in the same proportion as those species for which enough information was available, the percentage of threatened mollusc species increases to $30 \%$. This level of threat is very similar to the results of the Pan-African assessment, for which the proportion of total threatened mollusc species across mainland continental Africa was 29\% (Seddon et al. 2011).

In general, caenogastropods are the most threatened of the freshwater molluscs groups, while three species, all unionoids (U. madagascariensis, U. malgachensis and Germainaia geayi), have become extinct on Madagascar. One species, Etheria elliptica, has also become extinct on Madagascar, however, it is still widespread across Africa and has been assessed globally as Least Concern (LC).

Only two paludomid species, Cleopatra colbeaui and Cleopatra grandidieri, and one Madagasikara species have been

Table 4.2 The number of freshwater mollusc species within each Red List Category for the entire hotspot.

\begin{tabular}{|l|l|c|c|}
\hline \multirow{4}{*}{ IUCN Red List Categories } & $\begin{array}{c}\text { No. } \\
\text { species }\end{array}$ & $\begin{array}{c}\text { No. } \\
\text { endemic } \\
\text { species }\end{array}$ \\
\hline $\begin{array}{l}\text { Threatened } \\
\text { Categories }\end{array}$ & Critically Endangered (CR) & 3 & 3 \\
\cline { 2 - 4 } & Endangered (EN) & 9 & 9 \\
\cline { 2 - 4 } & Vulnerable (VU) & 4 & 4 \\
\hline \multirow{3}{*}{$\begin{array}{l}\text { Other } \\
\text { Categories }\end{array}$} & Near Threatened (NT) & 3 & 3 \\
\cline { 2 - 4 } & Least Concern (LC) & 35 & 9 \\
\cline { 2 - 4 } & Data Deficient (DD) & 9 & 5 \\
\cline { 2 - 4 } & Extinct & 3 & 3 \\
\hline \multicolumn{2}{|l|}{ Total number of species assessed } & $\mathbf{6 6}$ & $\mathbf{3 6}$ \\
\hline
\end{tabular}

Figure 4.2 The proportion (\%) of freshwater mollusc species in each IUCN Red List Category in Madagascar and the Indian Ocean islands hotspot.

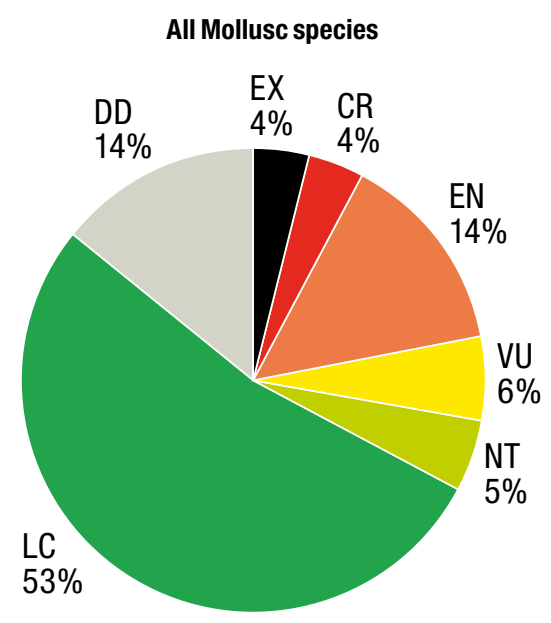


classed as Near Threatened (NT) (Table 4.2). Considering that Cleopatra colbeaui was formerly widespread, it should not yet meet the thresholds to qualify under the threatened categories but it inevitably will if the current rate for degradation of the aquatic environments continues. A new survey is necessary to establish the present distribution of Cleopatra grandidieri, which may fall into one of the threatened categories. In the absence of recent data, but taking into account the severe regression of its natural habitat, the species has been provisionally assessed as NT. Madagasikara spinosa is the only representative of the genus with a relatively wide range (i.e. several basins in east Madagascar) and does also occur in some protected areas. These gastropods, like most pacgychilids, occur in fresh, clear and fast-running waters in rainforest areas. The dramatically increasing turbidity in the eastern rivers is likely to have a significant negative effect on this species population, therefore the species has been assessed as NT.

More than half of the mollusc species occurring in the hotspot are Least Concern (LC) (Table 4.2). This includes endemic species, such as Pila cecillei, Bulinus liratus and $B$. obtusispira, that have benefited from extension of the artificial paludal environment created by rice paddies as well as Afrotropical pulmonates such as Ceratophallus natalensis, Bulinus forskalii, Segmentorbis angustus, and many sphaeriids, that are thriving in artificial waters with abundant plant growth and are able to tolerate eutrophic conditions and moderate chemical pollution.

\subsubsection{Threatened species}

Critically Endangered (CR) species: Two caenogastropods and one bivalve are considered as CR (Table 4.2). The Malagasy Madagasikara zazavavindrano is only known from a single location in the upper part of the Mahavavy River in central western Madagascar where it is threatened by agricultural expansion and increasing siltation and habitat degradation due to erosion along the river banks. The amphibious lymnaeid Lantzia coronata is restricted to its type locality on Réunion and has been assessed as CR (Possibly Extinct) due to a continuing decline in its habitat quality caused by invasive plant species. The sphaeriid Pisidium betafoense is only known from its type locality in Betafo, central Madagascar, with an area of occupancy of $4 \mathrm{~km}^{2}$. This area has become densely populated and intensively cultivated and thus, the species has been assessed as CR (Possibly Extinct).

Endangered (EN) species: Nine species have been assessed as EN (Table 4.2). Four of these belong to the endemic Malagasy genus Madagasikara. They are considered EN due to their restricted range and continuing decline due to habitat loss and degradation. Of equal
EN status is the Malagasy pulmonate, Africanogyrus starmuehlneri, which is restricted to some small mountain streams above $1,800 \mathrm{~m}$ in the Ankaratra Mountains, a region facing increasing human encroachment. Two endemic Malagasy bivalves, the sphaeriid E.degorteri and the cyrenid C. madagascariensis, were also assessed as Endangered. The other two EN species occur on the Indian Ocean islands. The neritid Neritina coronata has only been confirmed from the lower part of some rivers in Mauritius and Réunion while the brackish/freshwater caenogastropod Paludomus ajanensis is only known with certainty from the Island of Mahé (Seychelles). Its population size is estimated to be only 100 adults following a single pollution event in 2002 which caused a $20 \%$ decline.

Vulnerable (VU) species: Four species have been assessed as VU (Table 4.2). The ampullariid Lanistes grasseti is endemic to the island of Madagascar, where it has only been cited from the south-western river systems (Brown 1994). The degradation and the exhaustion of water supplies in southern Madagascar (Valentine 2016) is thought to have had a significant impact on this species. Africanogyrus rodriguezensis is endemic to Rodrigues with a restricted range. The ecosystems on this island are presently in relatively good condition considering increases in the human population have been levelling off since the 1990s and in the 1980s reforestation of the island was in full progress. However, increased frequency and/or severity of droughts due to climate change is also a plausible future threat to this species. The Malagasy sphaeriid Pisidium johnsoni has a limited range in the central part of Madagascar and has last been collected in the late 1980s. However, Pisidium species are easily overlooked and the habitat of $P$. johnstoni seems to be artificial waters such as ditches. Taking these factors into consideration, it is possible that a detailed investigation might show that the species is not that rare after all. Clithon madecassinum is restricted to nine localities on the coastal zone of north-eastern Madagascar and has been facing habitat loss and deteriorating ecological conditions since 1970. However, if its occurrence in Durban (South Africa) is confirmed, this assessment will need to be updated.

On Madagascar the regions where the number of threatened species is the highest (2-3) are the mountainous forested areas situated immediately west of the capital and also in the north-eastern part of Mahajanga province (Figure 4.3), which originally had an extensive covering of tropical forest. Due to severe land shortages and lack of urban jobs in these presently densely populated areas, Malagasy farmers have moved further up the mountain slopes burning the remaining forest patches or cutting them for firewood. As a consequence, relatively more species in these regions have disappeared as the ecological conditions rapidly shifted from being pristine to heavily degraded. 


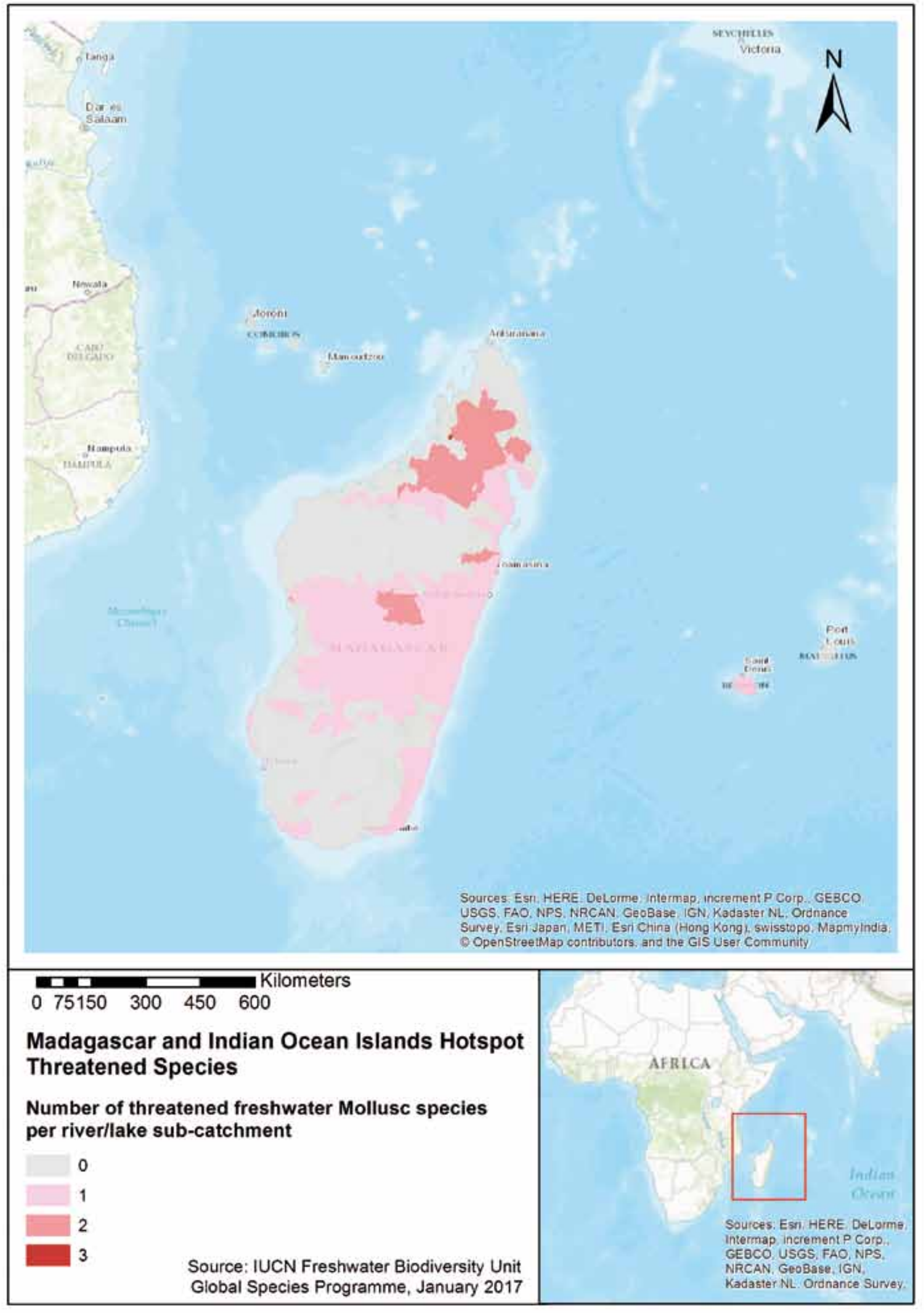


It should be noted that the distribution map of threatened species may partly reflect differences in the intensity of survey work carried out to date, such that areas of high threat may not yet be identified.

On the Indian Ocean islands the number of threatened species is relatively low (two species) as the freshwater mollusc fauna is a mixture of species which can also survive in brackish water, and opportunistic pulmonates tolerant of eutrophic conditions and pollution. Only the amphibious lymnaeid Lantzia carinata, restricted to its type locality, and the planorbid Africanogyrus rodriguenzis, which is only known from two localities on Rodrigues, are under threat.

\subsubsection{Data Deficient species}

Nine freshwater mollusc species were assessed as DD. The two main reasons for data deficiency in molluscs are taxonomic uncertainty and poor geographic knowledge. Two ellobiid species (Laemodonta livida and $L$. madagascariensis) were assessed as DD since they were recently described with little information available on their distribution range. The endemic status of a third ellobiid, Allochroa succinea, is doubtful. Two neritids and two assimineids also remain DD as there is no real consensus about their taxonomy and hence about their distribution. Finally the taxonomy of two thiarids, Thiara datura (one or more species?) and Melanoides psorica (endemic rare
Malagasy species or a form of $M$. tuberculata?) also needs to be resolved and, therefore, they are classed as DD (Table 4.2 and Annex 4.1). Further research is needed to better understand these species, taxonomy, distribution patterns and the impacts of threatening activities.

\subsection{Main threats}

There are multiple threats to freshwater molluscs in Madagascar and the Indian Ocean islands. In the majority of cases there is no single threat to a species, but usually a series of threats that combine to lead to a population decline. The main threats identified are as follows:

\section{Sedimentation of organic-rich material}

A major threat is siltation and subsequent alteration of mollusc microhabitats. Most caenogastropod species are benthic or epibenthic, tracing furrows through the surface of the bottom sediment, or they live within the sediment (e.g. Thiaridae and most bivalves). When river banks are cleared of their forest cover, nutrient-enriched soils rapidly accumulate in the water (Figure 4.4). These accumulations change the physical and chemical characteristics of the sediments through altering the ratio between clastic inorganic sediments and organic muds. The decomposition of the latter depletes the oxygen levels in the water and sediments, negatively effecting bottom dwelling molluscs.

Figure 4.4 The extensive logging of Madagascar's rainforests has resulted in severe rates of soil erosion. After the cyclonic storms and heavy rains caused by EI Niño, the red lateritic soils are washed from the hill slopes into the streams and rivers, increasing turbidity and reducing river's water quality and flow, threatening the populations of freshwater molluscs, fishes, decapods and Odonata species. () Laura Máiz-Tomé

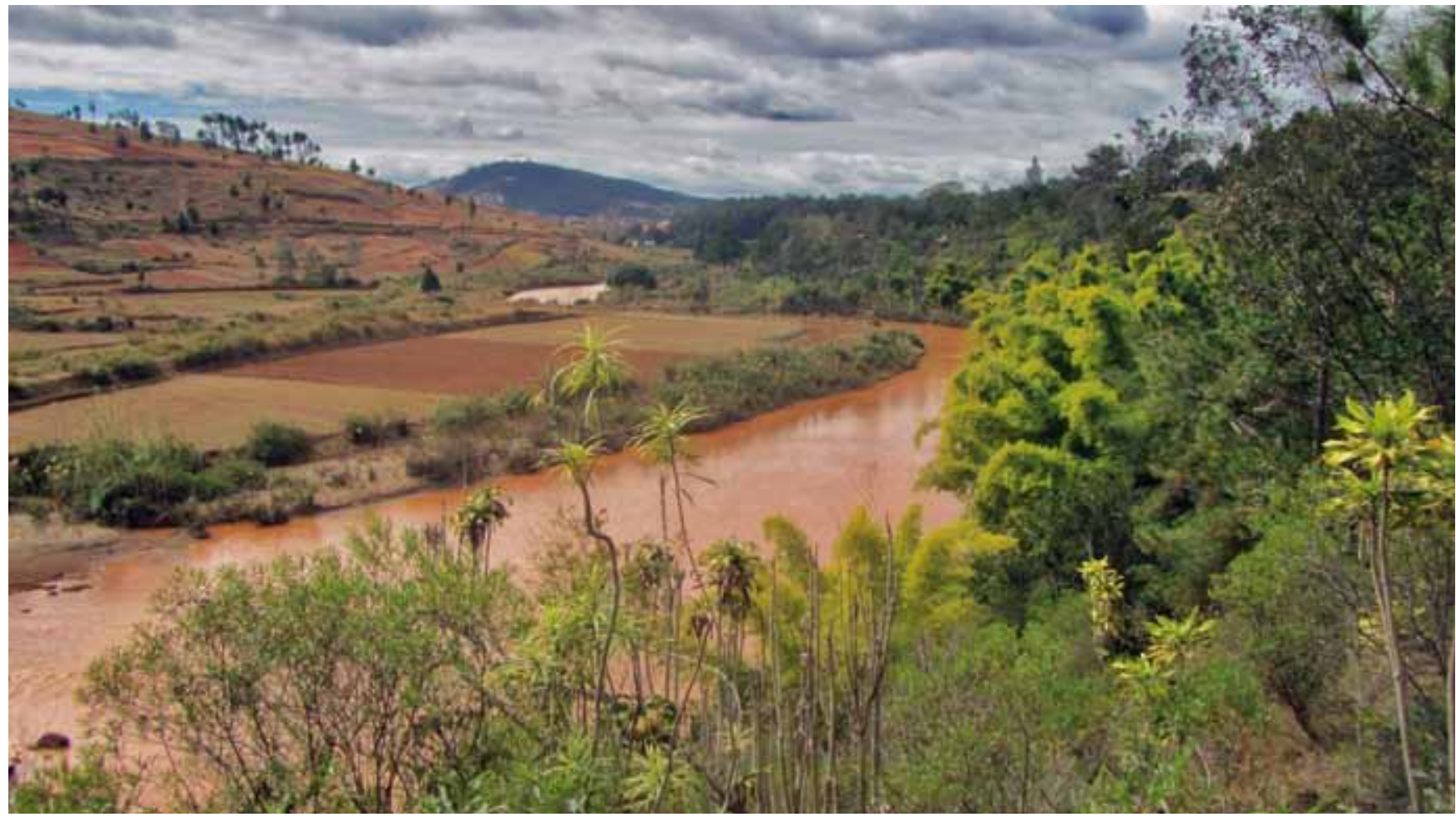




\section{Pollution and water quality decline}

Decline in the water quality of rivers and lakes is ongoing throughout Madagascar and the Indian Ocean islands. Artisanal and industrial mining spills, agricultural run-off and domestic waste water and sewage are discharged directly into rivers and lakes, polluting the waters with chemicals and nutrients. Many mollusc species are susceptible to these pollutants.

\section{Invasive species}

The nutrient enrichment mentioned above leads to algal blooms and the proliferation of invasive floating plant species such as Nile cabbage (Pistia spp.) and Water hyacinth (Eichhornia crassipes). Such proliferations can have dramatic effects such as slowing the water flow, reducing oxygen levels and blocking sunlight when covering lakes and ponds. These plants also create a prime habitat for mosquitos and some snail genera that host parasitic flatworms which cause schistosomiasis (snail fever). Molluscicides are subsequently used to control the transmission of schistosomiasis, however they also cause a simultaneous decline in populations of noncarrier endemic species that represent no threat to human health or livelihoods.

The introduction of exotic trees that alter the physicochemical properties of water, such as eucalyptus and pine plantations (both widespread in Madagascar), can also be highly negative (Verhaege et al. 2011). The latter acidifies surface waters ( $\mathrm{pH}=4$ or less) and eucalyptus leaves and bark are highly toxic to freshwater molluscs (Cheruiyot et al. 1984).

\section{Climate change}

The increased frequency and intensity of droughts poses a threat to freshwater molluscs by further lowering the water table of rivers and lakes where there are already problems such as over-abstraction of water for agricultural and domestic uses. Several rivers and streams now have periods when outflow completely dries up, increasing the vulnerability of populations. Freshwater molluscs are also sensitive to changes in water quality such that extreme weather events, such as flooding, can have serious consequences, altering for example sediment levels so that smaller species become buried, habitats destroyed and the gills of filter feeders get clogged.

\section{Wetland loss and degradation}

Major changes in land use, especially an increase in agriculture, water diversion through dams, dikes and canalisation as well as drainage of lower and upper marshes for rice cultivation (Figure 4.5) decrease water quality and quantity which impacts the survival of freshwater molluscs.

\subsection{Conservation recommendations}

At present there are no known targeted conservation measures in place to protect threatened freshwater molluscs in the hotspot.

Figure 4.5 Freshwater wetlands are a key resource for food security, providing fertile soils and water for rice cultivation, however, they are being lost and degraded at an alarming rate as a result of agriculture's growing demands for land and water and large-scale development initiatives (e.g. dam contruction). () Laura Máiz-Tomé

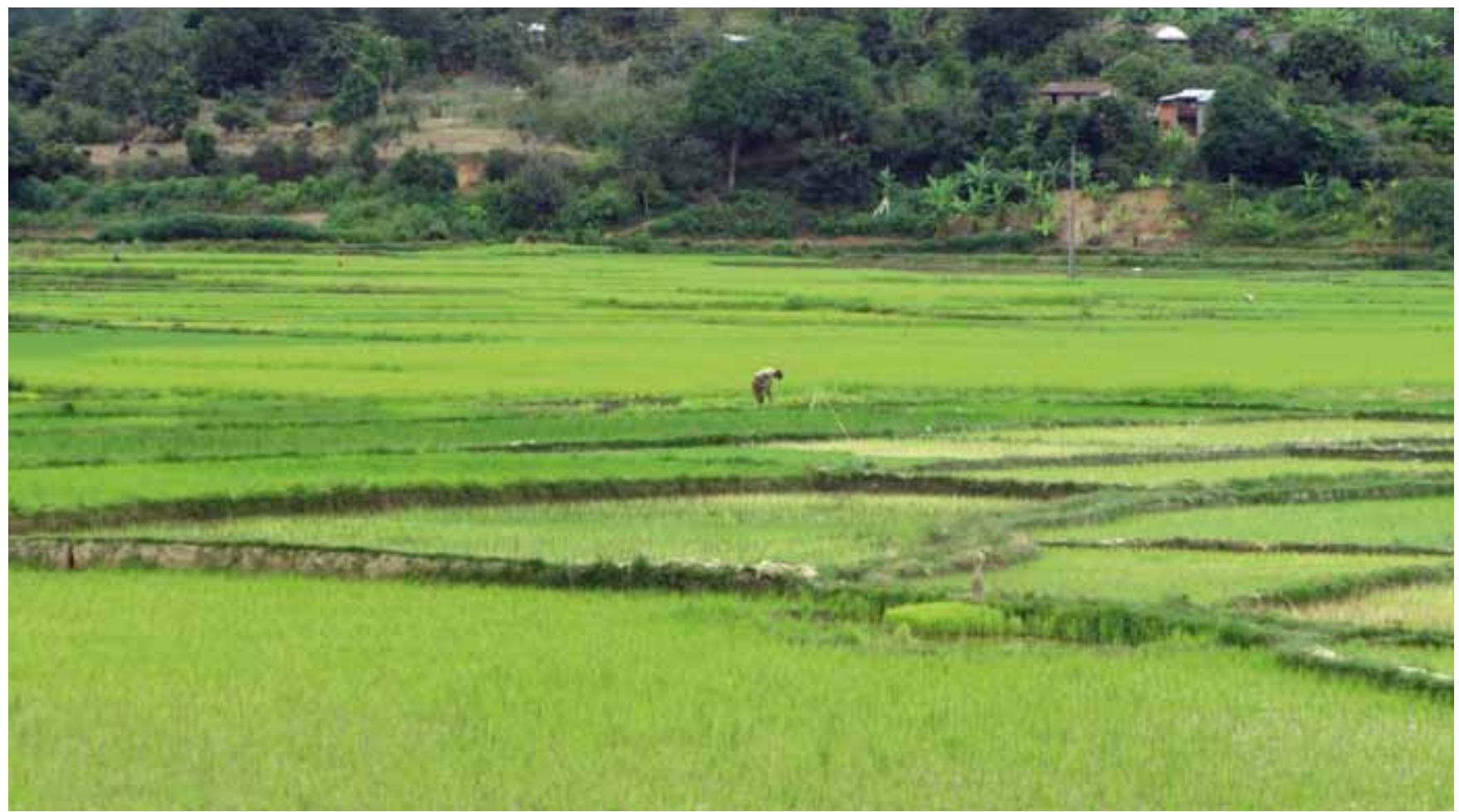




\section{Recommendations for Madagascar}

- Environmental Impact Assessments (EIAs) need to be conducted for all development projects upstream of freshwater KBAs that could alter water quality in the KBA. These EIAs should be mandatory for any proposed developments likely to impact mollusc species, such as dam construction, fish farm developments, large-scale timber extraction involving clear-felling of gallery forests, mining developments using open surface extraction methods, all agricultural activities that involve denuding land surfaces, and expansion of human settlements.
- Sewage treatment and water management needs to be improved, especially regarding the over-abstraction of springs and groundwater and the pollution resulting from agriculture and urbanisation.

- Invasive species should be controlled and a tighter control of introductions needs to be implemented to reduce their impact on native fauna. This also includes species intentionally imported such as eucalyptus and pine, because of their toxic effects on surface waters (Baohanta et al. 2012).

\subsection{Species in the spotlight}

\section{Madagascar's endemic river snails of the genus Madagasikara}

Dr Frank Köhler, Senior Research Scientist, Australian Museum

Madagasikara is the name of Madagascar in the national malagasy language. Not too long ago, this name was given to a genus of endemic freshwater snails. The genus Madagasikara has a lot in common with other groups of Malagasy animals and plants, having radiated into a flock of rather peculiar species due to their long evolutionary isolation. Just like other endemic groups, the snails were once thought to be descendants of a former Gondwanan fauna that arrived in Madagascar before it became an island (Yoder et al. 2006; Gibbons et al. 2013). However, a recent molecular phylogenetic study (Köhler \& Glaubrecht 2007) suggested otherwise, placing their arrival on Madagascar into the Cainozoic, well after the break-up of Gondwan. Interestingly, at least one species of these Malagasy snails has evolved a live-bearing reproductive strategy, which differs from similar viviparous strategies realised in other members of this family. While the Malagasy species breeds young in its mantle cavity, its distant relatives in Asia have developed special brood pouches in their body.

Just recently it was found that none of the names used in the taxonomic literature of the last 150 years were actually applicable to these species and that, although fairly well-known, these snails had not been correctly named until 2010 (Köhler \& Glaubrecht 2010). Currently, six species of the genus Madagasikara are known to exist, but given the paucity of survey data more species may be discovered. With virtually no field studies ever conducted, very little is known about the ecology of these snails and their current distribution and abundance. However, other members of the Pachychilidae family generally prefer clear, well-oxygenated rainforest streams. Therefore, there is a significant concern about these endemic species

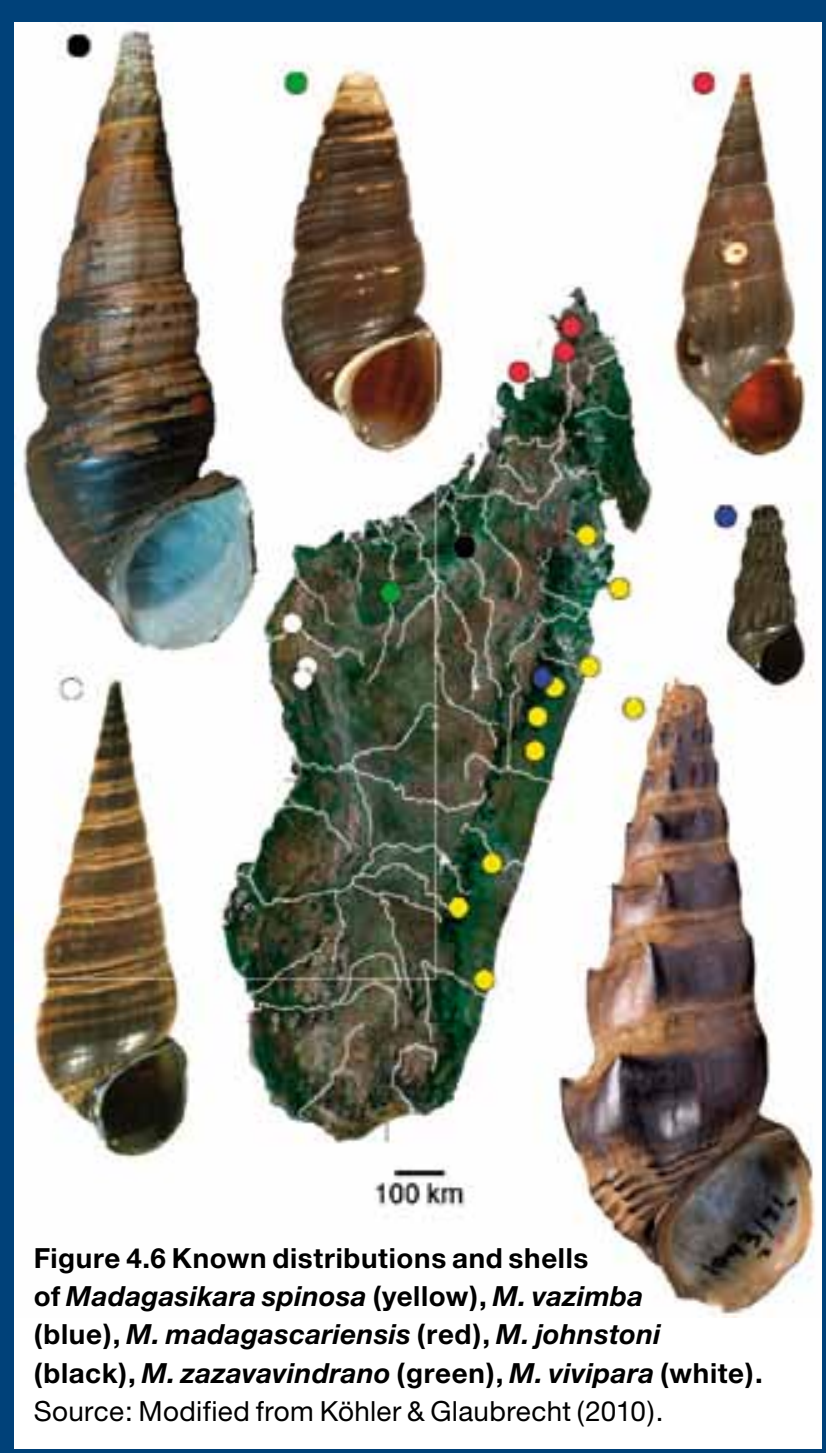

given the high levels of threat driven by deforestation and water pollution across Madagascar. Most species of Madagasikara are only known from a few records and it is likely that they are restricted to certain river catchments. Further research and monitoring are recommended to be able to assess these species against the IUCN Red List Categories and Criteria and raise awareness about the conservation needs of this endemic species. 
- Key Biodiversity Areas (KBAs) identified for freshwater molluscs (see Chapter 9) need to be recognised and protected as appropriate under national policies for protected areas and/or International Conventions (e.g. Ramsar). The management of these sites needs to take into consideration the habitat requirements for sustaining healthy populations of freshwater molluscs, securing water quality and minimal siltation rates.

- The importance and role of molluscs in maintaining healthy freshwater ecosystems should be promoted through a campaign to raise awareness.

Riparian forest vegetation should be preserved.

\section{Recommendations for the Indian Ocean islands}

The aquatic invertebrate fauna of Mauritius and Réunion was recently sampled and identified to create a Biotic Index and the threats to biodiversity have been assessed. On the basis of these findings the Landell Mills Consortium, under the supervision of the Indian Ocean Commission, has written three action plans for each island group. The first of these is a general action plan focused on short, medium and long term actions (e.g. the Mauritius and Rodrigues Freshwater Biodiversity Action Plan 2015-2020) and the second plan is for immediate actions (already implemented) (Bonne \& Lee 2015).

Species assessment: The first essential step for gathering knowledge on the aquatic fauna and using it for water quality assessment has been completed. The Mascarene authorities, responsible for the surface waters, are therefore significantly more advanced in this area of monitoring than on Madagascar.

Biotic Index: The development of a Biotic Index provides a tool to assess the ecological quality of (running) freshwater systems (using eight scores from very good quality to very bad quality). This is a simple and quick system used in many countries. It requires taxonomic knowledge of the different groups of aquatic macro-invertebrates either on family, genus or species level. In the Mascarenes a water quality assessment team responsible for this indexing of waters has been formed and the water quality of the river drainages and the distribution of different aquatic macroinvertebrate genera and species has been mapped.

\subsection{Research actions}

- Monitoring of species population size, distribution and trends (possibly through the monitoring of habitat as a proxy) should be undertaken for the threatened and DD species.
- Field surveys for DD species is of critical importance to determine their distributions and levels of threat.

- Further taxonomic research should be undertaken to clarify the taxonomic status of Madagascar and the Indian Ocean islands freshwater molluscs (e.g. Madagasikara). This might include DNA analysis to better understand some hybrid species mainly within the genus Bulinus.

- Facilitate the flow of information on species conservation priorities to the relevant authorities such as the Système d'Aires Protégées de Madagascar (SAPM), through the publication of policy briefs and reports, as well as ensuring data availability through the IUCN Red List website http://www.iucnredlist.org and the Key Biodiversity Areas Database http://www.keybiodiversityareas.org.

\subsection{References}

Andriamaro, L. 2010. Influence des situations environnementales sur la répartition des hôtes intermédiaires des schistosomes à Madagascar. PhD Dissertation.

Baohanta, R., Thioulouse, J., Ramanankierana, H., et al. 2012. Restoring native forest ecosystems after exotic tree plantation in Madagascar: combination of the local ectotrophic species Leptolena bojeriana and Uapaca bojeri mitigates the negative influence of the exotic species Eucalyptus camaldulensis and Pinus patula. Biological Invasions 14(11): 2407-2421. https://doi. org/10.1007/s10530-012-0238-5

Bonne, G. and Lee, P. 2015. STE13 Mission Report. The status of freshwater biodiversity in Mauritius and Rodrigues. A desktop review. Coastal, Marine and Island Specific Biodiversity Management in ESA-I0 Coastal States. Ebene, Mauritius.

Burney, D. 1996. Climate change and fire ecology as factors in the Quaternary biogeography of Madagascar. Biogéographie de Madagascar 49-58.

Breuil, C. and Damien, G. 2014. Baseline Report Madagascar. SmartFish Programme of the Indian Ocean Commission, Fisheries Management FAO component, Ebene, Mauritius.

Brown, D.S. 1994. Freshwater snails of Africa and their medical importance. Taylor and Francis, London.

IUCN. 2016. The IUCN Red List of Threatened Species. Version 2016-3. Available at: www.iucnredlist.org

Cheruiyot, H.K., Broberg, G., Wamae, L.W. and Wachira, T.M. 1980. Effect of Eucalyptus leaves on the survival of aquatic snails. East African Agricultural and Forestry Journal 46: 77-80.

Fischer-Piette, E. and Vukadinovic, D. 1973. Freshwater Mollusks of Madagascar. Malacologia 12(2): 339-78. 
Gibbons, A., Whittaker, J. and Müller, D. 2013. The breakup of East Gondwana: Assimilating constraints from Cretaceous ocean basins around India into a best-fit tectonic model. Journal of Geophysical Research 118(3): 808-822. https:// doi.org/10.1002/jgrb.50079

Glaubrecht, M., Fehér, Z. and Von Rintelen, T. 2006. Brooding in Corbicula madagascariensis (Bivalvia, Corbiculidae) and the repeated evolution of viviparity in corbiculids. Zoologica Scripta 35(6): 641-646. https://doi.org/10.1111/j.14636409.2006.00252.x

Graf, D. and Cummings, K. 2009. Actual and alleged freshwater mussels (Mollusca: Bivalvia: Unionoida) from Madagascar and the Mascarenes, with description of a new genus, Germainaia. Proceedings of the Academy of Natural Sciences of Philadelphia 158: 221-238. https:// doi.org/10.1635/053.158.0112

Graf, D. and Cummings, K. 2011. Freshwater mussels (Mollusca: Bivalvia: Unionoida), richness and endemism in the ecoregions of Africa and Madagascar based on comprehensive museum sampling. Hydrobiologia 678(1) 17-36. https://doi.org/10.1007/s10750-011-0810-5

Graf, D., Jones, H., Geneva, A., et al. 2015. Molecular phylogenetic analysis supports a Gondwanan origin of the Hyriidae (Mollusca: Bivalvia: Unionida) and the paraphyly of Australasian taxa. Molecular Phylogenetics and Evolution 85: 1-9. https://doi.org/10.1016/j.ympev.2015.01.012

IUCN. 2012. Guidelines for Application of IUCN Red List Criteria at Regional and National Levels: Version 4.0. Gland, Switzerland and Cambridge, UK: IUCN.

Köhler, F. and Glaubrecht, M. 2007. Out of Asia and into India: on the molecular phylogeny and biogeography of the endemic freshwater gastropod Paracrostoma Cossmann, 1900 (Caenogastropoda:Pachychilidae). Biological Journal of the Linnean Society 91(4): 627-651. https://doi. org/10.1111/j.1095-8312.2007.00866.x
Köhler, F. and Glaubrecht, M. 2010. Uncovering an overlooked radiation: molecular phylogeny and biogeography of Madagascar's endemic river snails (Caenogastropoda: Pachychilidae: Madagasikara gen. nov.). Biological Journal of the Linnean Society 99: 867-894. https://doi. org/10.1111/j.1095-8312.2009.01390.x

Mandahl-Barth, G. 1984. Studies on African freshwater bivalves. Kristensen, T. and Svenningsen, E. (eds.) Danish Bilharziasis Laboratory, Charlottenlund.

Seddon, M., Appleton, C., Van Damme, D. and Graf, D. 2011. Chapter 4. Freshwater molluscs of Africa: diversity, distribution and conservation, In: Darwall, W.R.T., Smith, K.G., Allen, D.J. et al. (eds.). 2011. The Diversity of Life in African freshwaters: Under Water, Under Threat. An analysis of the status and distribution of freshwater species throughout mainland Africa. Cambridge, United Kingdom and Gland, Switzerland: IUCN. xiii+347pp+4pp cover.

Yang, Z. and Yoder, A. 2003. Comparison of likelihood and Bayesian methods for estimating divergence times using multiple gene loci and calibration points, with application to a radiation of cute-looking mouse lemur species. Syst. Biol. 52:705-716. https://doi.org/10.1080/10635150390235557 Yoder, A. and Nowak, M. 2006. Has vicariance or dispersal been the predominant biogeographic force in Madagascar? Only time will tell. Annu. Rev. Ecol. Evol. Syst. 37: 405-431. https://doi.org/10.1146/annurev.ecolsys.37.091305.110239

Valentine, K.F. 2016. An investigation of Water Access and Quality in the Ambovombe Area of Southern Madagascar. Oregon State University.

Verhaegen, D., Randrianjafy, H., Montagne, P. et al. 2011. Historique de l'introduction du genre Eucalyptus à Madagascar. Bois et forêts des tropiques 309(3): 1. 
Annex 4.1 Red List status of Madagascar and the Indian Ocean islands hotspot freshwater molluscs.

\begin{tabular}{|c|c|c|c|}
\hline Family & Species & $\begin{array}{l}\text { Red List } \\
\text { Category }\end{array}$ & $\begin{array}{c}\text { Endemic } \\
\text { to the } \\
\text { hotspot }\end{array}$ \\
\hline UNIONIDAE & Unio madagascariensis & EX & Yes \\
\hline UNIONIDAE & Unio malgachensis & EX & Yes \\
\hline UNIONIDAE & Germainaia geayi & EX & Yes \\
\hline LYMNAEIDAE & Lantzia carinata & $\mathrm{CR}$ & Yes \\
\hline SPHAERIIDAE & Pisidium betafoense & $\mathrm{CR}$ & Yes \\
\hline PACHYCHILIDAE & $\begin{array}{l}\text { Madagasikara } \\
\text { zazavavindrano }\end{array}$ & CR & Yes \\
\hline NERITIDAE & Neritina coronata & EN & Yes \\
\hline CYRENIDAE & $\begin{array}{l}\text { Corbicula } \\
\text { madagascariensis }\end{array}$ & EN & Yes \\
\hline SPHAERIIDAE & Eupera degorteri & EN & Yes \\
\hline PACHYCHILIDAE & Madagasikara vazimba & EN & Yes \\
\hline PLANORBIDAE & $\begin{array}{l}\text { Africanogyrus } \\
\text { starmuehlneri }\end{array}$ & EN & Yes \\
\hline PACHYCHILIDAE & Madagasikara johnsoni & EN & Yes \\
\hline PACHYCHILIDAE & $\begin{array}{l}\text { Madagasikara } \\
\text { madagascarensis } \\
\end{array}$ & EN & Yes \\
\hline PALUDOMIDAE & Paludomus ajanensis & EN & Yes \\
\hline PACHYCHILIDAE & Madagasikara vivipara & EN & Yes \\
\hline AMPULLARIIDAE & Lanistes grasseti & VU & Yes \\
\hline PLANORBIDAE & $\begin{array}{l}\text { Africanogyrus } \\
\text { rodriguezensis }\end{array}$ & VU & Yes \\
\hline NERITIDAE & Clithon madecassinum & VU & Yes \\
\hline SPHAERIIDAE & Pisidium johnsoni & VU & Yes \\
\hline PALUDOMIDAE & Cleopatra grandidieri & NT & Yes \\
\hline PALUDOMIDAE & Cleopatra colbeaui & NT & Yes \\
\hline PACHYCHILIDAE & Madagasikara spinosa & NT & Yes \\
\hline ELLOBIIDAE & Laemodonta livida & $\mathrm{DD}$ & Yes \\
\hline ELLOBIIDAE & $\begin{array}{l}\text { Laemodonta } \\
\text { madagascariensis }\end{array}$ & $\mathrm{DD}$ & Yes \\
\hline ELLOBIIDAE & Allochroa succinea & $\mathrm{DD}$ & Yes \\
\hline ASSIMINEIDAE & Assiminea parvula & $\mathrm{DD}$ & Yes \\
\hline ASSIMINEIDAE & Assiminea hidalgoi & $\mathrm{DD}$ & No \\
\hline NERITIDAE & Neripteron simoni & $\mathrm{DD}$ & No \\
\hline NERITIDAE & Neripteron mauriciae & $\mathrm{DD}$ & Yes \\
\hline THIARIDAE & Melanoides psorica & DD & Yes \\
\hline THIARIDAE & Thiara datura & $\mathrm{DD}$ & No \\
\hline
\end{tabular}

\begin{tabular}{|l|l|c|c|}
\hline Family & \multicolumn{1}{|c|}{ Species } & $\begin{array}{c}\text { Red List } \\
\text { Category }\end{array}$ & $\begin{array}{c}\text { Endemic } \\
\text { to the } \\
\text { hotspot }\end{array}$ \\
\hline NERITIDAE & Neritilia vulgaris & LC & No \\
\hline PALUDOMIDAE & $\begin{array}{l}\text { Cleopatra } \\
\text { madagascariensis }\end{array}$ & LC & Yes \\
\hline ETHERIIDAE & Etheria elliptica & LC & No \\
\hline PLANORBIDAE & $\begin{array}{l}\text { Africanogyrus } \\
\text { crassilabrum }\end{array}$ & LC & Yes \\
\hline SPHAERIIDAE & Pisidium casertanum & LC & No \\
\hline NERITIDAE & Neripteron auriculatum & LC & Yes \\
\hline PLANORBIDAE & Ferrissia modesta & LC & Yes \\
\hline PLANORBIDAE & Bulinus bavayi & LC & Yes \\
\hline AMPULLARIIDAE & Pila cecillei & LC & Yes \\
\hline NERITIDAE & Neritina turrita & LC & No \\
\hline PLANORBIDAE & Bulinus cernicus & LC & Yes \\
\hline ELLOBIIDAE & Auriculastra subula & LC & No \\
\hline THIARIDAE & Melanoides tuberculata & LC & No \\
\hline SPHAERIIDAE & Pisidium ovampicum & LC & No \\
\hline SPHAERIIDAE & Pisidium viridarium & LC & No \\
\hline PLANORBIDAE & Bulinus liratus & LC & Yes \\
\hline PLANORBIDAE & Bulinus obtusispira & LC & Yes \\
\hline NERITIDAE & Neritilia rubida & LC & Yes \\
\hline NERITIDAE & Neritina pulligera & LC & No \\
\hline SPHAERIIDAE & Pisidium reticulatum & LC & No \\
\hline LYMNAEIDAE & Radix natalensis & LC & No \\
\hline POTAMIDIDAE & Cerithidea decollata & LC & No \\
\hline PLANORBIDAE & Ceratophallus natalensis & LC & No \\
\hline PLANORBIDAE & Bulinus forskalii & LC & No \\
\hline PLANORBIDAE & Lentorbis junodi & No \\
\hline SPHAERIIDAE & Eupera ferruginea & LC \\
\hline PLANORBIDAE & Segmentorbis angustus & Le & \\
\hline
\end{tabular}




\title{
The status and distribution of freshwater decapod crustaceans
}

\author{
Neil Cumberlidge', Jeanne Rasamy Razanabolana², Christian H. Ranaivoson², William Darwall ${ }^{3}$, Laura Máiz-Tomé \\ 5.1 Overview of freshwater decapods of Madagascar and the Indian Ocean islands hotspot ...............................................................42

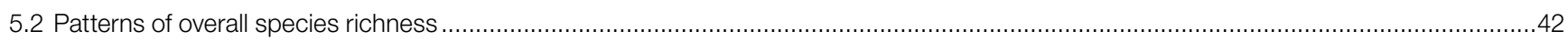

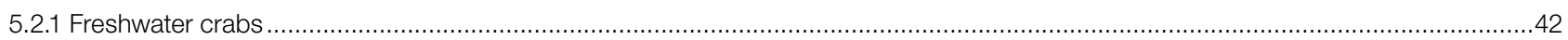

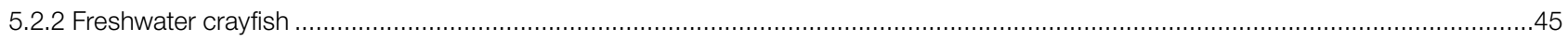

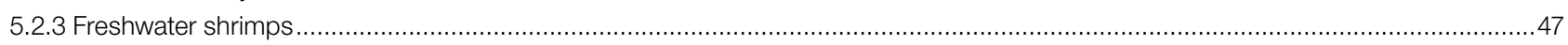

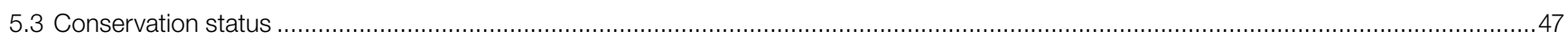

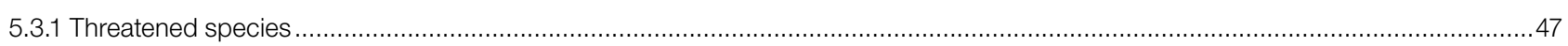

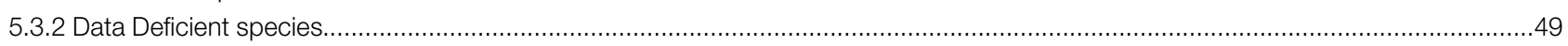

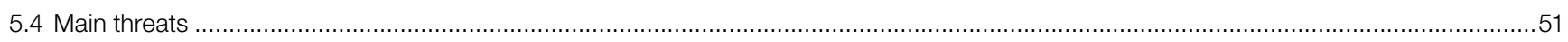

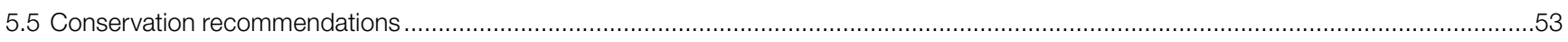

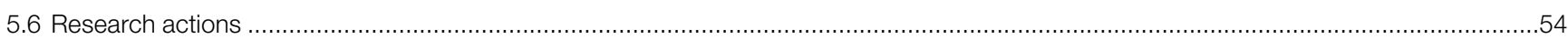

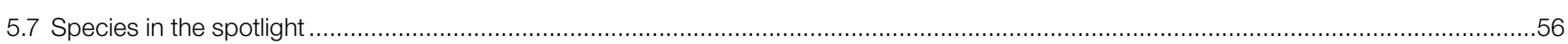

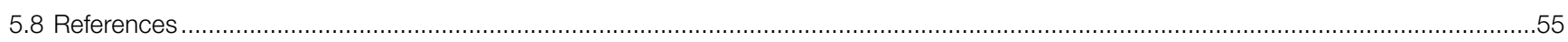 \\ Annex 5.1 Red List Status of Madagascar and the Indian Ocean islands freshwater crabs ...........................................................................58

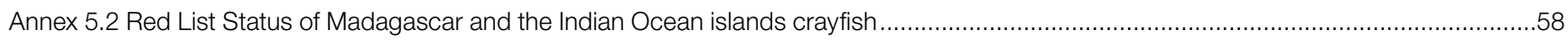 \\ Annex 5.3 Red List Status of Madagascar and the Indian Ocean islands freshwater shrimps ............................................................58
}

\subsection{Overview of freshwater decapods of Madagascar and the Indian Ocean islands hotspot}

The freshwater decapod fauna of Madagascar and the Indian Ocean islands hotspot (Comoros, Rodrigues, Mauritius, Réunion, and the Seychelles) comprises 72 species of freshwater crabs, crayfish, and freshwater shrimps in four families. This fauna is undoubtedly rich in comparison with other similar-sized and better-studied areas of continental Africa. Recent exploration and new taxonomic studies have shown that this region has 20 species of freshwater crabs (Potamonautidae), 45 species of freshwater shrimps (Atyidae and Palaemonidae), and seven species of crayfish (Parastacidae). It is likely that these numbers will rise as exploration continues and taxonomic skills are refined. Levels of endemism are high (100\% at the genus and species levels for crayfish and freshwater crabs, and $62 \%$ of species and $33 \%$ of genera for freshwater shrimps) which is a characteristic that they share with many other freshwater organisms from these long-isolated tropical islands (Cumberlidge et al. 2009; De Grave et al. 2014; Richman et al. 2014). Freshwater shrimps and crayfish in Madagascar and the Indian Ocean islands live in lakes, streams, and rivers, while freshwater crabs also occur in adjacent terrestrial habitats such as forest floors, rocky crevices, and rain forest phytotelmata (Cumberlidge \& Sternberg 2002; Cumberlidge et al. 2005).

\subsection{Patterns of overall species richness}

Patterns of species richness are described below for each group (20 species of freshwater crabs, seven species of crayfish, and 45 species of freshwater shrimps) within the context of the eight freshwater ecoregions in Madagascar and the Indian Ocean islands (Abell et al. 2008; Thieme et al. 2005) (Figure 1.1 in Chapter 1).

\subsubsection{Freshwater crabs}

Freshwater crabs are found in the Seychelles Archipelago (three species) and in Madagascar (17 species) but are absent elsewhere in the Indian Ocean hotspot. In Madagascar, these large and conspicuous crustaceans are present in almost all freshwater habitats, from mountain streams to large lowland rivers and small bodies of standing water (Cumberlidge \& Sternberg 2002), while in 


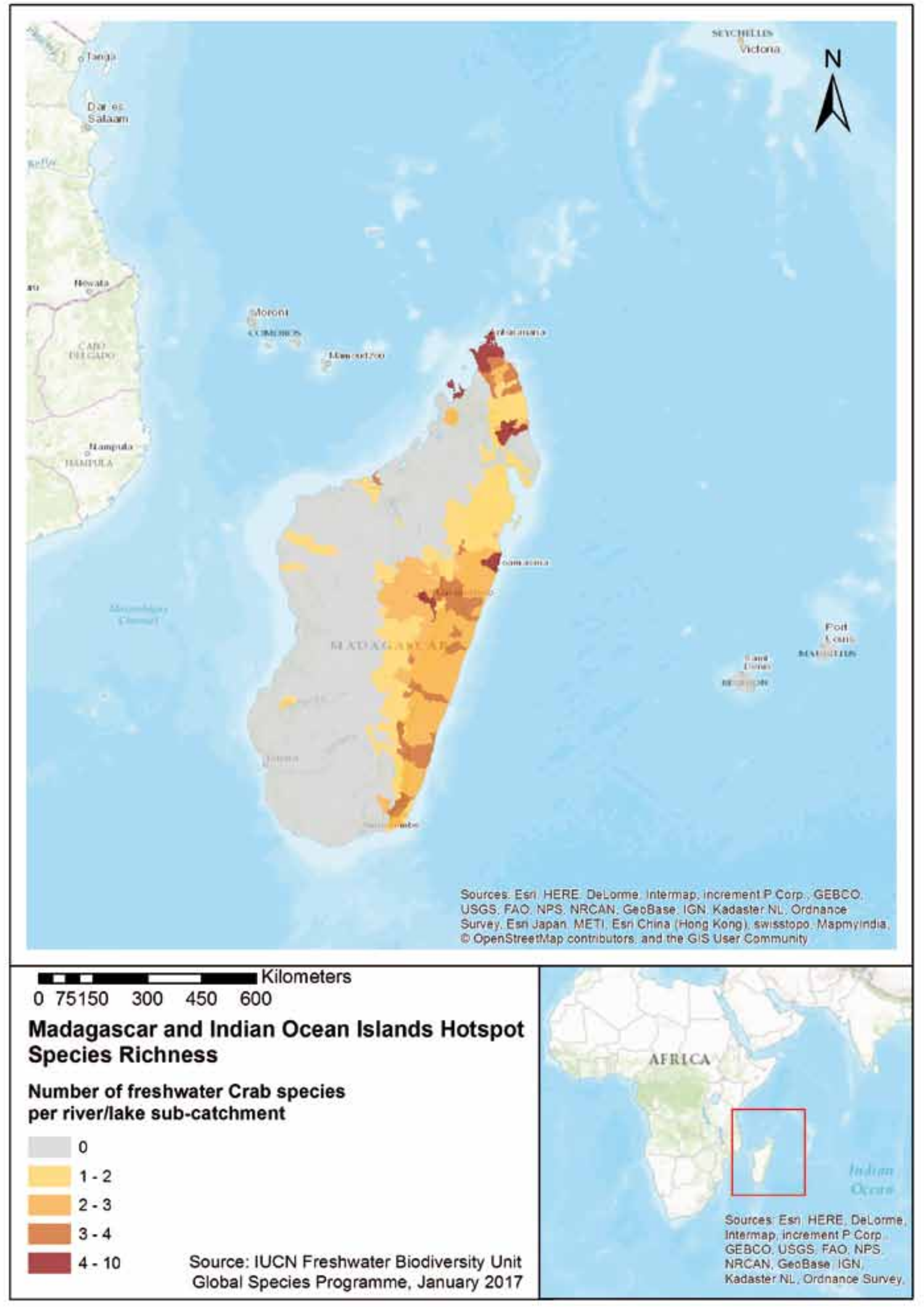


the Seychelles Archipelago freshwater crabs are found in freshwater habitats from sea level to higher altitudes (Daniels 2011; Cumberlidge \& Daniels 2014) (Figure 5.1). Species such as Madagapotamon humberti (Figure 5.2) from northern Madagascar live in seasonally arid areas and are semi-terrestrial living in burrows or rock crevices, while Malagasya goodmani lives in water pools that collect in leaf axils in trees in the eastern lowland forests (Cumberlidge \& Sternberg 2002). Some species of freshwater crabs (Marojejy longimerus, Foza manonae, and Malagasya goodmani) are known from a single locality, while others (all three species of Seychellum and Skelosophusa, and Madagapotamon humberti) are known from just a few localities, and some (all four species of Hydrothelphusa) have a wide-ranging distribution.

Endemism for freshwater crabs in Madagascar and the Seychelles Archipelago is $100 \%$ at the species and genus level, but not at the family level (Cumberlidge \& Sternberg 2002). Much of the diversity and endemism of these crustaceans is due to their isolation in fragmented habitats or those with a complicated topography. Endemism is further amplified by the limited dispersal abilities of freshwater crabs because they reproduce by direct development which means they mostly remain in the habitat where they were born because they lack a free-living larval dispersal stage (Cumberlidge et al. 2009). Additional surveys are required to establish the actual distribution of many of these species. In Madagascar, approximately $80 \%$ of the freshwater crab species are restricted to the island's northern province of Antsiranana (43,406 km²) which includes forested mountains, dry forests, and karst landscapes but represents only about $8 \%$ of the island's area. They are most common in the rainforest biome, rare in the dry deciduous forest and savanna biome, and absent from the southern xeric biome.

The Western Madagascar Ecoregion includes the headwaters of major rivers above $800 \mathrm{~m}$ asl that drain the western slopes of the central highlands in southwestern Antananarivo Province where three species of Hydrothelphusa are found. However, freshwater crabs are absent from the low altitude habitats in western Madagascar where the slow-flowing and turbid rivers run through deciduous forests and dry savannas. The water levels of these freshwater habitats are greatly reduced and significantly warmer during the dry season from April to November, and sometimes there is complete desiccation. This may be one reason that there are no species of freshwater crabs reported from the lowland part of this ecoregion (below $800 \mathrm{~m}$ ). Another reason for the absence of freshwater crabs in this part of the ecoregion could be the tidal nature of the lower reaches of some of the rivers that consequently have an increased salinity. Freshwater crabs exhibit a strong aversion to saltwater and do not occur either in full-strength seawater, or even brackish

Figure 5.2 Madagapotamon humberti (LC) This semi-terrestrial crab species is restricted to deciduous forests on limestone in northern Madagascar. Individuals have been found climbing on trees during the rainy season. They are extremely active in the dry season, living in very deep fissures and sinkholes in the karst. @ Lubomír Klátil

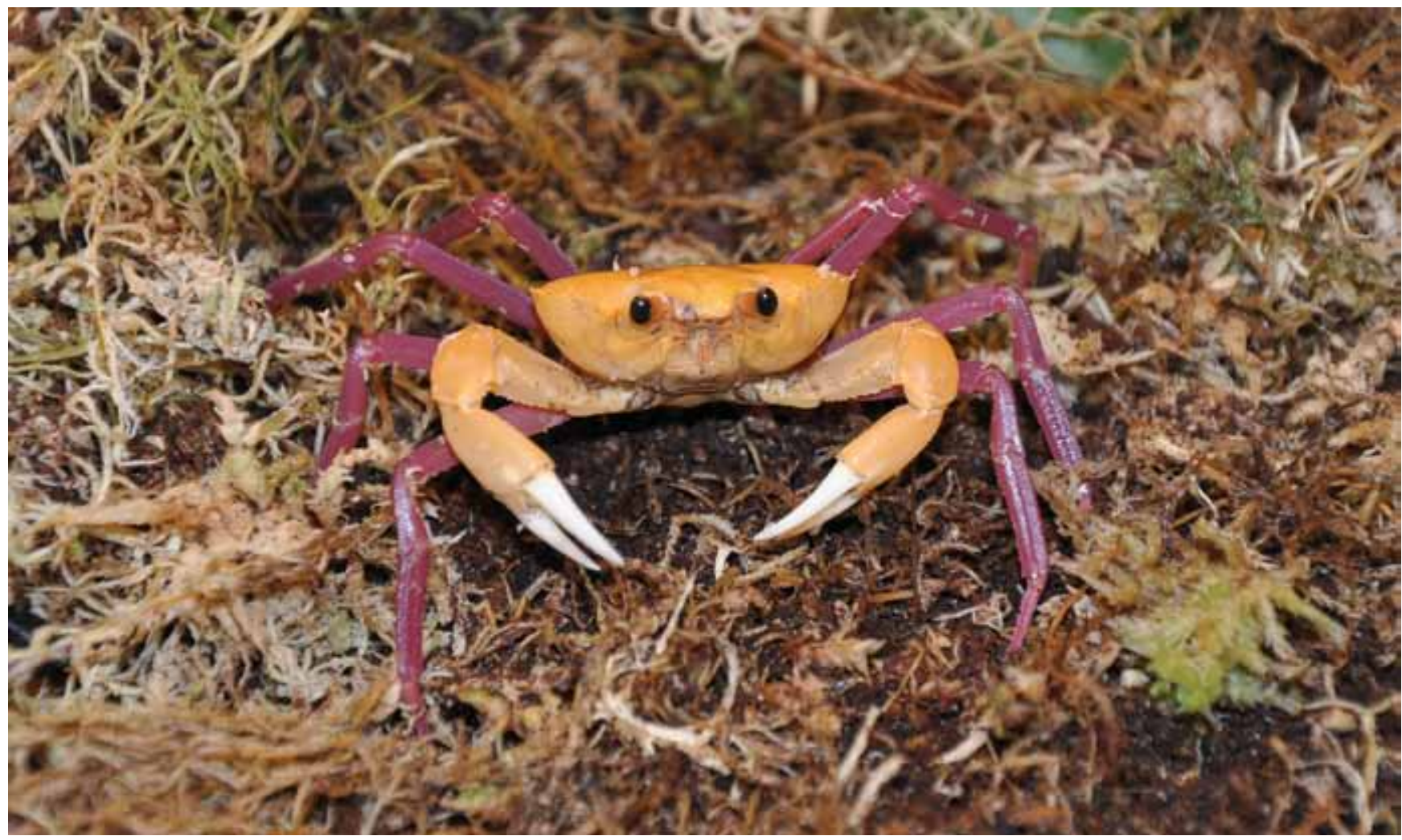


water environments in any part of their range globally (Cumberlidge 1999; Cumberlidge \& Esser 2011).

The highest diversity of freshwater crab species is in the North-Western Ecoregion (Figure 1.1 in Chapter 1) with nine species. This includes two monotypic genera (Boreas and Madagapotamon), one species of Malagasya, one species of Foza, three species of Skelosophusa, and two species of Hydrothelphusa (Cumberlidge \& Sternberg 2002). Five species (Madagapotamon humberti, B. uglowi, S. gollardi, $S$. prolixa and $S$. eumeces) have a narrow distribution and are endemic to this ecoregion, while three widely distributed species (Malagasya antongilensis, $H$. agilis and H. madagascariensis) also occur elsewhere (Cumberlidge 2008b). One species, Marojejy longimerus, is restricted to the high-altitude forest in the highland region of southeast Antsiranana Province. The apparent absence of records for freshwater crabs in the southern part of this ecoregion below $800 \mathrm{~m}$ may be because the rivers draining the Tsaratanana massif, as well as a number of other drainages in North-Western Madagascar, remain largely unsurveyed. Freshwater crabs are completely absent from the Southern Madagascar Ecoregion south of a line between Toliara (Tule'ar) and Tolagnaro (Fort Dauphin), even in the major rivers (Menarandra, Mananbovo and Mandrare). Many of the rivers in the extreme South-West of Madagascar dry up completely during the dry season, and others retain only low levels of relatively warm water. These conditions would make it difficult for most species of freshwater crabs to survive (Esser \& Cumberlidge 2011).

The forested Eastern Lowlands and Eastern Highlands Ecoregions together cover an area that lies in Antsiranana, Mahajanga, Toamasina, and Fianarantsoa Provinces, and the freshwater habitats in this part of Madagascar are the best surveyed on the island. Freshwater crab distributions here broadly conform to the limits of these two ecoregions from sea level to $1,800 \mathrm{~m}$, but there is no obvious subdivision into a highland and lowland fauna. The southern limit of the distribution of freshwater crabs in these two ecoregions corresponds to the boundary between the year round freshwater habitats of the humid forest zone and the seasonally dry waterways of the arid south-west. All four species of Hydrothelphusa live in these two ecoregions (Cumberlidge et al. 2007), as do the widely distributed Malagasya antongilensis and the narrowly distributed $M$. goodmani that is restricted to the eastern lowland forests in Toamasina Province. Freshwater crabs are not found either in the Comoros-Mayotte Ecoregion or in the Mascarenes (Mauritius, Réunion, Rodrigues) Ecoregion, but they are found in the Seychelles Ecoregion where they occur on five of the granitic islands (Mahe, Frégate, Silhoutte, La Digue and Praslin). The three species of Seychellum seem to occupy similar habitats (lowland and highland freshwater streams and the adjacent land) (Daniels 2011; Cumberlidge \& Daniels 2014).

\subsubsection{Freshwater crayfish}

In Madagascar and the Indian Ocean islands hotspot crayfish are only found in Madagascar and are not present in any of the other islands in the region. The seven species of Malagasy crayfish (Astacoides crosnieri, A. petiti, A. hobbsi, A. madagascariensis, $A$. granulimanus, $A$. betsileoensis and $A$. caldwelli) all belong to a single endemic genus in the family Parastacidae (Hobbs 1987; Boyko et al. 2005). In terms of the ecoregions in Madagascar, crayfish are found in the Eastern Lowlands and Eastern Highlands Ecoregions, and are completely absent from the ecoregions in Western Madagascar, North-Western Madagascar and Southern Madagascar (Figure 5.3). The first estimations of the distributional range of the Madagascan crayfish by Monod \& Petit (1929) suggested they occupy an area of at least $70,000 \mathrm{~km}^{2}$, but additional survey work has now increased this area to between 86,683 and $122,960 \mathrm{~km}^{2}$, representing $15-21 \%$ of the area of the island. The natural range of crayfish stretches from Anjozorbe District in the north, to the Isaka valley in Taolagnaro District to the south. In Madagascar, crayfish are found in the Central Highlands in headwater forest streams draining the eastern and western slopes as well as in streams at higher elevations on the high plateau (Hobbs 1987). Most species of Malagasy crayfish occur in primary forest streams in the Central Highlands, where they are restricted to forested mountains with cool streams and rivers including the eastern slopes (escarpment) and the headwaters of the western slopes in just four provinces (Antananarivo, Toamasina, Fianarantsoa, and Toliara). The northern boundary is in Anjozorobe District about $80 \mathrm{~km}$ north of Antananarivo, the southern boundary is in Taolagnaro District, the western boundary is in Faratsiho and Ambalavao Districts, and the eastern boundary is in Moramanga District and the Isaka River Valley. This represents about $15 \%$ of the area of Madagascar (Cumberlidge et al. 2017), most of which (61.7\%) lies in Fianarantsoa Province, where five of the seven species $(71.4 \%)$ occur.

Species richness for crayfish is highest in the central parts of the remaining primary forest in Fandriana District where four species live in small headwater streams in the forest. The elevational range of Malagasy crayfish is from $120 \mathrm{~m}$ to 1,756 $\mathrm{m}$ asl (Ramilijaona et al. 2007). The most widespread species is $A$. granulimanus that lives in small forest streams along the eastern escarpment, while $A$. madagascariensis is restricted to small forest streams and swampy areas at the edge of the forest in the northern part of the range for Astacoides. Finally, A. hobbsi is known only from a single locality in Fandriana District. All species of Astacoides are adapted to life in the headwater streams in the primary 


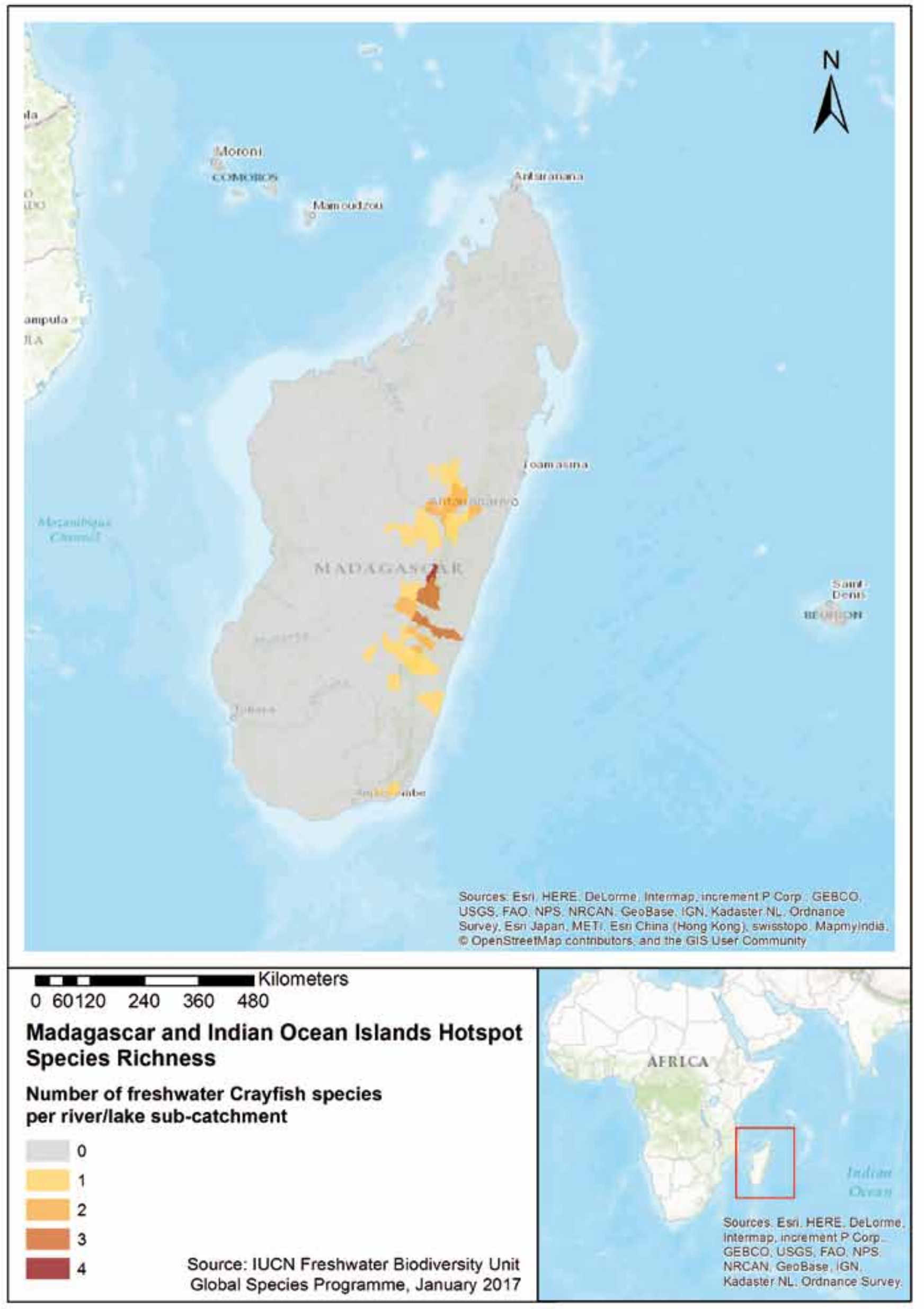


forests of the eastern slopes of the central highlands. However, A. caldwelli is also found in waters below the eastern escarpment of the central mountains in the large lowland streams and rice paddies in degraded open areas, and $A$. petiti is found at the lowest elevation of any species of crayfish in the far south in Taolagnaro District (Ramilijaona et al. 2007; Jones 2004). The strong ecological tie of crayfish to the high elevation forested headwater streams on the eastern and western slopes of the central highlands may be one of the factors that has limited the dispersal of these crustaceans beyond the mountains. However, it is still not known with any certainty why crayfish have such a narrow range in Madagascar, and why they are not found in suitable habitats elsewhere on the island given that freshwater crabs and shrimps have an island-wide distribution. This is an interesting question for future research.

\subsubsection{Freshwater shrimps}

Some 45 species of freshwater shrimps are found throughout the Indian Ocean hotspot region, in Madagascar (40 species), Rodrigues (five species), Réunion (three species), Mauritius (three species), the Seychelles Archipelago (one species), and the Comoros (one species). Shrimps are found throughout Madagascar in all five ecoregions (Eastern Lowlands, Eastern Highlands, Western Madagascar, NorthWestern Madagascar, and Southern Madagascar), and there are 11 species in the Mascarenes Ecoregion, four species (Caridina similis, C. typus, Macrobrachium idea, M. australe) in the Seychelles Ecoregion, and only one species (Atyoida serrata) in the Comoros-Mayotte Ecoregion. Although the vast majority of freshwater shrimp species in this region are found in Madagascar their presence there is part of a wider distributional range, and only 23 of these species are endemic to the island. In Madagascar, shrimps are present in almost all freshwater habitats from mountain streams to large lowland rivers and small bodies of standing water including caves (Figure 5.4). Many of the widespread species of freshwater shrimp live in both freshwater and saltwater habitats in different parts of their life cycle, and migrate downstream to the sea to breed. There their larvae disperse widely across many parts of the Indian and Pacific Oceans. For example, 17 of the 45 species freshwater shrimps have a very wide distribution that includes Madagascar and the Indian Ocean islands hotspot, and extends to different parts of the Indian and western Pacific Oceans. There are also a few species that have a more narrow distribution on the smaller islands in the region: three species are endemic to Mauritius (Caridina mauritii, C. richtersi, C. spathulirostris), one species is endemic to the Seychelles (Caridina similis), and one species is endemic to the islands of Réunion and Mauritius (Macrobrachium hirtimanus). A different distribution pattern is shown by species such as Atyoida serrata that is restricted to most of the islands in the region
(Madagascar, Mauritius, Comoros, and Réunion) but it is not found in the Seychelles. Caridina typus and Macrobrachium lar are both widespread species, each with a distribution that includes Madagascar, Mauritius, Rodrigues, Réunion, and the Seychelles, but that also extends across the Indian and west Pacific Oceans from eastern Africa to Guam and the Marquesas Islands in the Pacific (Chace 1997). Other species such as Macrobrachium lepidactylus are widespread in Eastern Africa and have a distribution that includes Madagascar and Réunion, while M. patsa is found in Kenya and Madagascar.

\subsection{Conservation status}

\subsubsection{Threatened species}

The freshwater decapod fauna in Madagascar and the Indian Ocean islands hotspot is increasingly threatened by habitat disturbance, extreme fragmentation, poor land use practice, invasive species, and overharvesting. The Red List assessments for crabs, crayfish, and shrimps are presented separately below. A very high proportion of species are Data Deficient (DD): $43 \%$ of shrimps, $35 \%$ of freshwater crabs, and $14 \%$ of crayfish. However, this DD status does not imply they are not threatened; on the contrary, they may prove to be threatened when more data become available. Some DD species may never be assessed because either the type material has been lost, their taxonomic status is doubtful, or the provenance of the specimen is unknown (Bland et al. 2017).

Freshwater crabs. Red List assessments of the 20 species of freshwater crabs revealed just two species (10\% of the fauna) to be threatened (Table 5.1): Boreathelphusa uglowi Endangered (EN) and Seychellum alluaudi Vulnerable (VU) (Annex 5.1; Figure 5.5 and 5.6). Assuming that all DD species are threatened in the same proportion as those species for which enough information was available, the percentage of threatened freshwater crab species increases to $15 \%$. Boreathelphusa uglowi was uplisted from VU due to a continuing decline in the extent and quality of its habitat (Cumberlidge 2008b; Cumberlidge et al. 2009;

Table 5.1 The number of freshwater crab species endemic to Madagascar in each IUCN Red List Category.

\begin{tabular}{|l|l|c|}
\hline \multicolumn{2}{|l|}{ IUCN Red List Categories } & No. endemic species \\
\hline \multirow{3}{*}{$\begin{array}{l}\text { Threatened } \\
\text { Categories }\end{array}$} & Critically Endangered (CR) & - \\
\cline { 2 - 3 } & Endangered (EN) & 1 \\
\cline { 2 - 3 } & Vulnerable (VU) & 1 \\
\hline \multirow{3}{*}{$\begin{array}{l}\text { Other } \\
\text { Categories }\end{array}$} & Near Threatened (NT) & - \\
\cline { 2 - 3 } & Least Concern (LC) & 11 \\
\cline { 2 - 3 } & Data Deficient (DD) & 7 \\
\hline \multicolumn{2}{|l|}{ Total number of species assessed } & $\mathbf{2 0}$ \\
\hline
\end{tabular}


Figure 5.4 The distribution of freshwater shrimp species per river/lake sub-catchment across Madagascar and the Indian Ocean islands hotspot.

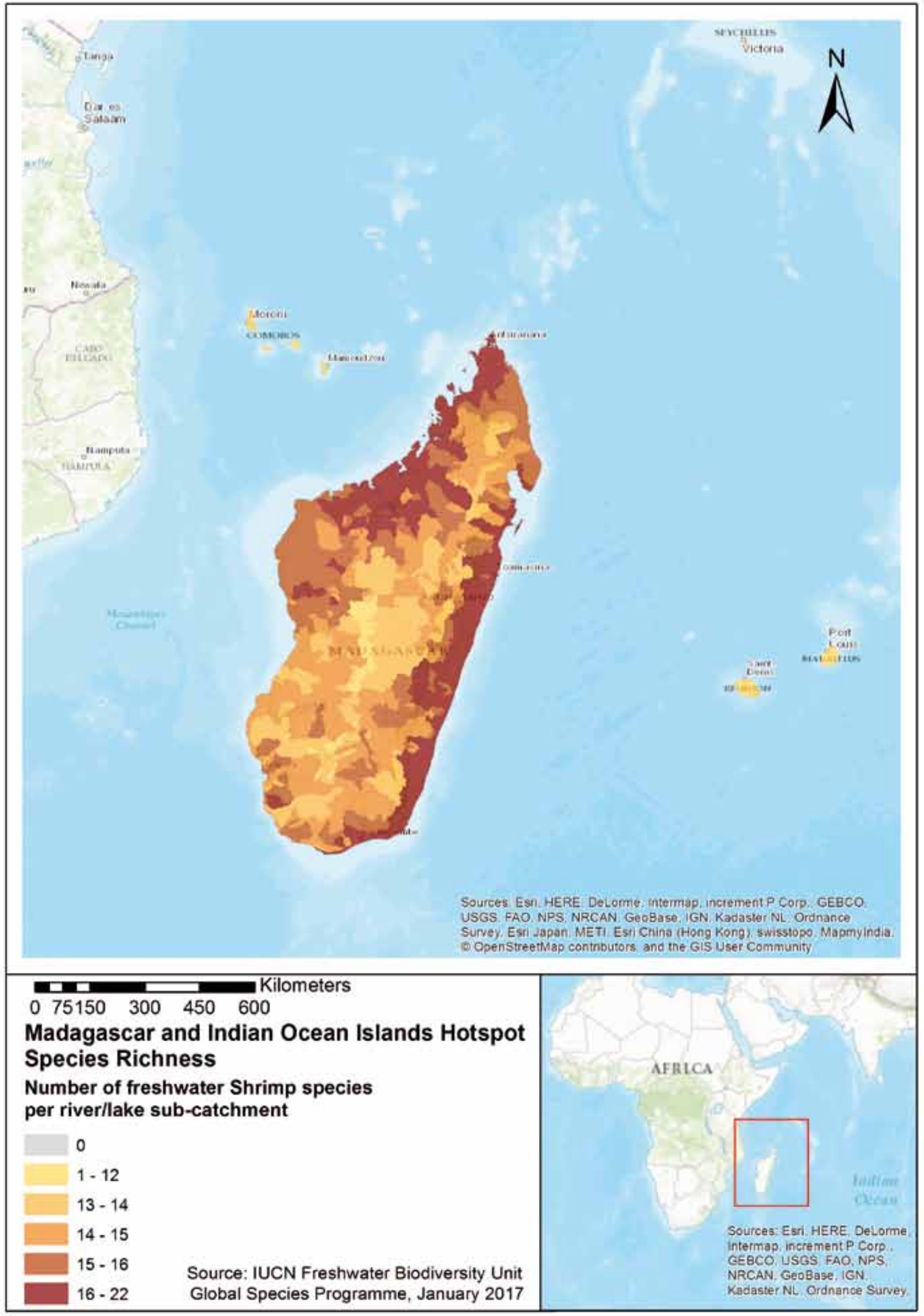


Figure 5.5 The percentage (\%) of freshwater crab species in each IUCN Red List Category.

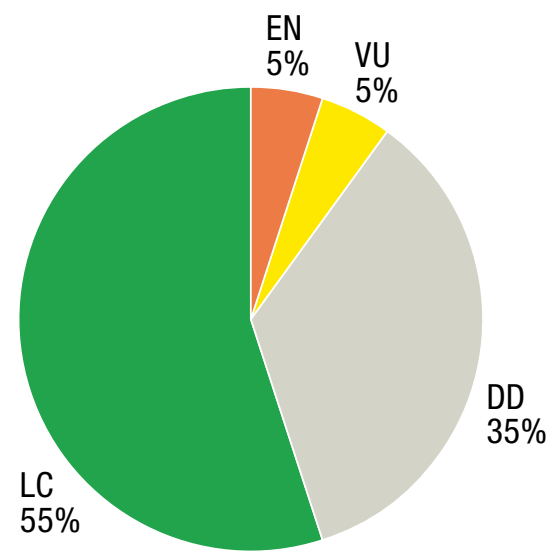

2015; 2017). S. alluaudi is endemic to La Digue and Praslin islands in the Seychelles and has been assessed as VU due to its restricted range and potential threats including pollution and habitat degradation and loss. In addition, the recent collection of $M$. humberti from a number of new localities in Antsiranana Province that are all within protected areas (Ankarana Special Reserve, Montagne des Français Reserve, Orangea Reserve, and Analamerana Special Reserve) (Cumberlidge et al. 2015) has resulted in its downlisting from VU (Cumberlidge 2008a; Cumberlidge et al. 2009) to Least Concern (LC) (Cumberlidge et al. 2017).

Crayfish. Four species (Astacoides betsiloensis, $A$. caldwelli, A. crosnieri, A. hobbsi) were assessed as VU, two species ( $A$. granulimanus, $A$. madagascariensis) were assessed as LC, and one ( $A$. petiti) was assessed as DD (Cumberlidge et al. 2017; Table 5.2; Figure 5.7). Assuming that all Data Deficient species are threatened in the same proportion as those species for which enough information was available $67 \%$ of the crayfish species assessed are threatened. The four VU species have restricted geographic ranges, occur in 10 or fewer locations, and all are experiencing continuing declines in the area, extent and/ or quality of their habitat and, in the case of $A$. crosnieri, in the number of mature individuals. Threatened species of crayfish are found throughout much of the distributional range of the genus with the exception of the far south of the island. Astacoides betsileoensis is found in the northern part of the range of the genus, while $A$. caldwelli (Figure 5.13) is found to the west, and $A$. hobbsi has a restricted distribution in just a few streams in Fandriana District (Cumberlidge et al. 2017). Two thirds of the sites where VU species occur are located either within or near a protected area.

Shrimps. Red List assessments of the 45 species of freshwater shrimps (Annex 5.3; Figure 5.9; Table 5.3) indicate a low level of threat to the fauna, with 22 species (49\%) assessed as LC and just one species threatened, Macrobrachium hirtimanus (EN) that is endemic to Mauritius and Réunion. Assuming that all DD species are threatened in the same proportion as those species for which enough information was available only $4 \%$ of the freshwater shrimp species assessed are threatened.

However, three species (Caridina mauritii, C. richtersi, C. spathulirostris) were assessed as Near Threatened (NT) and all of these are endemic to Mauritius. The high numbers of DD species are of concern as they may yet be found to be threatened should sufficient information becomes available to complete the assessments.

\subsubsection{Data Deficient species}

Some $44 \%$ of Madagascar's freshwater decapods are DD, meaning that they are too poorly known to complete an assessment of their extinction risk (Figures 5.5; 5.7 and 5.9). This lack of data reflects the poor amount of research attention paid to this fauna, especially the freshwater crabs and shrimps. The Malagasy crayfish are, however, relatively well studied with only one species ( $A$. petiti) assessed as DD. This species is found in the far south of the range of the genus, where it is the only species of crayfish. The southern part of the island is, however, poorly surveyed for crayfish, and more field surveys are needed to better define the true distributional range of $A$. petiti. This geographical bias in our knowledge of crayfish distributions is apparent because most studies of crayfish in Madagascar have focused on just three Provinces: Antananarivo, Fianarantsoa, and Toamasina.

Seven species of freshwater crabs (35\%) were assessed as DD (Cumberlidge et al. 2017). These species are Malagasya goodmani, Marojejy longimerus Skelosophusa gollhardi, S. prolixa, S. eumeces, Glabrithelphusa angene and $F$. manonae (Bott, 1965; Ng \& Takeda 1994; Cumberlidge et al. 2002; Meyer et al. 2014; Cumberlidge et al. 2015). All have a restricted distributional range and all have been encountered recently, and so it is only the shortage of material and lack of knowledge of threats that is preventing their assessment.

Red List assessments of the 45 species of freshwater shrimps found $42 \%$ (19 species) DD, and all of these are endemic to Madagascar (De Grave et al. 2014; Cumberlidge et al. 2017). Sixteen of the 19 DD species are atyids and three are palaemonids (De Grave et al. 2014; Cumberlidge et al. 2017) and all are found throughout the island. The DD species of atyids include 10 species of Caridina, four species of Parisia, and one species each of Monsamnis and Typhlopatsa, while the three palaemonid species are all in the genus Macrobrachium.

The lack of knowledge of freshwater crabs, crayfish, and freshwater shrimps on Madagascar reflects an apparent 


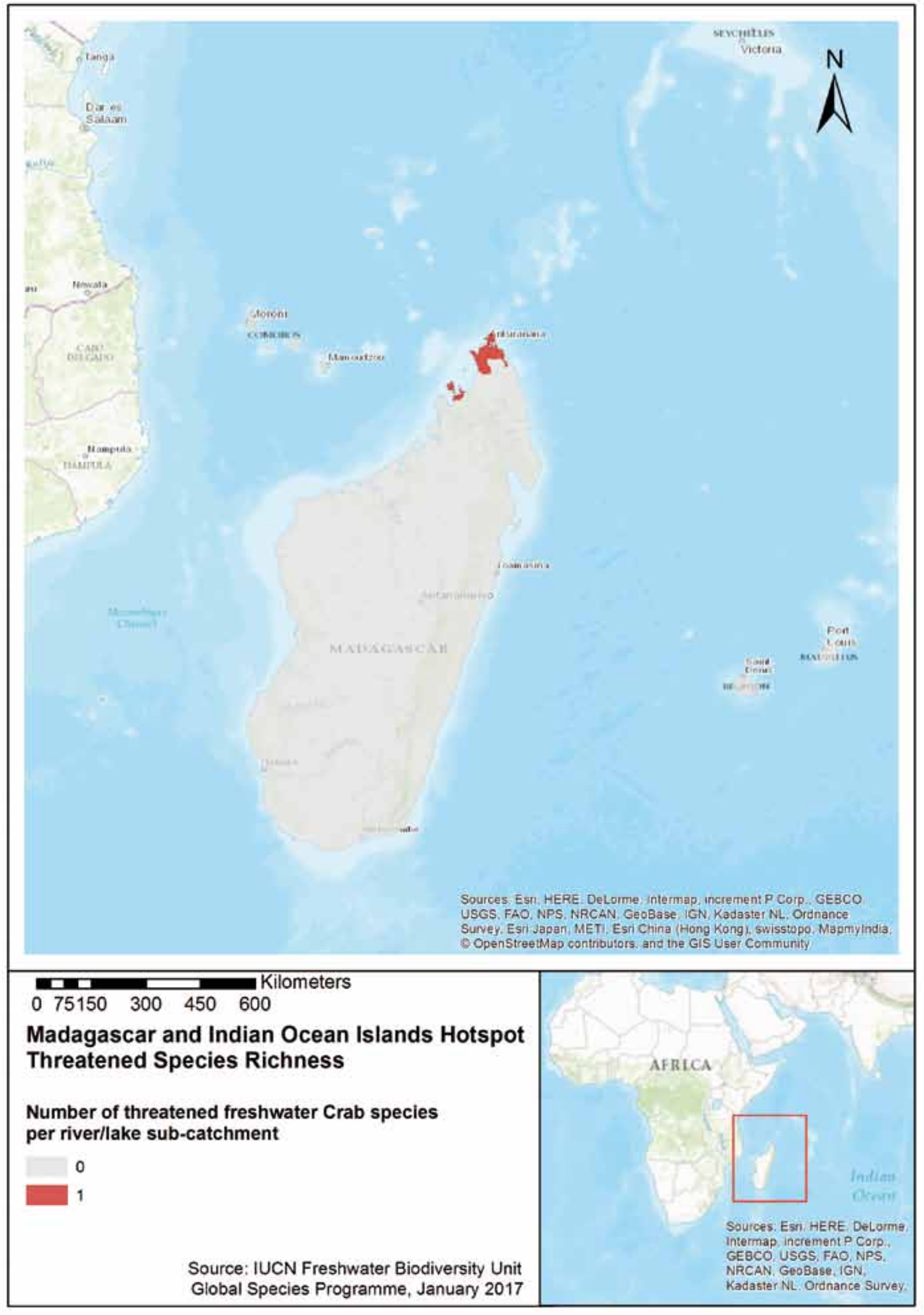


Table 5.2 The number of crayfish species endemic to Madagascar in each IUCN Red List Category.

\begin{tabular}{|l|l|c|}
\hline \multicolumn{2}{|l|}{ IUCN Red List Categories } & No. endemic species \\
\hline \multirow{3}{*}{$\begin{array}{l}\text { Threatened } \\
\text { Categories }\end{array}$} & Critically Endangered (CR) & - \\
\cline { 2 - 3 } & Endangered (EN) & - \\
\cline { 2 - 3 } & Vulnerable (VU) & 4 \\
\hline \multirow{4}{*}{$\begin{array}{l}\text { Other } \\
\text { Categories }\end{array}$} & Near Threatened (NT) & - \\
\cline { 2 - 3 } & Least Concern (LC) & 2 \\
\cline { 2 - 3 } & Data Deficient (DD) & 1 \\
\hline \multicolumn{2}{|l|}{ Total number of species assessed } & 7 \\
\hline
\end{tabular}

Figure 5.7 The percentage (\%) of crayfish species in each IUCN Red List Category.

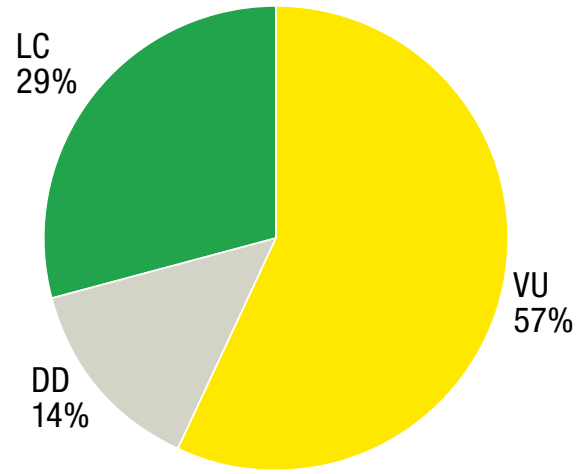

Table 5.3 The total number of freshwater shrimp species and endemic shrimp species in each IUCN Red List Category for the entire hotspot.

\begin{tabular}{|l|l|c|c|}
\hline \multirow{4}{*}{ IUCN Red List Categories } & $\begin{array}{c}\text { No. } \\
\text { Total no. } \\
\text { species }\end{array}$ & $\begin{array}{c}\text { Nondemic } \\
\text { endecies } \\
\text { spect }\end{array}$ \\
\hline \multirow{3}{*}{$\begin{array}{l}\text { Threatened } \\
\text { Categories }\end{array}$} & Critically Endangered (CR) & - & - \\
\cline { 2 - 4 } & Endangered (EN) & 1 & 1 \\
\cline { 2 - 4 } & Vulnerable (VU) & - & - \\
\hline \multirow{4}{*}{$\begin{array}{l}\text { Other } \\
\text { Categories }\end{array}$} & Near Threatened (NT) & 3 & 3 \\
\cline { 2 - 4 } & Least Concern (LC) & 22 & 6 \\
\cline { 2 - 4 } & Data Deficient (DD) & 19 & 19 \\
\hline \multicolumn{2}{|l|}{ Total number of species assessed } & $\mathbf{4 5}$ & $\mathbf{2 9}$ \\
\hline
\end{tabular}

Figure 5.9 The proportion (\%) of freshwater shrimp species in each IUCN Red List Category in Madagascar and the Indian islands hotspot.

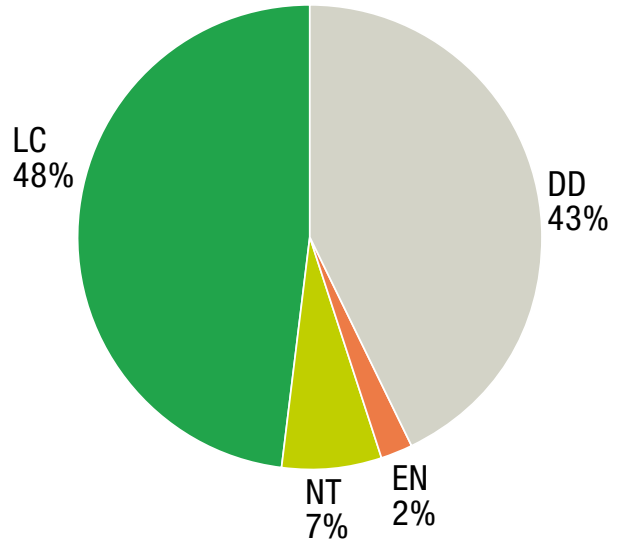

lack of research interest rather than intransient underlying taxonomic problems. This means that with more survey work the large numbers of DD species in Madagascar can become better known and their extinction risk evaluated (De Grave et al. 2014), an activity that may discover a number of species of freshwater shrimps to be threatened.

\subsection{Main threats}

The main threats to Madagascar's freshwater decapod fauna are driven by a high human population density, increasingly disturbed habitats, severe fragmentation of habitats, poor land use practices (including pollution), exotic species introductions, and overharvesting.

\section{Habitat loss and over exploitation}

The very high rate of deforestation in Madagascar has led to the loss of about $80 \%$ of natural habitat of the island (MEFT, USAID, CI, 2009). This has affected freshwater decapods in general but the species of crayfish that require highland streams in forested areas are particularly heavily impacted. Expanding human activities such as slash-andburn agriculture, wood harvesting, bush fires, and mining have resulted in significant reductions of the natural forest cover each year (Figure 5.10). Astacoides populations have therefore suffered because they are strongly linked to natural forest streams either within, or on the edges of natural forests.

\section{Invasive species}

Native crayfish populations in particular are threatened by the recent and expanding invasion of Madagascar's freshwater habitats by the non-native marbled crayfish (Procambarus spp.). This invasive species adapts well to all habitat types, has a very high growth rate, produces high numbers of eggs in relation to its small size and can reproduce by parthenogenesis - a female is able to reproduce without being fertilised by a male. This means that a single individual is sufficient to start a whole new population (Jones et al. 2009). Another species of invasive crayfish, $P$. clarkii, native to the USA, not only disrupts aquatic ecosystems and the animals and plants that live there, but is also a known vector of the crayfish plague, Aphanomyces astaci, which represents a serious threat to native Malagasy crayfish populations (Dieguez-Uribeondo and Soderhall 1993). The spread of $P$. clarkii into Madagascar's natural forest habitats would be catastrophic not only for the crayfish, but also for many other species in these freshwater ecosystems. There are no known impacts of invasive species on freshwater crabs and freshwater shrimps from this region.

\section{Overharvesting}

All species of crayfish and some species of freshwater crabs and freshwater shrimps (especially the large species of 


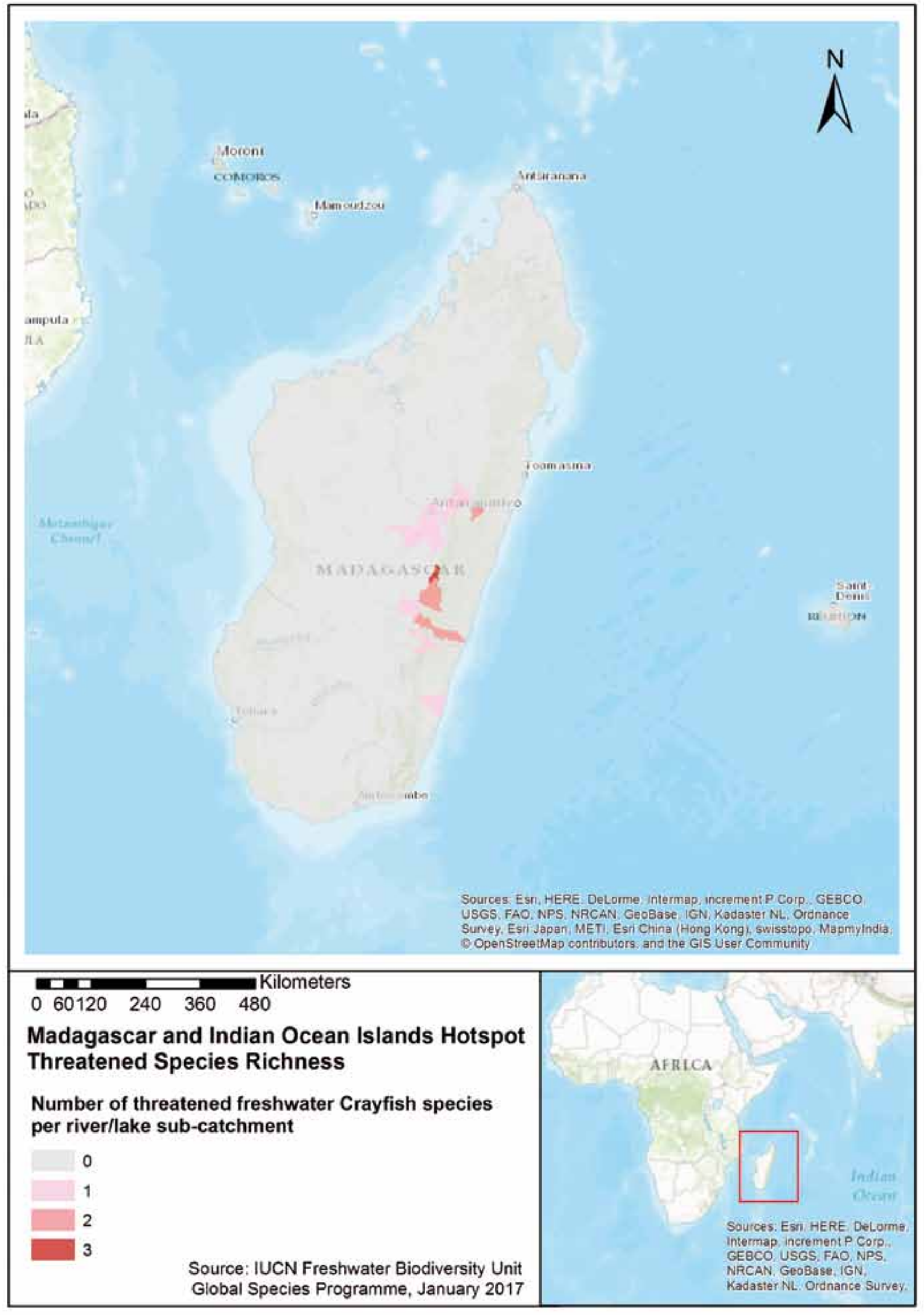




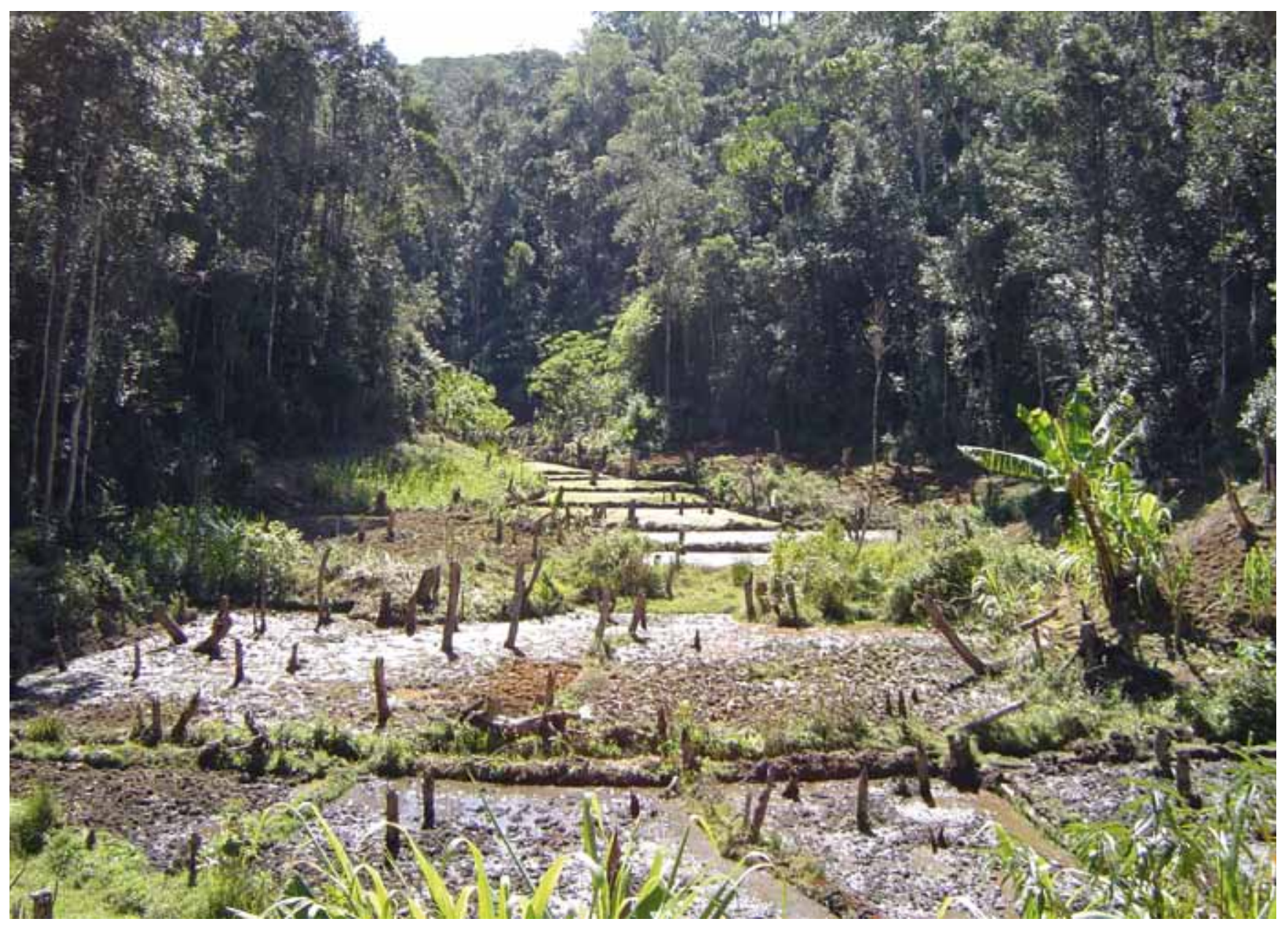

Figure 5.10 Rainforest converted to paddy rice fields. @ Jeanne Rasamy

Macrobrachium) are subject to harvesting by local people in all regions of Madagascar (Figure 5.11 and 5.12). The impact of overharvesting is particularly clear in those parts of the island where crayfish are present, and in some localities crayfish constitute an important part of household income. Harvesting crayfish at night using lights to attract them catches hundreds of animals and puts heavy pressure on population levels, and the subsequent recovery of these populations is slow. All crayfish located outside protected areas in Madagascar are heavily exposed to overexploitation for food, but only $32 \%$ of VU species of crayfish and $16 \%$ of LC crayfish species live within protected areas. A study conducted in the vicinity of Ranomafana National Park suggested that sustainable harvesting of crayfish might be possible under certain conditions (Jones 2004). However, high poverty in Madagascar means that crayfish and other forest products still represent an important income source for households in these areas (Jenkins et al. 2011) and exposes crayfish to uncontrolled exploitation.

\subsection{Conservation recommendations}

Although the latest IUCN Red List assessments of Madagascar's freshwater decapod fauna found only seven of its 72 species $(10 \%)$ to be threatened with extinction this may underestimate the level of threat because of the high number of DD species (28 out of 72 species (38.9\%)). These DD species introduce an element of uncertainty into the conservation planning process. It is likely that many of the DD species will eventually prove to be threatened, because most are single-locality endemics with a very narrow distributional range, a profile typical of many of the betterknown species currently assessed as threatened in other parts of the world (Cumberlidge et al. 2009). Clearly, the threatened and DD species of endemic Malagasy freshwater decapods represent a focus for future ecological fieldwork, biotic inventories, and conservation prioritisation activities.

Several important questions remain unanswered. The recent DD assessments are all based on a lack of information for the true distribution ranges of species. A number of these species are known from very small areas and/or small populations. These species may either be naturally restricted and difficult to find, or they may be the remnants of a previously more abundant and widespread population that is now in decline due to habitat loss or other impacts. Data on habitat requirements and population trends also need to be obtained. Until then, it is appropriate to treat DD species as potentially threatened until proven otherwise. 
Recovery plans need to be developed for the threatened species of crayfish (four species), freshwater crabs (two species), and freshwater shrimps (one species) found in Madagascar and the Indian Ocean Island hotspot, and studies on the 27 DD species in all three groups of freshwater decapods need to be intensified. The effective conservation of freshwater decapods depends on preserving large enough patches of natural freshwater habitat to maintain good water quality because many species are sensitive to polluted or silted water. It is therefore of great concern that water quality is deteriorating even in key natural habitats in Madagascar and the other islands.

It is encouraging that almost half (48.6\%) of the region's decapod fauna is assessed as LC. This includes almost two-thirds (64\%) of the Malagasy freshwater crab fauna (11 out of 17 species), almost half (49\%) of the freshwater shrimp fauna, and $28 \%$ of the crayfish fauna (two species out of seven). The primary conservation focus for the threatened species of crayfish, freshwater crabs, and freshwater shrimps living in Madagascar's forested central areas (and for Seychellum alluaudi from two islands in the Seychelles) is the preservation of remaining natural habitats, especially natural forest streams. Natural habitat destruction is an ongoing threat to all species, and the additional overexploitation of crayfish by intensive harvesting throughout their range is of great concern, especially for species found outside protected areas.
The most widespread but also the most exploited of all Malagasy species of crayfish is Astacoides granulimanus (LC) (Figure 5.11). A sustained awareness campaign is essential to the long-term protection of crayfish and the forests in which they are found. Efforts should also be made to find alternative sources of income for the local people who rely on harvesting crayfish. The goal should be to involve local people in the conservation of threatened species, and in the sustainable harvesting of presently abundant but heavily exploited species. Finally, effective measures for halting the spread of invasive species need to be developed and implemented before the destructive impacts reach the remaining primary unspoiled forest stream ecosystems.

\subsection{Research actions}

No local conservation measures are in place to protect any of the threatened freshwater decapod species of Madagascar or the other Indian Ocean islands. Although preliminary information on species distributional ranges is starting to be made available, ecological and population data for many of Madagascar's freshwater decapod taxa are still lacking. Targeted surveys to determine the status and ecologies of threatened and DD species should be undertaken in this understudied island, especially on the impacts of pollution and deforestation on stream systems and their decapods. For example, large areas of western

Figure 5.11 Harvested crayfish being transported along the road to the market. $\odot$ Jeanne Rasamy

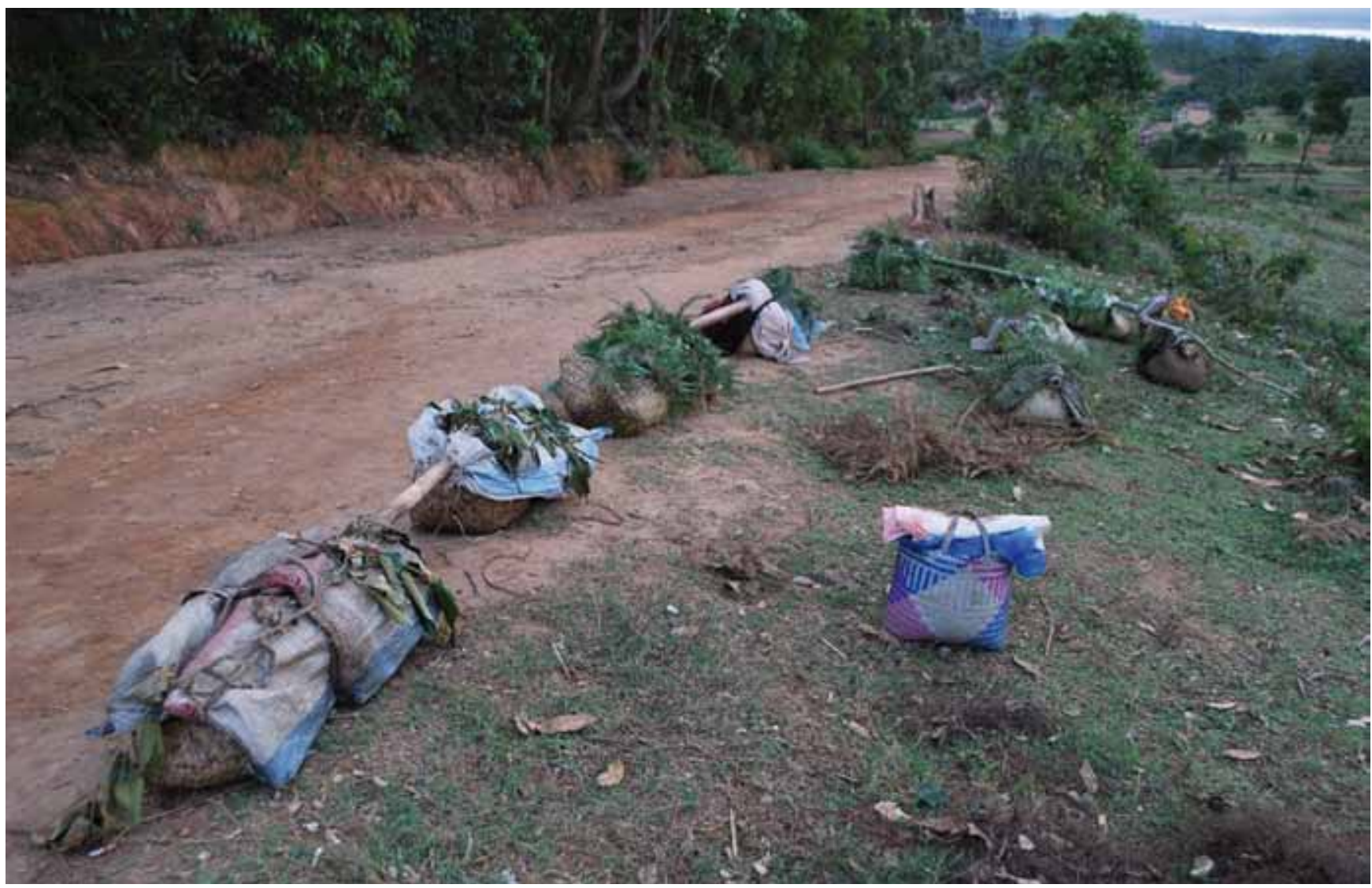




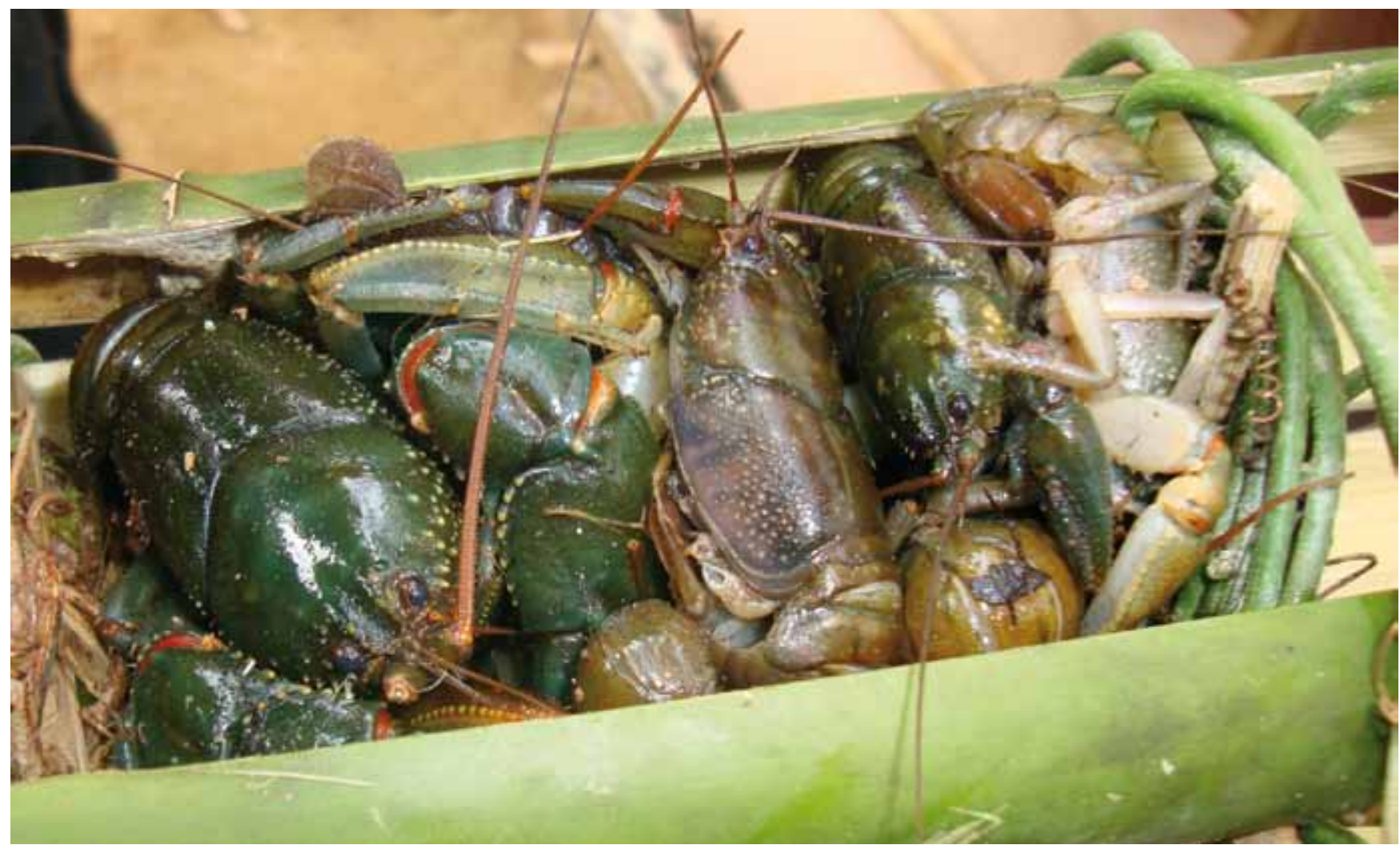

Figure 5.12 Astacoides granulimaus on sale in the market. $\odot$ Christian Ranaivoson

and southern Madagascar are still seriously undersurveyed, and many places have no records at all. This lack of basic information makes it difficult to make meaningful predictions about how species will respond to changing freshwater environments.

New protected areas for freshwater ecosystems may represent a powerful tool for the conservation of freshwater decapods. Terrestrial wetlands are currently underrepresented in the present system of protected areas in Madagascar (Conservation International 2014) as well as more widely in continental Africa (Darwall et al. 2011). Encouragingly, the Government of Madagascar has recently reiterated its commitment to triple the protected area coverage of land and to ensure the effective management of all of its protected areas (IISD 2014). We recommend the greater representation of freshwater habitats within the expanding protected area network in Madagascar, and the more effective protection of those freshwater species found within the existing protected areas. Finally, experiments on captive breeding are needed for the threatened endemic species of Malagasy crayfish.

\subsection{References}

Abell, R., Thieme, M.L., Revenga, C., et al. 2008. Freshwater Ecoregions of the World: A New Map of Biogeographic Units for Freshwater Biodiversity Conservation. BioScience 58: 403. https://doi.org/10.1641/B580507
Andriamarovololona, M.M. and Jones, J.P.G. 2012. The role of taboos and traditional beliefs in aquatic conservation in Madagascar. In: Pungetti, G., Oviedo, G. and Hooke, D. (eds.) Sacred Species and Sites: Advances in Biocultural Conservation Cambridge University Press, 2012. https:// doi.org/10.1017/CBO9781139030717.021

Bland, L.M., Bielby, J., Kearney, J.S., et al. 2017. Toward reassessing data deficient species. Conservation Biology, 31: 531-539. https://doi.org/10.1111/cobi.12850

Boyko, C.B., Ramilijaon, O.R., Randriamasimanana,D., et al. 2005. Astacoides hobbsi, a new crayfish (Crustacea: Decapoda : Parastacidae) from Madagascar. Zootaxa 51: 41-51. https://doi.org/10.11646/zootaxa.1091.1.3

Chace, F.A. 1997. The caridean shrimps (Crustacea: Decapoda) of the Albatross Expedition, 1907-1910, Part 7: Families Atyidae, Eugonatonotidae, Rynchocinetidae, Bathypalaemonellidae, Processidae, and Hippolytidae. Smithsonian Contributions to Zoology 587: i-v, 1-106.

Conservation International. 2014. Ecosystem profile. Madagascar and Indian Ocean islands. Conservation International, Antananarivo.

Cumberlidge, N. 1999. The freshwater crabs of West Africa. Family Potamonautidae. Faune et Flore Tropicales 35: Institut de recherché pour le development (IRD, EXorstom), Paris, 1-382.

Cumberlidge, N. and Sternberg, R.V. 2002. The freshwater crabs of Madagascar (Decapoda: Potamoidea: Potamonautidae). Zoosystema 24(1): 41-79.

Cumberlidge, N. and Sternberg, R.V. 2003. The freshwater crabs of Madagascar. In: S.M. Goodman and J.P. 


\subsection{Species in the spotlight}

Although a lively trade in freshwater crayfish exists in many parts of Madagascar, a traditional system of prohibitions known as 'fady' is central to the culture of some Malagasy people (Andriamarovololona \& Jones 2012). It is believed, for example, that pregnant women should not eat crayfish species (Astacoides spp.) as this could result in multiple births; and in some regions of Madagascar crabs (Hydrothelpusa spp.) cannot be brought into some villages while there is still rice growing in the fields (Jones et al. 2008). It is difficult to unveil the origins of these cultural taboos. Nevertheless, Andriamarovololona \& Jones (2012) and Jones et al. (2008) in their studies about the role of taboos and traditional beliefs in aquatic conservation in Madagascar, found clear evidence that norms of acceptable behaviour, enforced by social pressure, govern the timing and method for harvesting valued freshwater species such as crabs and crayfishes, and can provide significant protection for threatened species such as the rare endemic Astacoides caldwelli (Figure 5.13; Jones et al. 2008; Jones 2010b).

Figure 5.13 The study by Jones et al. (2007) revealed Astacoides caldwelli (VU) as the rarest of all Malagasy crayfish sampled. This species occurs mainly in the eastern highlands of Madagascar, where it is found in rivers draining forested catchments. Monitoring is required to better understand the rate at which this is species is being lost due to the conversion of lowland forests to paddy rice fields. (๑) Christian Ranaivoson

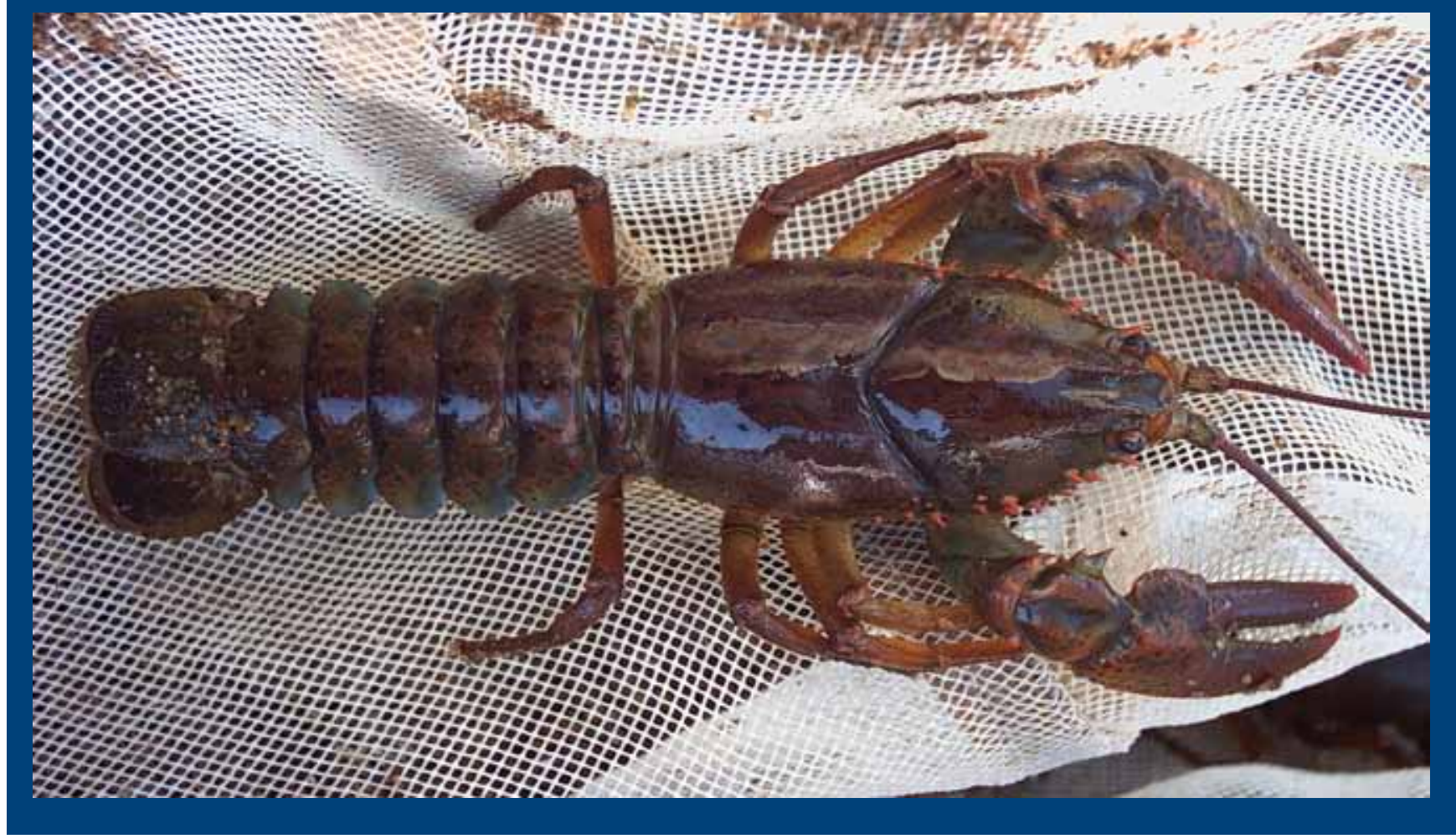

Benstead (eds.). The Natural History of Madagascar, pp. 612-617. The Universty of Chicago Press, Chicago.

Cumberlidge, N., Fenolio, D.B., Walvoord, M.E., et al. 2005. Tree-climbing crabs (Potamonautidae and Sesarmidae) from phytotelmic microhabitats in rainforest canopy in Madagascar. Journal of Crustacean Biology 25: 302-308. https://doi.org/10.1651/C-2532

Cumberlidge, N., Marijnissen, S.A.E. and Thompson, J. 2007. Hydrothelphusa vencesi, a new species of freshwater crab (Brachyura: Potamoidea: Potamonautidae) from southeastern Madagascar. Zootaxa 1524: 61-68.

Cumberlidge, N. 2008a. Madagapotamon humberti. In: IUCN 2013. IUCN Red List of threatened species. Version 2013.2. www.iucnredlist.org. Downloaded 13 May 2014.
Cumberlidge, N. 2008b. Boreas uglowi. In: IUCN 2013. IUCN Red List of Threatened Species. Version 2013.2. www. iucnredlist.org. Downloaded 13 May 2014.

Cumberlidge, N. and Meyer, K.S. 2009. A new species of Foza Reed and Cumberlidge, 2006, from northern Madagascar (Decapoda, Brachyura, Potamoidea, Potamonautidae), with a redescription of $F$. goudoti $(H$. Milne Edwards, 1853) comb. n., and comments on Skelosophusa prolixa $\mathrm{Ng}$ and Takeda, 1994. ZooKeys 18: 77-89. https://doi.org/10.3897/zookeys.18.102

Cumberlidge, N., Ng, P.K.L., Yeo, D.C.J. et al. 2009. Freshwater crabs and the biodiversity crisis: Importance, threats, status, and conservation challenges. Biological Conservation 142 1665-1673. https://doi.org/10.1016/j.biocon.2009.02.038 
Cumberlidge, N. and Daniels, S.R. 2014. Recognition of two new species of freshwater crabs from the Seychelles based on molecular evidence (Potamoidea: Potamonautidae). Invertebrate Systematics 28: 17-31. https://doi.org/10.1071/IS13017

Cumberlidge, N., Klaus, S., Meyer, K.S., et al. 2015. New collections of freshwater crabs from northern Madagascar, with the description of a new species of Foza Reed and Cumberlidge, 2006 (Brachyura, Potamonautidae). European Journal of Taxonomy 109: 1-15.

Cumberlidge, N., Rasamy Razanabolana, J., Ranaivoson, C.H., et al. 2017. Updated extinction risk assessments of Madagascar's freshwater decapod crustaceans reveal fewer threatened species but more Data Deficient species. Malagasy Nature 12: 32-41.

Daniels, S.R. 2011. Reconstructing the colonisation and diversification history of the endemic freshwater crab (Seychellum alluaudi) in the granitic and volcanic Seychelles Archipelago. Molecular Phylogenetics and Evolution 61: 534-542. https://doi.org/10.1016/j.ympev.2011.07.015

Daniels, S.R., Phiri, E.E. and Bayliss, J. 2014. Renewed sampling of inland aquatic habitats in southern Africa yields two novel freshwater crab species (Decapoda: Potamonautidae: Potamonautes). Zoological Journal of the Linnean Society 171: 356-369. https://doi.org/10.1111/ zoj.12139

Darwall, W.R.T., Holland, R.A., Smith, K.G., et al. 2011. Implications of bias in conservation research and investment for freshwater species. Conservation Letters 4: 474-482. https://doi.org/10.1111/j.1755-263X.2011.00202.x

De Grave, S., Smith, K.G., Adeler, N.A., et al. 2014. Dead shrimp blues: A global assessment of extinction risk in freshwater shrimps (Crustacea: Decapoda: Caridea). PLOS ONE 10(3): e0120198.8 https://doi.org/10.1371/ journal.pone.0120198

Dieguez-Uribeondo, J. and K. Soderhall. 1993. Procambarus clarkii Girard as a vector for the crayfish plague fungus, Aphanomyces astaci Schikora. Aquaculture Research 24: 761-765. https://doi.org/10.1111/j.1365-2109.1993. tb00655.x

Esser, L. and Cumberlidge, N. 2011. Evidence that salt water may not be a barrier to the dispersal of Asian freshwater crabs (Decapoda: Brachyura: Gecarcinucidae and Potamidae). Raffles Bulletin of Zoology 59: 259-268.

Hobbs, H.H. 1987. A review of the crayfish genus Astacoides (Decapoda: Parastacidae). Smithsonian Contributions to Zoology 443: 1-50. https://doi.org/10.5479/ si.00810282.443

International Institute for Sustainable Development (IISD). 2014. IUCN World Parks Congress. 2014. Summary report. www.iisd.ca/iucn/wpc/2014, 89(16): 22 November 2014.
Jenkins, R.K.B., Keane, A., Rakotoarivelo, A.R., et al. 2011. Analysis of patterns of bushmeat consumption reveals extensive exploitation of protected species in eastern Madagascar. PLoS ONE 6: e27570. https://doi.org/10.1371/ journal.pone.0027570

Jones, J.P.G. 2004. The sustainability of crayfish harvesting in Ranomafana National Park, Madagascar. PhD Thesis. University of Cambridge, UK.

Jones, J.P.G. 2010a. Astacoides betsileoensis. The IUCN Red List of threatened species 2010: e.T2188A9335181. Downloaded on 01 October 2016. https://doi.org/10.2305/ IUCN.UK.2010-3.RLTS.T2188A9335181.en

Jones, J.P.G. 2010b. Astacoides caldwelli. The IUCN Red List of threatened species 2010: e.T2187A9332994. Downloaded on 01 October 2016. https://doi.org/10.2305/ IUCN.UK.2010-3.RLTS.T2187A9332994.en

Jones, J.P.G., Andriamarovololona, M.M. and Hockley, N.J. 2008. The importance of taboos and social norms to conservation in Madagascar. Conservation Biology 22: 976-986. https://doi.org/10.1111/j.1523-1739.2008.00970.x Jones, J.P.G., Rasamy, J.R., Harvey, A., Toon, A., Oidtmann, B., Randrianarison, M.H., Raminosoa, N. and Ravoahangimalala, O.R. 2009. The perfect invader: A parthenogenic crayfish poses a new threat to Madagascar's freshwater biodiversity. Biological Invasions 11: 1475-1482. https://doi.org/10.1007/s10530008-9334-y

MEFT, USAID, and CI. 2009. Evolution de La Couverture de Forêt Naturelles À Madagascar, 1990-2000-2005.

Meyer, S.K., Cumberlidge, N. and Koppin, K.C. 2014. A new genus and species of freshwater crab from Madagascar (Decapoda, Brachyura, Potamoidea, Potamonautidae). Zootaxa 3884: 65-72. https://doi. org/10.11646/zootaxa.3884.1.5

Monod, T. and Petit, G. 1929. Crustacea, I: Parastacidae. In: G. Petit (ed.). Contribution a L'étude de La Faune de Madagascar. Faune Des Colonies Françaises, pp 3-43.

Ramilijaona, R.O., Raminosoa, R.N., Rasamy, J.R., et al. 2007. Les écrevisses de Madagascar. Série Sciences biologiques. Antananarivo: Recherche pour le Développement: Université d'Antananarivo: Conservation International Madagascar.

Richman, N., Böhm, M., Adams, S.B., et al. 2014. Multiple drivers of decline in the global status of freshwater crayfish (Decapoda: Astacidea). Philosophical Transactions of the Royal Society of London B, 370. https://doi.org/10.1098/ rstb.2014.0060

Thieme, M.L., Abell, R., Stiassny, M.L.J., et al. 2005. Freshwater Ecoregions of Africa and Madagascar: a conservation assessment. Island Press, Washington DC, USA. 
Annex 5.1 Red List Status of Madagascar and the Indian 0cean islands freshwater crabs.

\begin{tabular}{|c|c|c|c|}
\hline Family & Species Name & $\begin{array}{l}\text { Red List } \\
\text { Category }\end{array}$ & $\begin{array}{c}\text { Endemic } \\
\text { to the } \\
\text { notspot }\end{array}$ \\
\hline POTAMONAUTIDAE & $\begin{array}{l}\text { Boreathelphusa } \\
\text { uglowi }\end{array}$ & EN & Yes \\
\hline POTAMONAUTIDAE & Seychellum alluaudi & VU & Yes \\
\hline POTAMONAUTIDAE & Foza manonae & DD & Yes \\
\hline POTAMONAUTIDAE & $\begin{array}{l}\text { Glabrithelphusa } \\
\text { angene }\end{array}$ & $\mathrm{DD}$ & Yes \\
\hline POTAMONAUTIDAE & Malagasya goodmani & $\mathrm{DD}$ & Yes \\
\hline POTAMONAUTIDAE & Marojejy longimerus & DD & Yes \\
\hline POTAMONAUTIDAE & $\begin{array}{l}\text { Skelosophusa } \\
\text { eumeces }\end{array}$ & $\mathrm{DD}$ & Yes \\
\hline POTAMONAUTIDAE & Skelosophusa gollardi & $\mathrm{DD}$ & Yes \\
\hline POTAMONAUTIDAE & Skelosophusa prolixa & $\mathrm{DD}$ & Yes \\
\hline POTAMONAUTIDAE & Foza ambohitra & LC & Yes \\
\hline POTAMONAUTIDAE & Foza goudoti & $\mathrm{LC}$ & Yes \\
\hline POTAMONAUTIDAE & Foza raimundi & $\mathrm{LC}$ & Yes \\
\hline POTAMONAUTIDAE & Hydrothelphusa agilis & $\mathrm{LC}$ & Yes \\
\hline POTAMONAUTIDAE & $\begin{array}{l}\text { Hydrothelphusa } \\
\text { bombetokensis }\end{array}$ & LC & Yes \\
\hline POTAMONAUTIDAE & \begin{tabular}{|l} 
Hydrothelphusa \\
madagascariensis \\
\end{tabular} & LC & Yes \\
\hline POTAMONAUTIDAE & $\begin{array}{l}\text { Hydrothelphusa } \\
\text { vencesi }\end{array}$ & LC & Yes \\
\hline POTAMONAUTIDAE & $\begin{array}{l}\text { Madagapotamon } \\
\text { humberti }\end{array}$ & LC & Yes \\
\hline POTAMONAUTIDAE & \begin{tabular}{|l|} 
Malagasya \\
antongilensis
\end{tabular} & LC & Yes \\
\hline POTAMONAUTIDAE & $\begin{array}{l}\text { Seychellum } \\
\text { mahefregate }\end{array}$ & LC & Yes \\
\hline POTAMONAUTIDAE & Seychellum silhouette & LC & Yes \\
\hline
\end{tabular}

Annex 5.2 Red List Status of Madagascar and the Indian Ocean islands freshwater crayfish.

\begin{tabular}{|l|l|c|c|}
\hline Family & Species Name & $\begin{array}{c}\text { Red List } \\
\text { Category }\end{array}$ & $\begin{array}{c}\text { Endemic } \\
\text { to the } \\
\text { hotspot }\end{array}$ \\
\hline PARASTACIDAE & $\begin{array}{l}\text { Astacoides } \\
\text { betsileoensis }\end{array}$ & VU & Yes \\
\hline PARASTACIDAE & Astacoides caldwelli & VU & Yes \\
\hline PARASTACIDAE & Astacoides crosnieri & VU & Yes \\
\hline PARASTACIDAE & Astacoides hobbsi & VU & Yes \\
\hline PARASTACIDAE & Astacoides petiti & DD & Yes \\
\hline PARASTACIDAE & $\begin{array}{l}\text { Astacoides } \\
\text { granulimanus }\end{array}$ & LC & Yes \\
\hline PARASTACIDAE & $\begin{array}{l}\text { Astacoides } \\
\text { madagascarensis }\end{array}$ & LC & Yes \\
\hline
\end{tabular}

Annex 5.3 Red List Status of Madagascar and the Indian Ocean islands freshwater shrimps.

\begin{tabular}{|c|c|c|c|}
\hline Family & Species Name & $\begin{array}{l}\text { Red List } \\
\text { Category }\end{array}$ & $\begin{array}{c}\begin{array}{c}\text { Endemic } \\
\text { to the } \\
\text { hotspot }\end{array} \\
\end{array}$ \\
\hline PALAEMONIDAE & $\begin{array}{l}\text { Macrobrachium } \\
\text { hirtimanus }\end{array}$ & EN & Yes \\
\hline ATYIDAE & Caridina mauritii & NT & Yes \\
\hline ATYIDAE & Caridina richtersi & NT & Yes \\
\hline ATYIDAE & Caridina spathulirostris & NT & Yes \\
\hline ATYIDAE & Caridina crurispinata & $\mathrm{DD}$ & Yes \\
\hline ATYIDAE & Caridina edulis & DD & Yes \\
\hline ATYIDAE & Caridina lamiana & DD & Yes \\
\hline ATYIDAE & Caridina lipalmaria & DD & Yes \\
\hline ATYIDAE & Caridina norvestica & DD & Yes \\
\hline ATYIDAE & Caridina parvocula & DD & Yes \\
\hline ATYIDAE & Caridina petiti & DD & Yes \\
\hline ATYIDAE & Caridina steineri & DD & Yes \\
\hline ATYIDAE & Caridina troglophila & DD & Yes \\
\hline ATYIDAE & Caridina unca & DD & Yes \\
\hline ATYIDAE & Monsamnis carpolongus & DD & Yes \\
\hline ATYIDAE & Parisia dentata & $\mathrm{DD}$ & Yes \\
\hline ATYIDAE & Parisia edentata & DD & Yes \\
\hline ATYIDAE & Parisia macrophthalma & $\mathrm{DD}$ & Yes \\
\hline ATYIDAE & Parisia microphthalma & DD & Yes \\
\hline ATYIDAE & Typhlopatsa pauliani & DD & Yes \\
\hline PALAEMONIDAE & Macrobrachium glabrum & DD & Yes \\
\hline PALAEMONIDAE & $\begin{array}{l}\text { Macrobrachium } \\
\text { hildebrandti }\end{array}$ & DD & Yes \\
\hline PALAEMONIDAE & Macrobrachium petiti & DD & Yes \\
\hline ATYIDAE & Atyoida serrata & $\mathrm{LC}$ & Yes \\
\hline ATYIDAE & Caridina angulata & $\mathrm{LC}$ & No \\
\hline ATYIDAE & Caridina brachydactyla & $\mathrm{LC}$ & No \\
\hline ATYIDAE & Caridina calmani & $\mathrm{LC}$ & Yes \\
\hline ATYIDAE & Caridina gracilirostris & $\mathrm{LC}$ & No \\
\hline ATYIDAE & Caridina hova & $\mathrm{LC}$ & Yes \\
\hline ATYIDAE & Caridina isaloensis & $\mathrm{LC}$ & Yes \\
\hline ATYIDAE & Caridina natalensis & $\mathrm{LC}$ & No \\
\hline ATYIDAE & Caridina serratirostris & $\mathrm{LC}$ & No \\
\hline ATYIDAE & Caridina similis & $\mathrm{LC}$ & Yes \\
\hline ATYIDAE & Caridina typus & $\mathrm{LC}$ & No \\
\hline ATYIDAE & Caridina xiphias & $\mathrm{LC}$ & Yes \\
\hline PALAEMONIDAE & Macrobrachium australe & $\mathrm{LC}$ & No \\
\hline PALAEMONIDAE & $\begin{array}{l}\text { Macrobrachium } \\
\text { dolichodactylus }\end{array}$ & $\mathrm{LC}$ & No \\
\hline PALAEMONIDAE & Macrobrachium equidens & $\mathrm{LC}$ & No \\
\hline PALAEMONIDAE & Macrobrachium idae & $\mathrm{LC}$ & No \\
\hline PALAEMONIDAE & Macrobrachium idella & $\mathrm{LC}$ & No \\
\hline PALAEMONIDAE & Macrobrachium lar & $\mathrm{LC}$ & No \\
\hline PALAEMONIDAE & $\begin{array}{l}\text { Macrobrachium } \\
\text { lepidactylus } \\
\end{array}$ & $\mathrm{LC}$ & No \\
\hline PALAEMONIDAE & Macrobrachium patsa & $\mathrm{LC}$ & No \\
\hline PALAEMONIDAE & Macrobrachium rude & $\mathrm{LC}$ & No \\
\hline PALAEMONIDAE & $\begin{array}{l}\text { Macrobrachium } \\
\text { scabriculum }\end{array}$ & LC & No \\
\hline
\end{tabular}




\title{
Chapter 6
}

\section{The status and distribution of aquatic plants}

\author{
Peter Phillipson $^{1}$ and $^{2}$, Sylvie Andriambololonera ${ }^{3}$, Rokiman Letsara ${ }^{4}$, Cyrille Maharombaka ${ }^{5}$, Botovao Auguste \\ Ramiandrisoa ${ }^{5}$, Nadiah Manjato ${ }^{3}$, Hery Lisy Ranarijaona ${ }^{5}$, William Darwall ${ }^{6}$, Laura Máiz-Tomé ${ }^{6}$
}

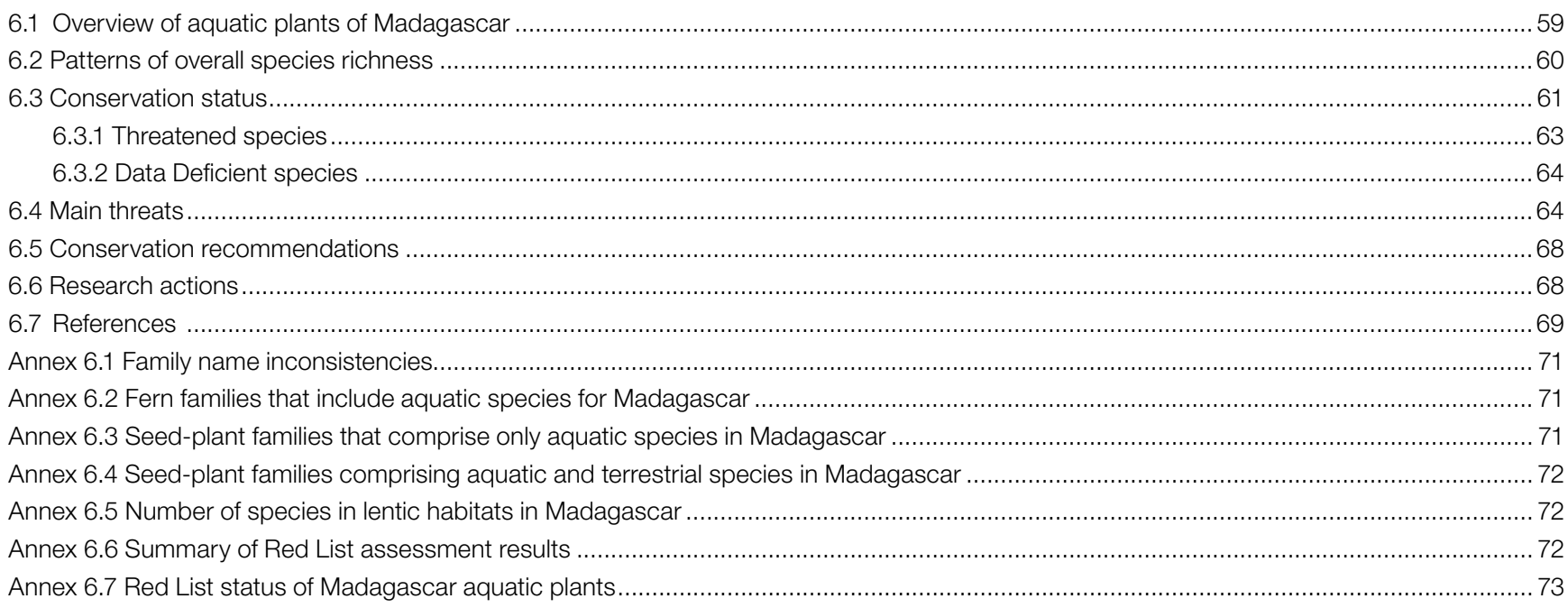

\subsection{Overview of aquatic plants of Madagascar}

Madagascar exhibits a great topographical and bioclimatic diversity that gives rise to a remarkable range of ecosystems. The country has an extensive surface with groundwater systems and a profusion of freshwater habitats that link the high mountains and the central highlands with the dry and semi-arid regions in the north, west and south and the humid regions of the east (Carret 2014). The different ecosystems across the country are among the richest in plant species diversity in the world, each possessing characteristic floristic elements and an exceptionally high level of local endemism. The smaller islands of the hotspot are linked to Madagascar biogeographically but each island group has fewer endemic and restricted range species compared to Madagascar. For the purposes of this project we have only evaluated endemic species from Madagascar's mainland.

Since the start of botanical exploration of Madagascar in the mid-17th century most efforts have focused on terrestrial ecosystems. Even through much of the 20th century, when botanical inventory of the country took great strides forward, botanists paid relatively little attention to aquatic ecosystems and their plants. A few botanists, including J.M.H.A. Perrier de la Bâthie, J.M. Bosser and A.M. Raynal-Roques, did however collect extensively in freshwater habitats describing numerous new species, but the lack of literature on the freshwater flora of the country has discouraged interest in these plants and their habitats.

Climate and geology play an important role in plant distributions in Madagascar, and the work of Cornet (1974), Du Puy \& Moat (1996) and Schatz (2000) has helped bring these into focus. A good introduction to the phytogeography of Madagascar was provided by Gautier \& Goodman (2003). Freshwater species display patterns of distribution based on isolation within river catchment systems; they are subject to (and benefit from) conditions relating to dispersal and migration within and between catchments. Wilmé et al. (2006) provided valuable insights into the potential role of river catchments and inter-fluvial zones in Madagascar in determining biogeographic patterns.

Missouri Botanical Garden, P.O. Box 299, St Louis, MO, 63166-0299, USA. E-mail: peter.phillipson@mobot.org

2 Institut de Systématique, Évolution, et Biodiversité (UMR 7205 - Centre National de la Recherche Scientifique/Muséum national d'Histoire naturelle/École Pratique des Hautes Études, Université Pierre et Marie Curie, Sorbonne Universités), C.P. 39, rue Cuvier 57, F-75231 Paris CEDEX 05, France.

3 Missouri Botanical Garden, Madagascar Research and Conservation Program, BP 3391, Antananarivo 101, Madagascar.

4 Département Flore, Parc Botanique et Zoologique de Tsimbazaza, Antananarivo 101, Madagascar.

5 Ecole Doctorale sur les Ecosystèmes Naturels, Ecole Doctorale sur les Ecosystèmes Naturels (EDEN), Université de Mahajanga, Rue Georges $\mathrm{V}$, Immeuble Kakal, Mahajangabe, 401, Mahajanga, Madagascar.

6 Freshwater Biodiversity Unit, IUCN Global Species Programme, The David Attenborough Building, Pembroke Street, Cambridge CB2 3QZ, UK. 
There are various definitions of aquatic plants, or hydrophytes as they are sometimes termed, but they all include those plants that are adapted to grow in water-logged habitats. These range from deep water to bogs and marshes, and include seasonally and perennially flooded areas. Both physiological and morphological modifications enable these plants to flourish in places where others would die. Although morphologically diverse with adaptations to aquatic habitats in many different plant groups, some basic growth forms are prevalent and can be classified under two broad habitat types. The first of these, the helophytes, are rooted underwater but produce emergent stems that bear leaves and reproductive parts above water, and the second are the hydrophytes, adapted for living submerged in water or at the water surface. The latter are divided into species that have roots fixed in the underlying substrate, are free-floating, have leaves and/or reproductive parts immersed underwater or at the water surface, or have leaves and/or reproductive parts above water (Ranarijaona 1999). Plants adapted to survive saline conditions such as salt marshes, referred to as halophytes, are excluded from this study.

The occurrence of aquatic plants is largely dependent on the depth and speed of water flow, and water quality. Some species prefer stagnant or at least calm waters (lentic conditions) - lakes, ponds, marshes and bogs. These lentic species, such as the water lilies (Nymphaea spp.), are rooted in the bed of the water body. Floating species include the duckweeds (Lemna and Wolffia spp.) and the water hyacinth (Eichhornia crassipes). Other species proliferate in running waters (lotic conditions) - rivers, streams, torrents and waterfalls, where floating species are generally absent. Finally, some species are attached to submerged rocks and are able to withstand exceptionally high rates of water flow, notably members of the Hydrostachyaceae and Podostemaceae.

Exploration and study of Madagascar's rich flora continues apace. For example, in 2016 ninety new species names were published (Phillipson et al. 2017), but none of these were freshwater plants. Data on all known freshwater species in Madagascar are compiled in the Tropicos database, and presented through the Madagascar Catalogue project interface (http://www.tropicos.org/Project/Madagascar). Renewed efforts to document and study the freshwater plants of Madagascar have, however, been initiated more recently at the University of Mahajanga, the Parc Botanique et Zoologique de Tsimbazaza (PBZT), and by Missouri Botanical Garden (MBG).

Freshwater plants are important to the livelihoods of many people in the region providing traditional medicines and raw materials for the production of artefacts and building of traditional huts (Rakotoarivelo \& Manjato, in prep.). They also play an important ecological role in aquatic ecosystems providing food, shelter and a variety of habitats for a wide range of organisms (Cook 1996). Throughout Madagascar people make extensive use of freshwater species for making mats, baskets, traps and ropes for which the raphia palm (Raphia farinifera) and sedges (species of the family Cyperaceae) are especially important (Basiza 2015). The tubers of the water lily, Nymphaea nouchali, are also used for dyeing fabric (Ranarijaona 2009).

The study of aquatic medicinal plants in Madagascar began in the 1960s with the work of Boiteau et al. (1964), Rakoto-Ratsimamanga et al. (1969) and Boiteau (1979; 1986). More recently, an ethnobotanical study in western Madagascar identified 49 aquatic plant species used in traditional medicine (Ranarijaona 2009) and a study of northern Madagascar listed five aquatic plant species traditionally used to combat malaria (Boyer 2009). A study of Hydrostachys plumosa identified it as a potential candidate for use in chemotherapy to fight cancer (Ranarijaona et al. 2014).

In ecological studies freshwater plants can serve as bioindicators because, at any given wetland site, the species and their growth form helps to determine the properties and quality of the ecosystem. Important studies on the ecology of aquatic plants include those of Alvarez (1982) on Lake Mandroseza, demonstrating the influence of aquatic plants on fish (Andrianjohany 1988).

A note on plant family names: For this study we use the APG system of plant families (latest version APG IV: The Angiosperm Phylogeny Group, 2016). This system has been adopted almost universally by botanists and in botanical databases, and represents a consensus of scientific opinion on the limitations and relationships of the seed plant families and their phylogeny. The IUCN Red List authority has retained a legacy family dataset for plants and there is therefore a mismatch in certain family names which may cause confusion with respect to the certain taxa (Annex 6.1).

\subsection{Patterns of overall species richness}

The known vascular plant flora of Madagascar includes 11,254 native species, of which $82 \%$ are endemic to the country (Madagascar Catalogue 2017), but only 388 (3.5\%) of these are specifically associated with freshwater habitats, of which just over half are Malagasy endemics (Manjato et al. 2017). Furthermore, comparing our data with that provided by Ranarijaona (1999; 2003), it appears that lentic systems in Madagascar are generally poorer in endemic species than are lotic systems. Ferry et al. (1999) have suggested that the low endemicity of aquatic plants in Madagascar relative to terrestrial plants may be the result of climatic fluctuations 
during the quaternary period. The aquatic plant species of Madagascar are nevertheless diverse, being represented within 85 (34.1\%) of Madagascar's 249 vascular plant families and $226(13.3 \%)$ of its 1,704 genera, revealing a considerably higher proportion of the flora than the average of $1-2 \%$ reported for the global proportion of aquatic plant species (Cook 1996). In addition to the native flora, to date 387 introduced species have been documented as having become naturalised across the whole of Madagascar (Phillipson et al. 2017), and among these 52 species (13.4\%) occur in freshwater habitats. The high number of naturalised plant species in freshwater habitats is, in part, because the habitats are very dynamic and prone to rapid colonisation by pioneers, a characteristic of successful naturalised weed species; it is also due to the high incidence of long-distance dispersal of plant propagules by migratory birds that visit wetlands.

Twenty-six species of aquatic ferns have been recorded, for which summary data are provided in Annex 6.2. Endemism among the native aquatic ferns species is under $25 \%$, and only two species are known to have been introduced and become naturalised. Among the seed plants, 414 species have been recorded; 75 belong to 16 families that comprise only aquatic species in Madagascar; only one of these species, Canna indica (Cannaceae), is recorded as introduced and naturalised. Among the native species there is a relatively high level of endemism (69.3\%). Data for the 16 families are summarised in Annex 6.3.

Of the remaining seed plants, 339 species are spread across 57 families and some of these are predominantly aquatic, notably: Alismataceae, Droseraceae, Haloragaceae, Hydrocharitaceae, Linderniaceae, Polygonaceae, Pontederiaceae and Potamogetonaceae (each with over $50 \%$ aquatic species in Madagascar). Numerous other large polymorphic families also contain a significant number of aquatic species, notably the Asteraceae with 66 aquatic species, of which 49 are regarded as introduced, naturalised species. A summary of these plants, which include only the numerically dominant families (those with five or more aquatic species in Madagascar), is presented in Annex 6.4. No attempt has been made to include any nonvascular plants or freshwater algae in this study due to an almost total lack of data.

A study undertaken by Ranarijaona (1999) on the geographic distribution, habitat and growth forms of the Malagasy freshwater flora in lentic conditions provides some useful results which were discussed in relation to conservation and threats to freshwater species in Madagascar. Plant diversity in lentic ecosystems (lakes, ponds and marshes) was recorded across all six provinces of Madagascar (Ranarijaona 1999) and 76 sites were visited over a five-year period and eight different types of lentic environments were identified. The study included 338 species, of which 128 species (38\%) are endemic. Among these species 142 (42\%) belong to the Cyperaceae and 17 (5\%) belong to the Poaceae, suggesting the importance of these families in freshwater habitats in the Madagascar Catalogue may be considerably underestimated. The study also suggests that both families are currently under much needed taxonomic revision.

The distributions of most of the 338 lentic aquatic plant species listed by Ranarijaona $(2003,2011)$ demonstrate a clear relationship to the phytogeographic and bioclimatic regions of Madagascar, as shown in Annex 6.5.

Geographic distributions for the 169 species (168 strict Malagasy endemics and a single regional endemic) assessed for the IUCN Red List were mapped to river basins (sub-catchments) (Figure 6.1). Locality data for some species were not sufficiently precise to be mapped with certainty, and these records were omitted. The most species-rich basins, each with $>20$ assessed species present, are found in the central highlands near Antananarivo. Areas with 16-20 species show a similar pattern, but also include a single basin on the eastern escarpment. This trend is repeated for basins with 10-15 species, which include a number of other catchments that drain eastwards, but also include a few other scattered areas, including the Sambirano Basin in the north-east, and the short coastal basins near Mahajanga. Basins with 10 or fewer species are widely scattered across the country, but are largely absent from the semi-arid southwest and the western slopes of the central plateau. These patterns broadly follow Madagascar's bioclimatic regions (Cornet 1974; Schatz 2000) and its Freshwater Ecoregions (Freshwater Ecoregions of the World 2017), but can also be explained partially by sampling bias according to the accessibility of catchments and the extent of dedicated botanical inventory that has been undertaken.

\subsection{Conservation status}

Given the large number of aquatic plant species in the region, and the limited resources, the study focused on completing global Red List assessments of only those species endemic to Madagascar. From an initial list of 199 species recorded as endemic (Madagascar Catalogue 2017), 31 species were eliminated due to taxonomic uncertainties. A single near-endemic species, the grass Leersia perrieri, was also assessed as it is known only from Madagascar and one locality in the Comoro Islands, making it endemic to the Malagasy Region.

The resulting set of 169 endemic (or near-endemic) freshwater plant species included in the Red List assessment comprised 


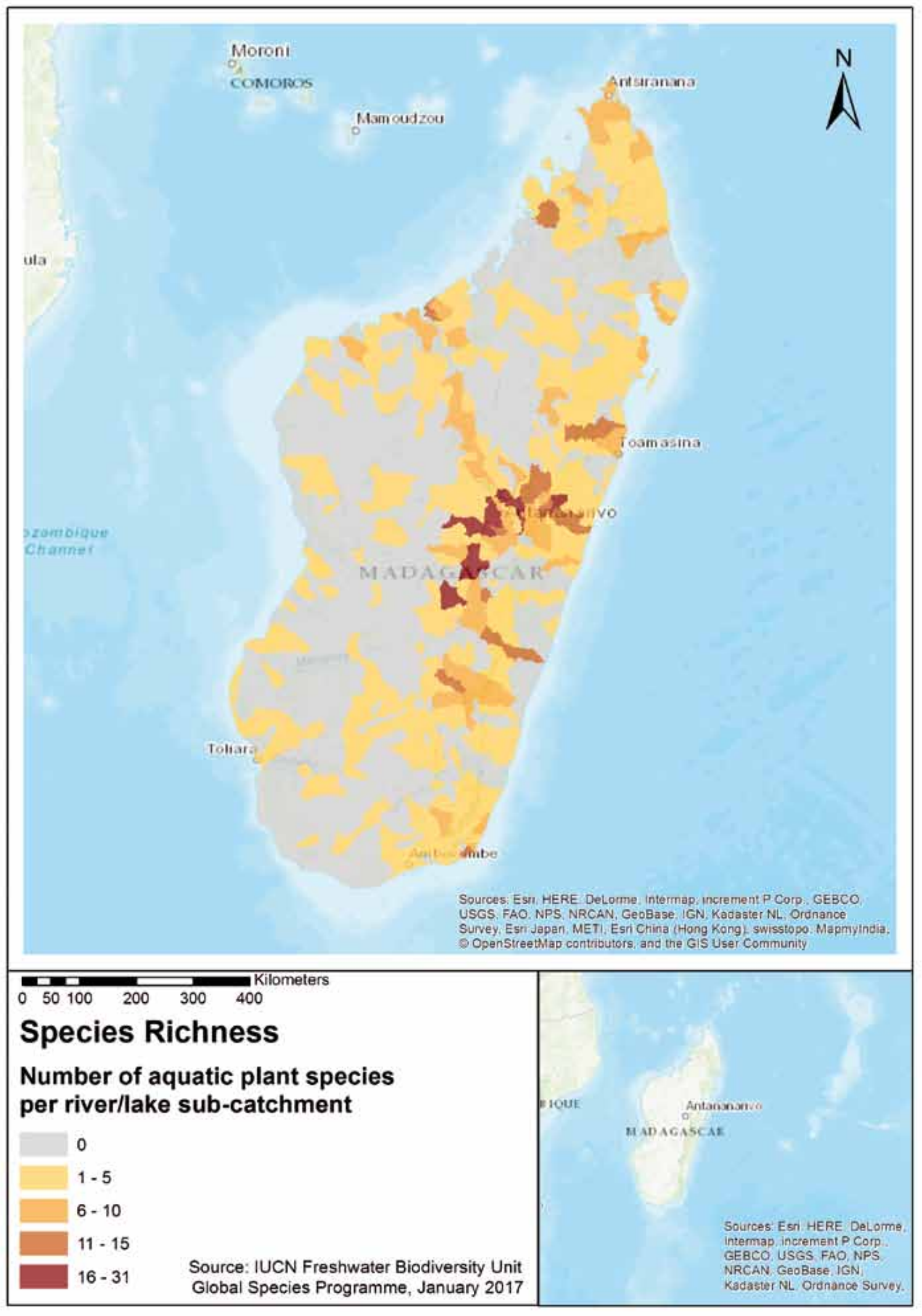


plants belonging to 44 plant families, of which the five best represented were the Asteraceae (24 spp.), Cyperaceae (15 spp.), Hydrostachyaceae (14 spp.), Aponogetonaceae (13 spp.) and the Orchidaceae (10 spp.). While the Asteraceae and Orchidaceae are very large families with species occurring in a wide range of habitats, the Cyperaceae are well-known to be especially abundant in freshwater habitats, and the remaining two families consist of only freshwater species. Four of the genera are endemic to Madagascar, and comprise only freshwater species: Endocaulos (one sp.), Paleodicraea (one sp.) and Thelethylax (two spp.) - all members of the Podostemaceae; and Hydrotriche belonging to the Plantaginaceae (four described spp., see Species in the spotlight at the end of this chapter). The genus Scholleropsis (Pontederiaceae) comprising a single species, S. lutea, was described as a Malagasy endemic but was subsequently discovered in West and Central Africa, so it was not included in our study and it has recently been transferred to the genus Heteranthera (de Oliveira Pellegrini 2017).

Seven different genera of aquatic ferns were represented, each by a single endemic species: Deparia (Athyriaceae), Didymoglossum (Hymenophyllaceae), Isoetes (Isoetaceae), Loxogramme and Zygophlebia (Polypodiaceae), Trachypteris (Pteridaceae) and Pneumatopteris (Thelypteridaceae). Assessments of species extinction risk at the global level were conducted on all of these species following the IUCN Guidelines on application of the IUCN Red List Categories and Criteria (IUCN 2012).

\subsubsection{Threatened species}

Of the 169 species assessed 133 (79\%) were classified as threatened, including 75 (44\%) assessed as EN and 34 (20\%) as Critically Endangered (CR) (see Annex 6.7; Table 6.1 and Figure 6.2 for summaries of the results for all Categories). Assuming that all Data Deficient (DD) species are threatened in the same proportion as those species for which enough information was available, the percentage of threatened aquatic plant species increases to $80 \%$. It is important to note, however, that assessment efforts have focused, with one exception (Leersia perrieri), exclusively on plant species that are endemic to Madagascar and which would be the most likely to be globally threatened. Therefore the percentage of threatened species reported for this group is biased accordingly. Assessments of the plant species occurring in the hotspot that are not endemic, but also occurring in continental Africa show a much lower level of threat (Juffe Bignoli 2011).

All 10 species of Orchidaceae were assessed as EN (four) or CR (six). All families contain at least one threatened species except for Polypodiaceae (two species, both Least Concern [LC]) and Apocynaceae (one Near Threatened [NT] species). A full summary for the Red List status of all 44 plant families is provided in Annex 6.6.

Since the majority of species assessed are threatened, the distribution pattern of threatened species does not differ greatly from the pattern obtained for all species (Figure 6.1). On the central plateau around Antananarivo and near other major population centres, such as the city of Mahajanga, the low richness of the freshwater flora is coupled with high levels of threat from deforestation; in particular due to urbanisation and agriculture linked to population growth and human migration from rural areas. Many of the CR species are known from these peri-urban areas, including: Myriophyllum axilliflorum from the Eastern Highlands Ecoregion, and Schoenoplectiella perrieri and Ammannia calcicola from the North-Western Ecoregion, but none of which have been recorded for the past 80 years or more and which may be extinct. Other threatened species occur in areas that remain relatively intact, but they are highly localised endemics adapted to specific habitats, and are now under considerable pressure. These include: Lindernia natans (from the Ampasindava Peninsula - North-Western Ecoregion), with an estimated area of occupancy of $9 \mathrm{~km}^{2}$. Even though this species occurs within a protected area, it is threatened by agriculture, wild fire, grazing and mining exploitation. Aponogeton dioecus is threatened by habitat degradation or destruction due to frequent fires, agriculture

Table 6.1 The number of aquatic plant species endemic to Madagascar in each IUCN Red List.

\begin{tabular}{|l|l|c|}
\hline \multicolumn{2}{|l|}{ IUCN Red List Categories } & No. Endemic Species \\
\hline \multirow{3}{*}{$\begin{array}{l}\text { Threatened } \\
\text { Categories }\end{array}$} & Critically Endangered (CR) & 34 \\
\cline { 2 - 3 } & Endangered (EN) & 75 \\
\cline { 2 - 3 } & Vulnerable (VU) & 24 \\
\hline \multirow{3}{*}{$\begin{array}{l}\text { Other } \\
\text { Categories }\end{array}$} & Near Threatened (NT) & 22 \\
\cline { 2 - 3 } & Least Concern (LC) & 12 \\
\cline { 2 - 3 } & Data Deficient (DD) & 2 \\
\hline Total number of species assessed & $\mathbf{1 6 9}$ \\
\hline
\end{tabular}

Figure 6.2 The proportion (\%) of aquatic plant species endemic to Madagascar in each IUCN Red List Category.

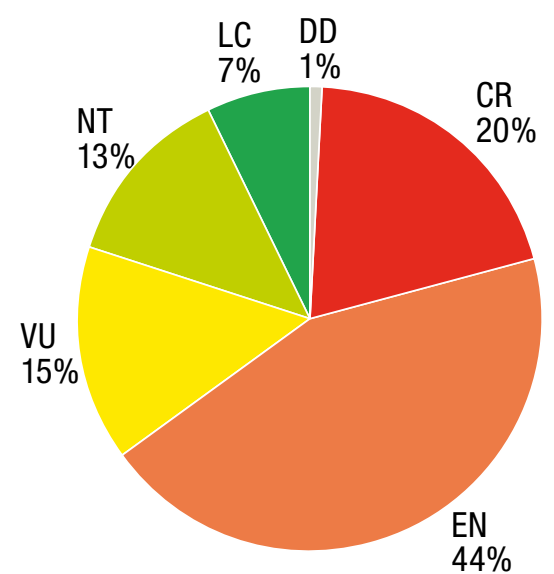


and disturbance by livestock as are Eriocaulon hildebrandtii, E. parvicapitulatum and Paepalanthus bosseri (all from Ankaratra Mountain in the Eastern Highlands Ecoregion).

Many species of lotic environments are narrow endemics, such as the numerous species of Hydrostachys (14 species in Madagascar), the four species of Hydrotriche, most species of Aponogeton, and representatives of the Podostemaceae (Figures 6.3 and 6.4). All of these genera include threatened species, with a particularly high diversity in the Western and North-Western Ecoregions.

\subsubsection{Data Deficient species}

Only two species were assessed as DD, Aponogeton cordatus (Aponogetonaceae) and Paleodicraeia imbricata (Podostemaceae). The former has been collected only once in the "Forêt d'Analamazaotra" in 1912 (Eastern Highlands Ecoregion). This area has been subject to relatively intensive botanical inventory, but although part of the forest is within a protected area, other parts have been affected by the development of a railway, mining, agriculture, housing, and tourism. As the locality data are rather vague it is impossible to tell whether the collection was made in an area that is now destroyed, and no targeted search has been made for the species within areas that are still intact. The second species is also known only from the type specimen collected at the end of the 18th century, with no more locality information than "Madagascar." It has not been recorded since. As the

Figure 6.3 Aponogeton decaryi (NT). @ P Peter B. Phillipson

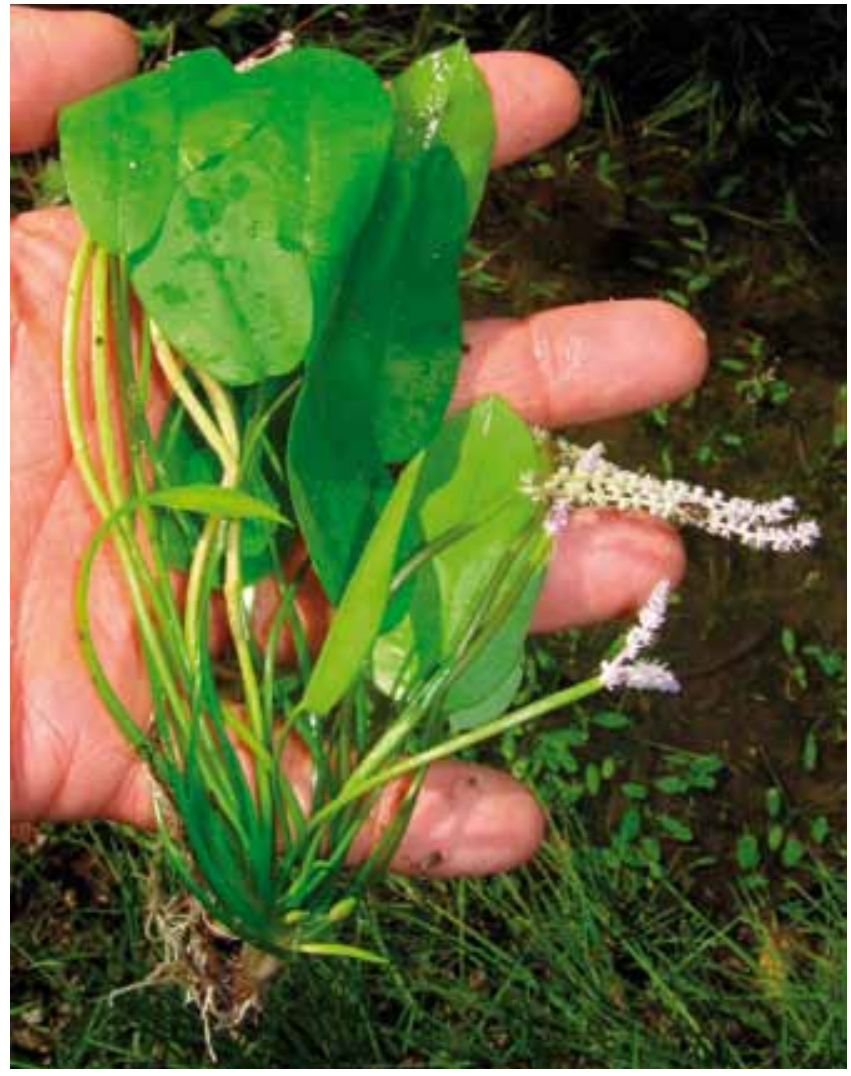

only species of the genus Paleodicraeia it is of great interest for studies of this highly specialised family of hydrophytes.

\subsection{Main threats}

The pressures and threats that affect aquatic plants can be anthropogenic or natural. Anthropogenic activities such as agriculture, landfill, backfilling, illicit collection, fire and urbanisation all contribute to the degradation of wetlands and their flora (Bamford et al. 2017; Maharombaka et al. 2017). In addition, natural phenomena, such as cyclones and drought, which are exacerbated by climate change, and invasion by alien species are also major threats to Malagasy freshwater habitats and species (Beisel \& Lévêque 2010; Maharombaka et al. 2017).

Across the 169 species for which we completed Red List assessments, all 11 major threat categories listed in IUCN's Threat Classification scheme (IUCN 2016) were considered to be applicable. The threats affecting most species were agriculture and aquaculture and natural system modifications (Table 6.2).

\section{Agriculture and aquaculture: habitat loss}

Loss of freshwater habitats in Madagascar continues at a rapid pace despite the efforts of environmental agencies. For example, following designation of the Torotorofotsy wetland complex as a legally protected area in 2015 , within a year

Figure 6.4 Hydrostachis imbricata (LC). @ C Charles Rakotovao

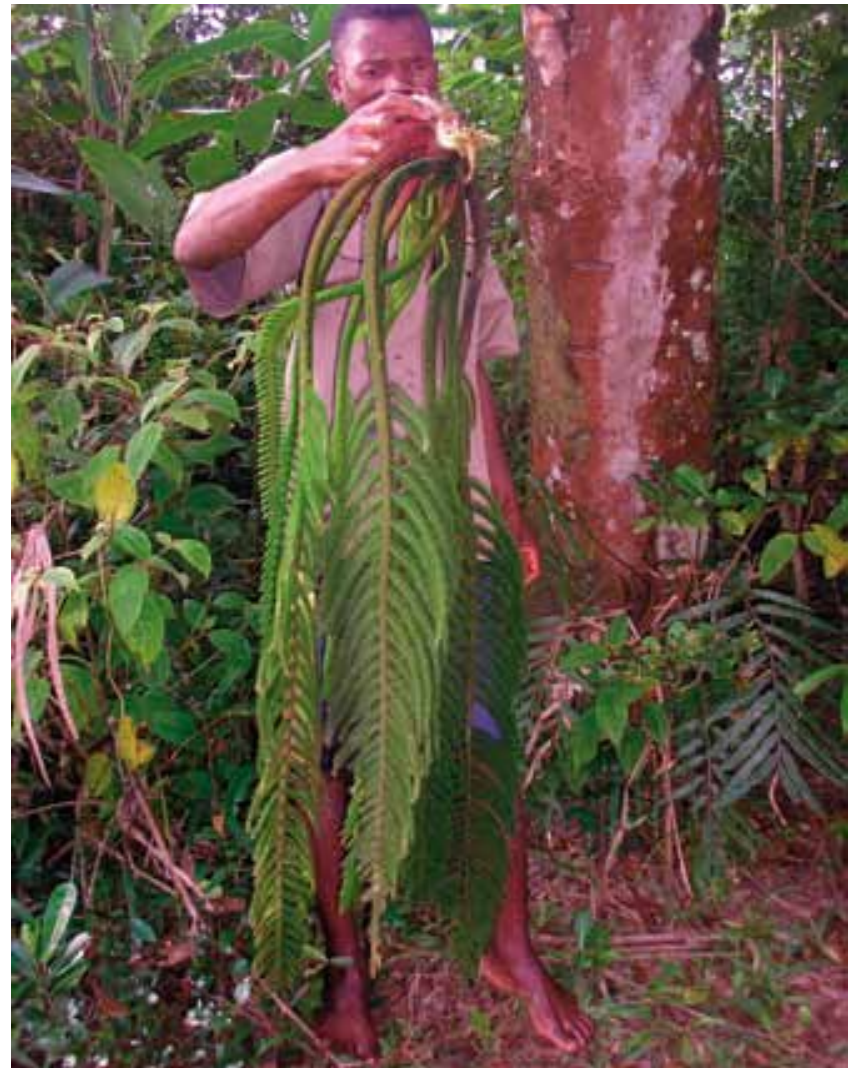


Figure 6.5 The distribution of threatened aquatic plant species per river/lake sub-catchment across Madagascar.

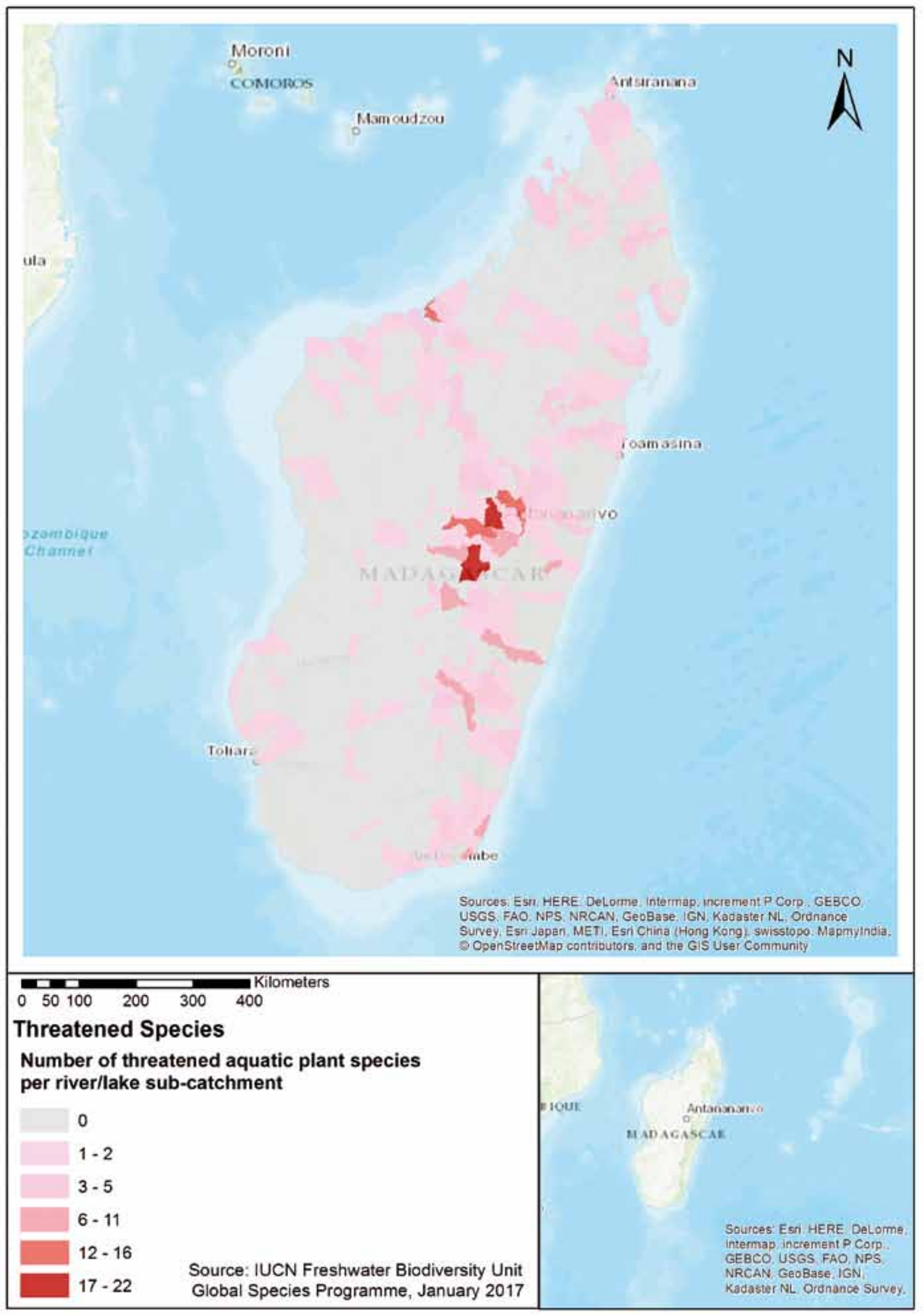


Table 6.2 Number of human activities or processes that have impacted, are impacting, or may impact the status of the aquatic plants assesed.

\begin{tabular}{|l|l|}
\hline Threat category & No. of species-threats \\
\hline Agriculture and aquaculture & $533(32.5 \%)$ \\
\hline Natural system modifications & $354(21.6 \%)$ \\
\hline Energy production and mining & $203(12.4 \%)$ \\
\hline Biological resource use & $154(9.4 \%)$ \\
\hline Pollution & $142(8.7 \%)$ \\
\hline $\begin{array}{l}\text { Infrastructure development; residential } \\
\text { and commercial }\end{array}$ & $101(6.2 \%)$ \\
\hline Human intrusions and disturbance & $67(4.1 \%)$ \\
\hline Climate change and severe weather & $37(2.3 \%)$ \\
\hline $\begin{array}{l}\text { Invasive and other problematic species, } \\
\text { genes and diseases }\end{array}$ & $27(1.6 \%)$ \\
\hline $\begin{array}{l}\text { Infrastructure development; } \\
\text { transportation and service corridors }\end{array}$ & $21(1.3 \%)$ \\
\hline Geological events & $1(0.1 \%)$ \\
\hline Total & $\mathbf{1 , 6 4 0}$ \\
\hline
\end{tabular}

$38 \%$ of the intact marshland planned for the conservation had been illegally transformed into rice fields (Lova 2016; Figure 6.6).

Given the ongoing expansion of agriculture across Madagascar, it is not surprising that this represents the greatest threat to aquatic plants, with annual and perennial non-timber crops having a major impact followed by shifting agriculture and small-holder farming (Figure 6.7 and 6.8). Other impacts of agriculture and aquaculture include livestock farming and ranching, wood and pulp plantations, and marine and freshwater aquaculture.

\section{Climate change and severe weather}

Global climate change may be a cause of the extreme weather conditions in Madagascar that have been experienced in recent years. The dry and semi-arid western and southern regions of Madagascar, in particular, have been seriously affected by low and unpredictable precipitation and an increase in the rate of evapotranspiration. In 2016 the international press reported that according to UN agencies 330,000 people in southern Madagascar were "on the brink of famine" (Lind 2016) and 1.4 million were suffering from malnutrition (Lepidi 2016). On the other hand, influenced by the humid winds from the Indian Ocean, the eastern part of the island is increasingly prone to cyclones and floods. Clearly any disruption to air and water temperatures, water levels, water flow and seasonality will have a direct impact on the plant species of wetlands. The aquatic plants in Madagascar have been shown to be highly sensitive to seasonal or permanent variations in environmental conditions (Maharombaka 2012).

Drought conditions and unpredictable precipitation, including flooding, threaten wetlands directly. They also place additional pressures on wetlands to provide for the

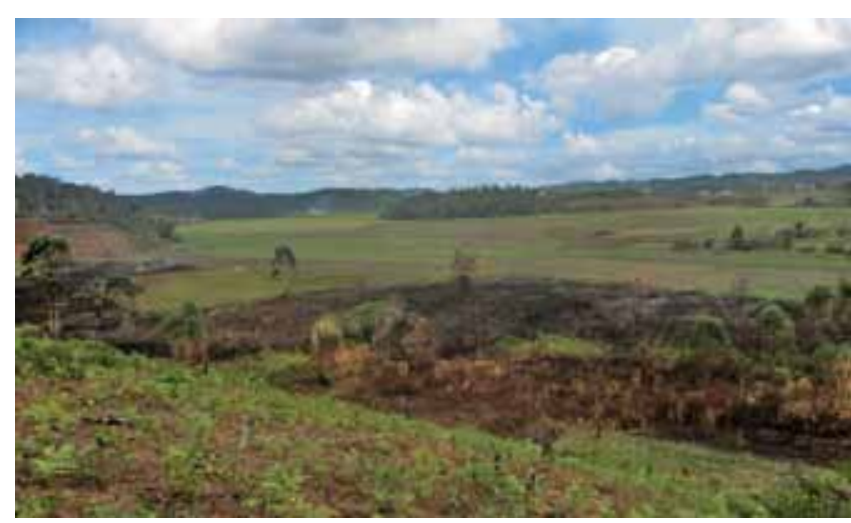

Figure 6.6 The practice of slash and burn agriculture 'Tavy' has converted most of the Ramsar site Les Marais de Torotorofotsy into rice fields. ( $)$ Laura Máiz-Tomé

needs of the human population and their livestock when dryland agriculture fails or becomes diminished; under these circumstances increased trampling by livestock in particular can cause irreparable damage to wetlands. These threats to aquatic ecosystems are exacerbated by the destruction and degradation of surrounding forests. The degradation of catchments associated with wetlands increases the likelihood of flooding and causes soil erosion leading to siltation of wetlands, and in some cases habitat fragmentation. This is the case at Lake Alaotra, one of Madagascar's most important highland wetlands: its surface area has decreased by $20 \%$ in recent years due to deforestation of its catchment, and subsequent soil erosion has led to massive sedimentation of the lake (Bakoariniana et al. 2006).

Most native aquatic plant species are likely to be affected by climate change, although it is impossible to quantify the scale of impact. EN and CR species occurring in the drier parts of Madagascar are likely to be the most threatened and most in need of conservation focus. Among these are Conyza mandrarensis (CR) in the Mandrare Basin (Southern Ecoregion), Hydrotriche mayacoides (CR) on the exposed

Figure 6.7 Exploitation of marshland margins for small-scale agriculture (Belobaka, Mahajanga). ( ) B.A. Ramiandrisoa

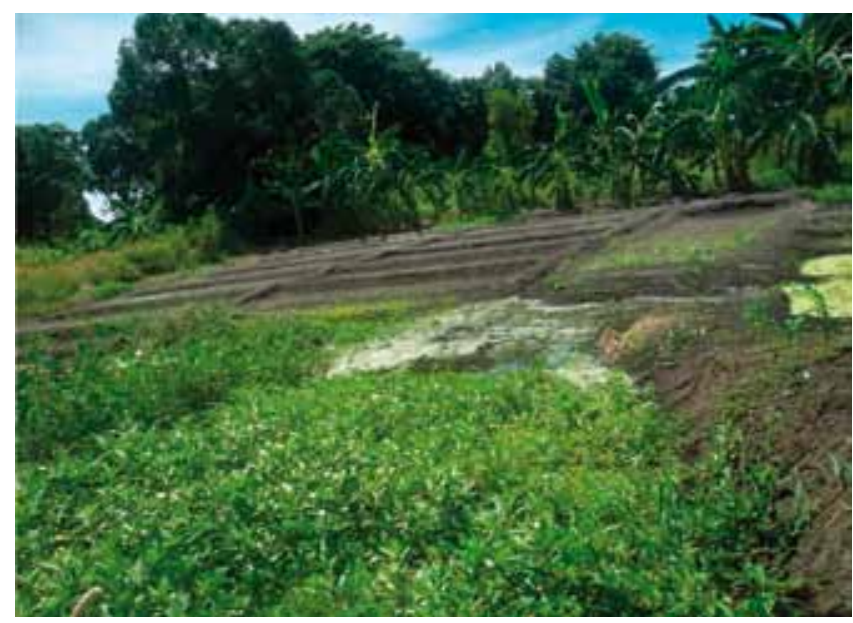


wetlands of Andringitra (Eastern Highlands Ecoregion), and the near endemic Leersia perrieri (EN) which is threatened by the drying up of the small pools near Mahajanga where it primarily occurs (North-Eastern Ecoregion). On the other hand, strictly hydrophytic species such as Hydrostachys monoica (CR) and Hydrotriche bryoides (CR) from (Eastern Highlands Ecoregion) may be threatened by increased inundation as a result of flooding.

\section{Infrastructure development}

Infrastructure development linked to urbanisation, energy generation, transport, population growth and migration, tourism, and industrial development may create a demand for water, either in the construction or operation phases (or both). Moreover, the development can affect natural drainage patterns, or increase water pollution. The impacts are widely reflected across Madagascar both near the major population centres, where the impacts on wetlands are compounded by other factors, as well as in areas that are unpopulated or have a low population-density. Several aquatic species are known only from areas heavily affected by infrastructure development, these include: Potamogeton parmatus (EN) only known from around Antananarivo and near Lake Alaotra (Eastern Highlands Ecoregion); Najas madagascariensis (EN) in scattered localities on the high plateau of Madagascar (Eastern Highlands Ecoregion), but not recorded for over 80 years and possibly already extinct; and Ravenea musicalis (CR) known from a single site north of Taolagnaro (Eastern Lowlands Ecoregion), where both mining and tourism are particularly important (Figure 6.9).

Urbanisation also has a considerable impact in Madagascar. Urbanisation destroys wetlands through backfilling and causing pollution from wastewater, sewage and the dumping of domestic and industrial waste. Of the threats due to infrastructure mining and quarrying is by far the most important, including both industrial scale developments and artisanal exploitation.

\section{Invasive species}

In aquatic systems, invasive species have colonised and affected very large areas of lakes and rivers. In Madagascar at Lake Ravelobe, the water hyacinth Eichhornia crassipes is having a major impact on the survival of other aquatic species, due to its aggressive domination of the habitat and monopolisation of space, nutrients and light (Ranarijaona et al. 2013a, b). Other invasive aquatic species inhibit the growth of other plants through allelopathy - the release of chemicals that influence the germination or growth of other species, as demonstrated by Ludwigia adscendens subsp. diffusa (Sakpere et al. 2010), a common invasive weedy aquatic plant in Madagascar.

Figure 6.8 Ravenea musicalis is a Critically Endangered species known from a single highly restricted locality in south-east Madagascar within the Eastern Lowlands Ecoregion. The species is harvested for the horticultural trade and the palm trunks are occasionally felled to make canoes (Rakotoarinivo \& Dransfield 2017). () B.A. Ramiandrisoa

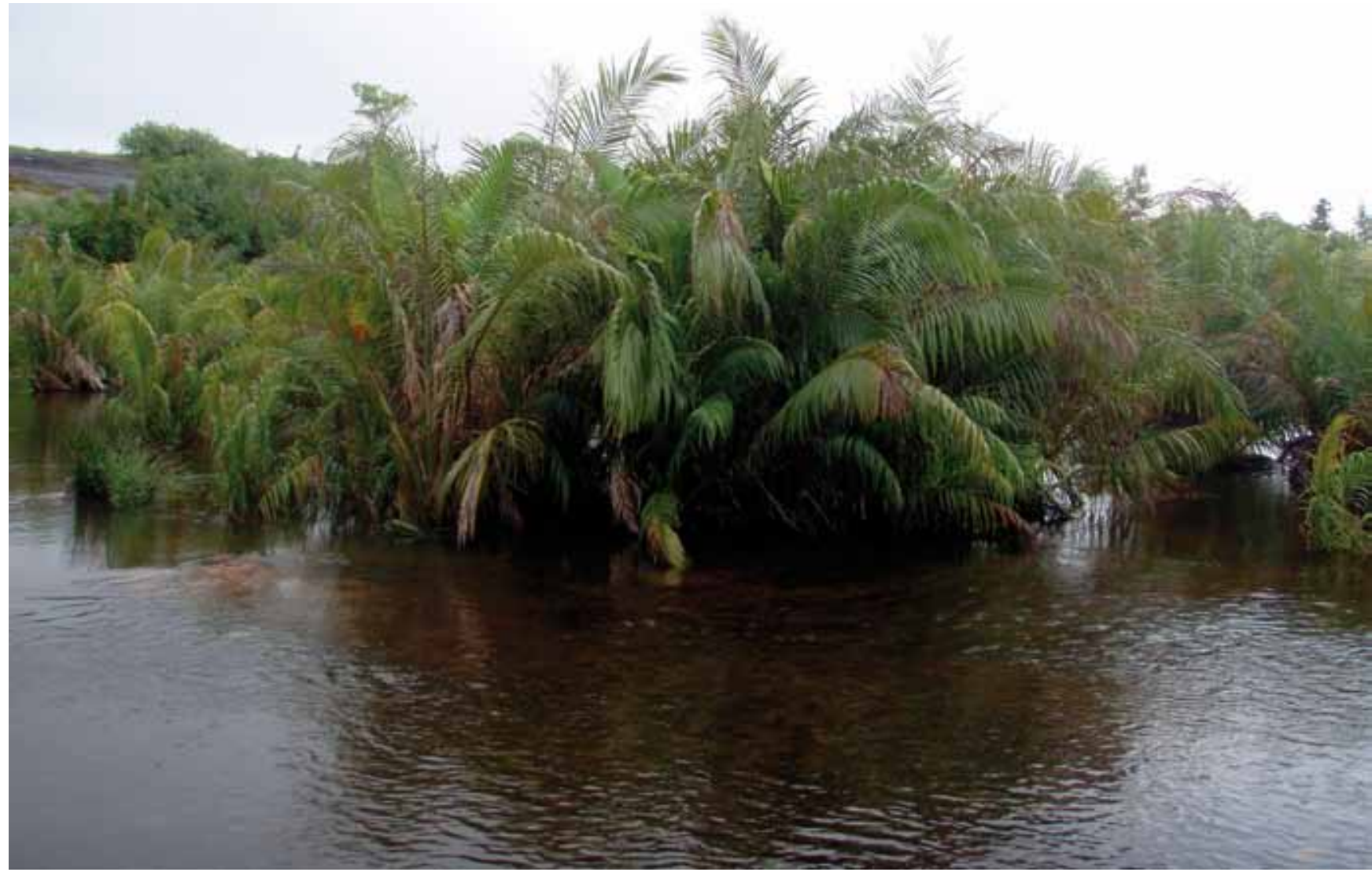




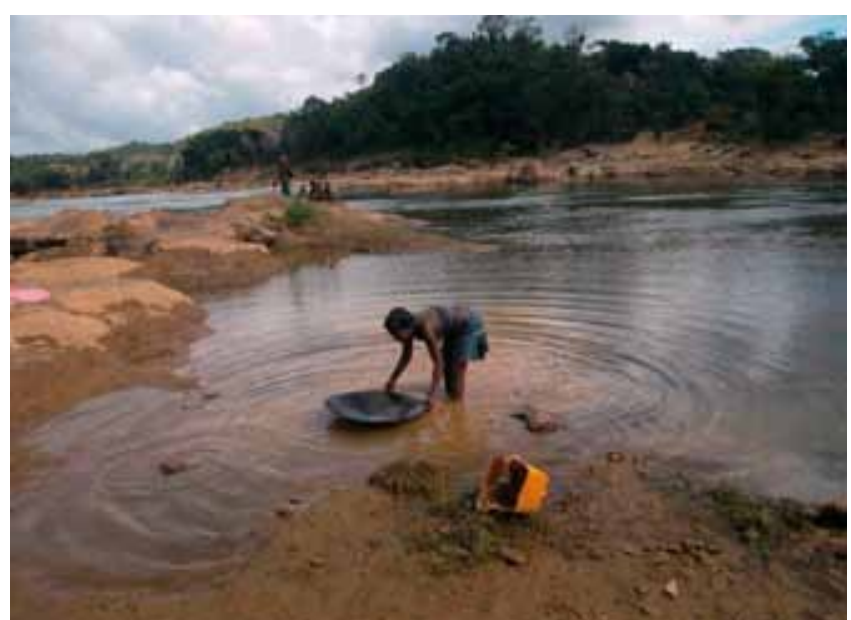

Figure 6.9 Artisanal small-scale gold panning at Matitanana River (Vatovavy-Fitovinany). () B.A. Ramiandrisoa

\section{Dams}

Dams for production of electricity or storage of water for irrigation and drinking water slow the water flow in the streams and rivers, leading to reduced habitat diversity, eutrophication and siltation. The impoundments resulting from dams also change upstream habitats from lotic to lentic systems, impacting plants specific to riverine habitats. Dams for hydropower are mostly constructed in areas that have a rapid drop in elevation where rivers narrow. These are areas where rapids and waterfalls occur and which naturally support unique assemblages of lotic species, likely to be threatened or extirpated by dam construction.

\section{Water pollution}

The greatest impact of water pollution is through soil erosion and sedimentation which affects much of the aquatic flora of Madagascar. Water pollution can also be an indirect consequence of infrastructure developments such as those discussed above, and is a direct impact of the use of chemical fertilisers and insecticides in agriculture, detergents, artisanal crafts such as brick-making, and domestic waste. Introduction of pollutants into water can cause toxicity and eutrophication, altering water properties such that naturally occurring plants and animals are unable to survive. For example, Thelethylax isalensis (CR), a species only known from near Isalo National Park (Western Ecoregion), is evidently affected by pollution from neighbouring human communities. Industrial and artisanal mining activities notably gold, cobalt and nickel extraction, are also a major source of pollutants.

\subsection{Conservation recommendations}

Planning and Policy. Madagascar has an extensive network of protected areas, and has recently added substantially to these, but most are focussed primarily on terrestrial habitats. The management of important freshwater species and habitats within these sites is not often addressed. The information presented through this study aims to ensure these freshwater species and habitats are now well recognised and that management plans are developed to specifically incorporate a targeted focus on their conservation. In the case of the few protected areas which have been established specifically for the conservation of freshwater habitats, the new information presented here will help to further inform management of those sites.

\section{Alien species removal}

The threat of alien plants is generally well recognised in Madagascar, at least for some of the most serious problem species. However, alien species that are currently not at a level to threaten habitats may represent a threat "waiting to happen". More effort is therefore needed to identify alien plants present in freshwater habitats, and to put in place control methods before they present a serious threat and become costly to remove. Methods for controlling invasive plant species can be classified into three categories: mechanical, chemical or biological control (van Wilgen et al. 2001). Physical control is most commonly used in Madagascar, but other means of control should be considered.

\section{Species and site-based actions}

The information presented here brings together important new data on the many aquatic plant species in Madagascar that are currently threatened, and provides information on their known distributions. A number of these species would benefit from the development of site-based action plans.

\section{Restoration}

Many freshwater ecosystems in Madagascar have undergone significant levels of degradation and will require restoration. However, effective restoration requires a thorough knowledge of the biological interactions within the system and, in most cases, this knowledge is lacking. Nevertheless, in some places restoration experiments have been carried out on a small scale, a good example being re-planting of the native sedge, Lepironia articulata (Cyperaceae) in swamps at a mining site in the south-east of Madagascar (Randriantafika et al. 2007). This has been highly successful and it is now important to replicate this work on a larger scale.

\subsection{Research actions}

The over-riding research need for the aquatic plants of Madagascar is to step-up efforts for basic field surveys across the country. It is evident that aquatic plants are more poorly known than terrestrial species, and basic upto-date taxonomic treatments for most groups are lacking. 
This is reflected in the number and age of aquatic plant specimens available in the relevant herbaria in comparison with terrestrial species - many aquatic plant species are not known from any recent collections. Although field work has been conducted by the MBG and University of Mahajanga teams to relocate some species such as Diospyros anosivolensis and Hydrostachys decaryi (both from the Eastern Highlands Ecoregion), many areas remain as significant data gaps.

The study of aquatic plants demands special techniques to dry specimens quickly and to preserve delicate forms that collapse when removed from the water, and equipment such as waders and boats. Targeted collection of species only known from a single locality or from old collections is important, but basic inventory of aquatic plants is required throughout Madagascar. These new data will help to inform and update the species Red List assessments and will better inform conservation and development decision making. It is also important that botanical inventory of wetlands within protected areas is also completed to ensure that site managers have the necessary information to more effectively conserve freshwater plants.

\subsection{References}

Alvarez, M.F. 1982. Contribution à l'étude écologique du lac de Mandroseza (étude de la flore). Mémoire de DEA, Université d'Antananarivo, Madagascar.

Andrianjohany, B.S. 1988. Analyse sur l'influence des plantes aquatiques sur la production piscicole du lac Itasy. Rapport PNUD.

Bakoariniaina, L.N., Kusky, T. and Raharimahefa, T. 2006. Disappearing Lake Alaotra: Monitoring catastrophic erosion, waterway silting, and land degradation hazards in Madagascar using Landsat imagery. Journal of African Earth Sciences 44(2): 241-252. https://doi.org/10.1016/j. jafrearsci.2005.10.013

Bamford, A.J., Razafindrajao, F., Young, R.P. and Hilton, G.M. 2017. Profound and pervasive degradation of Madagascar's freshwater wetlands and links with biodiversity. PLOS ONE 12(8): e0182673. https://doi.org/10.1371/journal. pone.0182673

Basiza, R. 2015. Evaluation de la régénération de Raphia farinifera dans la forêt marécageuse de Mariarano. Mémoire de Master, parcours : Valorisation de la Biodiversité Végétale, Faculté des Sciences, de Technologies et de l'Environnement, Université de Mahajanga.

Beisel, J.-N. and Leveque, C. 2010. Introductions d'espèces dans les milieux aquatiques. Faut-il avoir peur des invasions biologiques ? Editions QUAE.

Boiteau, P. 1979. Précis de matière médicale malgache avec formulaire. La librairie de Madagascar.
Boiteau, P. 1986. Médecine traditionnelle et pharmacopée. Précis de matière médicale malgache. Paris.

Boiteau, P., Pasich, B. and Rakoto Ratsimamanga, A. 1964. Les triterpenoides en physiologie végétale et animale. CNRS, Gauthiers-villars, Paris.

Boyer, A. 2009. Ethnobotanique appliquée : plantes utilisées traditionnellement centre les fièvres dans le nord de Madagascar. Thèse de doctorat en Pharmacie. Faculté de Pharmacie de Châtenay-Malabry. Université Paris Sud 11. France.

Carret, P. 2014. Profil d'écosystème. Hotspot de Madagascaret des îles de l'Océan indien. Critical Ecosystem Partnership Fund.

Cook, C.D.K. 1996. Aquatic Plant Book (2nd revised edition). SPB Academic Publishing. Amsterdam/New York.

Cornet, A. 1974. Essai de cartographie bioclimatique à Madagascar. Notic. Explic. No. 55. ORSTOM.

de Oliveira Pellegrini, M.O. 2017. Two new synonyms in Heteranthera (Pontederiaceae, Commelinales). Nordic Journal of Botany 35: 124-128. https://doi.org/10.1111/ njb.01152

Du Puy, D.J. and Moat, J. 1996. A refined classification of the vegetation types of Madagascar, and their current distribution. In: W.R. Lourenço (ed.). Biogéographie de Madagascar: 205-218. Éditions de l'ORSTOM, Paris.

Ferry L., Robison, L., Ranarijaona, H. and Gasse, F. 1999. Les lacs de Madagascar : présentation et typologie. Montpellier: Laboratoire Hydrologie.

FEOW. 2015. Freshwater Ecoregions of the World. Available online at: http://www.feow.org/

Gautier, L., Goodman, S.M. 2003. Introduction to the flora of Madagascar. In: Goodman, S.M., Benstead, J.P. (eds.). The natural history of Madagascar. University of Chicago Press; Chicago.

IUCN. 2012. Guidelines for Application of IUCN Red List Criteria at Regional Levels: Version 3.1 Second Edition. IUCN Species Survival Commission. IUCN, Gland, Switzerland and Cambridge, UK.

IUCN Standards and Petitions Subcommittee. 2016. Guidelines for Using the IUCN Red List Categories and Criteria. Version 12. Prepared by the Standards and Petitions Subcommittee. Downloadable from http://www. iucnredlist.org/documents/RedListGuidelines.pdf

Juffe Bignoli, D. 2011. Chapter 7. Aquatic plants of Africa: diversity, distribution and conservation. In: Darwall, W.R.T., Smith, K.G., Allen, D.J., Holland, R.A, Harrison, I.J. and Brooks, E.G.E. (eds.). The Diversity of Life in African Freshwaters: Under Water, Under Threat. An analysis of the status and distribution of freshwater species throughout mainland Africa. Cambridge, United Kingdom and Gland, Switzerland: IUCN. xiii+347pp+4pp cover.

Lepidi, P. 2016. La famine menace le sud de Madagascar frappé par la sécheress. Le Monde: 9 December 2016. http://www.lemonde.fr/afrique/article/2016/12/09/la- 
famine-menace-le-sud-de-madagascar-frappe-par-lasecheresse_5046094_3212.html\#qFQVwK3ZCQIKTo5c.99

Lind, P.L. 2016. Madagascar drought: 330,000 people 'one step from famine', UN warns. The Guardian: 25 November 2016.

Lova, R. 2016. Utilisation de la télédétection pour la conservation des zones humides : cas du site Ramsar Torotorofotsy. Conférence AlaRela, zones humide de Madagascar, 12-14 Octobre 2016. École Supérieur des Sciences Agronomique, Université d'Antananarivo

Madagascar Catalogue, 2017. Catalogue of the Plants of Madagascar. Missouri Botanical Garden, St Louis, USA and Antananarivo, Madagascar [http://www.tropicos.org/ Project/Madagascar. Accessed: August, 2017].

Maharombaka, C. 2012. Inventaire et suivi écologique des plantes aquatiques du complexe Mahavavy Kinkony, mémoire de DEA, parcours : Environnement et BioHydroSystèmes, Faculté des Sciences, de Technologies et de l'Environnement, Université de Mahajanga.

Maharombaka, C., Ramiandrisoa. B.A., Ranarijaona, H.L.T. 2017. Les devenirs de petites zones humides périurbaines

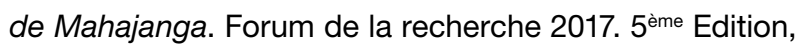
Biodiversité et développement durable, 15-16, Juin 2017, Antananarivo.

Manjato, N., Rakotonirina, N., Faranirina, L., Rabarimanarivo, M., Andriambololonera, S. and Phillipson, P.B. 2017. Biodiversity knowledge of freshwater aquatic plants of Madagascar. Oral presentation, 21st Congress of the Association for the Study of the Flora of Tropical Africa. Nairobi, 15-19 May, 2017.

Phillipson, P.B., Andriambololonera, S.R., Lowry, P.P., Manjato, N., Rabarimanarivo, M., Rakotonirina, N., Ravololomanana, N. and Schatz, G.E. 2017. The Madagascar Catalogue, progress to date and prospects for the future. Oral presentation, 21st Congress of the Association for the Study of the Flora of Tropical Africa. Nairobi, 15-19 May, 2017.

Rakoto-Ratsimamanga, A., Boiteau, P. and Mouton, M. 1969. Éléments de Pharmacopée malagasy. IMRA, Antananarivo, Madagascar.

Ranarijaona, H.L.T., Harilandy, E., Ravelontsoa, F., Rajaonarison, J.F., Ramanandraibe, V., Tsitomotra, A., Andrianasetra, G.S., Johnson, C.M. and Rabesa, Z.A. 2014. Etude ethnobotanique et screening phytochimique d'Hydrostachys plumosa A. Juss ex Tul. (Hydrostachyaceae) : espèce aquatique endémique de Mandritsara Madagascar. Paper presented at the colloquium "Les Zones Humides de Madagascar", 19-21 June, 2014, Antsirabe, Madagascar.

Ranarijaona, H.L.T., Zainabo, F.K., Andriamanantena, V.A. and Andrianasetra, G.S. 2013a. Évaluation de la prolifération de la jacinthe d'eau du lac Ravelobe Ankarafantsika et plan de restauration. Vertigo Sciences de l'Environnement, 13(1) URL: http://vertigo.revues.org/13522; DOI: 10.4000/vertigo. Ranarijaona, H.L.T., Koudossi, N., Andrianasetra, G.S. Miladera, C.J., Tsitomotra, A. and Rabesa, Z.A. 2013b.
Dynamisme de prolifération d'une plante aquatique envahissante, Eichhornia crassipes (Pontederiaceae), dans une aire protégée de Madagascar. Acte de colloque sur les espèces invasives. Octobre 2013. Antananarivo.

Ranarijaona, H.L.T. 2011. Inventaire, biologie, anatomie, architecture et conservation des macrophytes malgaches: cas des plantes carnivores du genre Utricularia $L$. (Lentibulariaceae). Thèse pour une Habilitation à Diriger la Recherche. Université de Mahajanga, Madagascar.

Randriantafika, F., Ramanamanjato, J.B., Vincelette, M., Soloarivelo, S. and Randrihasipara, L. 2007. Monitoring of Biometric and Ecological Parameters following restoration of a Lepironia mucronata (Family Cyperaceae) wetland in Mandena) in Biodiversity, Ecology and Conservation of littoral Ecosystems in Southeastern Madagascar, Tolagnaro (Fort-Dauphin). SI/MAB series 11.

Ranarijaona, H.L.T. 2003. Aquatic and semiaquatic vascular plants. In: Goodman, S. and Benstead, J.P. (eds.). The Natural History of Madagascar. The University of Chicago Press. Chicago and London.

Ranarijaona, H.L.T. 2009. Inventaire des plantes médicinales aquatiques dans les régions d'Androna et de Sofia. Rapport scientifique, Faculté des Sciences, Université de Mahajanga.

Ranarijaona, H.L.T. 1999. La flore des milieux lentiques malgaches : essai de typologie. Thèse de doctorat de $3^{\text {ème }}$ cycle. Université d'Antananarivo, Madagascar.

Rakotoarinivo, M. and Dransfield, J. 2017. Ravenea musicalis. The IUCN Red List of Threatened Species 2017: e.T38675A82841697. http://dx.doi.org/10.2305/IUCN. UK.2017-2.RLTS.T38675A82841697.en. Downloaded on 05 December 2017.

Sakpere, A.M., Oziegbe, M.I. and Bilesanmi, A. 2010. Allelopathic Effects of Ludwigia decurrens and $L$. adscendens subsp. diffusa on Germination, Seedling Growth and Yield of Corchorus olitorious L. Not. Sci. Biol. 2(2): 75-80.

Schatz, G.E. 2000. Endemism in the Malagasy tree flora. In W.R. Lourenço and S.M. Goodman (eds.). Diversity and endemism in Madagascar. Mémoires de la Société de Biogéographie, Paris.

The Angiosperm Phylogeny Group. 2016. An update of the Angiosperm Phylogeny Group classification for the orders and families of flowering plants: APG IV. Bot. J. Linn. Soc. 181: (1-20). https://doi.org/10.1111/boj.12385

Van Wilgen, B.W., Richardson, D.M., Le Maitre, D.C., Marais, C. and Magadlela, D. 2001. The economic consequences of alien plant invasions: examples of impacts and approaches to sustainable management in South Africa. Environment, Development and Sustainability 3: 145-168.

Wilmé, L., Goodman, S.M. and Ganzhorn, J.U. 2006. Biogeographic evolution of Madagascar's micro-endemic biota. Science 312: 1063-1065. https://doi.org/10.1126/ science. 1122806 
Annex 6.1 Family name inconsistencies between the IUCN Red List website and the APG IV system relevant for the Madagascar aquatic plant dataset.

\begin{tabular}{|c|c|c|c|c|}
\hline IUCN Family & APG IV Family & \multicolumn{3}{|c|}{ Genera concerned } \\
\hline Asclepiadaceae & Apocynaceae & Secamone & & \\
\hline Palmae & Arecaceae & Dypsis & Ravenea & \\
\hline Compositae & Asteraceae & \begin{tabular}{|l} 
Amphidoxa \\
Cineraria \\
Conyza \\
Emilia \\
Gerbera \\
\end{tabular} & $\begin{array}{l}\text { Grangea } \\
\text { Grangeopsis } \\
\text { Helichrysum } \\
\text { Hubertia } \\
\text { Inula } \\
\end{array}$ & $\begin{array}{l}\text { Pluchea } \\
\text { Sphaeranthus } \\
\text { Vernonia }\end{array}$ \\
\hline Cruciferae & Brassicaceae & Rorippa & & \\
\hline Leguminosae & Fabaceae & Indigofera & Leptodesmia & Phylloxylon \\
\hline Boraginaceae & \begin{tabular}{|l|} 
Heliotropaceae \\
\end{tabular} & Heliotropium & & \\
\hline Labiaceae & Lamiaceae & Orthosiphon & & \\
\hline Euphorbiaceae & Phyllanthaceae & Phyllanthus & & \\
\hline Scrophulariaceae & Plantaginaceae & Hydrotriche & & \\
\hline Gramineae & Poaceae & \begin{tabular}{|l|} 
Cenchrus \\
Eragrostis \\
Ischaemum
\end{tabular} & $\begin{array}{l}\text { Leersia } \\
\text { Neostapfiella } \\
\text { Sacciolepis }\end{array}$ & $\begin{array}{l}\text { Sacciolepis } \\
\text { Sporobolus }\end{array}$ \\
\hline
\end{tabular}

Annex 6.2 Fern families that include aquatic spp. for Madagascar, with numbers of: Malagasy endemic spp., native (but not endemic) spp., and naturalised spp.; family spp. total (including terrestrial spp.) for Madagascar with percentages of aquatics indicated.

\begin{tabular}{|l|c|c|c|c|c|}
\hline Family & Endemic & Native & Naturalised & Total & $\begin{array}{c}\text { Family } \\
\text { Total (\%) }\end{array}$ \\
\hline 1. Dryopteridaceae & - & 1 & - & 1 & $79(1.2 \%)$ \\
\hline 2. Equisetaceae & - & 1 & - & 1 & $1(100 \%)$ \\
\hline 3. Hymenophyllaceae & 1 & - & - & 1 & $55(1.8 \%)$ \\
\hline 4. Isoetaceae & 1 & 1 & - & 2 & $3(66.6 \%)$ \\
\hline 5. Marsileaceae & - & 4 & - & 4 & $4(100 \%)$ \\
\hline 6. Osmundaceae & - & 1 & - & 1 & $1(100 \%)$ \\
\hline 7. Polypodiaceae & 1 & - & - & 1 & $55(1.8 \%)$ \\
\hline 8. Pteridaceae & - & 5 & - & 5 & $94(5.3 \%)$ \\
\hline 9. Salviniaceae & - & 2 & 2 & 4 & $4(100 \%)$ \\
\hline 10. Schizaeaceae & - & 1 & - & 1 & $3(33.3 \%)$ \\
\hline 11. Thelypteridaceae & 1 & 3 & - & 4 & $33(12.1 \%)$ \\
\hline 12. Woodsiaceae & 1 & - & - & 1 & $21(4.7 \%)$ \\
\hline Totals & $\mathbf{5}$ & $\mathbf{1 9}$ & $\mathbf{2}$ & $\mathbf{2 6}$ & $\begin{array}{c}\mathbf{3 5 3} \\
\mathbf{( 7 . 3 \% )}\end{array}$ \\
\hline
\end{tabular}

Annex 6.3 Seed-plant families that comprise only aquatic spp. in Madagascar, with percentages of: Malagasy endemic spp., native (but not endemic) spp. and naturalised spp.; family spp. total and with percentages of species endemism for Madagascar indicated.

\begin{tabular}{|l|c|c|c|c|c|}
\hline Family & Endemic & Native & Naturalised & Total & $\begin{array}{c}\% \\
\text { endemism }\end{array}$ \\
\hline 1. Aponogetonaceae & 14 & 1 & - & 15 & $93.3 \%$ \\
\hline 2. Cannaceae & - & - & 1 & 1 & $0 \%$ \\
\hline 3. Ceratophyllaceae & - & 1 & - & 1 & $0 \%$ \\
\hline 4. Elatinaceae & 1 & 1 & - & 2 & $50 \%$ \\
\hline 5. Eriocaulaceae & 15 & 7 & - & 22 & $68.1 \%$ \\
\hline 6. Gunneraceae & - & 1 & - & 1 & $0 \%$ \\
\hline 7. Hydroleaceae & - & 1 & - & 1 & $0 \%$ \\
\hline 8. Hydrostachyaceae & 14 & - & - & 14 & $100 \%$ \\
\hline 9. Juncaceae & - & 2 & - & 2 & $0 \%$ \\
\hline 10. Menyanthaceae & 2 & 1 & - & 3 & $66.6 \%$ \\
\hline 11. Nepenthaceae & 2 & - & - & 2 & $100 \%$ \\
\hline 12. Nymphaeaceae & - & 2 & - & 2 & $0 \%$ \\
\hline 13. Podostemaceae & 4 & 2 & - & 6 & $66.6 \%$ \\
\hline 14. Restionaceae & - & 1 & - & 1 & $0 \%$ \\
\hline 15. Sphenocleaceae & - & 1 & - & 1 & $0 \%$ \\
\hline 16. Typhaceae & - & 1 & - & 1 & $0 \%$ \\
\hline Totals & $\mathbf{5 2}$ & $\mathbf{2 2}$ & $\mathbf{1}$ & $\mathbf{7 5}$ & $\mathbf{6 9 . 3 \%}$ \\
\hline
\end{tabular}


Annex 6.4 Seed-plant families comprising aquatic and terrestrial spp. in Madagascar, with more than five aquatic spp. in Madagascar, with numbers of: Malagasy endemic spp., native (but not endemic) spp. and naturalised spp.; family spp. total (including terrestrial spp.) for Madagascar with percentages of aquatics indicated.

\begin{tabular}{|c|c|c|c|c|c|}
\hline Family & Endemic & Native & Naturalised & Total & \begin{tabular}{|c|} 
Family \\
total (\%)
\end{tabular} \\
\hline 1. Asteraceae & 41 & 19 & 6 & 66 & $\begin{array}{c}543 \\
(12.1 \%)\end{array}$ \\
\hline 2. Cyperaceae & 10 & 44 & 1 & 55 & $\begin{array}{c}317 \\
(17.3 \%) \\
\end{array}$ \\
\hline 3. Fabaceae & 5 & 6 & 5 & 16 & $\begin{array}{c}663 \\
(2.4 \%) \\
\end{array}$ \\
\hline 4. Linderniaceae & 7 & 6 & - & 13 & $\begin{array}{c}21 \\
(61.9 \%)\end{array}$ \\
\hline 5. Polygonaceae & - & 1 & 11 & 12 & $\begin{array}{c}21 \\
(57.1 \%) \\
\end{array}$ \\
\hline 6. Orchidaceae & 8 & 3 & - & 11 & $\begin{array}{c}903 \\
(1.2 \%)\end{array}$ \\
\hline 7. Poaceae & - & 5 & 4 & 9 & $\begin{array}{c}603 \\
(1.4 \%)\end{array}$ \\
\hline 8. Plantaginaceae & 5 & 3 & 1 & 9 & $\begin{array}{c}24 \\
(37.5 \%)\end{array}$ \\
\hline 9. Potamogetonaceae & 1 & 8 & - & 9 & $\begin{array}{c}10 \\
(90.0 \%)\end{array}$ \\
\hline 10. Commelinaceae & 2 & 1 & 4 & 7 & $\begin{array}{c}32 \\
(21.8 \%) \\
\end{array}$ \\
\hline 11. Campanulaceae & 3 & 4 & - & 7 & $\begin{array}{c}30 \\
(23.3 \%) \\
\end{array}$ \\
\hline 12. Lythraceae & 6 & 1 & - & 7 & $\begin{array}{c}21 \\
(33.3 \%) \\
\end{array}$ \\
\hline 13. Lamiaceae & 4 & - & 2 & 6 & $\begin{array}{c}254 \\
(2.3 \%) \\
\end{array}$ \\
\hline 14. Gentianaceae & 5 & - & 1 & 6 & $65(9.2 \%)$ \\
\hline 15. Orobanchaceae & - & 6 & - & 6 & $\begin{array}{c}31 \\
(19.3 \%) \\
\end{array}$ \\
\hline 16. Araceae & - & 5 & 1 & 6 & $\begin{array}{c}28 \\
(21.4 \%)\end{array}$ \\
\hline 17. Hydrocharitaceae & 2 & 4 & & 6 & $\begin{array}{c}11 \\
(54.5 \%)\end{array}$ \\
\hline 18. Arecaceae & 4 & - & 1 & 5 & $\begin{array}{c}202 \\
(2.4 \%)\end{array}$ \\
\hline 19. Balsaminaceae & 5 & - & - & 5 & $\begin{array}{c}177 \\
(2.8 \%)\end{array}$ \\
\hline 20. Amaranthaceae & - & 2 & 3 & 5 & $65(7.6 \%)$ \\
\hline 21. Caryophyllaceae & - & 5 & - & 5 & $\begin{array}{c}16 \\
(31.2 \%)\end{array}$ \\
\hline All other families & 34 & 25 & 9 & 68 & $\begin{array}{c}3410 \\
(1.9 \%)\end{array}$ \\
\hline Total & 142 & 148 & 49 & 339 & $\begin{array}{c}7447 \\
(4.5 \%)\end{array}$ \\
\hline
\end{tabular}

Annex 6.5 Number of spp. in lentic habitats in Madagascar showing biogeographical distribution (from Ranarijaona 1999).

\begin{tabular}{|l|l|c|}
\hline $\begin{array}{l}\text { Phytogeographic } \\
\text { Domain (s) }\end{array}$ & $\begin{array}{l}\text { Bioclimatic } \\
\text { Region (s) }\end{array}$ & Total species \\
\hline Widespread in Madagascar & $116(34 \%)$ \\
\hline Central Highlands only & Subhumid & $100(30 \%)$ \\
\hline West and south & Dry and Subarid & $57(17 \%)$ \\
\hline East & Humid & $14(4 \%)$ \\
\hline Sambirano & Subhumid & $5(1 \%)$ \\
\hline Central and west & Subhumid and Dry & $15(4 \%)$ \\
\hline East and south & Humid and Subarid & $5(1 \%)$ \\
\hline No clear pattern discerned & $24(8 \%)$ \\
\hline
\end{tabular}

Annex 6.6 Summary of Red List assessment results: number of spp. per plant family and group (Fern or Seed plant), per Red List Category.

\begin{tabular}{|c|c|c|c|c|c|c|c|c|}
\hline Family & Group & CR & EN & VU & NT & LC & DD & $\begin{array}{l}\text { Family } \\
\text { totals }\end{array}$ \\
\hline $\begin{array}{l}\text { Asteraceae } \\
\text { (Compositae) }\end{array}$ & Seed & 2 & 6 & 6 & 7 & 3 & - & 24 \\
\hline Cyperaceae & Seed & 3 & 8 & 4 & - & - & - & 15 \\
\hline Hydrostachyaceae & Seed & 2 & 4 & 2 & 4 & 2 & - & 14 \\
\hline Aponogetonaceae & Seed & 2 & 6 & - & 3 & 1 & 1 & 13 \\
\hline Orchidaceae & Seed & 6 & 4 & - & - & - & - & 10 \\
\hline Eriocaulaceae & Seed & 3 & 2 & 1 & 2 & - & - & 8 \\
\hline Poaceae (Gramineae) & Seed & - & 7 & 1 & - & - & - & 8 \\
\hline Lythraceae & Seed & 1 & 4 & 1 & - & - & - & 6 \\
\hline Gentianaceae & Seed & 3 & 2 & - & - & - & - & 5 \\
\hline Plantaginaceae & Seed & 1 & 2 & 1 & 1 & - & - & 5 \\
\hline Rubiaceae & Seed & - & 3 & 1 & 1 & - & - & 5 \\
\hline Arecaceae (Palmae) & Seed & 2 & - & 1 & 1 & - & - & 4 \\
\hline Ebenaceae & Seed & - & 1 & 2 & - & 1 & - & 4 \\
\hline $\begin{array}{l}\begin{array}{l}\text { Fabaceae } \\
\text { (Leguminosae) }\end{array} \\
\end{array}$ & Seed & 1 & 3 & - & - & - & - & 4 \\
\hline Podostemaceae & Seed & 1 & 1 & - & - & 1 & 1 & 4 \\
\hline Pandanaceae & Seed & 1 & 1 & - & 1 & - & - & 3 \\
\hline Primulaceae & Seed & - & 2 & - & 1 & - & - & 3 \\
\hline Acanthaceae & Seed & - & 2 & - & - & - & - & 2 \\
\hline Balsaminaceae & Seed & 1 & 1 & - & - & - & - & 2 \\
\hline Haloragaceae & Seed & 1 & 1 & - & - & - & - & 2 \\
\hline Hydrocharitaceae & Seed & - & 1 & - & - & 1 & - & 2 \\
\hline Linderniaceae & Seed & 1 & - & - & - & 1 & - & 2 \\
\hline Menyanthaceae & Seed & - & 2 & - & - & - & - & 2 \\
\hline Polypodiaceae & Fern & - & - & - & - & 2 & - & 2 \\
\hline Apocynaceae & Seed & - & - & - & 1 & - & - & 1 \\
\hline Begoniaceae & Seed & - & 1 & - & - & - & - & 1 \\
\hline Boraginaceae & Seed & 1 & - & - & - & - & - & 1 \\
\hline $\begin{array}{l}\text { Brassicaceae } \\
\text { (Cruciferae) }\end{array}$ & Seed & - & 1 & - & - & - & - & 1 \\
\hline Buxaceae & Seed & - & 1 & - & - & - & - & 1 \\
\hline Campanulaceae & Seed & - & 1 & - & - & - & - & 1 \\
\hline Capparaceae & Seed & - & 1 & - & - & - & - & 1 \\
\hline Crassulaceae & Seed & - & 1 & - & - & - & - & 1 \\
\hline Elatinaceae & Seed & - & - & 1 & - & - & - & 1 \\
\hline Heliotropaceae & Seed & - & 1 & - & - & - & - & 1 \\
\hline Hymenophyllaceae & Fern & 1 & - & - & - & - & - & 1 \\
\hline Isoetaceae & Fern & - & 1 & - & - & - & - & 1 \\
\hline Lamiaceae (Labiatae) & Seed & - & 1 & - & - & - & - & 1 \\
\hline Phyllanthaceae & Seed & - & 1 & - & - & - & - & 1 \\
\hline Potamogetonaceae & Seed & - & 1 & - & - & - & - & 1 \\
\hline Pteridaceae & Fern & - & - & 1 & - & - & - & 1 \\
\hline Sapotaceae & Seed & 1 & - & - & - & - & - & 1 \\
\hline Thelypteridaceae & Fern & - & - & 1 & - & - & - & 1 \\
\hline Urticaceae & Seed & - & 1 & - & - & - & - & 1 \\
\hline Xyridaceae & Seed & - & - & 1 & - & - & - & 1 \\
\hline Category totals & Seed & 34 & 75 & 24 & 22 & 12 & 2 & 169 \\
\hline
\end{tabular}


Annex 6.7 Red List status of Madagascar aquatic plants.

\begin{tabular}{|c|c|c|c|c|c|}
\hline Family & Species & $\begin{array}{l}\text { Red List } \\
\text { Category }\end{array}$ & Family & Species & $\begin{array}{l}\text { Red List } \\
\text { Category }\end{array}$ \\
\hline SAPOTACEAE & Mimusops nossibeensis & CR & PODOSTEMACEAE & Endocaulos mangorense & EN \\
\hline ORCHIDACEAE & Cynorkis marojejyensis & $\mathrm{CR}$ & COMPOSITAE & Helichrysum filaginoides & EN \\
\hline ORCHIDACEAE & Tylostigma herminioides & $\mathrm{CR}$ & GRAMINEAE & Leersia perrieri & EN \\
\hline ORCHIDACEAE & Tylostigma filiforme & $\mathrm{CR}$ & APONOGETONACEAE & Aponogeton schatzianus & EN \\
\hline CYPERACEAE & Rhynchospora hildebrandtii & $\mathrm{CR}$ & APONOGETONACEAE & Aponogeton viridis & EN \\
\hline ERIOCAULACEAE & Paepalanthus bosseri & $\mathrm{CR}$ & COMPOSITAE & Grangeopsis perrieri & EN \\
\hline ORCHIDACEAE & Eulophia nervosa & $\mathrm{CR}$ & CYPERACEAE & Pycreus compressiformis & EN \\
\hline LEGUMINOSAE & Indigofera ankaratrensis & $\mathrm{CR}$ & CYPERACEAE & Costularia melleri & EN \\
\hline BORAGINACEAE & Cynoglossum tsaratananense & $\mathrm{CR}$ & ORCHIDACEAE & Tylostigma nigrescens & EN \\
\hline PODOSTEMACEAE & Thelethylax isalensis & $\mathrm{CR}$ & \begin{tabular}{|l} 
LYTHRACEAE \\
\end{tabular} & Ammannia pauciramosa & EN \\
\hline PANDANACEAE & Pandanus ambalavaoensis & $\mathrm{CR}$ & CYPERACEAE & Bulbostylis andringitrensis & EN \\
\hline SCROPHULARIACEAE & Hydrotriche mayacoides & $\mathrm{CR}$ & GRAMINEAE & Cenchrus pseudotriticoides & EN \\
\hline CYPERACEAE & Schoenoplectiella aberrans & $\mathrm{CR}$ & RUBIACEAE & Anthospermum palustre & EN \\
\hline PALMAE & Dypsis aquatilis & $\mathrm{CR}$ & CAMPANULACEAE & Lobelia lingulata & EN \\
\hline BALSAMINACEAE & Impatiens boinensis & $\mathrm{CR}$ & GENTIANACEAE & Exacum gracile & EN \\
\hline HYDROSTACHYACEAE & Hydrostachys perrieri & CR & LEGUMINOSAE & Leptodesmia bojeriana & EN \\
\hline GENTIANACEAE & Exacum nossibeense & $\mathrm{CR}$ & BUXACEAE & Buxus itremoensis & EN \\
\hline HYDROSTACHYACEAE & Hydrostachys monoica & $\mathrm{CR}$ & BALSAMINACEAE & Impatiens rudicaulis & EN \\
\hline PALMAE & Ravenea musicalis & $\mathrm{CR}$ & \begin{tabular}{|l} 
ACANTHACEAE \\
\end{tabular} & Hygrophila baronii & EN \\
\hline ORCHIDACEAE & Benthamia catatiana & $\mathrm{CR}$ & APONOGETONACEAE & Aponogeton capuronii & EN \\
\hline HALORAGACEAE & Myriophyllum axilliflorum & $\mathrm{CR}$ & LEGUMINOSAE & Phylloxylon xiphoclada & EN \\
\hline ORCHIDACEAE & Tylostigma madagascariense & $\mathrm{CR}$ & CYPERACEAE & Bulbostylis perrieri & EN \\
\hline HYMENOPHYLLACEAE & Didymoglossum pygmaeum & $\mathrm{CR}$ & \begin{tabular}{|l} 
LYTHRACEAE \\
\end{tabular} & Ammannia calcicola & EN \\
\hline APONOGETONACEAE & Aponogeton dioecus & $\mathrm{CR}$ & \begin{tabular}{|l} 
COMPOSITAE \\
\end{tabular} & Helichrysum dubardii & EN \\
\hline GENTIANACEAE & Tachiadenus umbellatus & $\mathrm{CR}$ & HYDROSTACHYACEAE & Hydrostachys laciniata & EN \\
\hline LINDERNIACEAE & Lindernia natans & $\mathrm{CR}$ & COMPOSITAE & Helichrysum tanacetiflorum & EN \\
\hline LYTHRACEAE & Ammannia alternifolia & $\mathrm{CR}$ & \begin{tabular}{|l} 
COMPOSITAE \\
\end{tabular} & Gerbera hypochaeridoides & EN \\
\hline COMPOSITAE & Helichrysum coursii & $\mathrm{CR}$ & \begin{tabular}{|l} 
LYTHRACEAE \\
\end{tabular} & Ammannia quadriciliata & EN \\
\hline CYPERACEAE & Schoenoplectiella perrieri & $\mathrm{CR}$ & GRAMINEAE & Eragrostis stolonifera & EN \\
\hline APONOGETONACEAE & Aponogeton masoalaensis & $\mathrm{CR}$ & CYPERACEAE & Cyperus ankaratrensis & EN \\
\hline GENTIANACEAE & Exacum conglomeratum & $\mathrm{CR}$ & \begin{tabular}{|l} 
MENYANTHACEAE \\
\end{tabular} & Nymphoides bosseri & EN \\
\hline ERIOCAULACEAE & Eriocaulon hildebrandtii & $\mathrm{CR}$ & HALORAGACEAE & Myriophyllum mezianum & EN \\
\hline ERIOCAULACEAE & Eriocaulon parvicapitulatum & $\mathrm{CR}$ & APONOGETONACEAE & Aponogeton tenuispicatus & EN \\
\hline COMPOSITAE & Conyza mandrarensis & $\mathrm{CR}$ & ORCHIDACEAE & Cynorkis tenerrima & EN \\
\hline ACANTHACEAE & Hygrophila velata & EN & HYDROSTACHYACEAE & Hydrostachys fimbriata & EN \\
\hline GRAMINEAE & Neostapfiella chloridiantha & EN & GRAMINEAE & Ischaemum heterotrichum & EN \\
\hline APONOGETONACEAE & Aponogeton longiplumulosus & EN & BEGONIACEAE & Begonia erminea & EN \\
\hline EUPHORBIACEAE & Phyllanthus venustulus & EN & GENTIANACEAE & Klackenbergia stricta & EN \\
\hline HYDROCHARITACEAE & Najas madagascariensis & EN & SCROPHULARIACEAE & Hydrotriche galiifolia & EN \\
\hline PANDANACEAE & Pandanus peyrierasii & EN & ERIOCAULACEAE & Eriocaulon flumineum & EN \\
\hline RUBIACEAE & Pyrostria italyensis & EN & \begin{tabular}{|l} 
CYPERACEAE \\
\end{tabular} & Schoenoplectiella heterophylla & EN \\
\hline HYDROSTACHYACEAE & Hydrostachys trifaria & EN & COMPOSITAE & Grangea madagascariensis & EN \\
\hline BORAGINACEAE & Heliotropium perrieri & EN & ISOETACEAE & Isoetes perrieriana & EN \\
\hline EBENACEAE & Diospyros dicorypheoides & EN & APONOGETONACEAE & Aponogeton eggersii & EN \\
\hline GRAMINEAE & Sacciolepis delicatula & EN & CYPERACEAE & Cyperus heterocladus & EN \\
\hline GRAMINEAE & Sporobolus elatior & EN & POTAMOGETONACEAE & Potamogeton parmatus & EN \\
\hline ORCHIDACEAE & Benthamia calceolata & EN & CRASSULACEAE & Kalanchoe daigremontiana & EN \\
\hline
\end{tabular}


Annex 6.7 cont'd. Red List status of Madagascar aquatic plants.

\begin{tabular}{|l|l|c|}
\hline Family & Species & Red List \\
Category
\end{tabular}

\begin{tabular}{|c|c|c|}
\hline Family & Species & $\begin{array}{l}\text { Red List } \\
\text { Category } \\
\end{array}$ \\
\hline PANDANACEAE & Pandanus platyphyllus & NT \\
\hline APONOGETONACEAE & Aponogeton bernierianus & NT \\
\hline HYDROSTACHYACEAE & Hydrostachys multifida & NT \\
\hline SCROPHULARIACEAE & Hydrotriche hottoniiflora & NT \\
\hline COMPOSITAE & Emilia capillaris & NT \\
\hline COMPOSITAE & Sphaeranthus cotuloides & NT \\
\hline HYDROSTACHYACEAE & Hydrostachys longifida & NT \\
\hline COMPOSITAE & Pluchea grevei & NT \\
\hline COMPOSITAE & Helichrysum luzulaefolium & NT \\
\hline HYDROSTACHYACEAE & Hydrostachys distichophylla & NT \\
\hline RUBIACEAE & Ixora ripicola & NT \\
\hline ASCLEPIADACEAE & Secamone ligustrifolia & NT \\
\hline PRIMULACEAE & Lysimachia rubricaulis & NT \\
\hline COMPOSITAE & Helichrysum aphelexioides & NT \\
\hline COMPOSITAE & Vernonia platylepis & NT \\
\hline COMPOSITAE & Inula perrieri & NT \\
\hline HYDROSTACHYACEAE & Hydrostachys stolonifera & NT \\
\hline APONOGETONACEAE & Aponogeton decaryi & NT \\
\hline ERIOCAULACEAE & Mesanthemum pubescens & NT \\
\hline PALMAE & Dypsis crinita & NT \\
\hline ERIOCAULACEAE & Mesanthemum rutenbergianum & NT \\
\hline APONOGETONACEAE & Aponogeton ulvaceus & NT \\
\hline PODOSTEMACEAE & Paleodicraeia imbricata & $\mathrm{DD}$ \\
\hline APONOGETONACEAE & Aponogeton cordatus & $\mathrm{DD}$ \\
\hline PODOSTEMACEAE & Thelethylax minutiflora & $\mathrm{LC}$ \\
\hline APONOGETONACEAE & Aponogeton madagascariensis & $\mathrm{LC}$ \\
\hline POLYPODIACEAE & Loxogramme humblotii & $\mathrm{LC}$ \\
\hline LINDERNIACEAE & Torenia stolonifera & $\mathrm{LC}$ \\
\hline HYDROCHARITACEAE & Lagarosiphon madagascariensis & $\mathrm{LC}$ \\
\hline COMPOSITAE & Inula speciosa & $\mathrm{LC}$ \\
\hline COMPOSITAE & Conyza neocandolleana & $\mathrm{LC}$ \\
\hline EBENACEAE & Diospyros cinnamomoides & $\mathrm{LC}$ \\
\hline POLYPODIACEAE & Zygophlebia subpinnata & $\mathrm{LC}$ \\
\hline COMPOSITAE & Emilia citrina & $\mathrm{LC}$ \\
\hline HYDROSTACHYACEAE & Hydrostachys imbricata & $\mathrm{LC}$ \\
\hline HYDROSTACHYACEAE & Hydrostachys plumosa & LC \\
\hline
\end{tabular}




\title{
Chapter 7
}

\section{The status and distribution of Odonata}

\author{
Kai Schütte', Klaas-Douwe B. Dijkstra² ${ }^{2}$ William Darwall ${ }^{3}$ Laura Máiz-Tomé ${ }^{3}$

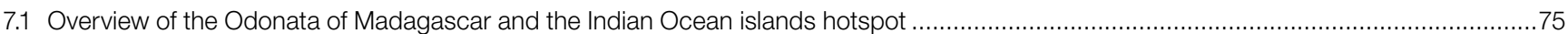

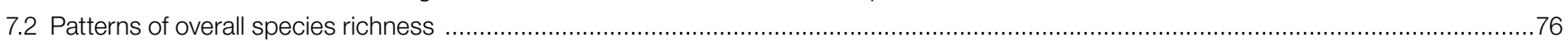

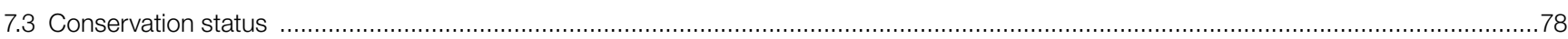

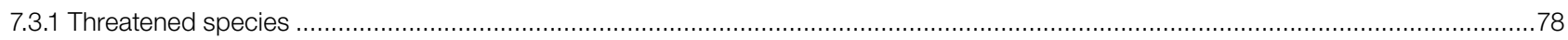

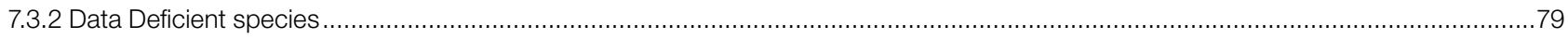

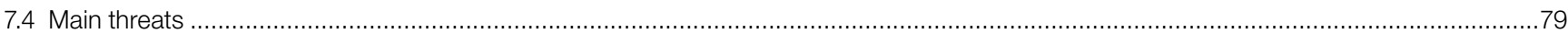

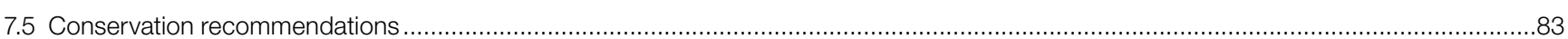

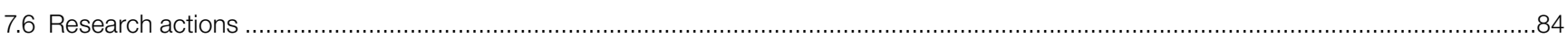

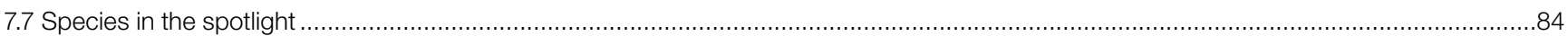

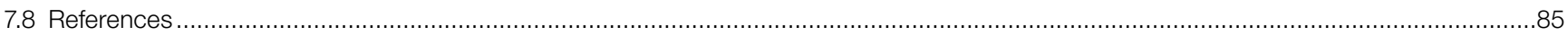 \\ Annex 7.1 Red List status of Odonata species from Madagascar and the Indian Ocean islands hotspot ...................................................87
}

\subsection{Overview of the Odonata of Madagascar and the Indian Ocean islands hotspot}

Dragonflies and damselflies (Odonata) are conspicuous freshwater insects that are sensitive to both aquatic and terrestrial habitat quality, making them among the best environmental sentinels (Darwall et al. 2011). Their sensitivity to habitat quality (e.g. forest cover, water chemistry, rivers and bank structure), their amphibious life cycle, and the relative ease of their identification make Odonata well suited for evaluating environmental changes both in the long term (biogeography, climatology) and in the short term (biology conservation, water pollution, structural alteration of running and standing waters). Due to their attractive appearance, they function not only as flagships for conservation of waterrich habitats such as wetlands and rainforests, but also for habitats where water is scarce and, therefore, especially vital to the survival of life.

Odonata larvae prey on all kinds of small animals up to the size of tadpoles and small fish. They take from a few weeks to several years to develop. Emergence takes place above the water on plants or on the shore, after which most species leave the water edge to mature. The males return to the water to search for females or to establish territories, whereas the females often return only to mate and to lay their eggs (Kalkman et al. 2008). Odonata are recognised by their long and slender abdomen, their large globular eyes, which often make up a large portion of the head, their short antennae and their long wings. They are divided into two suborders, namely Zygoptera (damselflies) and Anisoptera (true dragonflies). In this report the word 'dragonflies' is used for both suborders.

This chapter shows where the highest levels of diversity and endemism, and the greatest proportion of threatened dragonflies are found within Madagascar and the Indian Ocean islands hotspot. With about 5,680 species globally, dragonflies constitute a relatively small insect order (Kalkman et al. 2008), with most species found in the tropics. A total of 172 described species are present in Madagascar, of which $94 \%$ of the Zygoptera and $67 \%$ of the Anisoptera are endemic. There are 30 additional described species in the Comoros, Mascarenes and Seychelles islands (Dijkstra

Figure 7.1 Onychogomphus aequistylus. @ Dave Smallshire

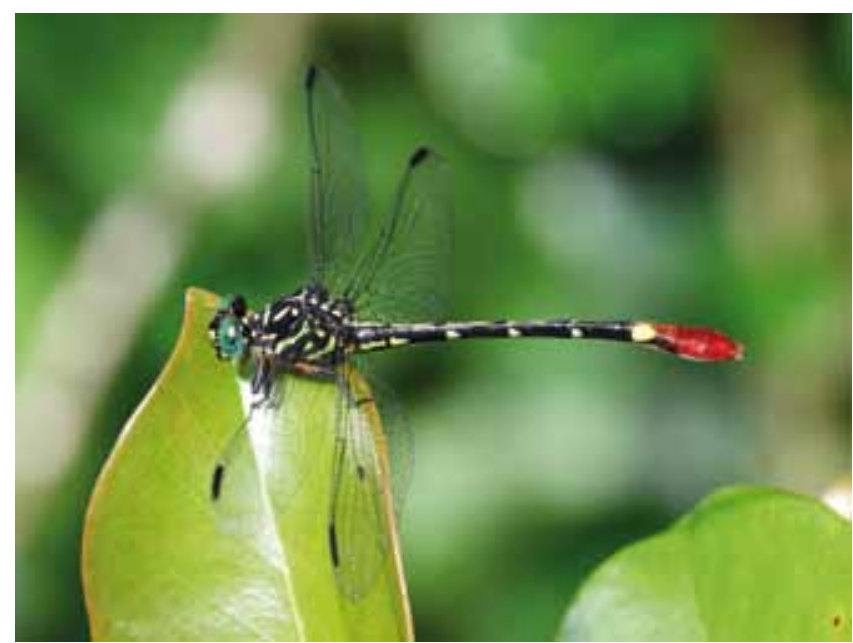

Universität Hamburg, Martin-Luther-King-Platz 3 20146, Hamburg, Germany. Email: Kai.Schuette@uni-hamburg.de

Naturalis Biodiversity Center Darwinweg 2, 2333 CR Leiden, Netherlands.

Freshwater Biodiversity Unit, IUCN Global Species Programme, The David Attenborough Building, Pembroke Street, Cambridge CB2 3QZ, UK. 
\& Cohen, submitted). Currently less than 10 undescribed species are known. A total of $\mathbf{1 5 1}$ endemic species and 50 non-endemic species of dragonflies were assessed against the IUCN Red List Categories and Criteria: Version 3.1 (IUCN 2012) under this project. Six endemic species were not assessed because three of them Orthetrum lugubre, O. malgassicum and Trithemis maia were only recently raised from subspecies to species status (Dijkstra \& Cohen, submitted). The other three Allolestes maclachlani, Gynacantha comorensis and G. stylata were overlooked - but their assessment is in progress and will be available shortly on the IUCN Red List.

The following background information is largely based on the book Dragonflies and Damselflies of Madagascar and Indian Ocean Islands produced by Klaas-Douwe B. Dijkstra $\&$ Callan Cohen (submitted), who have granted permission to IUCN and the authors for its use as presented below.

Odonata of the Madagascar and Indian Ocean islands hotspot are highly unique although distinctly Afrotropical: while less than $22 \%$ of the 209 described and undescribed species are shared with continental Africa or Asia, $74 \%$ of the 58 genera are shared. Despite clear African affinities, families broadly distributed on the mainland, such as Calopterygidae, Chlorocyphidae and Macromiidae are not at all or very poorly represented in the hotspot, as are the subfamilies Allocnemidinae and Disparoneurinae of Platycnemididae. Only three families make up two-thirds of species richness in mainland Africa: Coenagrionidae, Libellulidae, and Gomphidae. The first two have most species in Africa and are even more dominant on Madagascar. The Gomphidae, however, is notably impoverished in Madagascar (Table 7.1). The platycnemidid subfamilies Onychargiinae and Platycnemidinae are, however, respectively absent and less diverse on the continent, while genera placed formerly

Table 7.1 Diversity and endemism of Odonata families in the Madagascar and Indian Ocean islands hotspot.

\begin{tabular}{|c|l|c|c|c|}
\hline \multirow{4}{*}{ Suborder } & Family & $\begin{array}{c}\text { Number of } \\
\text { species }\end{array}$ & $\begin{array}{c}\text { Number of } \\
\text { endemic } \\
\text { species }\end{array}$ & $\begin{array}{c}\% \text { of } \\
\text { endemic } \\
\text { species }\end{array}$ \\
\hline \multirow{5}{*}{ Zygoptera } & Lestidae & 4 & 3 & $75 \%$ \\
\cline { 2 - 5 } & Argiolestidae & 17 & 17 & $100 \%$ \\
\cline { 2 - 5 } & Calopterygidae & 1 & 1 & $100 \%$ \\
\cline { 2 - 5 } & Platycnemididae & 13 & 13 & $100 \%$ \\
\cline { 2 - 5 } & Coenagrionidae & 54 & 45 & $86.7 \%$ \\
\cline { 2 - 5 } & Incertae sedis & 18 & 18 & $100 \%$ \\
\hline \multirow{5}{*}{ Anisoptera } & Aeshnidae & 13 & 8 & $61.5 \%$ \\
\cline { 2 - 5 } & Gomphidae & 10 & 9 & $90 \%$ \\
\cline { 2 - 5 } & Incertae sedis & 7 & 7 & $100 \%$ \\
\cline { 2 - 5 } & Macromiidae & 1 & 1 & $100 \%$ \\
\cline { 2 - 5 } & Corduliidae & 3 & 3 & $100 \%$ \\
\cline { 2 - 5 } & Libellulidae & 66 & 32 & $48.4 \%$ \\
\hline
\end{tabular}

in the Megapodagrionidae (now partly in Argiolestidae) and Corduliidae are also relatively well represented in the hotspot. Indeed, Protolestes and Tatocnemis may even represent endemic but still unrecognised families.

A total of 104 species of damselflies (representing a $93 \%$ of Zygoptera) are endemic, while only $63 \%$ of the 97 species of the generally better-dispersing true dragonflies (Anisoptera) are endemic to the hotspot. About 20\% of Madagascar's endemics have close African relatives and are probably derived from recent arrivals of savannah species, which have good dispersal capacity. Examples of such 'new endemics' are Paragomphus madegassus, Hemistigma affine and Zygonyx elisabethae, which are close relatives of $P$. genei, $H$. albipunctum and $Z$. natalensis respectively. These species occur throughout the island in open, often anthropogenic, habitats. The other endemics have few or no close relatives elsewhere. These 'old endemics' belong to (near) endemic genera and are largely restricted to running waters in rainforest, including the five damselfly radiations Nesolestes, Protolestes, Tatocnemis, Proplatycnemis and Pseudagrion. Wilmé et al. (2006) hypothesise that Madagascar's high levels of micro-endemism are associated with speciation by isolation in lowland watersheds. This model may apply to Odonata with strong ties to forested streams.

\subsection{Patterns of overall species richness}

The Malagasy fauna is notably insular, with about half the species belonging to numerous unrelated African lineages that are widespread but have barely diverged into distinct lineages on and within the island. The rest belong to a few lineages with limited continental affinities that have diversified into numerous localised and specialised species. This dichotomy reflects the finding of Samonds et al. (2012) that few poorly-dispersing freshwater vertebrate groups arrived in Madagascar after the Cretaceous, while only strong fliers reached the island in the past 15 million years.

The fauna's insularity is also reflected in the species' size and behaviour. The Malagasy counterparts of the continental Phaon iridipennis, Chalcostephia flavifrons, Diplacodes lefebvrii, Hemistigma albipunctum, Orthetrum abbotti and probably other species are notably large, suggesting island gigantism. Endemic species like Anax tumorifer and Phyllomacromia trifasciata perch more frequently than their patrolling relatives on the mainland. Indeed, most odonates in Madagascar appear more approachable than in continental Africa.

The Comoro, Mascarene and Seychelles archipelagos have less than 40 species each, of which around a quarter are 


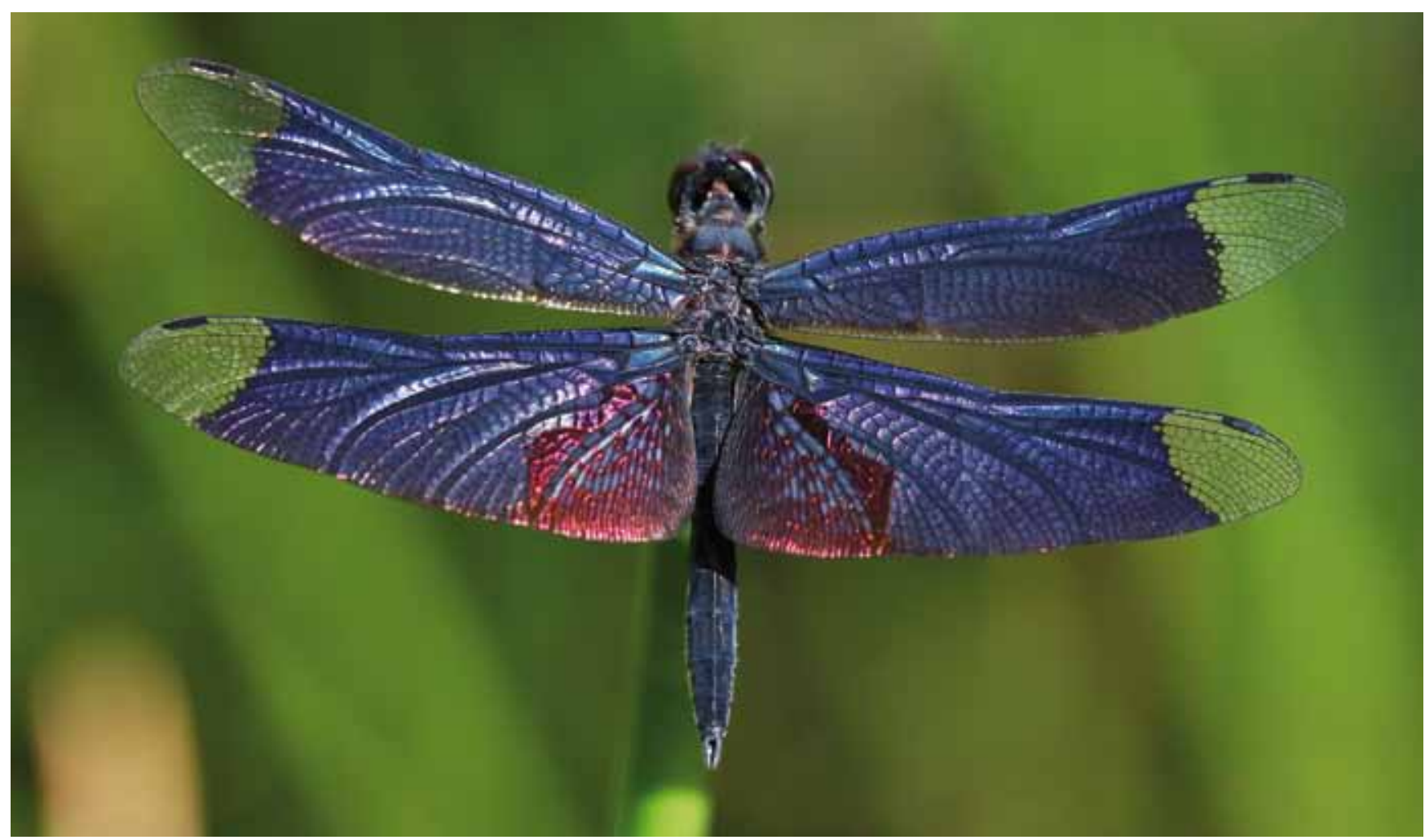

Figure 7.2 Rhyothemis cognata. @ Callan Cohen/www.birdingafrica.com

endemic. Thirty-eight species are now known from the Comoros, of which 36 are from Mayotte, but less than half are found on the other islands. Mayotte is the oldest island, is closest to Madagascar, and is also the most frequently visited. The Comoros fauna is similar to that of Madagascar, as shown by endemic species of Nesolestes, Proplatycnemis, Pseudagrion, Nesocordulia and Thermorthemis (Dijkstra 2004). Most of the 12 species with closer affinities in Madagascar are limited to streams and differ distinctly (Gynacantha comorensis, Orthetrum lugubre, Thermorthemis comorensis, Trithemis maia, new Zygonyx species) from their relatives, sometimes even strongly so (Nesolestes pauliani, Proplatycnemis agrioides, Pseudagrion pontogenes, Nesocordulia villiersi). The remainder are found in continental Africa, favour standing water, and are not distinct. Only Paragomphus genei on the Comoros is distinct being very dark, but it may in fact be more closely related to $P$. madegassus. This dichotomy suggests these volcanic islands were first colonised from Madagascar, while continental African species may only have arrived after humans created disturbed habitats.

The Mascarenes and Seychelles harbour 27 and 19 confirmed species respectively, but have no Malagasy genera, although both island groups each have two endemic genera. However, while Allolestes maclachlani and Leptocnemis cyanops of the granitic Seychelles represent relict genera (i.e. without close relatives elsewhere) surviving on ancient continental fragments, the genera Coenagriocnemis and Thalassothemis of the volcanic
Mascarenes have clear affinities with the well-dispersing mainland genera Aciagrion and Trithemis respectively and are likely more recent arrivals. The Mascarenes and Seychelles share the bispina-group of Gynacantha and the genus Hemicordulia with Madagascar, as does the Seychelles Teinobasis alluaudi. Each of these taxa also occur in eastern Africa, probably arriving relatively recently by transoceanic dispersal from the east (Dijkstra 2007).

Rodrigues has only eight species confirmed, while Mauritius and Réunion have just over 20 species each, their lists of widespread species being almost identical. While the Mascarene endemic Gynacantha bispina inhabits all three islands, the remaining endemics occur on only one. Coenagriocnemis insularis, C. rufipes, Hemicordulia virens and Thalassothemis marchali are highly localised on Mauritius, while Coenagriocnemis ramburi and Ischnura vinsoni have not been observed for 70 years. Only Coenagriocnemis reuniensis and Hemicordulia atrovirens are restricted to Réunion, although its highlands also have isolated populations of the continental Africallagma glaucum and Sympetrum fonscolombii, while Gynacantha stylata and Zygonyx luctiferus are the only endemics confirmed in the Seychelles.

The distribution of endemic Odonata species across Madagascar and the Indian Ocean islands hotspot, for which point locality data were available, is shown in Figure 7.5. Most of these endemic species depend upon forested stream habitats (Figure 7.3), while others are 
found in swamps and rivulets in or near forest sites. The overall species distribution pattern on Madagascar is, however, most likely affected by poor sampling, especially in areas expected to be species rich such as mountain and isolated forests as well as the more inaccessible lowland and highland rainforest sites in eastern and northern Madagascar freshwater eco-regions. Sites with the highest endemism may therefore reflect greater sampling efforts. The smaller Indian Ocean islands are, in most cases, more accessible but additional surveys especially on the Comoro archipelagos are still required to improve our knowledge of patterns and species richness. The need for additional field survey is even more important for clarifying the status of the $45 \%$ of species classified as Data Deficient (DD) from Madagascar.

\subsection{Conservation status}

\subsubsection{Threatened species}

Eight of the 201 species assessed against the IUCN Red List Categories and Criteria in the Madagascar and Indian Ocean islands hotspot are threatened with extinction and only one species was assessed as Near Threatened (NT) (Table 7.2; Figure 7.4; Annex 7.6). Hence, $7 \%$ of all Odonata species in the region are threatened, assuming that the DD species are threatened in the same proportion as those species for which enough information was available. Of these threatened species, four are native to Mauritius, one of which has not been found for more than 70 years on Mauritius but is still present on Rodrigues. Three threatened species are found on the Comoros, one of which is also found on Mayotte, where they are restricted to forests. Three species from Madagascar are threatened and these occur in littoral forests and isolated forest fragments.

Acisoma ascalaphoides Endangered (EN) is endemic to the eastern littoral forests of Madagascar where it is known from only three sites. The two known subpopulations are in the south-eastern and the north-eastern coast. The species

Table 7.2 The number of Odonata species in each Red List Category for the entire hotspot.

\begin{tabular}{|l|l|c|c|}
\hline \multirow{2}{*}{ IUCN Red List Categories } & $\begin{array}{c}\text { No. } \\
\text { Total No. } \\
\text { Species }\end{array}$ & $\begin{array}{c}\text { Nondemic } \\
\text { Species }\end{array}$ \\
\hline \multirow{3}{*}{$\begin{array}{l}\text { Threatened } \\
\text { Categories }\end{array}$} & Critically Endangered (CR) & - & - \\
\cline { 2 - 4 } & Endangered (EN) & 6 & 6 \\
\cline { 2 - 4 } & Vulnerable (VU) & 2 & 2 \\
\hline \multirow{4}{*}{$\begin{array}{l}\text { Other } \\
\text { Categories }\end{array}$} & Near Threatened (NT) & 1 & 1 \\
\cline { 2 - 4 } & Least Concern (LC) & 104 & 55 \\
\cline { 2 - 4 } & Data Deficient (DD) & 88 & 87 \\
\hline \multicolumn{2}{|l|}{ Total number of species assessed } & $\mathbf{2 0 1}$ & $\mathbf{1 5 1}$ \\
\hline
\end{tabular}

Figure 7.3 Most endemic species of Odonata depend on forested stream habitats such as this stream in the Ampasy valley in the Tsitongambarika lowland rainforest. Odonata larvae ("nymphs") feed on a range of freshwater invertebrates and larger ones can prey on tadpoles and small fish. (C) Kai Schütte

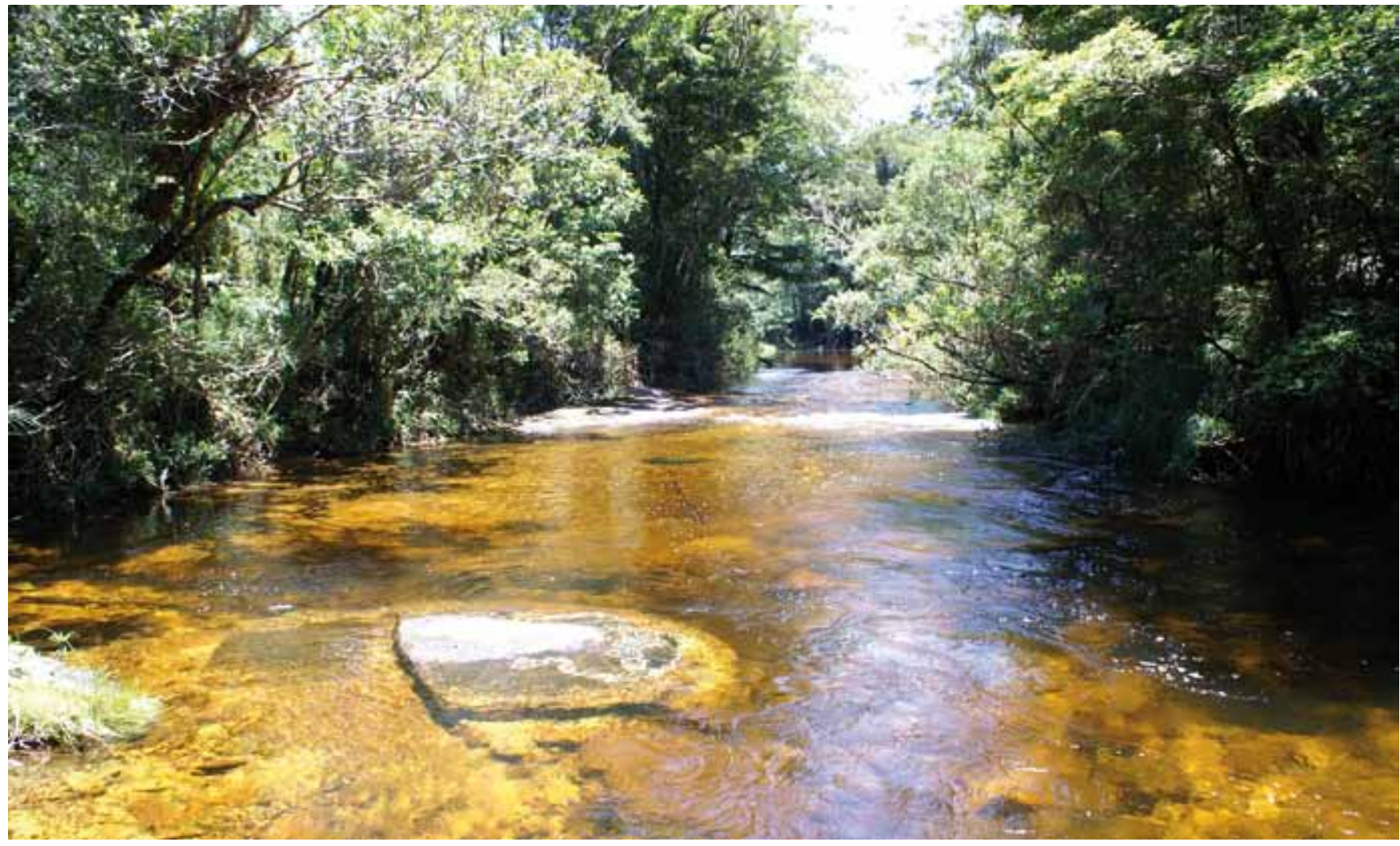


Figure 7.4 The percentage (\%) of Odonata species in each IUCN Red List Category for the entire hotspot.

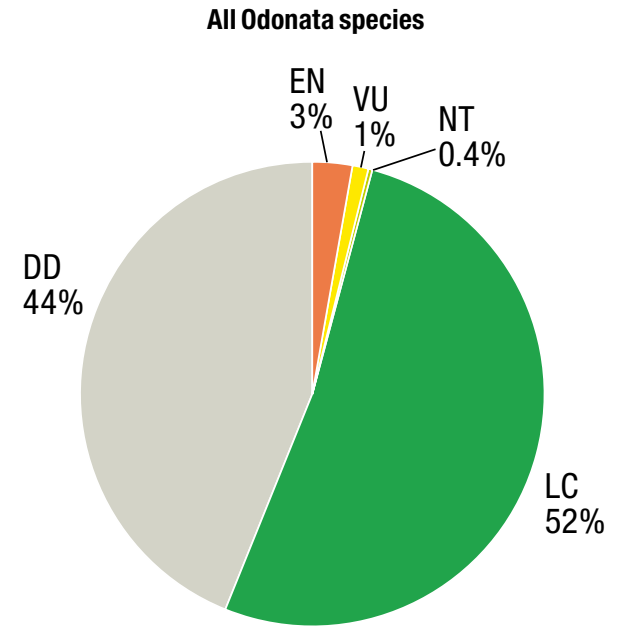

experiences continuing decline in its habitat quality and extent due to ongoing deforestation in the north-east and mining activities in the south-eastern parts of its range (Consiglio et al. 2006). Only the type specimen of Lestes auripennis (EN) is known, collected from south-western Madagascar (Analavelona forest) in 1954. The species is threatened by undergoing deforestation causing a continuing decline in suitable habitat. Nesocordulia villiersi (EN) and Nesolestes pauliani (EN) are endemic to Mwali Island (with a surface area of $290 \mathrm{~km}^{2}$ ) in the Comoros archipelago. Both species are known only from their type localities but some populations may have been overlooked. They both have a restricted range and there is a continuing decline in suitable habitat due to urban pollution and deforestation.

The Mauritian endemic Thalassothemis marchali (EN) is restricted to rocky mountain forest streams and rivers. It is known from just four localities, three of which are situated in the south-eastern mountains (Martens unpublished). A drastic past, present and future decline of suitable habitat is inferred for this species. Coenagriocnemis insularis (EN) and Coenagriocnemis rufipes (EN) are endemic to Mauritius $\left(2,040 \mathrm{~km}^{2}\right)$ where they were recorded recently from just two localities (Martens unpublished data 2001). Suitable habitats for these species are forest patches and gallery forest remnants within sugar cane plantations. The extent and quality of suitable habitat is however undergoing a continuous decline.

Two species are assessed as Vulnerable (VU). Pseudagrion pontogenes (VU) is found on the islands of Mayotte and Ngazidja (Comoros) where it is restricted to forest streams. Suitable habitat continues to decline due to loss and degradation caused by urban pollution and deforestation. Gynacantha bispina (VU) is endemic to the Mascarenes. Recent records are from Réunion and Rodrigues in forest stream habitats (Couteyen and Papazian 2002; Grand 2004; Martens unpublished data). Again, this species is threatened
Endemic Odonata species

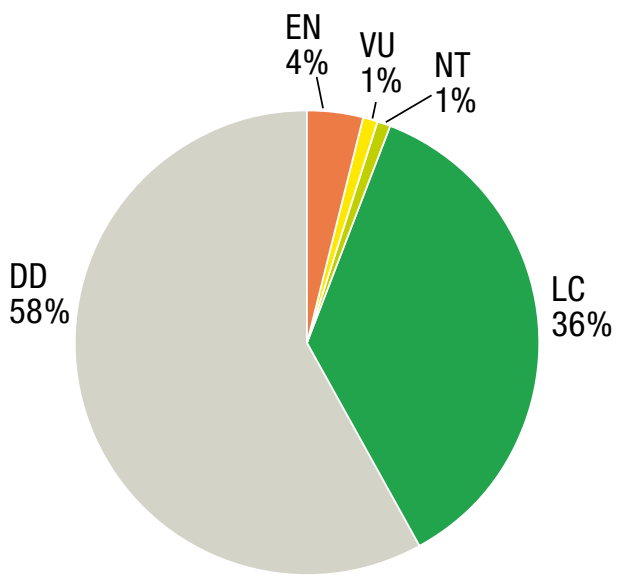

by a continuing decline in the extent and quality of its habitat as deforestation continues across its range.

\subsubsection{Data Deficient species}

Species assessed as DD are those for which the taxonomy remains uncertain or for which there is insufficient information to make a reliable assessment of the species risk of extinction (IUCN 2012). A total of 88 endemic species representing $44 \%$ of Odonata species are classified as DD. The most commonly missing information relates to the distribution of species since many are known from only one or a few specimens or a single collection (type locality). Historical collections frequently contain ambiguous locality information, such that the presence or absence of a species in a particular river system cannot be determined with certainty.

Even allowing for this underrepresentation of species that can't be mapped, the map showing the distribution of DD species (Figure 7.7) highlights areas where major data gaps exist, clearly indicating that data deficiency is a significant concern for Odonata species in the hotspot. Most species rich areas on Madagascar (Figure 7.5) coincide with areas of high data deficiency (Figure 7.7) so further emphasizing the need for additional information to support conservation of these species.

\subsection{Main threats}

\section{Habitat degradation and deforestation}

Transformation of the natural landscape through deforestation, urbanisation and agricultural encroachment, and the subsequent alteration of water bodies by erosion, eutrophication and siltation is the major threat to Odonata in the hotspot (Figure 7.8). These factors have led to the loss of approximately $60 \%$ of wetlands and $37 \%$ of the riparian 
Figure 7.5 The distribution of Odonata species per river/lake sub-catchment across Madagascar and the Indian Ocean islands hotspot.

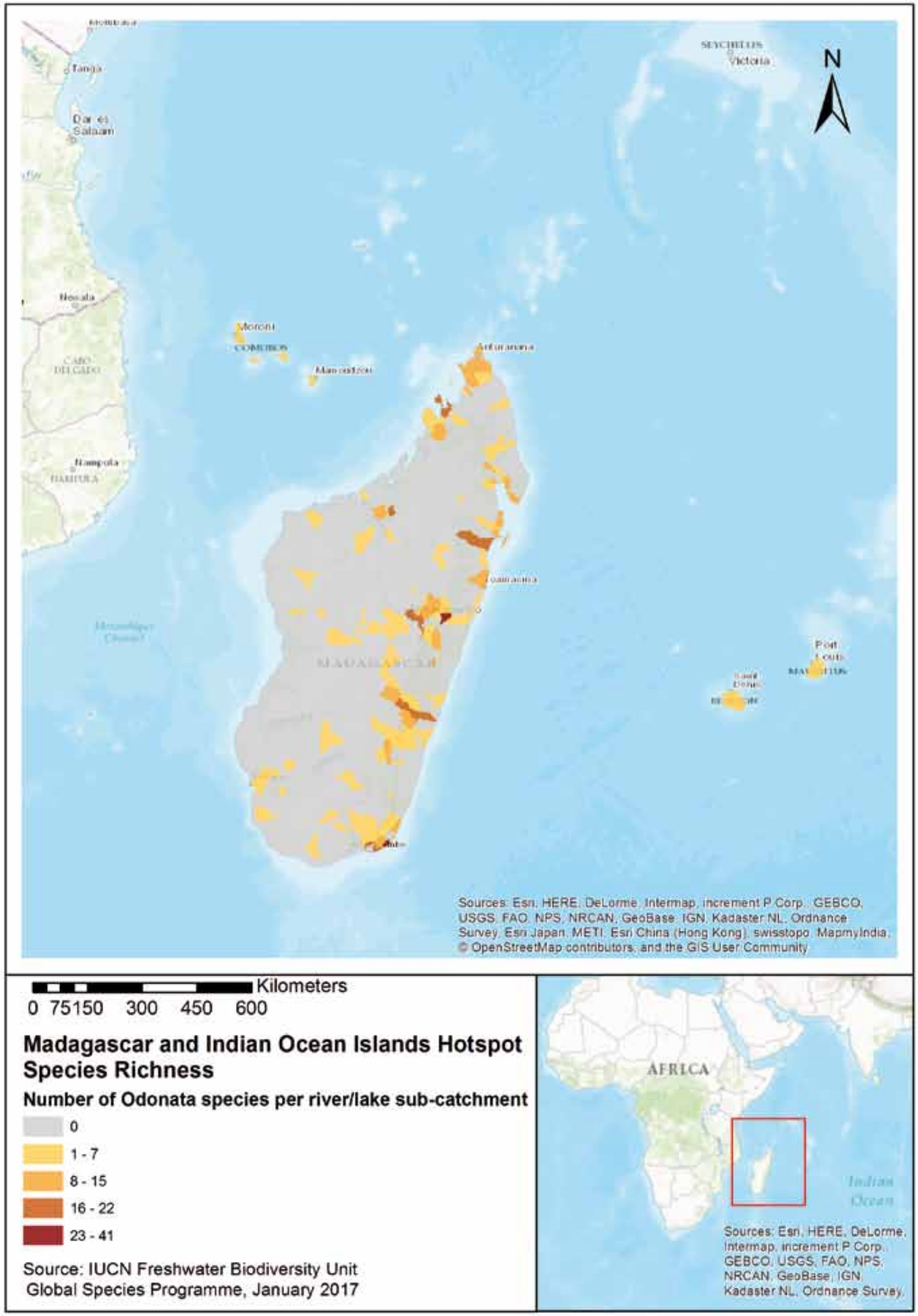


Figure 7.6 The distribution of threatened Odonata species per river/lake sub-catchment across Madagascar and the Indian Ocean islands hotspot.

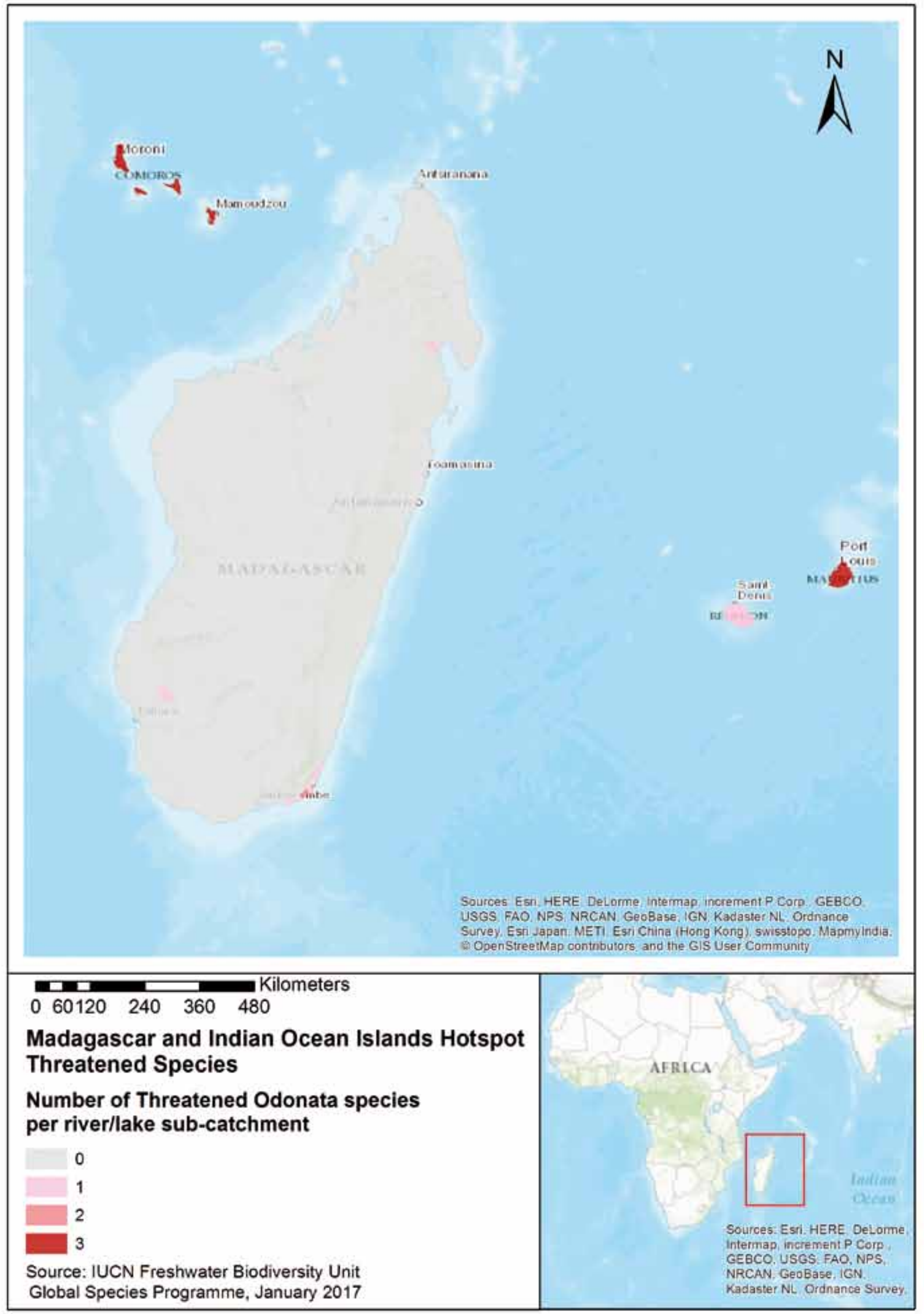


Figure 7.7 Distribution of Data Deficient species of Odonata across Madagascar and the Indian Ocean islands hotspot. The map shows only those species with distribution information that could be mapped.

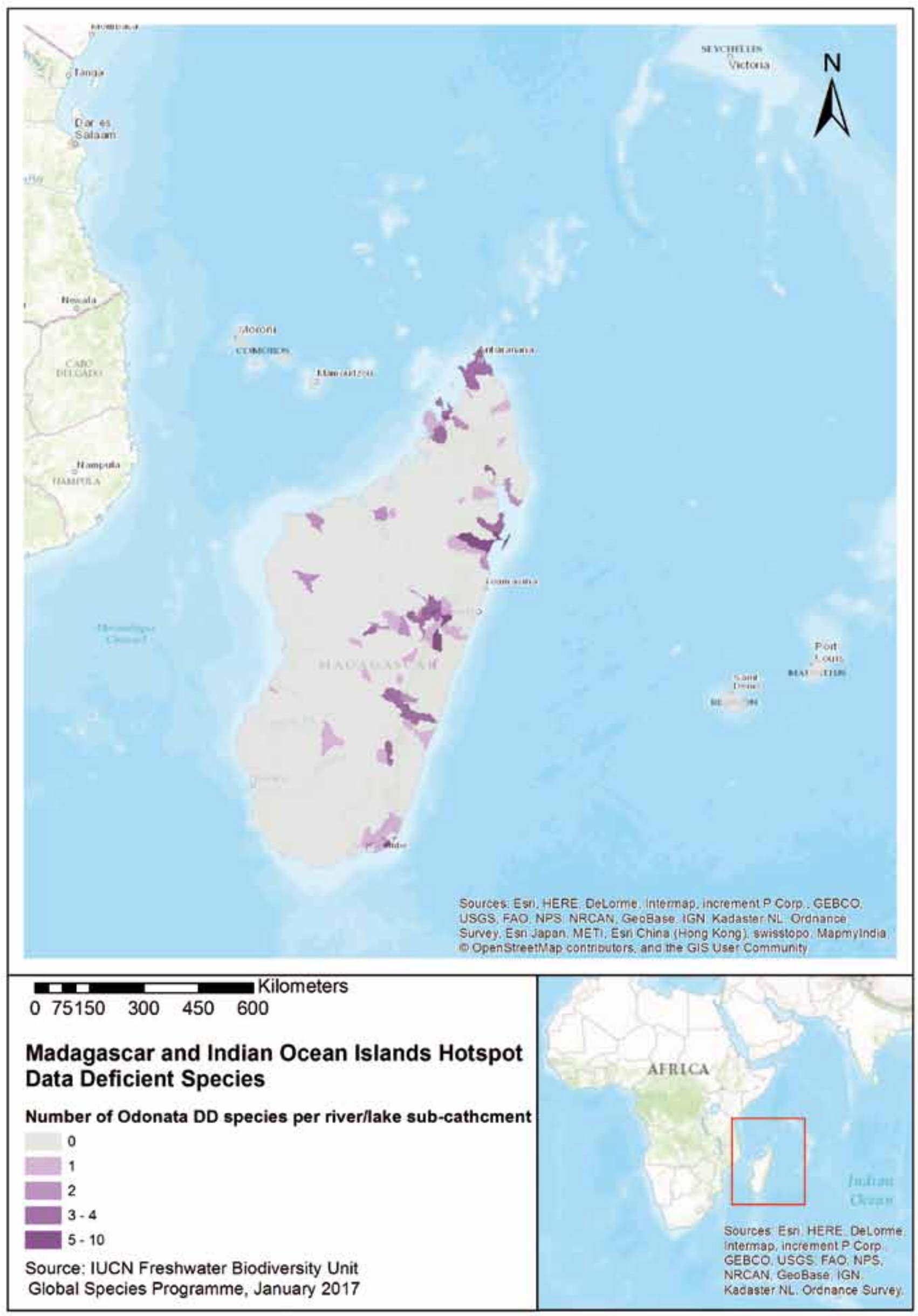


forest in Madagascar (Kull 2012). Most endemic species are restricted to rainforests, and are therefore experiencing continuing population declines due to habitat loss and degradation.

\section{Mining activities}

Mining activities located in the last remaining fragments of coastal forest such as the Rio Tinto/QMM project near Tolagnaro at the south-east tip of Madagascar are causing extensive damage to the landscape and river catchments (Seagle 2011). Mining activities lead to increased turbidity, water pollution and siltation of streams, reducing visibility for larvae and increasing the risk of extinction of threatened species such as Acisoma ascalaphoides (EN).

\section{Water abstraction and pollution}

Over-abstraction of water for human consumption, agriculture irrigation and industry is an increasing concern, particularly considering future climate change scenarios where some regions are predicted to have lower rainfall (USAID 2016). Water abstraction and pollution is most critical in the driest regions of Madagascar as it transforms permanent water bodies into ephemeral or even uninhabitable areas. The impacts may include destruction of larval habitats as well as disruption of established patterns of competition between species (Martens et al. 2010).

\section{Invasive Alien Species}

It is unknown what impact the many alien invasive species of fish and aquatic and terrestrial plant species has on Odonata; this is an area for immediate research. The invasive Asian Common Toad, Duttaphrynus melanostictus, was recently introduced at the east coast near Toamasina (Kolby et al. 2014) and is expected to have a negative impact on the Odonata communities, so its spread needs to be controlled as a matter of urgency. It is also unknown if introduced plants such as Melaleuca trees in swamps or along rivers that replace natural gallery forest (Figure 7.9) are home to

\section{Figure 7.8 Slash and burn agriculture in littoral forest near} Sainte Luce. (C) Kai Schütte

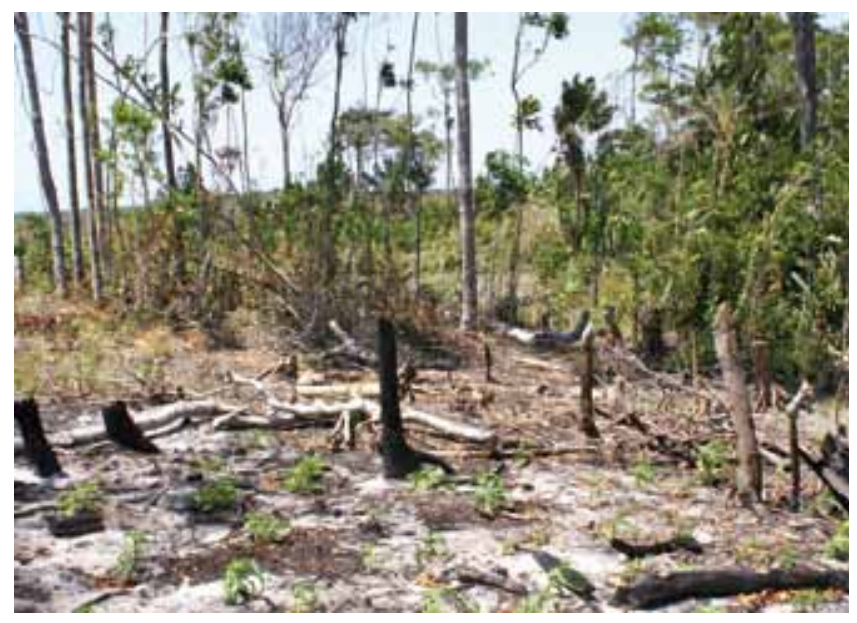

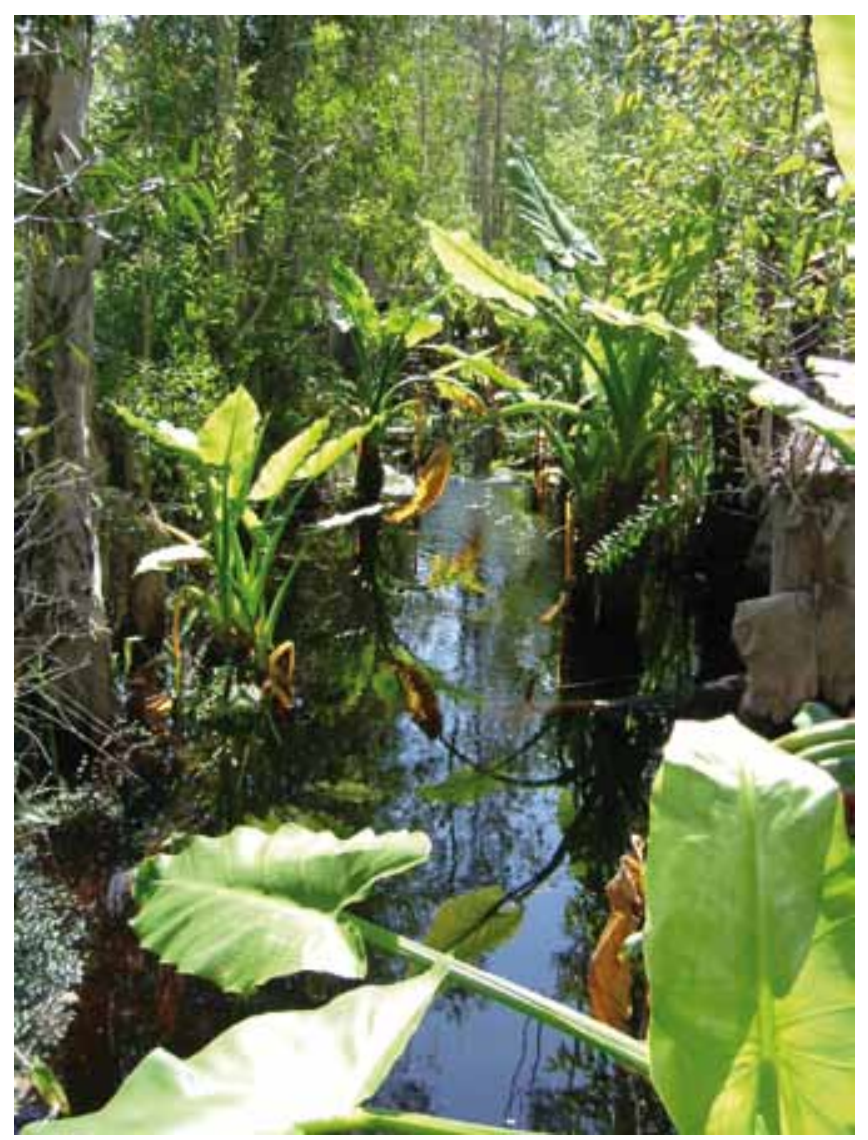

Figure 7.9 Stream densely covered by exotic Melaleuca trees. (c) Kai Schütte.

Odonata species; so further research is needed to clarify the potential impact of these habitat alterations.

\section{Bycatch}

Odonata larvae are occasionally harvested for food in some villages (Randrianandrasana \& Berenbaum 2015) but this is expected to have a much lower impact than the bycatch of Odonata larvae through the use of small mesh mosquito nets by local fishermen.

\subsection{Conservation recommendations}

To conserve Odonata it is necessary to maintain the structural integrity of both larval and adult habitats, which means both the water bodies and their surrounding landscapes. In particular, the protection of Madagascar's forests is crucial for the survival of its unique Odonata fauna. Connection of forest fragments through creation of forest corridors to form larger networks will benefit much of biodiversity such as Odonata where subpopulations may already have become isolated (Dijkstra \& Clausnitzer 2004). Large-scale mining developments and plantations should also be required to leave broad buffer zones of natural vegetation around water bodies in order to protect sub-catchments. Riparian forest removal should be avoided as many freshwater organisms, including Odonata, require shade in their adult stages. 


\subsection{Species in the spotlight}

\section{The Littoral Pintail rediscovered at one of the hottest hotspots on Madagascar}

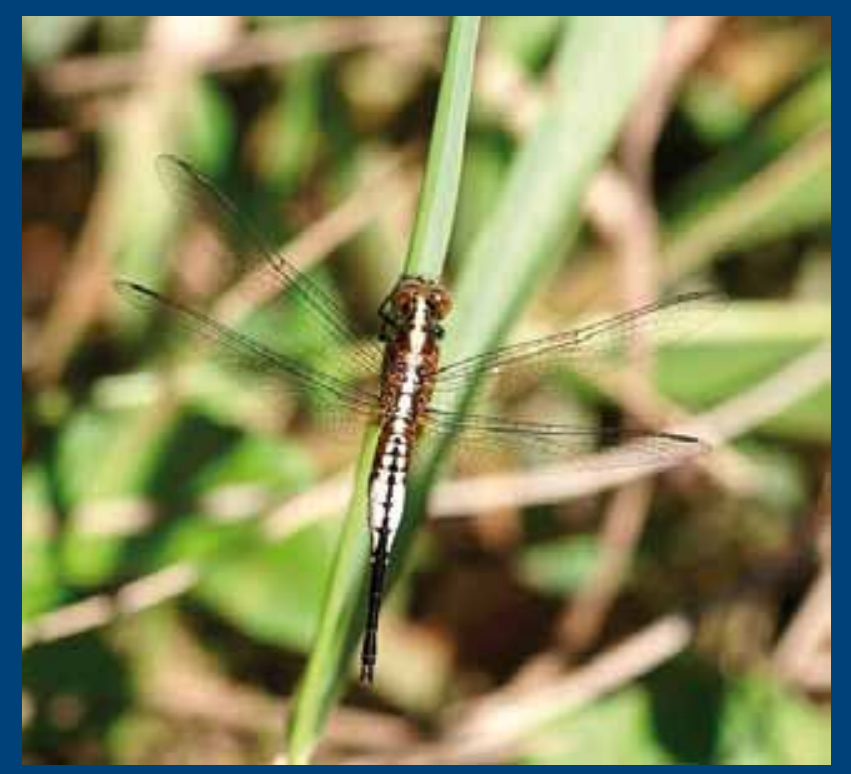

Figure 7.10 Acisoma ascalaphoides. @ Kai Schütte

Described as one of the first dragonflies from Madagascar, the Littoral Pintail Acisoma ascalaphoides (Rambur 1842) was originally misidentified in terms of its type locality and Red List status, until it was rediscovered in 2004 in and around the littoral forest fragments of Mandena and Sainte Luce in south-eastern Madagascar (Mens et al. 2016).

The distinct colour patterns of males and females with a ventrally largely brown head and thorax and a completely dark abdomen with distinct dorsally white markings from segments S3 to S6 make the species unmistakable. The larvae of Littoral Pintail are probably adapted to the more acidic waters of coastal habitats, however the species specific biology and habitat preferences remain unknown. The second known species population is found in Voloina, north-eastern Madagascar, where the latest samples were collected in 1971 and deposited in the Natural History Museum in Paris. The distance between the two known localities from the northern to the south-eastern coast is about $1,000 \mathrm{~km}$. There might be populations between the two distinct localities, but further field surveys are urgently needed to confirm this as well as research on the currently known populations and their trends.

Mandena is covered by the new protected area network of Madagascar and at least one of the forest fragments in Sainte Luce belongs to a Rio Tinto-QMM mining offset conservation site near Fort-Dauphin. However, it is recommended that the species populations at these sites are closely monitored and taken into account in future mining and forestry developments in the area. Littoral forests of eastern Madagascar have been reduced by over $80 \%$ of their original cover and the few remaining patches critical for the survival of the species are very likely to disappear if immediate protection is not granted.

Given the species restricted range and the continuing decline in its habitat quality and extent due to ongoing deforestation in the north and mining activities in the south it has been assessed as Endangered (EN) and protection of its natural habitat is urgently needed.
Environmental Impact Assessments and future species action plans should take note of the new information presented here on the distributions of Odonata. In particular, those species that are now known to be threatened.

Finally, invasive alien species should be controlled and removed where possible as the impacts to Odonata are yet to be understood.

\subsection{Research actions}

The priority focus for research is to learn more about the distributions of species, and their current status and ecological requirements. Despite the assessment of 201 Odonata species a high proportion are classified as DD, so highlighting the need to learn more about these species if we are to effectively inform conservation actions. The lack of information, combined with high apparent levels of threat, are a major concern for these islands (e.g. Samways, 2003a,b; Clausnitzer \& Martens 2004) and further research and monitoring are urgently needed.

Priority regions for field survey are those with high numbers of DD species (e.g. along the east coast, in the region of Tsitongambarika and Andohahela; the Makira catchment including Masoala, Analamazaotra, Analavelona; as well as the Sambirano and Antsiranana region and isolated mountain areas). It is also important to learn more about Odonata within existing conservation areas so that management actions can be implemented to benefit freshwater species, including Odonata, that are rarely the focus of existing management plans.

Finally, Odonata can serve as reliable indicators of habitat quality and they are potentially useful for monitoring the 


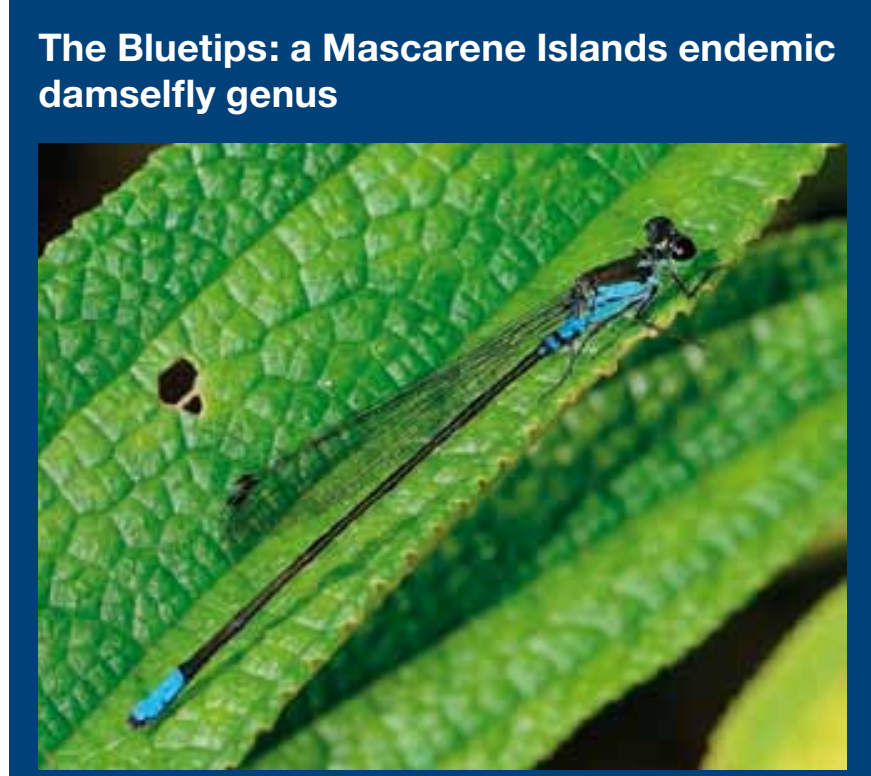

Figure 7.11 Coenagriocnemis reuniensis. () Michel Yerokine

While their relatives in Africa, Asia and Madagascar are mostly widespread and similar-looking blue species (e.g. in the genera Aciagrion and Azuragrion) of standing and often temporary and exposed waters, the endemic genus Coenagriocnemis in the Mascarenes is a typical island radiation of more colourful species restricted to rocky streams and rivers within forest. Unlike most damselfly species, females are not guarded by males when laying eggs, perhaps because of the reduced predator pressure often found on islands.

The Orange-legged Bluetip Coenagriocnemis rufipes is the most abundant damselfly at such habitats on Mauritius. However, the extent and quality of these sites is declining due to agricultural expansion, making remaining populations increasingly sensitive to random events such as cyclone impacts. The species is therefore considered Endangered (EN). Males perch near the water, often on rocks, where they display their orange face and legs in contests. The Black-legged Bluetip C. insularis is also confined to Mauritius and considered EN, where it is limited to eight catchments (Andreas Martens, unpublished data 2001). Half its sites are in isolated forest patches or gallery forest remnants within sugar cane plantations. Males perch mostly at breast height on vegetation and are less aggressive, with black legs and a green face. Rambur's Bluetip C. ramburi is known only from two males collected on the island in 1947 but was never seen again and may have been a hybrid between $C$. insularis and $C$. rufipes and was therefore assessed as Data Deficient.

The Réunion Bluetip C. reuniensis replaces $C$. insularis on Réunion. Water levels on that island fluctuate greatly, with seasonal torrents leaving riverbeds devoid of vegetation or dead wood. Therefore, males perch on rocks and females lay eggs in porous volcanic material, unlike the Mauritian species that prefer plant tissue (Martens 2001). Living among the rocks, the larvae are vulnerable to introduced Rainbow Trout (Salmo gairdneri) (Couteyen 2006a). Nonetheless, the species is not yet considered threatened, being widespread on the island, occurring regularly up to $1,500 \mathrm{~m}$ above sea level. Indeed, Réunion's greater overall altitude helps explain why this species is not as threatened as its congeners on Mauritius, which is largely below $600 \mathrm{~m}$ in elevation. Interestingly, highland adults of $C$. reuniensis can be up to a quarter as long as ones at sea level (Couteyen 2006b). overall status of freshwater across Madagascar and the Indian Ocean islands hotspot. In order to use dragonflies as a habitat quality indicator further research is needed from basic inventories and systematic work to studies on ecology, biogeography and conservation needs.

\subsection{References}

Clausnitzer, V. and Martens, A. 2004. Critical species of Odonata in the Comoros, Seychelles, Mascarenes and other small western Indian Ocean islands. International Journal of Odonatology 7: 207-218. https://doi.org/10.1 080/13887890.2004.9748210

Consiglio, T., Schatz, G.E., McPherson, G., Lowry II, P.P., Rabenantoandro, J., Rogers, Z.S., Rabevohitra, R. and Rabehevitra, D. 2006. Deforestation and plant diversity of Madagascar's littoral forests. Conservation
Biology 20: 1799-1803. https://doi.org/10.1111/j.15231739.2006.00562.x

Couteyen, S. and Papazian, M. 2002. Les Odonates de la Réunion. Eléments de biogéographie et de biologie, atlas préliminaire, réconnaissance des espèces, synthèse bibliographique. Martinia 18: 79-106.

Couteyen, S. 2006a. Effets de l'introduction de la truite arcen-ciel (Oncorhynchus mykiss Walbaum, 1792) sur les populations larvaires de deux espèces de Zygoptères de l'île de la Réunion. Martinia 22: 55-63.

Couteyen, S. 2006b. Evolution de la taille de Coenagriocnemis reuniensis Fraser, 1957, en fonction de l'altitude à l'ile de la Réunion (Odonata, Coenagrionidae). Bulletin de la Société entomologique de France 111: 439-444.

Samonds, K.E., Godfrey, L.R. and Ali, J.R. et al. 2012. Spatial and temporal arrival patterns of Madagascar's vertebrate fauna explained by distance, ocean currents, and ancestor type. Proceedings of the National Academy of Sciences of 
the United States of America 109 (14):5352-5357. https:// doi.org/10.1073/pnas.1113993109

Darwall, W.R.T., Holland, R.A., Smith, K.G., Allen, D.J., Brooks, E.G.E., Katarya, V., Pollock, C.M., Shi, Y., Clausnitzer, V., Cumberlidge, N., Cuttelod, A., Dijkstra, K.-D. B., Diop, M.D., García, N., Seddon, M.B., Skelton, P.H., Snoeks, J., Tweddle, D. and Vié, J.-C. 2011. Implications of bias in conservation research and investment for freshwater species. Conservation Letters 4: 474-482. https://doi. org/10.1111/j.1755-263X.2011.00202.x

Dijkstra, K.-D.B. and Clausnitzer, V. 2004. Critical species of Odonata on Madagascar. Int. Journal of Odonatology 7: 219-228. https://doi.org/10.1080/13887890.2004.97 48211 https://doi.org/10.1080/13887890.2004.9748212

Dijkstra, K.D.B. 2004. Odonates. In: M. Louette, D. Meirte and R. Jocqué (eds.). La faune terrestre de l'archipel des Comores, Studies in Afrotropical Zoology 293: 251-252.

Dijkstra, K.D.B. 2007. Gone with the wind: westward dispersal across the Indian Ocean and island speciation in Hemicordulia dragonflies (Odonata: Corduliidae). Zootaxa 1438: 27-48. https://doi.org/10.11646/zootaxa.1438.1.2

Dijkstra, K.D.B. and C. Cohen (submitted). Dragonflies and Damselflies of Madagascar and the Indian Ocean Islands. Fondation Vahatra, Antananarivo.

Grand, D. 2004. Compte rendu odonatologique d'un voyage à l'île de la Réunion. Martinia 20: 67-75.

Harper, G.J., Steininger, M.K., Tucker, C.J., Juhn, D. and Hawkins, F. 2007. Fifty years of deforestation and forest fragmentation on Madagascar. Environmental Conservation 34: 325-333. https://doi.org/10.1017/S0376892907004262 IUCN. 2012. IUCN Red List Categories and Criteria: Version 3.1. Second edition. Gland, Switzerland and Cambridge, UK: IUCN. iv+32p.

Kalkman, V.J., Clausnitzer, V., Dijkstra, K.-D.B., Orr, A.G., Paulson, D.R. and van Tol, J. 2008. Global diversity of dragonflies (Odonata; Insecta) in freshwater. Hydrobiologia 595:351-363. https://doi.org/10.1007/s10750-007-9029-x Kolby, J.E. 2014. Ecology: stop Madagascar's toad invasion now. Nature 509:563-563. https://doi.org/10.1038/509563a

Kull, C.A 2012. Air photo evidence of historical land cover change in the highlands: wetlands and grasslands give way to crops and woodlots. Madagascar Conservation and Development 7(3): 144-152.
Martens, A., Richter, O. and Suhling, F. 2010. The relevance of perennial springs for regional biodiversity conservation: In: U. Schmiedel and N. Jürgens (eds.), Biodiversity in Southern Africa 2: Patterns and processes at regional scale. Klaus Hess Publishers, Gottingen and Windhoek. pp70-74.

Samways, M.J. 2003a. Conservation of an endemic odonate fauna in the Seychelles archipelago. Odonatologica 32(2): 177-182. https://doi.org/10.1023/A:1024120505611

Martens, A. 2001. Oviposition of Coenagriocnemis reuniensis (Fraser) in volcanic rock as an adaptation to an extreme running water habitat (Zygoptera: Coenagrionidae). Odonatologica 30: 103-109.

Mens, L.P., Schütte, K., Stokvis, F.R. and Dijkstra, K.D.B. 2016. Six, not two, species of Acisoma pintail dragonfly (Odonata: Libellulidae). Zootaxa 4109: 153-172. https:// doi.org/10.11646/zootaxa.4109.2.3

Randrianandrasana and Berenbaum 2015. Edible NonCrustacean Arthropods in Rural Communities of Madagascar. Journal of Ethobiology 35(2): 354-383.

Samonds, K.E., Godfrey, L.R., Ali, J.R., Goodman, S.M., Vences, M., Sutherland, M.R., Irwin, M.T. and Krause, DW. 2012. Spatial and temporal arrival patterns of Madagascar's vertebrate fauna explained by distance, ocean currents, and ancestor type. PNAS. April 3; 109(14): 5352-5357.

Samways, M.J. 2003a. Conservation of an endemic odonate fauna in the Seychelles archipelago. Odonatologica 32(2): 177-182. https://doi.org/10.1023/A:1024120505611 https://doi.org/10.1023/A:1025840000200

Samways, M.J. 2003b. Threats to the tropical island dragonfly fauna (Odonata) of Mayotte, Comoro archipelago. Biodiversity and Conservation 12: 1785-1792.

Seagle, C. 2011. The mining-conservation nexus: Rio Tinto, development gifts and contested compensation in Madagascar. The Land Deal Politics Initiative. LDPI Working Paper.

USAID. 2016. Climate Change Risk Profile: Madagascar Fact Sheet. Available at: http://pdf.usaid.gov/pdf_docs/ pa00mtz8.pdf

Wilmé, L., Goodman, S.M. and Ganzhorn, J. 2006. Biogeographic evolution of Madagascar's micro-endemic biota. Science 312: 1063-1065. https://doi.org/10.1126/ science. 1122806 
Annex 7.1 Red List status of Odonata species from Madagascar and the Indian Ocean islands hotspot.

\begin{tabular}{|c|c|c|c|}
\hline Family & Species name & $\begin{array}{l}\text { Red List } \\
\text { Category }\end{array}$ & $\begin{array}{c}\begin{array}{c}\text { Endemic } \\
\text { to the } \\
\text { hotspot }\end{array} \\
\end{array}$ \\
\hline ARGIOLESTIDAE & Nesolestes pauliani & EN & Yes \\
\hline NOT ASSIGNED & Nesocordulia villiersi & EN & Yes \\
\hline LIBELLULIDAE & Thalassothemis marchali & EN & Yes \\
\hline COENAGRIONIDAE & Coenagriocnemis rufipes & EN & Yes \\
\hline COENAGRIONIDAE & Coenagriocnemis insularis & EN & Yes \\
\hline LESTIDAE & Lestes auripennis & EN & Yes \\
\hline COENAGRIONIDAE & Pseudagrion pontogenes & VU & Yes \\
\hline AESHNIDAE & Gynacantha bispina & VU & Yes \\
\hline PLATYCNEMIDIDAE & Proplatycnemis agrioides & NT & Yes \\
\hline COENAGRIONIDAE & Pseudagrion mohelii & $\mathrm{DD}$ & No \\
\hline GOMPHIDAE & Isomma robinsoni & $\mathrm{DD}$ & Yes \\
\hline COENAGRIONIDAE & Pseudagrion ambatoroae & $\mathrm{DD}$ & Yes \\
\hline LIBELLULIDAE & Neodythemis pauliani & $\mathrm{DD}$ & Yes \\
\hline COENAGRIONIDAE & Pseudagrion macrolucidum & DD & Yes \\
\hline COENAGRIONIDAE & Pseudagrion olsufieffi & $\mathrm{DD}$ & Yes \\
\hline COENAGRIONIDAE & Pseudagrion chloroceps & DD & Yes \\
\hline COENAGRIONIDAE & Pseudagrion mellisi & $\mathrm{DD}$ & Yes \\
\hline COENAGRIONIDAE & Coenagriocnemis ramburi & DD & Yes \\
\hline COENAGRIONIDAE & Pseudagrion simile & $\mathrm{DD}$ & Yes \\
\hline COENAGRIONIDAE & Pseudagrion pterauratum & $\mathrm{DD}$ & Yes \\
\hline COENAGRIONIDAE & Pseudagrion ungulatum & DD & Yes \\
\hline COENAGRIONIDAE & Millotagrion inaequistigma & $\mathrm{DD}$ & Yes \\
\hline COENAGRIONIDAE & Pseudagrion trigonale & $\mathrm{DD}$ & Yes \\
\hline COENAGRIONIDAE & Pseudagrion giganteum & DD & Yes \\
\hline GOMPHIDAE & Paragomphus z-viridum & $\mathrm{DD}$ & Yes \\
\hline COENAGRIONIDAE & Ischnura vinsoni & $\mathrm{DD}$ & Yes \\
\hline COENAGRIONIDAE & Pseudagrion merina & DD & Yes \\
\hline LIBELLULIDAE & $\begin{array}{l}\text { Malgassophlebia } \\
\text { mediodentata }\end{array}$ & $\mathrm{DD}$ & Yes \\
\hline COENAGRIONIDAE & Agriocnemis merina & $\mathrm{DD}$ & Yes \\
\hline LIBELLULIDAE & Neodythemis trinervulata & $\mathrm{DD}$ & Yes \\
\hline LIBELLULIDAE & Zygonyx luctifera & $\mathrm{DD}$ & Yes \\
\hline COENAGRIONIDAE & Pseudagrion stuckenbergi & DD & Yes \\
\hline COENAGRIONIDAE & Pseudagrion lucidum & $\mathrm{DD}$ & Yes \\
\hline LIBELLULIDAE & Zygonyx hova & $\mathrm{DD}$ & Yes \\
\hline LIBELLULIDAE & Malgassophlebia mayanga & $\mathrm{DD}$ & Yes \\
\hline PLATYCNEMIDIDAE & $\begin{array}{l}\text { Proplatycnemis } \\
\text { protostictoides }\end{array}$ & $\mathrm{DD}$ & Yes \\
\hline NOT ASSIGNED & $\begin{array}{l}\text { Tatocnemis } \\
\text { micromalgassica }\end{array}$ & $\mathrm{DD}$ & Yes \\
\hline PLATYCNEMIDIDAE & Proplatycnemis longiventris & DD & Yes \\
\hline PLATYCNEMIDIDAE & Proplatycnemis aurantipes & $\mathrm{DD}$ & Yes \\
\hline ARGIOLESTIDAE & Nesolestes pulverulans & $\mathrm{DD}$ & Yes \\
\hline ARGIOLESTIDAE & Nesolestes mariae & $\mathrm{DD}$ & Yes \\
\hline COENAGRIONIDAE & Pseudagrion cheliferum & $\mathrm{DD}$ & Yes \\
\hline NOT ASSIGNED & Nesocordulia flavicauda & $\mathrm{DD}$ & Yes \\
\hline ARGIOLESTIDAE & Nesolestes elizabethae & DD & Yes \\
\hline NOT ASSIGNED & Tatocnemis robinsoni & $\mathrm{DD}$ & Yes \\
\hline COENAGRIONIDAE & Pseudagrion hamulus & DD & Yes \\
\hline GOMPHIDAE & Onychogomphus vadoni & DD & Yes \\
\hline NOT ASSIGNED & Tatocnemis virginiae & $\mathrm{DD}$ & Yes \\
\hline ARGIOLESTIDAE & Nesolestes tuberculicollis & $\mathrm{DD}$ & Yes \\
\hline NOT ASSIGNED & Protolestes kerckhoffae & $\mathrm{DD}$ & Yes \\
\hline
\end{tabular}

\begin{tabular}{|c|c|c|c|}
\hline Family & Species name & $\begin{array}{l}\text { Red List } \\
\text { Category }\end{array}$ & $\begin{array}{c}\text { Endemic } \\
\text { to the } \\
\text { hotspot }\end{array}$ \\
\hline LIBELLULIDAE & Zygonyx ranavalonae & $\mathrm{DD}$ & Yes \\
\hline AESHNIDAE & Gynacantha malgassica & DD & Yes \\
\hline NOT ASSIGNED & Libellulosoma minuta & $\mathrm{DD}$ & Yes \\
\hline COENAGRIONIDAE & Pseudagrion nigripes & $\mathrm{DD}$ & Yes \\
\hline ARGIOLESTIDAE & Nesolestes forficuloides & $\mathrm{DD}$ & Yes \\
\hline COENAGRIONIDAE & Pseudagrion tinctipenne & $\mathrm{DD}$ & Yes \\
\hline NOT ASSIGNED & Tatocnemis olsufieffi & DD & Yes \\
\hline COENAGRIONIDAE & Pseudagrion deconcertans & $\mathrm{DD}$ & Yes \\
\hline LESTIDAE & Lestes silvaticus & $\mathrm{DD}$ & Yes \\
\hline NOT ASSIGNED & Protolestes furcatus & DD & Yes \\
\hline ARGIOLESTIDAE & Nesolestes robustus & $\mathrm{DD}$ & Yes \\
\hline NOT ASSIGNED & Nesocordulia mascarenica & $\mathrm{DD}$ & Yes \\
\hline PLATYCNEMIDIDAE & Paracnemis secundaris & DD & Yes \\
\hline ARGIOLESTIDAE & Nesolestes drocera & $\mathrm{DD}$ & Yes \\
\hline GOMPHIDAE & Isomma elouardi & $\mathrm{DD}$ & Yes \\
\hline AESHNIDAE & Anax mandrakae & DD & Yes \\
\hline ARGIOLESTIDAE & Nesolestes radama & DD & Yes \\
\hline COENAGRIONIDAE & Pseudagrion renaudi & $\mathrm{DD}$ & Yes \\
\hline NOT ASSIGNED & Nesocordulia malgassica & DD & Yes \\
\hline COENAGRIONIDAE & Pseudagrion vakoanae & $\mathrm{DD}$ & Yes \\
\hline COENAGRIONIDAE & Ceriagrion madagazureum & $\mathrm{DD}$ & Yes \\
\hline ARGIOLESTIDAE & Nesolestes ranavalona & $\mathrm{DD}$ & Yes \\
\hline LIBELLULIDAE & Crocothemis striata & DD & Yes \\
\hline AESHNIDAE & Gynacantha hova & DD & Yes \\
\hline NOT ASSIGNED & Nesocordulia rubricauda & DD & Yes \\
\hline NOT ASSIGNED & Nesocordulia spinicauda & $\mathrm{DD}$ & Yes \\
\hline NOT ASSIGNED & Tatocnemis sinuatipennis & $\mathrm{DD}$ & Yes \\
\hline NOT ASSIGNED & Tatocnemis mellisi & $\mathrm{DD}$ & Yes \\
\hline PLATYCNEMIDIDAE & Proplatycnemis melana & DD & Yes \\
\hline NOT ASSIGNED & Tatocnemis denticularis & DD & Yes \\
\hline ARGIOLESTIDAE & Nesolestes albicauda & DD & Yes \\
\hline NOT ASSIGNED & Protolestes milloti & $\mathrm{DD}$ & Yes \\
\hline PLATYCNEMIDIDAE & Leptocnemis cyanops & $\mathrm{DD}$ & Yes \\
\hline ARGIOLESTIDAE & Nesolestes albicolor & DD & Yes \\
\hline NOT ASSIGNED & Protolestes proselytus & DD & Yes \\
\hline ARGIOLESTIDAE & Nesolestes rubristigma & $\mathrm{DD}$ & Yes \\
\hline NOT ASSIGNED & \begin{tabular}{|l|} 
Tatocnemis \\
emarginatipennis
\end{tabular} & DD & Yes \\
\hline NOT ASSIGNED & Protolestes simonei & $\mathrm{DD}$ & Yes \\
\hline NOT ASSIGNED & Protolestes rufescens & $\mathrm{DD}$ & Yes \\
\hline ARGIOLESTIDAE & Nesolestes alboterminatus & DD & Yes \\
\hline ARGIOLESTIDAE & Nesolestes angydna & DD & Yes \\
\hline NOT ASSIGNED & Protolestes leonorae & DD & Yes \\
\hline COENAGRIONIDAE & Ceriagrion oblongulum & DD & Yes \\
\hline LIBELLULIDAE & Neodythemis arnoulti & $\mathrm{DD}$ & Yes \\
\hline CORDULIIDAE & Hemicordulia atrovirens & DD & Yes \\
\hline NOT ASSIGNED & Tatocnemis crenulatipennis & $\mathrm{DD}$ & Yes \\
\hline COENAGRIONIDAE & Pseudagrion ampolomitae & $\mathrm{DD}$ & Yes \\
\hline COENAGRIONIDAE & Pseudagrion divaricatum & LC & Yes \\
\hline LIBELLULIDAE & Aethiothemis modesta & $\mathrm{LC}$ & Yes \\
\hline COENAGRIONIDAE & Pseudagrion approximatum & $\mathrm{LC}$ & Yes \\
\hline COENAGRIONIDAE & Ceriagrion auritum & LC & Yes \\
\hline
\end{tabular}


Annex 7.1 cont'd. Red List status of Odonata species from Madagascar and the Indian 0cean islands hotspot.

\begin{tabular}{|c|c|c|c|c|c|c|c|}
\hline Family & Species name & $\begin{array}{l}\text { Red List } \\
\text { Category }\end{array}$ & $\begin{array}{c}\text { Endemic } \\
\text { to the } \\
\text { hotspot }\end{array}$ & Family & Species name & $\begin{array}{l}\text { Red List } \\
\text { Category }\end{array}$ & $\begin{array}{l}\text { Endemic } \\
\text { to the } \\
\text { hotspot }\end{array}$ \\
\hline GOMPHIDAE & Paragomphus madegassus & LC & Yes & NOT ASSIGNED & Protolestes fickei & LC & Yes \\
\hline COENAGRIONIDAE & Pseudagrion punctum & LC & Yes & AESHNIDAE & Anax tumorifer & LC & Yes \\
\hline LIBELLULIDAE & Diplacodes exilis & LC & Yes & AESHNIDAE & Anaciaeshna triangulifera & LC & No \\
\hline LIBELLULIDAE & Crocothemis sanguinolenta & $\mathrm{LC}$ & No & AESHNIDAE & Anax ephippiger & LC & No \\
\hline COENAGRIONIDAE & Pseudagrion dispar & LC & Yes & AESHNIDAE & Anax guttatus & LC & No \\
\hline COENAGRIONIDAE & Pseudagrion malgassicum & LC & Yes & AESHNIDAE & Anax imperator & $\mathrm{LC}$ & No \\
\hline LIBELLULIDAE & Rhyothemis cognata & LC & Yes & AESHNIDAE & Anax tristis & LC & No \\
\hline LIBELLULIDAE & Trithemis persephone & LC & Yes & COENAGRIONIDAE & Pseudagrion igniceps & LC & Yes \\
\hline LIBELLULIDAE & Zygonyx elisabethae & LC & Yes & COENAGRIONIDAE & Agriocnemis exilis & LC & No \\
\hline LIBELLULIDAE & Trithemis furva & LC & No & COENAGRIONIDAE & Agriocnemis gratiosa & $\mathrm{LC}$ & No \\
\hline LIBELLULIDAE & Trithemis hectae & LC & No & COENAGRIONIDAE & Ceriagrion glabrum & LC & No \\
\hline LIBELLULIDAE & Trithemis stictica & LC & No & COENAGRIONIDAE & Ischnura senegalensis & LC & No \\
\hline COENAGRIONIDAE & Azuragrion kauderni & LC & Yes & COENAGRIONIDAE & Teinobasis alluaudi & LC & No \\
\hline LIBELLULIDAE & Orthetrum lemur & LC & Yes & CORDULIIDAE & Hemicordulia virens & LC & Yes \\
\hline COENAGRIONIDAE & Pseudagrion seyrigi & LC & Yes & LIBELLULIDAE & Calophlebia karschi & LC & Yes \\
\hline LIBELLULIDAE & Acisoma attenboroughi & LC & Yes & LESTIDAE & Lestes ochraceus & LC & No \\
\hline GOMPHIDAE & Paragomphus fritillarius & LC & Yes & GOMPHIDAE & Paragomphus obliteratus & LC & Yes \\
\hline GOMPHIDAE & Isomma hieroglyphicum & LC & Yes & GOMPHIDAE & Paragomphus genei & LC & No \\
\hline COENAGRIONIDAE & Africallagma rubristigma & LC & Yes & LIBELLULIDAE & Acisoma variegatum & LC & No \\
\hline LIBELLULIDAE & Neodythemis hildebrandti & LC & Yes & LIBELLULIDAE & Aethriamanta rezia & LC & No \\
\hline LIBELLULIDAE & Hemistigma affine & LC & Yes & LIBELLULIDAE & Brachythemis leucosticta & $\mathrm{LC}$ & No \\
\hline LIBELLULIDAE & $\begin{array}{l}\text { Thermorthemis } \\
\text { madagascariensis }\end{array}$ & LC & Yes & LIBELLULIDAE & Chalcostephia flavifrons & $\mathrm{LC}$ & No \\
\hline COENAGRIONIDAE & Pseudagrion alcicorne & LC & Yes & LIBELLULIDAE & Crocothemis divisa & LC & No \\
\hline LIBELLULIDAE & Trithemis selika & LC & Yes & LIBELLULIDAE & Crocothemis erythraea & LC & No \\
\hline LIBELLULIDAE & Archaeophlebia martini & LC & Yes & |LIBELLULIDAE & Diplacodes lefebvrii & LC & No \\
\hline LIBELLULIDAE & Palpopleura vestita & LC & Yes & LIBELLULIDAE & Diplacodes luminans & LC & No \\
\hline COENAGRIONIDAE & Ischnura filosa & LC & Yes & LIBELLULIDAE & Macrodiplax cora & LC & No \\
\hline LIBELLULIDAE & Zygonyx viridescens & LC & Yes & LIBELLULIDAE & Olpogastra lugubris & LC & No \\
\hline PLATYCNEMIDIDAE & Proplatycnemis & $1 \mathrm{C}$ & Yoc & LIBELLULIDAE & Orthetrum icteromelas & LC & No \\
\hline & pseudalatipes & LU & TES & LIBELLULIDAE & Orthetrum trinacria & LC & No \\
\hline COENAGRIONIDAE & Coenagriocnemis & LC & Yes & LIBELLULIDAE & Palpopleura lucia & LC & No \\
\hline |LIBELLULIDAE & Orthetrum azureum & IC & Yes & LIBELLULIDAE & Pantala flavescens & LC & No \\
\hline |LIBELLULIDAE & Thermorthemis comorensis & 10 & Yes & LIBELLULIDAE & Rhyothemis semihyalina & LC & No \\
\hline LIBELLULIDAE & Zygonoides lachesis & 10 & Yes & LIBELLULIDAE & Sympethrum fonscolombii & LC & No \\
\hline PLATYCNEMIDIDAE & Proplatycnemis malgassica & IC & Yes & LIBELLULIDAE & Tetrathemis polleni & LC & No \\
\hline PLATYCNEMIDIDAE & Proplatycnemis alatipes & LC & Yes & LIBELLULIDAE & Tholymis tillarga & LC & No \\
\hline PLATYCNEMIDIDAE & Proplatycnemis sanguinipes & LC & Yes & LIBELLULIDAE & Tramea basilaris & LC & No \\
\hline PLATYCNEMIDIDAE & Proplatycnemis hova & LC & Yes & LIBELLULIDAE & Tramea limbata & LC & No \\
\hline CORDULIIDAE & Hemicordulia similis & LC & Yes & LIBELLULIDAE & Trithemis annulata & LC & No \\
\hline COENAGRIONIDAE & Ceriagrion nigrolineatum & LC & Yes & LIBELLULIDAE & Trithemis arteriosa & LC & No \\
\hline NOT ASSIGNED & Tatocnemis malgassica & LC & $\overline{Y e s}$ & LIBELLULIDAE & Trothemis hecatae & LC & No \\
\hline LIBELLULIDAE & Viridithemis viridula & LC & Yes & LIBELLULIDAE & Trithemis kirbyi & LC & No \\
\hline AESHNIDAE & Gynacantha radama & LC & Yes & LIBELLULIDAE & Urothemis assignata & LC & No \\
\hline ARGIOLESTIDAE & Nesolestes martini & LC & Yes & LIBELLULIDAE & Urothemis edwardsii & LC & No \\
\hline CALOPTERYGIDAE & Phaon rasoherinae & LC & Yes & LIBELLULIDAE & Zygonyx torridus & LC & No \\
\hline LESTIDAE & Lestes simulator & LC & $\overline{Y e s}$ & LIBELLULIDAE & Zyxomma petiolatum & LC & No \\
\hline GOMPHIDAE & Onychogomphus & 18 & & LIBELLULIDAE & Orthetrum stemmale & LC & No \\
\hline & aequistylus & LU & S & |LIBELLULIDAE & Diplacodes trivialis & LC & No \\
\hline MACROMIIDAE & Phyllomacromia trifasciata & LC & Yes & COENAGRIONIDAE & Pseudagrion sublacteum & LC & No \\
\hline PLATYCNEMIDIDAE & Paracnemis alluaudi & LC & Yes & COENAGRIONIDAE & Agriocnemis pygmaea & LC & No \\
\hline COENAGRIONIDAE & Pseudagrion apicale & LC & Yes & COENAGRIONIDAE & Azuragrion nigridorsum & LC & No \\
\hline
\end{tabular}




\title{
Chapter 8
}

\section{Synthesis for all taxa}

\author{
Laura Máiz-Tomé1, William Darwall'1
}

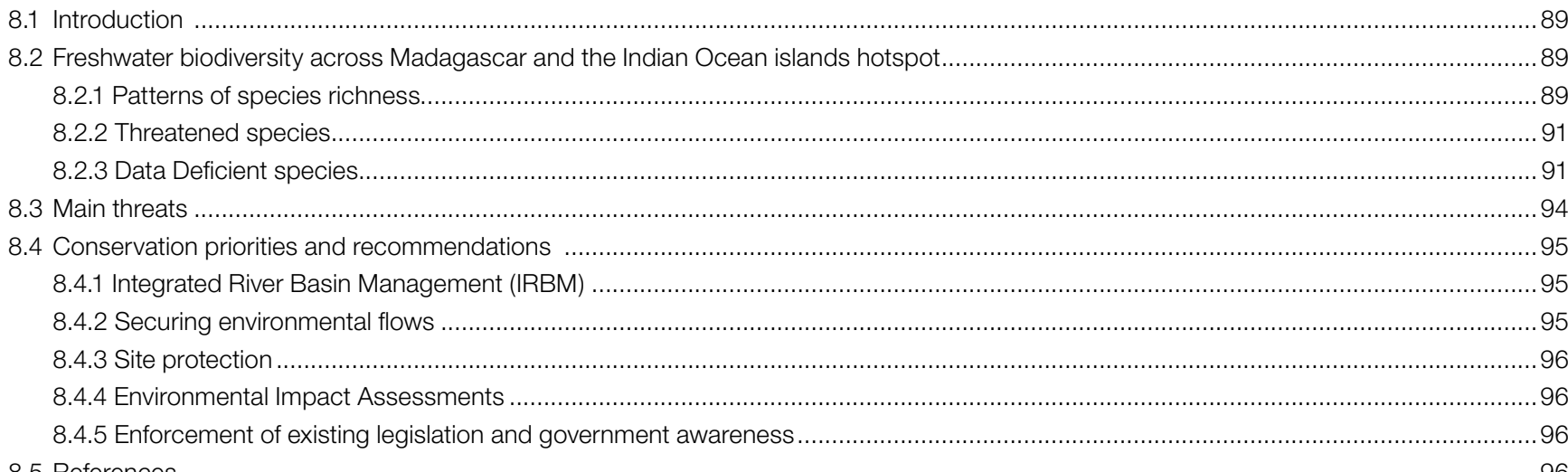

\subsection{Introduction}

The information presented in this synthesis chapter combines the collated IUCN Red List datasets for 653 species of freshwater fishes, molluscs, odonates, decapods and plants (Table 8.1), as presented for individual taxonomic groupings in Chapters 3 to 7 , to illustrate regional patterns of richness and threat. We propose that this combination of taxonomic groups provides a reasonable representation for the overall status and distribution of freshwater biodiversity in the hotspot. We discuss the main factors leading to the high threat status of many species, and research and conservation recommendations are provided at national, catchment and site scales.

Table 8.1 The number of species in each IUCN Red List Category by taxonomic grouping.

\begin{tabular}{|l|c|c|c|c|c|c|c|c|}
\hline $\begin{array}{l}\text { Taxonomic } \\
\text { Group }\end{array}$ & EX & CR & EN & VU & NT & LC & DD & Total \\
\hline Crabs & 0 & 0 & 1 & 1 & 0 & 11 & 7 & $\mathbf{2 0}$ \\
\hline Crayfishes & 0 & 0 & 0 & 4 & 0 & 2 & 1 & $\mathbf{7}$ \\
\hline Fishes & 2 & 14 & 30 & 6 & 2 & 64 & 27 & $\mathbf{1 4 5}$ \\
\hline Molluscs & 3 & 3 & 9 & 4 & 3 & 35 & 9 & $\mathbf{6 6}$ \\
\hline Odonata & 0 & 0 & 6 & 2 & 1 & 104 & 88 & $\mathbf{2 0 1}$ \\
\hline Plants & 0 & 34 & 75 & 24 & 22 & 12 & 2 & $\mathbf{1 6 9}$ \\
\hline Shrimps & 0 & 0 & 1 & 0 & 3 & 22 & 19 & $\mathbf{4 5}$ \\
\hline Total & 5 & 51 & 123 & 41 & 31 & 253 & 153 & $\mathbf{6 5 3}$ \\
\hline
\end{tabular}

\subsection{Freshwater biodiversity across Madagascar and the Indian Ocean islands hotspot}

As for previous chapters, spatial analysis has been conducted at the sub-catchment scale, as this represents the logical mapping unit for freshwater species.

\subsubsection{Patterns of species richness}

The Madagascar and the Indian Ocean islands hotspot supports a high diversity of freshwater species showing high levels of endemism: freshwater fishes (145 spp. assessed $58 \%$ endemic); molluscs (66 spp. assessed; 59\% endemic); crayfish (seven spp. assessed; $100 \%$ endemic); crabs (20 species assessed; $100 \%$ endemic); Odonata (201 spp. assessed; $75 \%$ endemic); shrimps (45 spp. assessed; $64 \%$ endemic); and selected species of aquatic plants (169 spp. assessed; $100 \%$ endemic).

Madagascar's geography with its great variety of environments favours diversity and specialisation. Areas of high species richness (48-107 species within a single subcatchment) in Madagascar are found in the upper reaches of the eastern coastal catchments, eastern wet lowland rainforests and the north-western tropical and subtropical floodplain river and wetland complexes (Figure 8.1). Areas of low species richness in southern and western Madagascar are a reflection of aridity and scarcity of permanent water, 
Figure 8.1 Map of species richness showing numbers of freshwater species per river/lake sub-catchment.

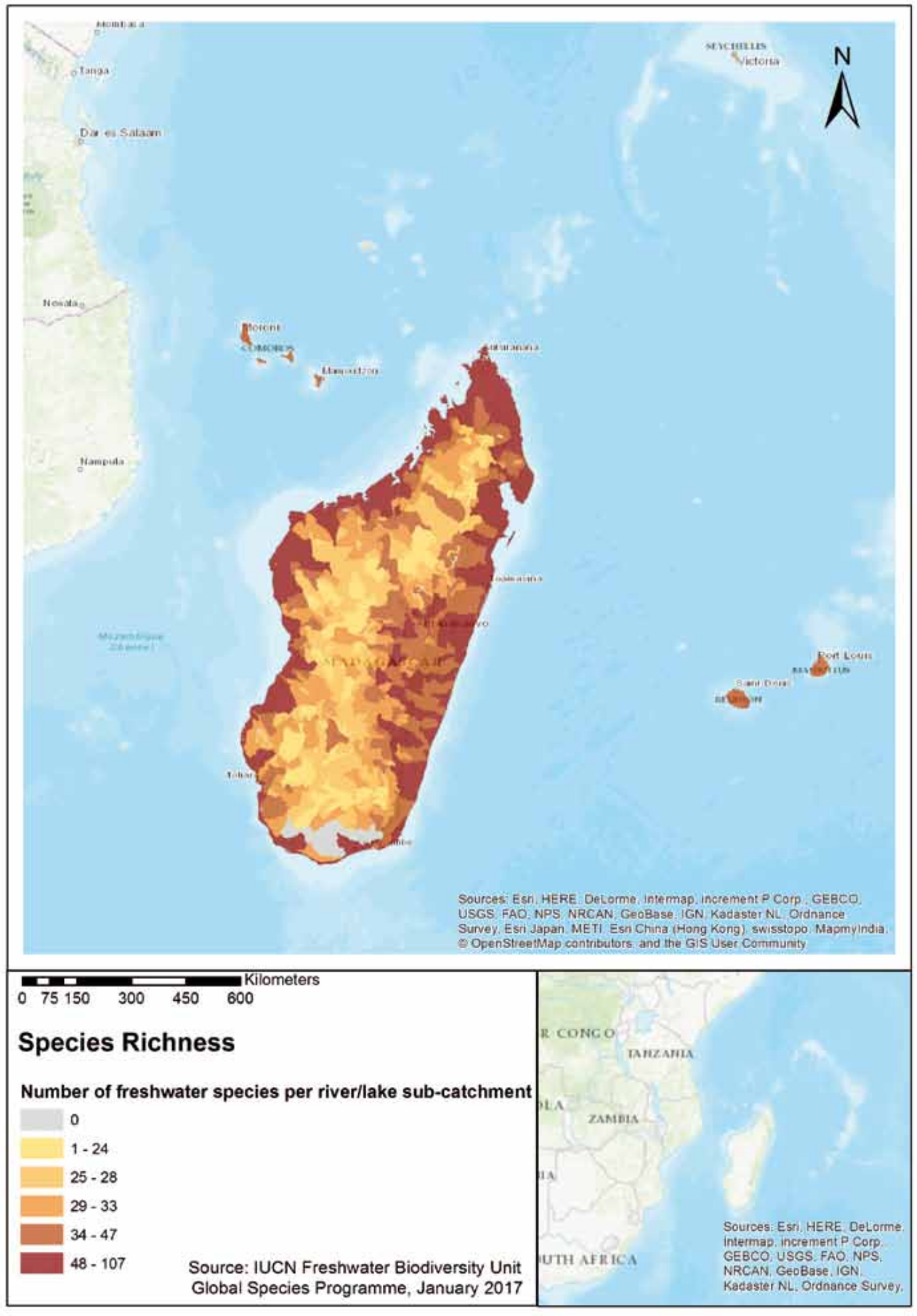


with most water sources being intermittent or seasonal, particularly in the south.

The Mascarene islands of Rodrigues, Comoros and Réunion and the Seychelles also support high levels of species richness (34-47 species in some sub-catchments) (Figure 8.1).

It is important to note that species richness maps have the potential to be biased by sampling intensity. For example, some parts of the hotspot benefit from relatively more intense survey and taxonomic study either historically or more recently, often because they happen to be more easily accessible.

\subsubsection{Threatened species}

Levels of threat to freshwater species are very high within the hotspot, with 215 species classed as Critically Endangered (CR), Endangered (EN) or Vulnerable (VU), representing 43\% of all the freshwater species assessed - assuming all Data Deficient (DD) species are threatened in the same proportion as those that could be assessed. This level of threat is very high in comparison to the pan-African freshwater biodiversity assessment conducted in 2011 where $21 \%$ of species were assessed as threatened (Darwall et al. 2011).

Four species groups have exceptionally high levels of threat: aquatic plants $(80 \%$ - noting that only hotspot endemic species have been assessed); crayfishes (67\%); fishes (43\%); and molluscs (30\%). It is likely however, that other taxonomic groups such as odonates and crabs with $44 \%$ and $35 \%$ of species assessed as DD respectively, will show higher levels of threat as more information becomes available. The global Red List status of all species assessed that are compiled in this report can be found on the IUCN Red List website: http://www.iucnredlist.org/

Spatially explicit data on the exact locations of threats are not normally collected as part of the Red List assessments, except in those cases where a threatened species has a highly restricted range. Spatial analysis highlighting centres of threatened species can, however, help identify broad priority areas for further research and conservation action (Figure 8.3). In general the spatial pattern of threatened species richness (Figure 8.3) reflects that of overall species richness (Figure 8.1). There are more threatened species (1523 species per sub-catchment) in eastern and northern Madagascar and in the Mascarene islands (5-9 species per sub-catchment) than in southern and western Madagascar, reflecting higher levels of threat around urban and agricultural areas.

\subsubsection{Data Deficient species}

One hundred and fifty-three species are classified as DD representing $23 \%$ of all freshwater species assessed. Figure 8.4 shows the number of DD species per river/lake subcatchment for those species for which spatial data were available. This high proportion of DD species demonstrates the need for further research and survey to gather additional information on species' distributions, taxonomy and threats. It should be noted that the majority of the 153 freshwater species assessed as DD are Odonata (88 taxa; 57\%) fishes (26 taxa; 18\%) and shrimps (19 taxa; $12 \%$ ). With $33 \%$ of freshwater species within the hotspot known to be at risk of extinction, it is likely that future research will uncover more threatened species amongst those currently classified as DD. In order to help fill this information gap, capacity

Figure 8.2 Percentage of all freshwater species assessed in Madagascar and the Indian Ocean islands hotspot within each IUCN Red List category.

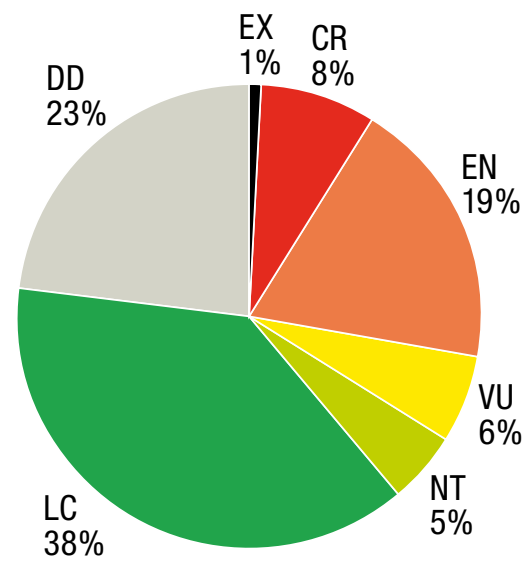

Table 8.2 The percentage of species in each IUCN Red List Category by taxonomic grouping. The total $\%$ of threat is calculated assuming that the all DD species are threatened in the same proportion as those species which could be assessed.

\begin{tabular}{|l|c|c|c|c|c|c|c|c|}
\hline Taxonomic Group & EX & CR & EN & VU & NT & LC & DD & $\%$ Threatened \\
\hline Crabs & $0 \%$ & $0 \%$ & $5 \%$ & $5 \%$ & $0 \%$ & $55 \%$ & $35 \%$ & $15 \%$ \\
\hline Crayfishes & $0 \%$ & $0 \%$ & $0 \%$ & $57 \%$ & $0 \%$ & $29 \%$ & $14 \%$ & $67 \%$ \\
\hline Fishes & $1 \%$ & $10 \%$ & $21 \%$ & $4 \%$ & $1 \%$ & $44 \%$ & $19 \%$ & $43 \%$ \\
\hline Molluscs & $4 \%$ & $4 \%$ & $14 \%$ & $6 \%$ & $4 \%$ & $53 \%$ & $14 \%$ & $30 \%$ \\
\hline Odonata & $0 \%$ & $0 \%$ & $3 \%$ & $1 \%$ & $0.4 \%$ & $52 \%$ & $44 \%$ & $7 \%$ \\
\hline Plants & $0 \%$ & $20 \%$ & $44 \%$ & $15 \%$ & $13 \%$ & $7 \%$ & $1 \%$ & $80 \%$ \\
\hline Shrimps & $0 \%$ & $0 \%$ & $2 \%$ & $0 \%$ & $7 \%$ & $49 \%$ & $42 \%$ & $4 \%$ \\
\hline
\end{tabular}


Figure 8.3 Map of species richness showing numbers of threatened freshwater species per river/lake sub-catchment.

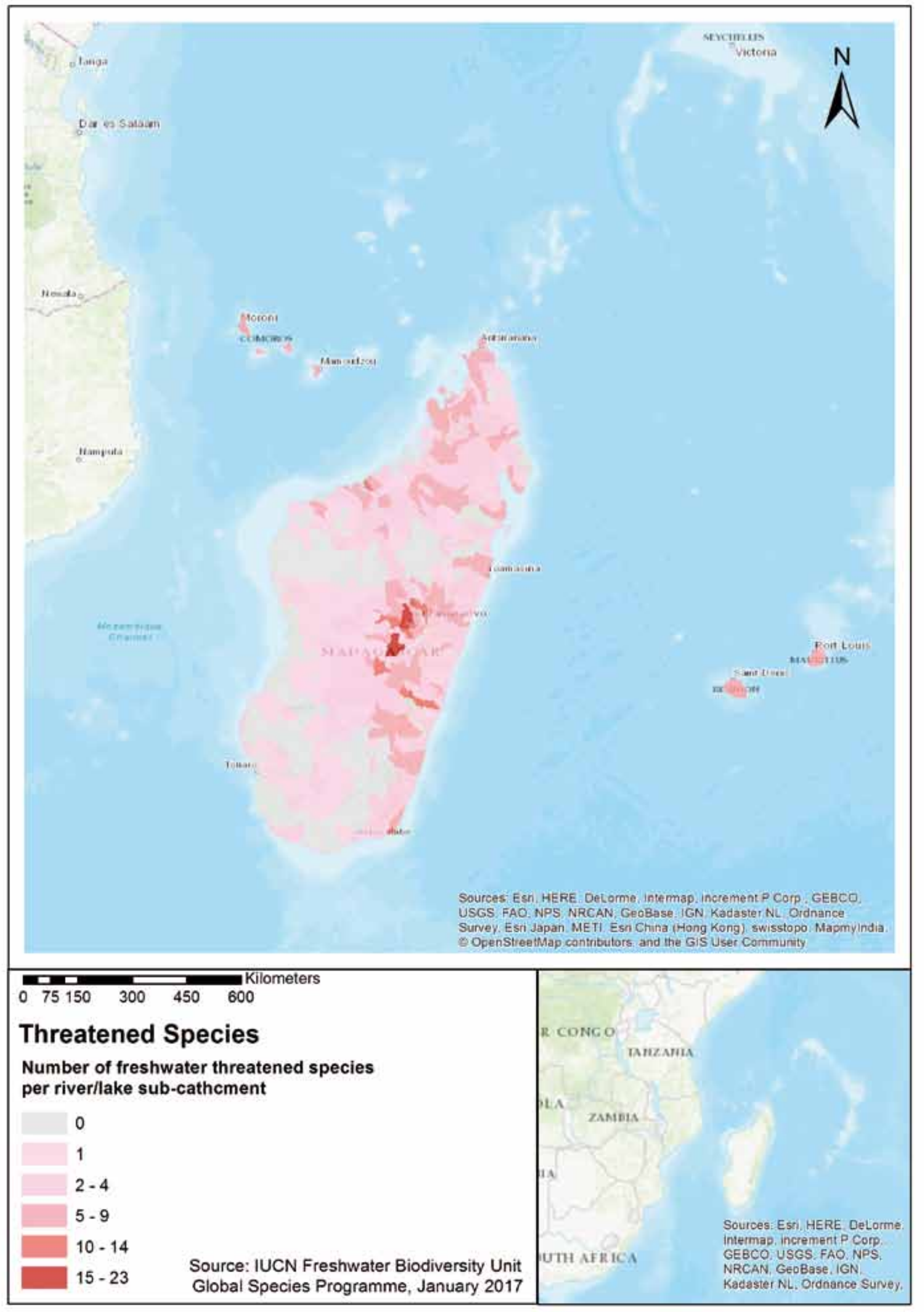


Figure 8.4 Map showing the number of Data Deficient species per river/lake sub-catchment. Noting that only those species for which we obtained spatial data could be mapped.

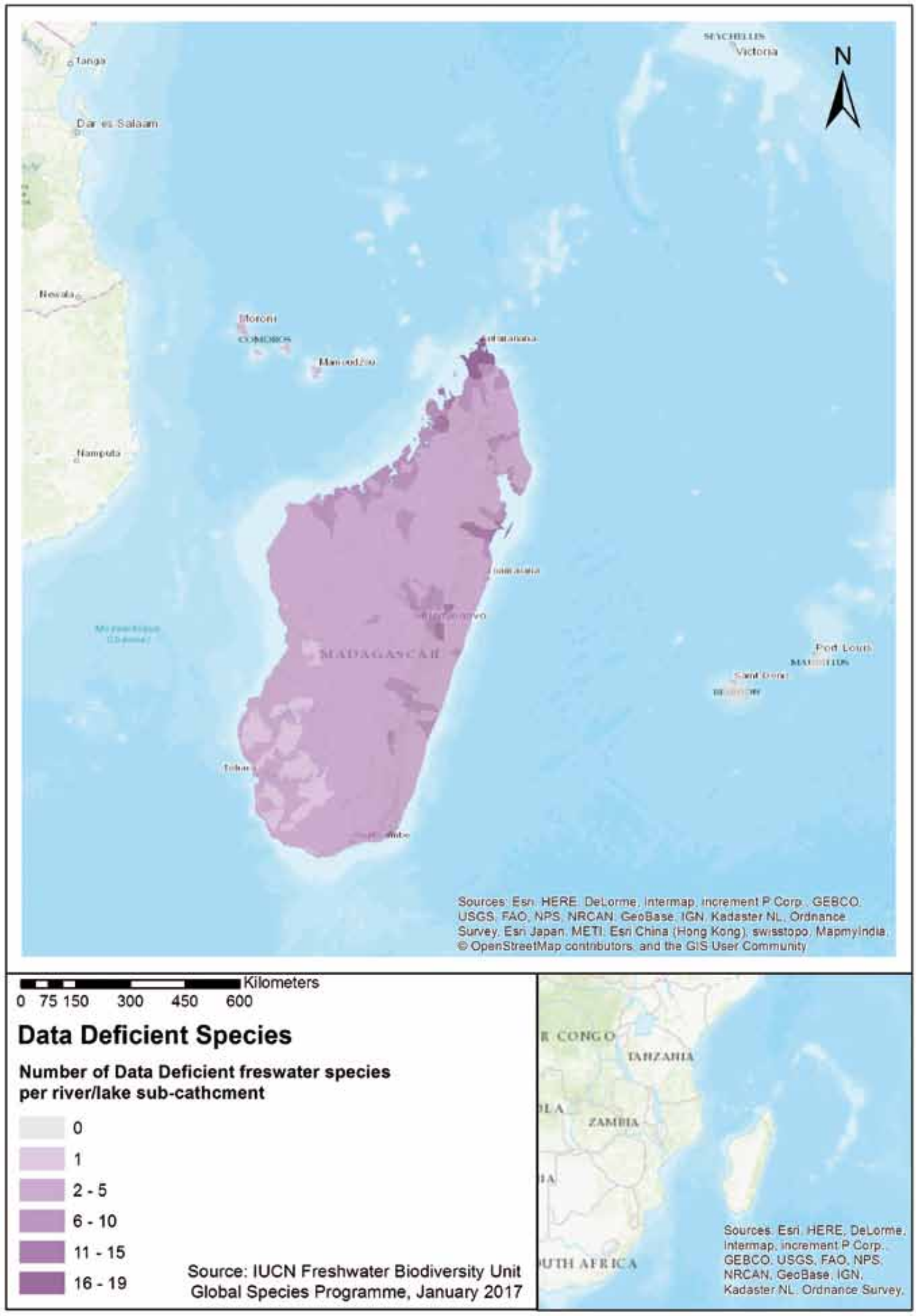


building within the region should include training in modern taxonomic research and species identification methods, and publication of national field guides and check lists in the languages of the hotspot to facilitate future field survey and monitoring.

\subsection{Main threats}

For each species assessed against the IUCN Red List Categories and Criteria the direct threats that have impacted, are impacting, or may impact the species were recorded using IUCN's threat classification scheme Version 3.2 (IUCN 2017). This allows for the major threatening processes to be identified and monitored in the long term. The main threats to all freshwater species are summarised below, and are presented in more detail for individual taxon groups in the preceding chapters.

In summary, the threats to freshwater species (Figure 8.5) are mainly related to habitat loss and degradation induced by human activities, primarily caused by unsustainable agricultural practices such as crop production and logging based on the slash and burn approach, and drainage of wetlands.

Given the high dependency of local communities upon open access natural resources such as wood, medicinal plants and artisanal fisheries in the hotspot, and particularly in Madagascar, it is not surprising that biological resource use is shown as the second most important threat to freshwater biodiversity, including over-fishing and deforestation.

Natural systems modifications caused by unsustainable water management and the construction of dams also have significant impacts on freshwater biodiversity. Overabstraction of water for rice cultivation and the construction of dams block important migration routes for native species and modify hydrological landscapes, affecting water flows, water temperature, oxygen content and sediment loading of rivers and streams. These types of impacts are particularly critical at certain times of the year (during the reproduction period for example) or in certain areas (e.g. spawning grounds, habitat refuges, etc.).

Human populations are increasing along freshwater systems in Madagascar and so is the level of water pollution from urban, agricultural, forestry and livestock farming effluents (Figure 8.6). Mining activities are also a current and growing threat to freshwater biodiversity, followed by invasive alien species such as the mosquitofish (Gambusia holbrooki) or the Asian snakehead (Channa maculata), which have a considerable impact on some indigenous species through predation and competition for resources (Benstead et al. 2003).

Finally, all these threats are expected to be compounded through the increasing effects of climate change. Droughts are becoming more frequent and their severity and extent are increasing across the hotspot. The impact of El Niño-induced

Figure 8.5 Numbers of threatened and Near Threatened species, for all the taxon groups combined, impacted by each category of threat based on published IUCN Red List data. Note that some species are impacted by more than one threat.

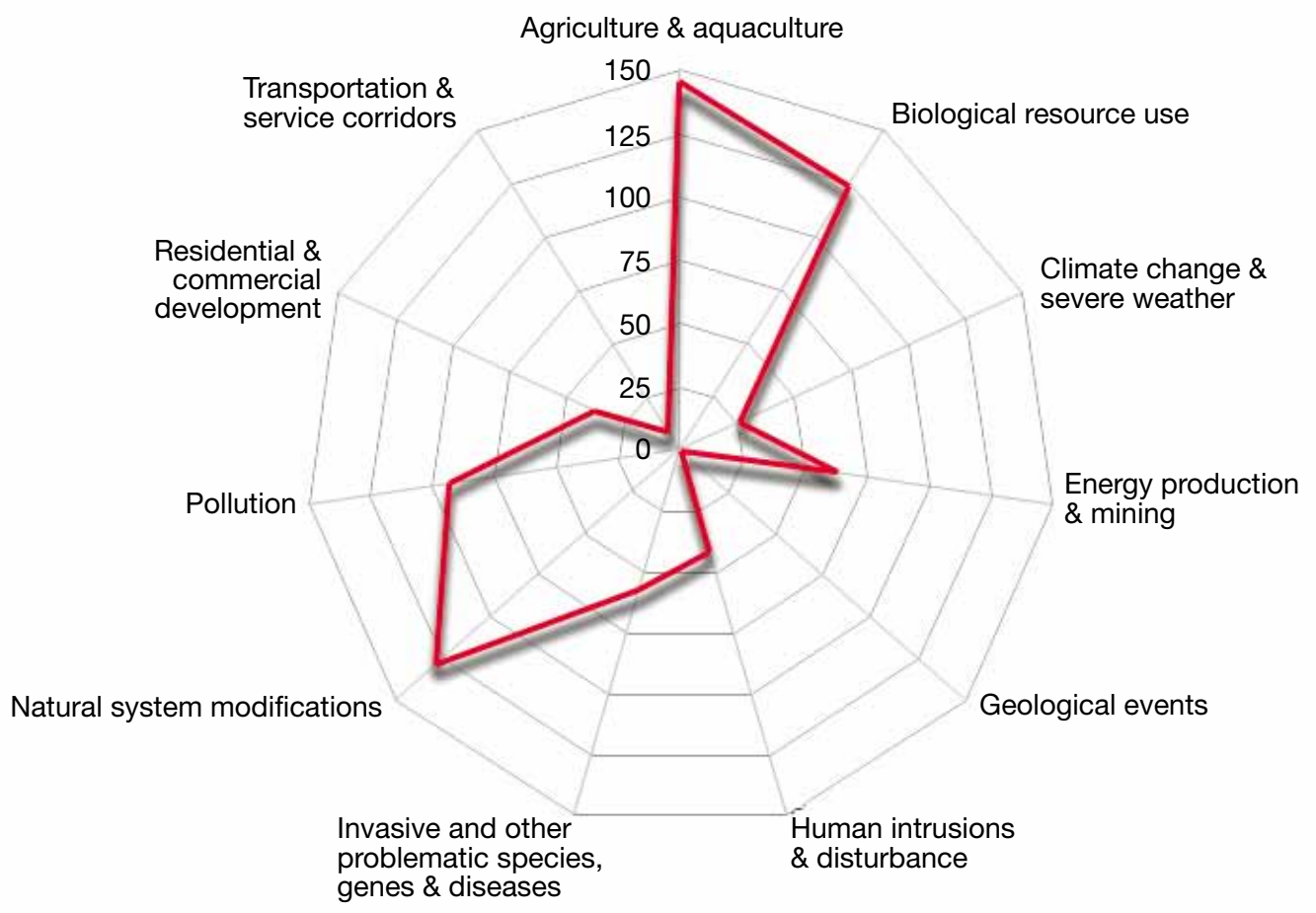




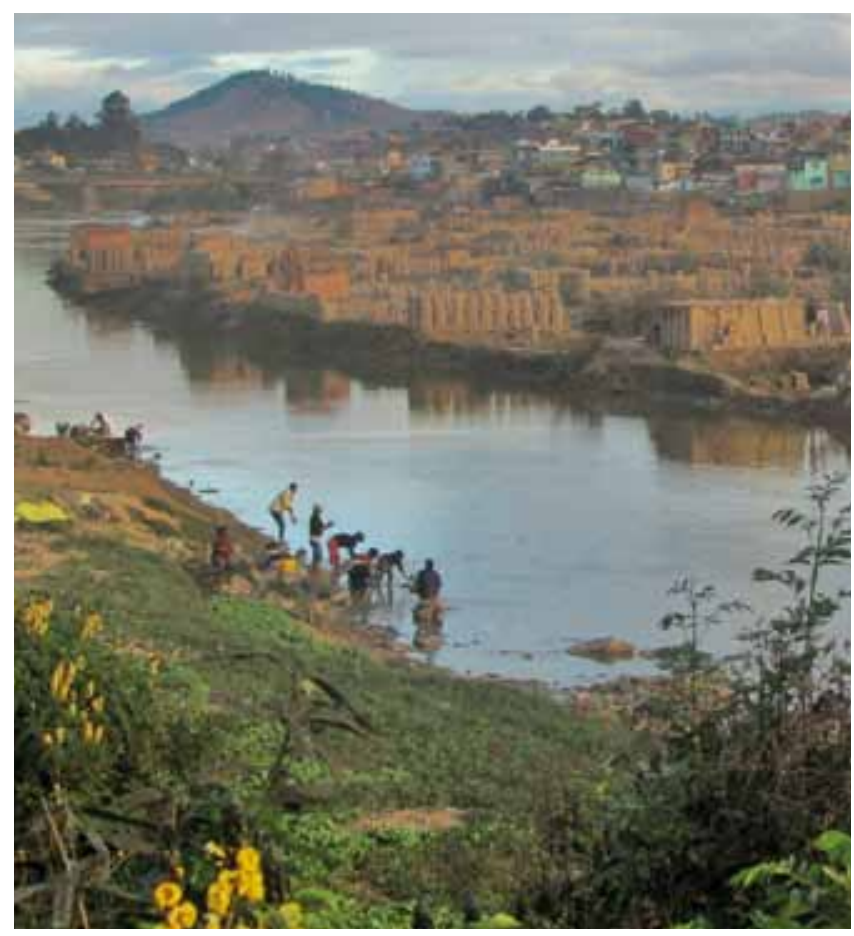

Figure 8.6 Brick-making along river banks generates high levels of sedimentation and water pollution. () Laura Máiz-Tomé

drought on crop production in southern Madagascar, where nearly 850,000 people are acutely food insecure, is likely to persist (FAO 2016), increasing human dependency and pressure on freshwater resources. On the other hand, devastating flooding episodes are also becoming more common, transporting enormous amounts of sediments and degrading aquatic habitats.

\subsection{Conservation priorities and recommendations}

This section builds on and summarises the conservation recommendations presented in each of the preceding chapters. We now incorporate an analysis of species assessments for which "Conservation actions needed" were recorded according to the IUCN CMP Unified Classification of Direct Threats and Actions ver. 2 (IUCN 2017) (Table 8.3).

An immediate priority is to implement these recommended conservation actions, especially in those sub-catchments identified to contain high numbers of threatened species. In the following sections we present a range of approaches commonly employed to address the threats and conservation needs of freshwater biodiversity.

\subsubsection{Integrated River Basin Management (IRBM)}

A primary conservation action recommended for freshwater biodiversity is management at the catchment scale.
Table 8.3 'Conservation actions needed' as coded within the IUCN Red List assessments for all threatened and Near Threatened freshwater species showing the proportions of species for which each type of conservation action is recommended.

\begin{tabular}{|l|c|}
\hline Conservation action needed & $\begin{array}{c}\% \text { of threatened } \\
\text { and NT species }\end{array}$ \\
\hline Site/area protection & $65 \%$ \\
\hline Ex-situ conservation & $61 \%$ \\
\hline Resource and habitat protection & $58 \%$ \\
\hline Site/area management & $47 \%$ \\
\hline Training & $26 \%$ \\
\hline Awareness and communications & $21 \%$ \\
\hline Habitat and natural process restoration & $14 \%$ \\
\hline Invasive/problematic species control & $10 \%$ \\
\hline Species management & $10 \%$ \\
\hline Policies and regulations & $3 \%$ \\
\hline Compliance and enforcement & $2 \%$ \\
\hline Species recovery & $1 \%$ \\
\hline Legislation & $1 \%$ \\
\hline
\end{tabular}

One recommended approach is Integrated River Basin Management (IRBM). IRMB is the process of coordinating conservation, management, and development of water, land and related resources across sectors within river basins, in order to maximise the economic and social benefits derived from water resources in an equitable manner while preserving, and when necessary, restoring freshwater ecosystems (Harwood et al. 2014).

Catchment management plans are particularly recommended for those areas that contain freshwater Key Biodiversity Areas (see Chapter 9). Such plans will likely need to restore natural flow regimes by working with local stakeholders to maintain the essential characteristics of water flows (see section 8.4.2) required to sustain freshwater ecosystems.

In many cases it will be hard to achieve the required degree of habitat restoration without a parallel reduction in the levels of water abstraction for agriculture (the main user of fresh water), especially in the face for extreme climate events such as El Niño, which will likely lead to more severe and prolonged periods of drought across the hotspot. In such cases, implementation of strategic ecosystem-based adaptation and disaster risk reduction management plans is crucial to increase resilience and reduce the vulnerability of people and the environment to climate change (SudmeierRieux et al. 2013).

\subsubsection{Securing environmental flows}

Over extraction of water resources is contributing to reduced river flows and in some cases a reduction in the fisheries on which local communities depend. Rivers with reduced flow which also receive polluted waters from urban and agricultural runoff are potential centres for diseases such 
as malaria, cholera and dysentery (O'Keeffe \& Le Quesne 2009). Environmental Flows (E-Flows) aim to maintain the quantity, timing and quality of water flows required to sustain freshwater and estuarine ecosystems and the human livelihoods that depend on them (Dyson et al. 2008). Implementation of E-Flows assessment methodologies is therefore recommended to ensure the future conservation and sustainable management of freshwater species and ecosystems (Harwood et al. 2017).

\subsubsection{Site protection}

A number of species require some degree of site protection below the spatial scale of river sub-catchments. Examples include protection of spawning areas, migration bottlenecks, and nursery grounds. Restricted habitats such as springs and seepages will also require protection at the site scale in addition to catchment management. Species subject to exploitation, such as through fisheries, will also require management at the site scale.

For those species occurring within existing protected areas, additional management actions may be required to specifically target freshwater biodiversity. In many cases protected areas are not currently designated or managed for freshwater species and their presence within the protected area may not be known. The Freshwater Key Biodiversity Areas presented in Chapter 9 can be used to alert managers to the presence of important components of freshwater biodiversity in their sites and also to inform management of new protected areas for these underrepresented freshwater taxonomic groups.

\subsubsection{Environmental Impact Assessments}

Environmental Impact Assessments (EIAs) can be a valuable tool for informing the development planning process. The information presented here and through the IUCN Red List website (www.iucnredlist.org) will help to support the initial planning stages of EIAs. It should be noted, however, that the spatial data presented are often limited to species presence/ absence within a sub-catchment, hence additional field surveys may be required.

\subsubsection{Enforcement of existing legislation and government awareness}

Capacity within some of the hotspot's national governments and their agencies is currently not thought sufficient to enforce compliance with existing legislation for the protection of freshwater biodiversity (Moore Gerety 2017). Many threatened and NT species will benefit from better compliance and enforcement of existing legislation, including for management of resource exploitation (e.g. fisheries), water extraction and pollution. Building capacity within government bodies (national to local) and raising awareness of conservation needs of freshwater biodiversity and the benefits people receive from healthy freshwater ecosystems will greatly improve future prospects for freshwater species and their associated habitats.

\subsection{References}

Benstead, J.P., De Rham, P.H., Gattolliat, J.L. et al. 2003. Conserving Madagascar's Freshwater Biodiversity, BioScience 53(11) 1101-1111. https://doi.org/10.1641/00063568(2003)053[1101:CMFB]2.0.CO;2

Darwall, W.R.T., Smith, K.G. and Allen, D.J. et al. 2011. The Diversity of Life in African Freshwaters: Under Water, Under Threat. An analysis of the status and distribution of freshwater species throughout mainland Africa. Cambridge, United Kingdom and Gland, Switzerland: IUCN. xiii+347pp+4pp cover.

Dyson, M., Bergkamp, G. and Scanlon, J. 2008. Flow: The Essentials of Environmental Flows. IUCN, Gland, 981 Switzerland and Cambridge, UK. xiv+118pp.

Bruno, D., Belmar, O., Sánchez-Fernández, D., et al. Responses of Mediterranean aquatic and riparian communities to human pressures at different spatial scales. Ecological Indicators 45: 456-464. 982

FAO. 2016. Press Release: Crop losses in southern Madagascar mean severe hunger likely to persist into 2017. Rome, 27 October 2016. Downloadable from: http://www.fao.org/ news/story/en/item/449030/icode/

Harwood, A., Johnson, S., Richter, B., et al. 2017. Listen to the river: Lessons from a global review of environmental flow success stories WWF-UK, Woking, UK.

IUCN. 2017. Guidelines for Using the IUCN Red List Categories and Criteria. Version 13. Prepared by the Standards and Petitions Subcommittee. Downloadable from http://www. iucnredlist.org/documents/RedListGuidelines.pdf

O'Keeffe, J. and Le Quesne, T. 2009. WWF Water Security series 2. Keeping Rivers Alive. A primer on environmental flows and their assessment. February 2009.

Moore, G.R. 2017. Conservation in a weak state: Madagascar struggles with enforcement. Mongabay Series. Downloadable from: https://news.mongabay.com/2017/10/conservationin-a-weak-state-madagascar-struggles-with-enforcement/

Sudmeier-Rieux, K., Ash, N. and Murti, R. 2013. Environmental Guidance Note for Disaster Risk Reduction: Healthy Ecosystems for Human Security and Climate Change Adaptation. 2013 edition. Gland, Switzerland: IUCN, iii+34pp. First printed in 2009 as Environmental Guidance Note for Disaster Risk Reduction: Healthy Ecosystems for Human Security. 


\section{PART 2 \\ SITES OF IMPORTANCE FOR FRESHWATER SPECIES}
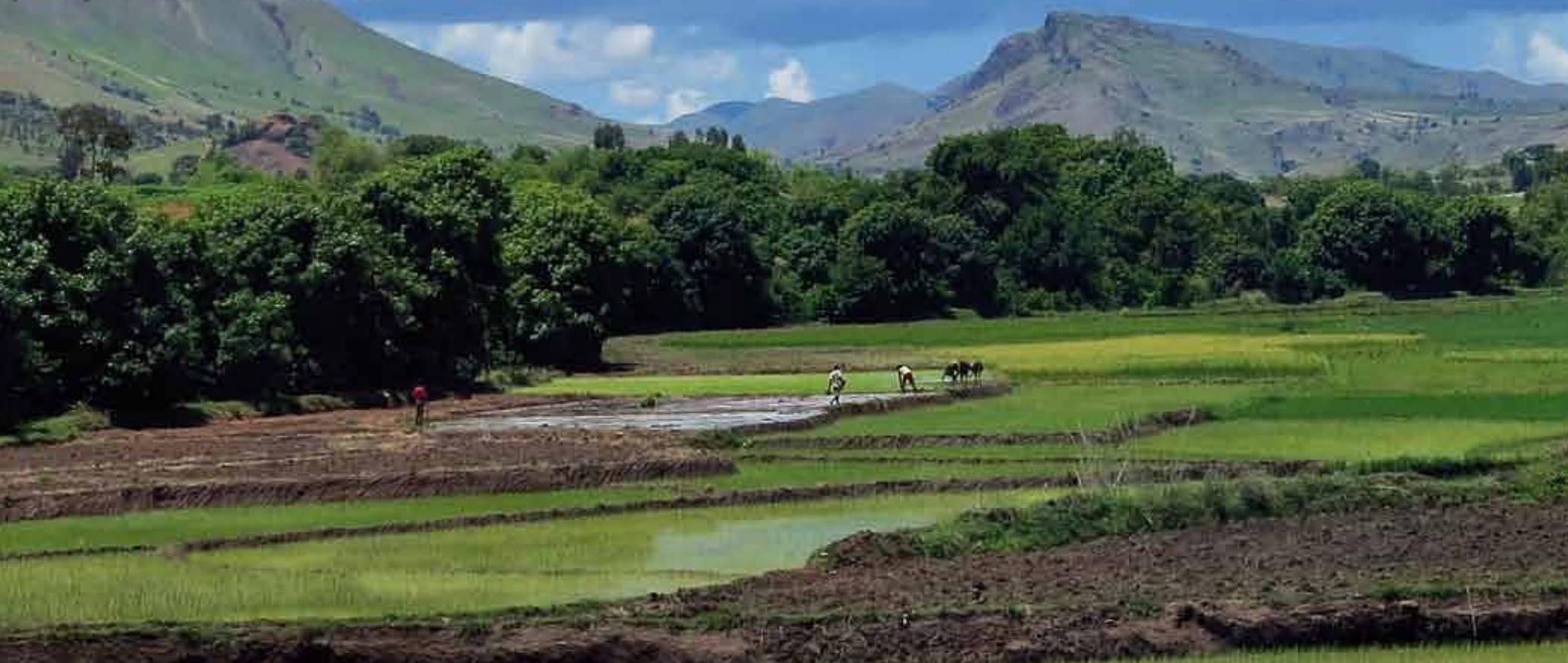

Lition

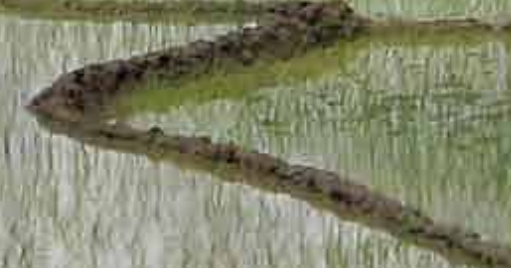




\title{
Chapter 9
}

\section{Freshwater Key Biodiversity Areas in Madagascar}

\author{
Laura Máiz-Tomé1, Catherine Sayer', William Darwall1

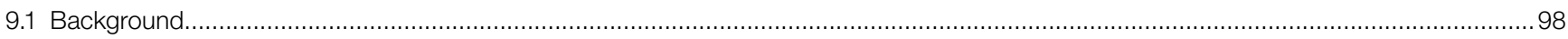

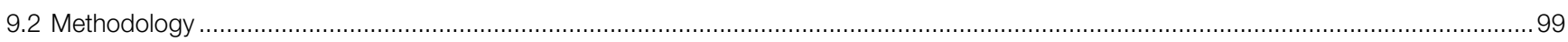

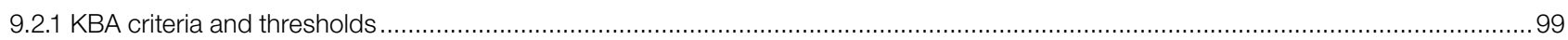

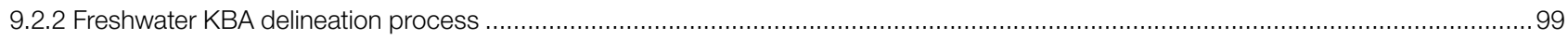

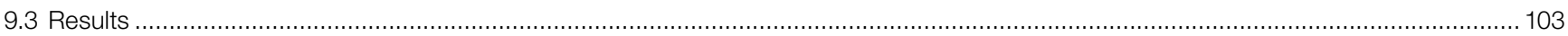

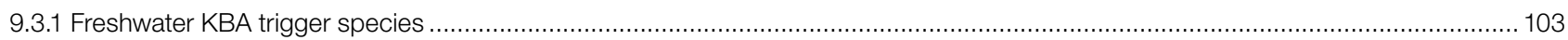

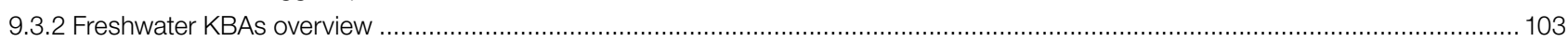

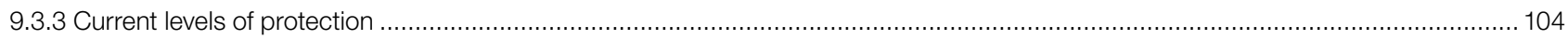

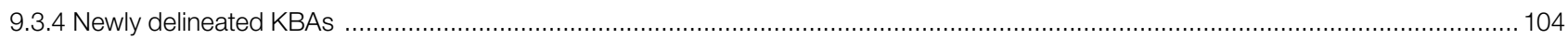

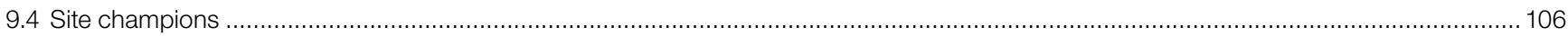

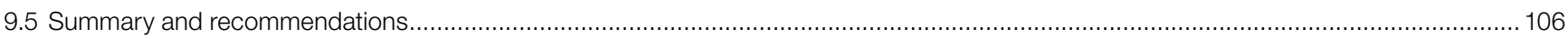

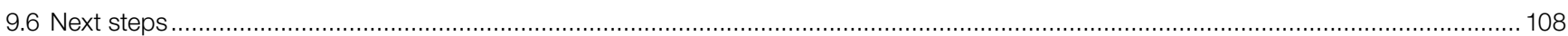

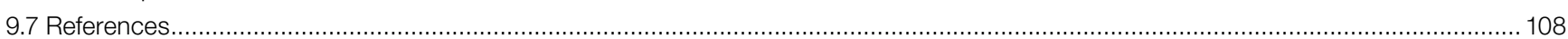

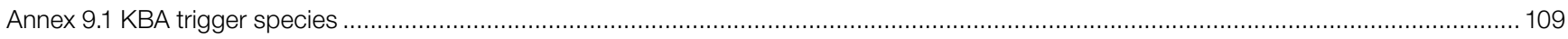

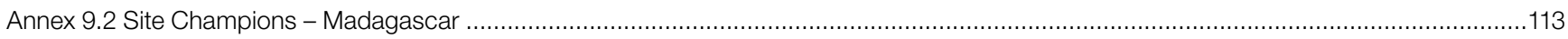

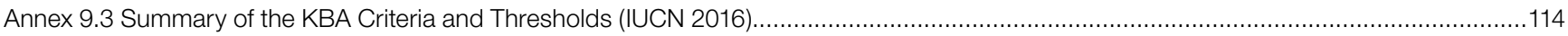

\subsection{Background}

Over the last four decades, a range of organisations have invested in compiling information on the location of sites that are significant for biodiversity. Since the late 1970s, Birdlife International has maintained criteria for the identification of Important Bird Areas (IBAs) and more than 12,000 sites have been identified worldwide (Dudley et al. 2014). Building on this approach, other methodologies have been developed, including Important Plant Areas (IPAs); Alliance for Zero Extinction (AZE) sites; Prime Butterfly Areas and Key Biodiversity Areas (KBAs) identified for multiple taxonomic groups in freshwater, terrestrial and marine environments. These approaches generally focus on one group of species or one biome, and use diverse assessment criteria, which has led to some confusion among decision-makers as well as duplication of conservation efforts (IUCN 2014).

As a consequence, during the World Conservation Congress held in Bangkok (Thailand) in 2004, IUCN Members requested IUCN "to convene a worldwide consultative process to agree a methodology to enable countries to identify Key Biodiversity Areas" (IUCN 2004). In response to this Resolution (WCC 3.013; https://portals.iucn.org/library/node/44299), the IUCN Species Survival Commission and the IUCN World
Commission on Protected Areas established a Joint Task Force on Biodiversity and Protected Areas which, since 2012, has mobilised expert input from IUCN Commissions, Members, Secretariat staff, conservation organisations, academics, decision-makers, donors, and the private sector to consolidate globally agreed scientific criteria and harmonise work for identifying KBAs (IUCN 2014).

All these efforts have culminated in "A Global Standard for the Identification of KBAs", approved by the IUCN Council during its 88th meeting on 11-13 April 2016, that can be robustly applied across taxonomic groups and all elements of biodiversity. Data generated through the application of the KBA Standard are expected to have multiple uses (Dudley et al. 2014). KBAs can support the strategic expansion of protected area networks by governments and civil society working toward the achievement of the Aichi Biodiversity Targets (in particular Targets 11 and 12), as established by the Convention on Biological Diversity (CBD) (Butchart et al. 2012); serve to inform the description or identification of sites under international conventions (such as wetlands of international importance designated under the Ramsar Convention, natural World Heritage Sites, and Ecologically and Biologically Significant Areas as described under the $\mathrm{CBD}$ ); contribute to the development of other effective 
area-based conservation measures (Jonas et al. 2014); inform private sector safeguard policies, environmental standards, and certification schemes; support conservation planning and priority-setting at national and regional levels; and provide local and indigenous communities with opportunities for employment, recognition, economic investment and societal mobilisation (IUCN 2016).

Key Biodiversity Areas are incorporated within the ecosystem profiles CEPF develops to identify and formulate an investment strategy for each targeted hotspot. Between the years 2001-2006 and 2009-2012 CEPF invested in the Madagascar and Indian Ocean islands biodiversity hotspot to identify globally threatened species, the sites (KBAs) that host these species, and the ecological corridors that preserve critical ecological processes for these sites. This investment resulted in the identification of 212 KBAs in Madagascar (Conservation International 2014), but mainly for terrestrial biodiversity. The project results presented in this report help to fill the gap on freshwater KBAs for Madagascar, paving the way for better representation of freshwater biodiversity within the National Protected Areas Network, and within other conservation efforts.

The process leading to the identification and delineation of freshwater KBAs in Madagascar included: (i) collating data on the distribution, abundance, ecology, risk of extinction, and utilisation by humans, for several groups of species that are considered reliable indicators of the biological structure and functioning of freshwater ecosystems (fishes, molluscs, crabs and crayfishes, dragonflies and damselflies (Odonata) and aquatic plants) (see Chapters 3-8, this volume); (ii) identifying those river/lake sub-catchments holding species that appear to meet the KBA criteria; (iii) validating (through stakeholder consultations) KBAs within those catchments, always taking

Key Biodiversity Areas are "sites of importance for the global persistence of biodiversity". However, this does not imply that a specific conservation action, such as protected area designation, is required. Such management decisions should be based on conservation priority-setting exercises, which combine data on biodiversity importance with the available information on site vulnerability and the management actions needed to safeguard the biodiversity for which the site is important. It is often desirable to incorporate other data into prioritysetting, such as conservation cost, opportunity for action, importance for conserving evolutionary history and connectivity. KBAs thus do not necessarily equate to conservation priorities but are invaluable for informing systematic conservation planning and priority-setting, recognising that conservation priority actions may also be outside of KBAs (IUCN 2016). into account the hydrological connectivity of the catchment where the KBAs reside and; (iv) compiling a set of additional information about each KBA to support management of the biodiversity elements triggering the criteria. Each of these processes is covered in more detail below.

\subsection{Methodology}

The methodology for identification and delineation of global freshwater KBAs in Madagascar followed the new Global Standard for identification of Key Biodiversity Areas (IUCN 2016).

\subsubsection{KBA criteria and thresholds}

The new global KBA criteria provide quantitative thresholds for identifying sites that contribute significantly to the global persistence of: A) threatened biodiversity; B) geographically restricted biodiversity; C) ecological integrity; D) biological processes; and E) biodiversity through comprehensive quantitative analysis of irreplaceability (IUCN 2016; Annex 9.3).

Sites identified as potential KBAs should ideally be assessed against all criteria. Although not all these criteria are applicable or relevant for the freshwater taxonomic groups considered at the workshop (e.g. not all taxonomic groups have species that aggregate), meeting any one of the criteria (or sub-criteria) is enough for a site to be considered for qualification as a KBA. Species meeting the KBA thresholds and criteria are defined as KBA trigger species. Some criteria such as B2, B3, D3 or E were not utilised due to lack of adequate data. The criteria and thresholds employed in this project are summarised in Table 9.1.

\subsubsection{Freshwater KBA delineation process}

The identification and delineation of freshwater KBAs in Madagascar followed a two-step process:

\section{Stage 1. Desk-based activities in preparation for stakeholder KBA validation workshop:}

The first step of the process was a primarily desktop analysis of data collated through IUCN Red List assessments for the following freshwater taxonomic groups: i) fishes, ii) molluscs; iii) Odonata (dragonflies and damselflies); iv) crabs and crayfish, and; v) aquatic plants.

The data sets collected include the required information on species distributions (digital shape files) and their IUCN Red List Categories of extinction risk as published on the IUCN Red List (IUCN 2017). 
Table 9.1 Selected KBA criteria used for the delineation of freshwater KBAs in Madagascar (IUCN 2016).

\begin{tabular}{|l|l|c|c|}
\hline \multirow{2}{*}{ A. Threatened biodiversity } & Biodiversity element at site & \% global pop. size/extent & $\begin{array}{c}\text { Reproductive } \\
\text { Units }\end{array}$ \\
\hline \multirow{2}{*}{ A1. Threatened species } & (a) CR or EN species & $\geq 0.5 \%$ & $\geq 5$ \\
\cline { 2 - 4 } & (b) VU species & $\begin{array}{c}\text { Entire global } \\
\text { population size }\end{array}$ & $\geq 10$ \\
\cline { 2 - 4 } & (e) CR or EN species & $\begin{array}{c}\text { \% global pop. size/extent } \\
\text { Reproductive } \\
\text { Units }\end{array}$ & $\geq 10 \%$ \\
\hline B1: Individually geographically restricted species & Any species & \% global pop. size/extent & $\geq 1 \%$ \\
\hline D. Biological processes & Biodiversity element at site & \\
\hline D1: Demographic aggregations & $\begin{array}{l}\text { (a) Species aggregation during one or more } \\
\text { key stages of its life cycle }\end{array}$ & $\begin{array}{l}\geq 10 \% \\
\end{array}$ \\
\hline D2: Ecological refugia & $\begin{array}{l}\text { Species aggregations during periods of past, } \\
\text { current or future environmental stress }\end{array}$ & \\
\hline
\end{tabular}

\section{a. Assemble spatial data sets of:}

i) Species Red List distribution maps for freshwater fishes, molluscs, odonates, crabs and crayfish, and aquatic plants;

ii) Existing KBAs, Ramsar sites and Protected Areas.

KBA delineation is an iterative process that makes use of better and more recent data as they become available (IUCN 2016). The species Red List Assessments were completed in 2016 through the first component of the project (see Chapters 2-8), to ensure that data are traceable to a reliable source and sufficiently recent (and updated) to give confidence that the biodiversity elements are still present at the sites.

\section{b. Derive proposed site boundaries based on biological data}

Using the species distribution maps assembled in Stage 1a above all river/lake sub-catchments in Madagascar that contain KBA trigger species were identified. River/lake sub-catchments were delineated according to the spatial data layer called HydroBASINS (Lehner \& Grill 2013; see Chapter 2).

The resolution used for selecting sub-catchments holding KBA trigger species was HydroBASINS Level 8 , which in Madagascar delineates sub-catchments with an average surface area of $605 \mathrm{~km}^{2}$. In this way, maps were created to show the numbers of potential trigger species per sub-catchment. Lists of potential trigger species thought to be present in each subcatchment were also compiled. This process was achieved through a screening of all sub-catchments against the full complement of species maps using " $R$ " scripts, a free software for statistical computing and data analysis (Venables et al. 2017) to identify the trigger species present and the criteria triggered for each subcatchment (Figure 9.1).
During the analysis those sites that potentially qualified as AZE sites were also identified. AZEs sites are places that contain the last or only populations of globally Critically Endangered or Endangered species almost entirely restricted to that single remaining site (Ricketts et al. 2005). The AZE database can be accessed at: http:// www.zeroextinction.org/

\section{Stage 2. Stakeholder KBA validation and delineation workshop:}

A KBA validation and delineation workshop was held in Antananarivo in January 2017 at the California Academy of Sciences Biodiversity Centre, in collaboration with the relevant stakeholders (species experts, conservation NGOs and government representatives) from Madagascar (Figure 9.2). The aim of KBA delineation workshop was to validate the proposed sub-catchments as meeting the KBA criteria and to then derive KBA site boundaries that are biologically relevant yet practical for management (IUCN 2016). Workshop participants were first asked to confirm the presence of the KBA trigger species within each sub-catchment identified through Stage 1 (desk analysis) and to then delineate KBA boundaries according to the following procedures:

Figure 9.2 Expert participants at the Freshwater KBA workshop, January 2017 - California Academy of Sciences Biodiversity Centre, Antananarivo, Madagascar. (C) IUCN

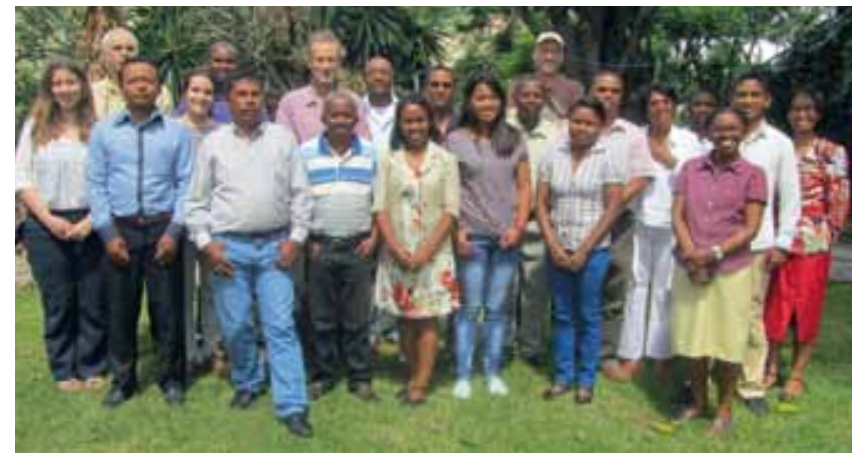


Figure 9.1 Map of all sub-catchments holding KBA trigger species, thus potentially qualifying areas within these sub-catchments as KBAs. AZE sites are highlighted with turquoise blue boundaries.

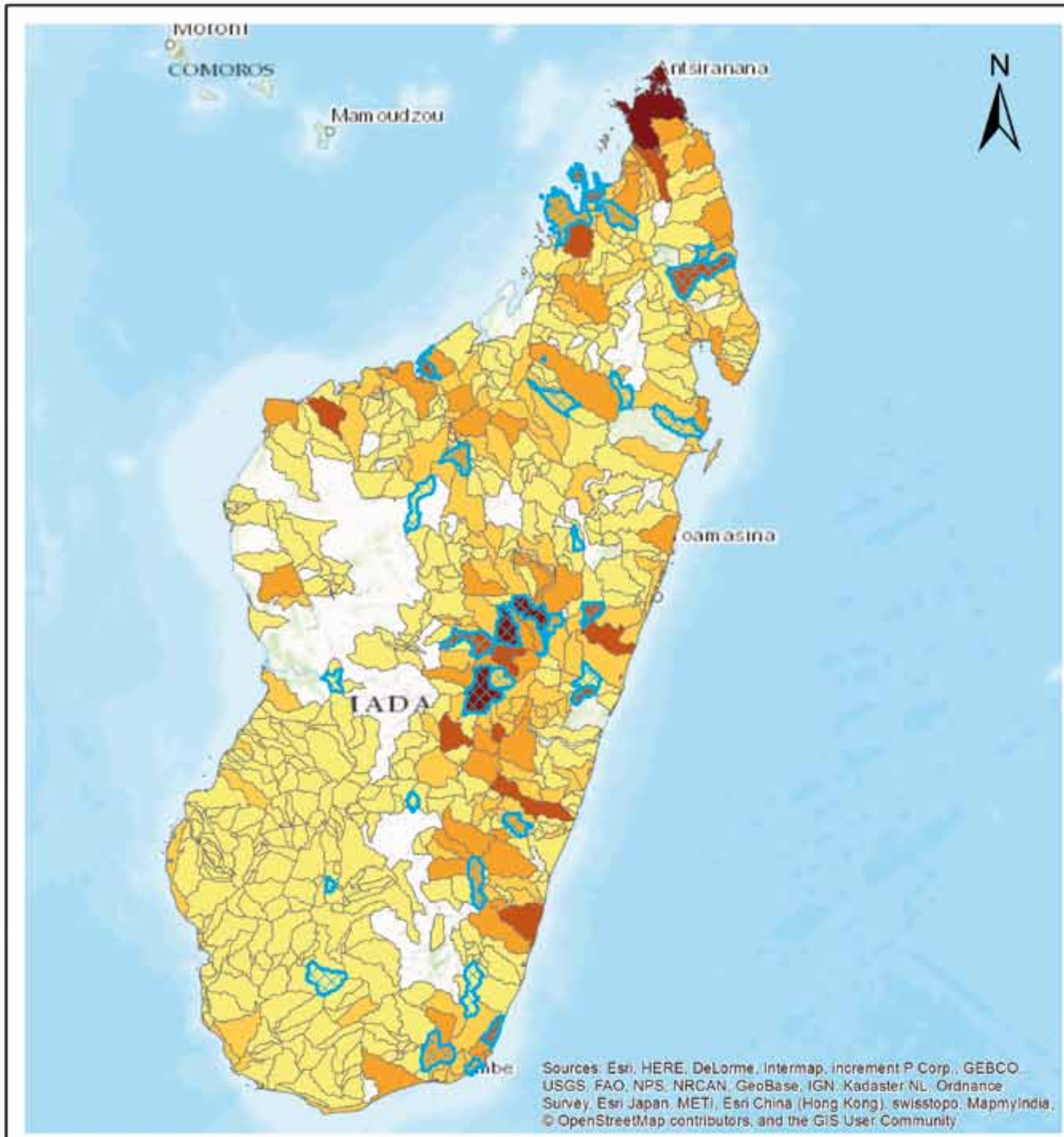

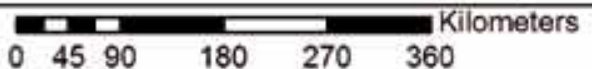

\section{Catchments containing potential} KBA Trigger Species

Q Potential AZE Sites

Number of potential trigger species per riverilake subcatchment 
a. Confirmation of KBA trigger species' presence within sub-catchments

The species' presence was confirmed based on museum records from major collections, coarse scale distribution records and regional and international expert knowledge. When the records were too old (>50 years) and there was not enough evidence to confirm the presence of the species within the sub-catchments the species were listed as "potential" KBA trigger species and fieldwork was recommended. This was the case for many species of freshwater plant, Odonata and fish species.

\section{b. Boundary delineation with respect to pre-existing KBAs}

Wherever possible, identification and delineation of new KBAs should take into consideration the boundaries of pre-existing terrestrial KBAs, IBAs, IPAs or AZE sites (all of which now fall under the umbrella term "Key Biodiversity Area"), because many have national recognition, active conservation and monitoring initiatives, and/or are linked to international, national, regional legislative and policy processes (IUCN 2016). Thus, where freshwater trigger species are present in sub-catchments overlapping existing sites, the boundary of the existing site should be adopted if:

- the trigger species presence within the site meets the KBA criteria thresholds; and

- the boundary is ecologically relevant for management of the freshwater trigger species.

\section{c. Boundary delineation with respect to Protected Areas}

Protected Areas (PA) are established and largely well recognised management units with the goal of safeguarding the biodiversity contained within them. Additional recognition of the site as a freshwater KBA, using the existing site boundaries, can bring further attention to their importance and better focus management towards any newly recognised freshwater species of conservation concern. Therefore, when a freshwater trigger species falls within a sub-catchment overlapping an existing PA it is often appropriate to use the protected area boundary to delineate the KBA if:

- the PA contains enough of the KBA trigger species to meet the threshold of significance; and

- the boundary is ecologically relevant for the species.

It is important to highlight, however, that regional-scale assessments of the coverage and effectiveness of PAs have shown them to be largely ineffective for conserving freshwater habitats and species (Juffe-Bignoli et al. 2016; Leadley et al. 2014). For example, rivers have often been used to delineate the borders of PAs rather than being the targets of conservation themselves (Abell et al. 2007). Protected Areas also often lack target actions for management of freshwater biodiversity and often fail in dealing with pressures coming from outside the protected area boundaries. Therefore, where the distribution of a freshwater trigger species partially overlaps an existing PA there are generally three options: i) disregard the area of overlap (if trivial); ii) adopt the PA boundary for the freshwater KBA if it is fully within it; or iii) delineate a second freshwater KBA covering the part of the trigger species distribution falling outside the PA, assuming both areas independently still meet the thresholds of significance, and iv) recommend an extension to the PA boundary to include the full distribution of the freshwater KBA trigger species. The choice of approach will be case specific.

\section{d. Delineation of new freshwater KBAs}

When there is no spatial overlap between the proposed freshwater KBA and any pre-existing KBAs or PAs, site boundaries should be based on the location of Focal Areas identified for the freshwater KBA trigger species (if the Focal Area meets the KBA thresholds and criteria). Focal Areas are distinct sites (e.g. river headwaters, lakes, or springs) of particular importance for the long-term survival of the species (e.g. spawning areas, feeding areas, or sites supporting a significant part of the population of a species) (see Abell et al. 2007). It is recommended where possible, to delineate Focal Areas using HydroBASINS Level 12 sub-catchments (the smallest spatial units).

The new KBA global standard acknowledges that when delineating sites that fall outside existing KBAs and Protected Areas, it is often necessary to incorporate other data on land/water management and catchments boundaries to derive practical site boundaries (IUCN 2016). In the case of freshwater KBAs, using subcatchments to delineate site boundaries provides clear benefits as they represent well defined and ecologically meaningful management units, they facilitate ease of data storage, search and management (tabular format), account for hydrological connectivity, facilitate input to conservation planning software such as Marxan, and can be flexibly applied at 12 different grain sizes, the smallest being approximately $10 \mathrm{~km}^{2}$.

For some species, the inherent connectivity of aquatic systems presents challenges for effective management at the site scale. Many aquatic species are highly mobile and maybe widespread throughout a catchment (e.g. migratory fish species) and may not therefore occur at identifiable sites at globally significant population levels. Such species may not benefit from site scale conservation, but from a wider catchment management approach. 


\section{e. Complete minimum documentation requirements for each KBA}

Finally, workshop participants were asked to complete the minimum documentation requirements for each associated KBA including: a site description, list of validated trigger species, description of threats and habitat types within the site, conservation actions in place and recommended, and details for potential Site Champions (See section 9.4). This information is required to justify confirmation of a site as a KBA, and as guidance for management of the KBA, site-scale monitoring, national conservation planning and prioritysetting, and global and regional analyses.

Additional information for the larger sub-catchments, within which the KBAs are located, was also collated to inform KBA management within the wider hydrological context.

\subsection{Results}

\subsubsection{Freshwater KBA trigger species}

The preliminary analysis identified 238 potential KBA trigger species, out of which 92 were confirmed by the regional experts as valid, meaning that their presence was confirmed within the sub-catchments of interest at a threshold to trigger the KBA criteria (See Annex 9.1 for the full list of the KBA trigger species validated).

The KBAs validated at the workshop support 80 globally threatened species (Critically Endangered [CR], Endangered [EN] or Vulnerable [VU]), 62 geographically restricted range species and 10 species with demographic aggregations during one or more key stages of their life cycle (see Tables 9.2 and 9.3). Moreover, 14 of these species are also identified as AZE species that face an overwhelming high risk of extinction, and confirming the urgency to develop and implement effective conservation actions and management plans for freshwater biodiversity in Madagascar.

\subsubsection{Freshwater KBAs overview}

At the workshop 23 important river, lake and wetlands systems were validated by the regional experts as freshwater KBAs, 10 of which are also AZE sites. Most of the freshwater KBAs confirmed by this project are found within the NorthWestern freshwater ecoregion, and the Eastern highlands of Madagascar (see Figure 9.3 below and Annex 9.1 for the list of KBA trigger species).

Two existing Ramsar Sites (Nosivolo River and tributaries and Kinkony Lake) and three Protected Areas (Isalo National
Park, Mikea National Park and Marojejy National Park) were adopted as freshwater KBAs for 17 trigger species (one crab, six fishes, one mollusc and nine plant species). The following summaries provide some representative examples of these freshwater KBAs, and are largely based on a synthesis of the information provided at the KBA workshop, Red List species assessments and general descriptions from the Ramsar Sites Information Service and the National Parks webpages.

Lake Kinkony in the province de Mahajanga is an extremely shallow and turbid, oligotrophic floodplain lake characteristic of catchments in North-Western Madagascar. The vegetation includes vast reed beds of Phragmites in the eastern part, and beds of Cyperus in adjacent areas. The lake connects with other satellite lakes during the rainy season. The whole catchment including the headwaters and the tributaries that feed the lake has been delineated as a freshwater KBA for the endemic and CR AZE fish species Paretroplus dambabe (Ravelomanana \& Sparks 2016). The KBA is partially covered by the Mahavavy-Kinkony wetlands National Protected Area (IBA) including Lac Kinkony Ramsar Site. Despite international recognition of the importance of the area for biodiversity, a substantial portion of the catchment has been converted for rice cultivation and for grazing of livestock, and little original riparian vegetation remains. Overfishing, habitat loss (especially the transformation of floodplains into rice fields and eradication of natural lakeshore vegetation) and competition and predation by invasive alien species are the main threats to the freshwater biodiversity in the lake. Site protection, integrated catchment management and an extension of the Mahavavy-Kinkony wetlands NPA boundary to include the river headwaters is recommended to ensure effective management of those threats originating outside the lake and to guarantee the long-term persistence of $P$. dambabe.

The boundary of the Ramsar Site Nosivolo River and tributaries in the province of Toamasina was adopted as a freshwater KBA for threatened and restricted range species of fishes and plants. The Nosivolo near-natural ecosystem is recognised as having the highest concentration of endemic freshwater fishes in Madagascar. The Ramsar Site is situated in a rich wetland area in the eastern part of Madagascar. It comprises $130 \mathrm{~km}$ of river with associated lakes, pools and irrigated lands spread throughout $200 \mathrm{~km}^{2}$, including 62 inland islets within the river. The wetland acts as a catchment area with the floodplain retaining significant amounts of sediment. This is a good example of a site boundary incorporating an entire catchment so allowing for catchment management that accounts for hydrological connectivity and the associated spread of threats, such as from habitat degradation due to rice cultivation and soil erosion, throughout the catchment area. 
Table 9.2 Number of trigger species, threatened species, geographically restricted species, demographic aggregations and AZE species per taxonomic group. Note: some trigger species may be categorised to more than one of the KBA criteria (threatened/geographically restricted), and "AZE Species" are also categorised as "Trigger Species". The "Total" represents the number of unique species and is thus not necessarily the sum of the preceding columns.

\begin{tabular}{|l|c|c|c|c|c|c|c|}
\hline Group & Fishes & Odonata & Plants & Molluscs & Grabs & Grayfish & Total \\
\hline KBA Trigger Species & 35 & 2 & 39 & 5 & 8 & 3 & 92 \\
\hline Threatened Species & 34 & 2 & 35 & 5 & 1 & 3 & 80 \\
\hline Geographically Restricted & 19 & 1 & 30 & 3 & 8 & 2 & 62 \\
\hline Demographic Aggregations & 10 & 0 & 0 & 0 & 0 & 0 & 10 \\
\hline AZE Trigger Species & 7 & 0 & 5 & 1 & 1 & 0 & 14 \\
\hline
\end{tabular}

Table 9.3 Validated trigger species and the associated qualifying KBA criteria. A1a: Critically Endangered (CR) and Endangered (EN) species; A1b: Vulnerable Species (VU); A1e: AZE species; B1: Restricted Range species; D1a: Species Demographic Aggregations; D2: Species Ecological Refugia. The "Total" represents the number of distinct trigger species and does not represent the sum of the columns, as some species may qualify for more than one criterion.

\begin{tabular}{|l|c|c|c|c|c|c|c|}
\hline Group & A1a & A1b & A1e & B1 & D1a & D2 & Total \\
\hline Fishes & 30 & 4 & 7 & 19 & 10 & 3 & 35 \\
\hline Molluscs & 4 & 1 & 1 & 3 & 0 & 0 & 5 \\
\hline Plants & 27 & 8 & 5 & 30 & 0 & 0 & 39 \\
\hline Crabs & 1 & 0 & 1 & 8 & 0 & 0 & 8 \\
\hline Crayfish & 0 & 3 & 0 & 2 & 0 & 0 & 3 \\
\hline Odonata & 2 & 0 & 0 & 1 & 0 & 0 & 2 \\
\hline
\end{tabular}

Marojejy National Park comprises the forested Marojejy massif and its neighbouring foothills. The massif is mountainous, with steep, granitic peaks, quartzite crests and narrow valleys. There are significant variations in microclimate, from sub-humid to humid, and from cold to temperate. The Androranga River flows along the northern boundary of the park and the Lokoho River to the south and east. Marojejy is the only one of the five large mountainous massifs in Madagascar whose high-altitude vegetation is still largely intact. Most of the site is covered in dense, humid evergreen forest. The Marojejy National Park has been adopted as a freshwater KBA for a number of threatened and restricted range species, including the EN AZE fish species Bedotia marojejy, currently known only from the type locality in the Manantenina River, an affluent of Lokoho River flowing from the southern part of the park (Stiassny \& Harrison 2000). This fish species requires fast flowing clear upland streams and rivers, as are present in the southern part of the KBA. A number of VU freshwater plant species are also restricted to this smaller river system including Deparia marojejyensis and Pneumatopteris humbertii. A species of freshwater crab, Marojejy longimerus, is only known from this site.

\subsubsection{Current levels of protection}

The area of validated freshwater KBAs is $23,920 \mathrm{~km}^{2}$ representing $4 \%$ of the total land area of Madagascar $\left(587,041 \mathrm{~km}^{2}\right)$. The area of existing Protected Areas adopted for freshwater trigger species is $9,159 \mathrm{~km}^{2}$ (38\% of the total area of confirmed freshwater KBAs).

Even though $38 \%$ of freshwater KBAs spatially overlap PAs, it is important to highlight that in most cases (except for the Ramsar Site Nosivolo River and tributaries), freshwater species, with the exception of water birds, are not often the focus of conservation and management actions within these areas that are delineated primarily for terrestrial species (mammals, reptiles and birds). Therefore, it is most important now to inform national parks and Ramsar Sites management authorities about the presence of these freshwater KBA trigger species within their site boundaries.

\subsubsection{Newly delineated KBAs}

Nineteen new freshwater KBAs (see Annex 9.1) were delineated for 77 trigger species, covering 14,761 km² (62\% the total area of confirmed freshwater KBAs). All these sites remain outside the boundaries of any pre-existing PAs or KBAs, suggesting that significant gaps remain in the coverage of freshwater biodiversity by existing conservation management units. A strategic expansion of the protected area network is recommended to include these critical areas of conservation concern.

The following summary provides some examples to demonstrate the rationale behind designation of the new freshwater KBAs delineated in Madagascar. This is largely based on information provided at the KBA workshop, Red List assessments and general descriptions from the Freshwater Ecoregions of the World (FEOWS 2015).

Antsiranana KBA located in northern Madagascar has been identified as a biodiversity hotspot for freshwater crabs. Seven species of freshwater crabs endemic to Madagascar are found here. These species inhabit a wide range of habitats including lakes, streams, rivers and the adjacent terrestrial habitats that include rocky crevices and phytotelmata (water bodies held by terrestrial plants). 
Figure 9.3 Map showing the location of newly confirmed freshwater KBAs in Madagascar.

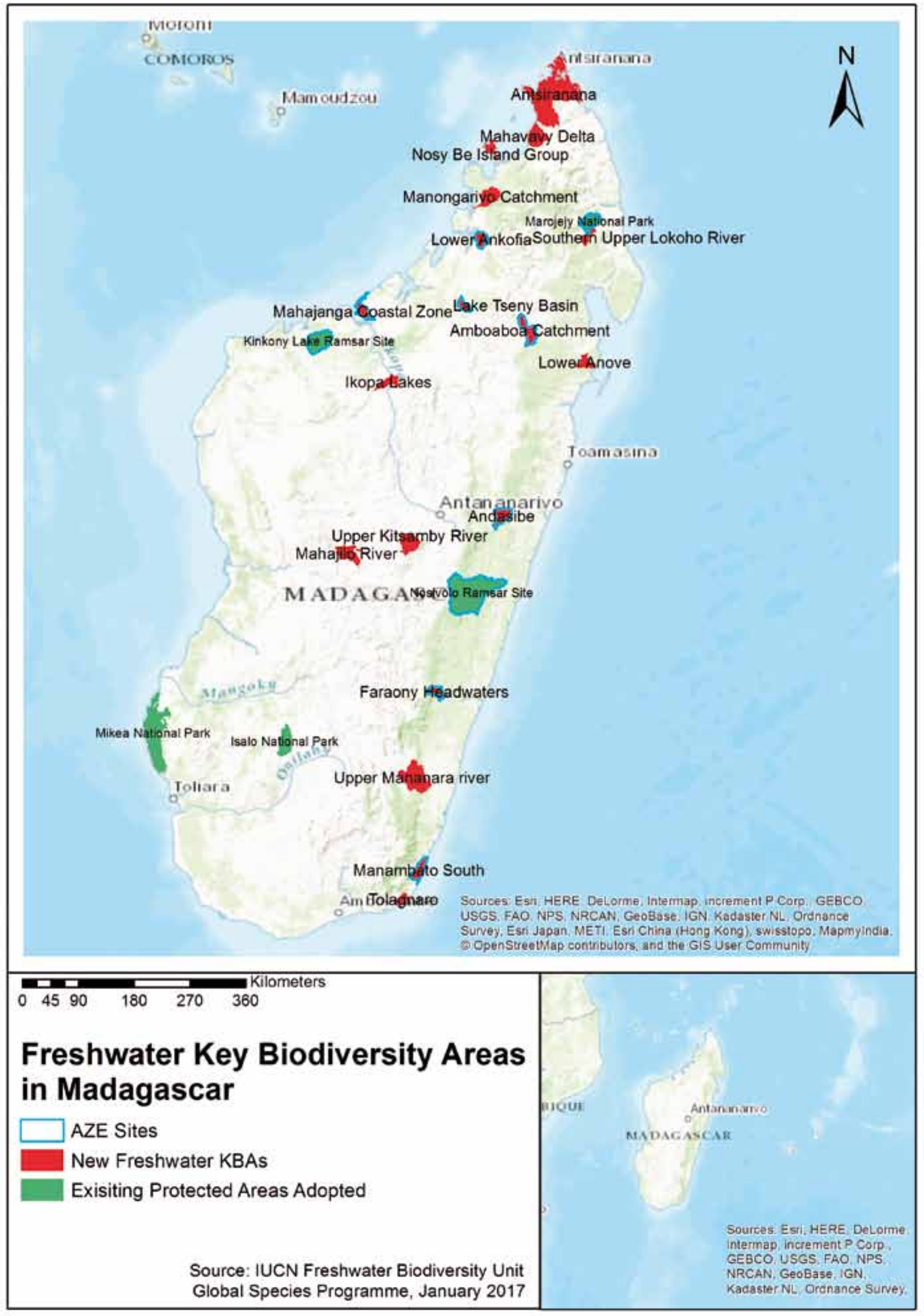


The KBA overlaps a number of existing National Parks and KBAs but given the importance of the region as a freshwater biodiversity hotspot for many restricted range, endemic species it was not thought ecologically appropriate to adopt any of the existing site boundaries nor to reduce the freshwater KBA size to below that for the boundary proposed. A number of other threatened and restricted range species of freshwater fishes, molluscs and plants are also present within the KBA. The main threats to the site include slash and burn agriculture, urban developments for tourism, sapphire mining and quarrying. Site protection and management, awareness rising, compliance and enforcement of policies and regulations and implementation of private sector environmental and social safeguards and standards are recommended.

The Amboaboa catchment in the province of Mahajanga has been delineated as a new freshwater KBA for five threatened and restricted range fish species. Within the catchment two Focal Areas have been identified based on the species spawning and feeding grounds in the lower and upper river reaches, however, it was decided to delineate the whole catchment as a KBA to take into account the ecological corridor of the species. The existing Marotandrano Protected Area partially overlaps the headwaters of the Amboaboa River, a Focal Area for the AZE freshwater fish species Rheocles derhami and Paretroplus gymnopreopercularis and the EN and CR Sauvagella robusta and Ptychochromis insolitus. The Amboaboa River flows through mountainous areas with generally degraded savannah vegetation and is threatened by sedimentation caused by deforestation and soil erosion, pollution by agricultural effluents, invasive species, overfishing and drought. The confluence of the Amboaboa River with the Mangarahara River has been identified as a Focal Area for Paretroplus gymnopreopercularis and Paretroplus nourissati. Integrated catchment management is recommended to account for hydrological connectivity and to ensure the long-term persistence of these CR and EN species of freshwater fishes.

The Tolagnaro KBA encompasses the coastal zone around the city of Tolagnaro, extending into the foothills of the Anosy mountain chain. The site is drained by several short rivers and contains a number of lagoons, marshlands and littoral forests that support two threatened species of plants (Aponogeton capuronii and Xyris baronii) and two threatened species of Odonata (Acisoma ascalaphoides and Aethiothemis modesta). In addition to an area of urban development, there is an airport and mining (operated by QIT Madagascar Minerals; QMM) takes place within the KBA. The southern part of Tsitongambarika Protected Area overlaps the KBA and includes the headwaters of the associated coastal rivers. The small Protected Area Mandena also overlaps with the
KBA. The main threats to biodiversity in the site are habitat loss and degradation caused by urbanisation and industrial activities. Even though efforts are being undertaken to offset mining impacts by QMM further site protection and management are recommended.

The Lower Anove KBA in the province of Toamasina includes the lower sub-catchments of the Anove River. A number of freshwater species are present within the Anove River system; the most notable being Bedotia longianalis, an EN species of fish restricted to the lower reaches of the river within the KBA. Aponogeton eggersii, an EN species of aquatic plant, is endemic to the Analanjirofo region of Madagascar and recorded in 2000 in the Anove River within the KBA. Two other rare species of freshwater plants, Didymoglossum pygmaeum and Peponidium anoveanum, are also known from the KBA but they have not been recorded since the early 1900s. Field surveys are recommended to look for the presence of these two plant species within the KBA. Management of the site should be conducted within the wider context of the Anove River catchment. The KBA Catchment Management Zone (the land area recommended for effective management of impacts to the KBA itself) includes the entire Anove River catchment upstream of the KBA itself. The Lower Anove River KBA is dominated by lowland hills with some remaining areas of humid forest. Other areas have mainly been converted to agriculture such as for rice farming and the growing of vanilla and cloves. The rivers within the KBA itself, being in the lowlands coastal plains, are relatively slow flowing. The rivers are also mined here for precious stones and gold. The main threats to the site include small scale but widespread gold mining, shifting agriculture, deforestation and competition with invasive species. Site protection and integrated catchment management are recommended.

\subsection{Site champions}

Thirty-four potential Site Champions have been identified by stakeholders as individuals/organisations best placed to raise awareness of the existence of the KBAs and the issues faced with respect to threats to freshwater biodiversity. It is recommended to engage and collaborate with these potential Site Champions in the development and implementation of required actions to safeguard these globally important sites (see Annex 9.2).

\subsection{Summary and recommendations}

The 23 freshwater KBAs confirmed by the experts for freshwater fishes, molluscs, odonates, crabs, crayfishes and aquatic plants, cover a total area of $23,920 \mathrm{~km}^{2}$ (almost $4 \%$ of 
the country area). These KBAs support 80 globally threatened species (CR, EN or VU) and 62 geographically restricted range species. Of these, 10 also meet the criteria for the AZE sites.

Around $38 \%$ of the total area of the freshwater KBAs $\left(9,159 \mathrm{~m}^{2}\right)$ confirmed through this project was found to lie within the boundaries of pre-existing Protected Areas. The additional recognition of these sites as global freshwater KBAs brings them greater individual recognition and collectively helps to highlight the urgent need to implement more effective conservation actions and environmental safeguards for freshwater biodiversity in Madagascar.

Most of these existing management units have been delineated primarily for terrestrial species such that they will often fail to focus on targeted management for the many restricted range and threatened species living in freshwater habitats. It is now a priority to inform the management authorities for these sites of the need to develop new management actions that specifically focus on conservation of these globally important freshwater species.

The remaining $62 \%$ of the freshwater KBAs area, located outside of any existing Protected Areas, represent priority gaps in the current network. The location of these KBAs will inform future strategies for improving the representation of freshwater biodiversity within the National Protected Areas Network, or as targets for habitat restoration efforts where protected area status might be inappropriate. It is hoped that the Site Champions identified through this project (see Annex 9.2) will help to stimulate these actions by building awareness of the existence of these priority freshwater sites and the need for conservation actions.

The identification and delineation of KBAs is necessarily a fluid and ongoing process responding to the provision of new information and a constantly changing environment and, thus, it is expected that this current freshwater KBA dataset for Madagascar will continue to be refined and updated. Ultimately the process for identification of KBAs should be nationally driven such that all relevant parties can be directly involved, especially to facilitate any recommendations to change boundaries of existing Protected Areas or KBAs. The work presented above represents the first steps in taking this process forwards and it provides a baseline data set to inform future KBA designations.

The primary threats to freshwater species identified across Madagascar, as identified through this project, include: i) habitat degradation and soil erosion caused by deforestation, slash and burn agriculture, and human encroachment; ii) surface water pollution by raw sewage and other organic wastes, sedimentation, and eutrophication; iii) competition with invasive alien species, and; iv) severe droughts and desertification driven by climate change. The impacts of these types of threat tend to spread rapidly throughout catchments such that localised conservation actions restricted to limited parts of a catchment will often fail to provide effective solutions. It is therefore necessary to focus on management of the wider catchment within which KBAs reside, taking into account both lateral and longitudinal hydrological connectivity.

Integrated River Basin Management (IRBM, or a similar strategy) is an approach recommended for most freshwater KBAs to ensure effective management of both upstream and downstream threats often originating outside of the KBA boundaries, in many cases some distance from the KBA itself. This approach is fundamental to better coordinate conservation, management and development planning of water, land and related resources across sectors, and to maximise the economic and social benefits derived from water resources in an equitable manner while preserving and, where necessary, restoring freshwater ecosystems.

The Environmental Flows (E-Flows) assessment methodology is also an important tool for the conservation and management of freshwater KBAs. E-Flows aim to maintain the quality, quantity and timing of water flows required to sustain freshwater ecosystems and the human livelihoods that depend on them (Dyson et al. 2008; Harwood et al. 2017). As a first priority E-Flows should be determined, where appropriate, for all freshwater AZE sites involving riverine systems, such as the Amboaboa catchment.

Invasive alien species are one of the major threats identified to freshwater biodiversity in Madagascar, so increased efforts are required to trace their pathways for introduction, prevent future introductions, and to manage or where feasible eradicate them. Information on the distribution of invasive alien species, their impacts, pathways of invasion and management recommendations them can be found in the Global Invasive Species Database (GISD) (ISSG 2015). Information collated through the KBA delineation and validation process should ultimately feed into the GISD, which is also linked to the IUCN Red List.

Periodic updates of IUCN Red List assessments and monitoring of KBAs sites will enable calculation of a Red List Index for all freshwater species assessed (currently this is only possible for endemic freshwater fishes). Consequently, it is possible to track trends in the projected overall extinction risk of freshwater species, thereby potentially helping to inform managers on the effectiveness of any management interventions.

The freshwater KBAs identified in this project will also help support the implementation of Multilateral Environmental 
Agreements in Madagascar, such as the Ramsar Convention, guiding conservation planning and prioritysetting at national level to: i) identify new and potential Wetlands of International Importance (Ramsar Sites) under Criteria 2 to 9 (Ramsar 2010); ii) update existing Ramsar site management to focus on the new freshwater trigger species found within their boundaries (e.g. Rivière Nosivolo et affluents Ramsar Site); and iii) identify existing Ramsar sites meeting the KBA criteria that are undergoing adverse changes in their ecological character and that might be eligible for inclusion on the Montreux Record and would potentially benefit from a Ramsar Advisory Mission.

The network of freshwater KBAs will also help Madagascar in its work towards meeting the Aichi Biodiversity Targets (in particular Targets 11 and 12) as established by the Convention on Biological Diversity. These two targets specifically address the need for conservation of species and sites. In addition, freshwater KBAs can help identify freshwater ecosystem priorities for the UN Sustainable Development Goals, and provide a better metric for measurement of Sustainable Development target 6.6 focused on protecting and restoring water-related ecosystems; target 6.5 focused on implementing integrated water resources management at all levels; target $\mathbf{1 5 . 1}$ focused on the conservation, restoration and sustainable use of terrestrial and inland freshwater ecosystems and their services; and target 15.5 focused on taking urgent and significant action to reduce the degradation of natural habitats, halt the loss of biodiversity and, by 2020, protect and prevent the extinction of threatened species (United Nations 2016).

Finally, it is expected that the list of freshwater KBAs presented in this report will guide conservation investment priorities and inform performance standards and environmental safeguard policies of financial institutions and the private sector to help avoid or minimise impacts of their operations in and around these critical sites for freshwater biodiversity in Madagascar.

\subsection{Next steps}

- This report and related policy briefs will be circulated to all Site Champions and cross-sectorial government departments.

- Information on the sites will be made available through the World Database on Key Biodiversity Areas http:// www.keybiodiversityareas.org/home (WDKBA) managed by Birdlife International and through the Integrated Biodiversity Assessment Tool https://www. ibatforbusiness.org/ (IBAT) - a tool that is already well known amongst the private sector and donor community.

\subsection{References}

Abell, R., Allan, J.D. and Lehner, B. 2007. Unlocking the potential of protected areas for freshwaters. Biological Conservation 134: 48-63. https://doi.org/10.1016/j. biocon.2006.08.017

Butchart, S.H.M., Scharlemann, J.P.W., Evans, M.I., et al. 2012. Protecting important sites for biodiversity contributes to meeting global conservation targets. PLoS One 7: e32529. https://doi.org/10.1371/journal.pone.0032529

Conservation International. 2014. Ecosystem profile: Madagascar and Indian Ocean Islands. Critical Ecosystem Partnership Fund. Final Version: December 2014.

Dyson, M., Bergkamp, G. and Scanlon, J. 2008. Flow - The Essentials of Environmental Flows, 2nd ed. IUCN Reprint, Gland, Switzerland.

Dudley, N., Boucher, J.L., Cuttelod, A., et al. 2014. Applications of Key Biodiversity Areas: end-user consultations. Cambridge, UK and Gland, Switzerland: IUCN.

Harry D.J., Barbuto, V., Jonas, H.C. et al. 2014. New Steps of Change: Looking Beyond Protected Areas to Consider Other Effective Area-Based Conservation Measures. Parks 20.2: 111-128. https://doi.org/10.2305/IUCN.CH.2014. PARKS-20-2.HDJ.en

Harwood, A., Johnson, S., Richter, B., et al. 2017. Listen to the river: Lessons from a global review of environmental flow success stories, WWF-UK, Woking, UK.

Invasive Species Specialist Group ISSG 2015. The Global Invasive Species Database. Version 2015.1. Available at: http://www.iucngisd.org/gisd

IUCN. 2004. Resolution (WCC 3.013) World Conservation Congress, Bangok, Thailand 17-25 November 2004. Available at: https://cmsdata.iucn.org/downloads/ wcc_res_rec_eng.pdf

IUCN. 2014. Consultation Document on an IUCN Standard for the Identification of Key Biodiversity Areas. Available at: http://www.kbaconsultation.org/\#!executive-summary/ c109f

IUCN. 2016. A Global Standard for the Identification of Key Biodiversity Areas, Version 1.0. First edition. Gland, Switzerland: IUCN.

IUCN. 2017. The IUCN Red List of Threatened Species. [Online] Available at: www.iucnredlist.org [Accessed 7 May 2017].

Juffe-Bignoli, J., Harrison, I., Butchart, S.H.M., et al. 2016. Achieving Aichi Biodiversity Target 11 to improve the performance of protected areas and conserve freshwater biodiversity. Aquatic Conservation: Marine and Freshwater Ecosystems 26: 133-151. https://doi.org/10.1002/ aqc.2638

Leadley, P.W., Krug, C.B., Alkemade, R., et al. 2014. Progress towards the Aichi Biodiversity Targets: an assessment of biodiversity trends, policy scenarios and key actions. Secretariat of the Convention on Biological Diversity, 
Montreal, Canada. Technical Series 78. https://www.cbd. int/doc/publications/cbd-ts-78-en.pdf

Lehner, B. and Grill, G. 2013. Global river hydrography and network routing: baseline data and new approaches to study the world's large river systems. Hydrological Processes 27(15): 2171-2186. Data is available at www. hydrosheds.org. https://doi.org/10.1002/hyp.9740

Ramsar Convention Secretariat. 2010. Designating Ramsar Sites: Strategic Framework and guidelines for the future development of the List of Wetlands of International Importance. Ramsar handbooks for the wise use of wetlands, 4th edition, vol. 17. Ramsar Convention Secretariat, Gland, Switzerland.

Ravelomanana, T. and Sparks, J.S. 2016. Paretroplus dambabe. The IUCN Red List of Threatened Species 2016: e.T44495A58308076. Downloaded on 30 June 2017. https://doi.org/10.2305/IUCN.UK.2016-3.RLTS. T44495A58308076.en

Ricketts, T.H., Dinerstein, E., Boucher, T., et al. 2005. Pinpointing and preventing imminent extinctions.
Proceedings of the National Academy of Sciences of the United States of America 102: 18497-18501. https://doi. org/10.1073/pnas.0509060102

Stiassny, M.L.J. and Harrison, I.J. 2000. Notes on a small collection of fishes from the Réserve Naturelle Intégrale de Marojejy, Northeastern Madagascar, with a description of a new species of the endemic genus Bedotia (Atherinomorpha: Bedotiidae). Fieldiana - Zoology 97: 143-156.

United Nations 2016. The Sustainable Development Goals Report 2016. Available at: www.un.org.lb/Library/Assets/ The-Sustainable-Development-Goals-Report-2016Global.pdf

Venables, W.N., Smith D.M. and the R Core Team. 2017. An Introduction to R. Notes on R: A Programming Environment for Data Analysis and Graphics. Version 3.4.1 (2017-0603). The R Manuals. Available at: https://cran.r-project. org/doc/manuals/r-release/R-intro.pdf

Annex 9.1 KBA trigger species.

$\mathrm{KBA}=$ Freshwater Key Biodiversity Area name. Trigger Species = Freshwater species meeting the KBA Criteria.

Selected KBA criteria used for the delineation of freshwater KBAs in Madagascar (IUCN 2016).

\begin{tabular}{|l|l|c|c|}
\hline \multirow{2}{*}{ A. Threatened biodiversity } & Biodiversity element at site & \% global pop. size/extent & $\begin{array}{c}\text { Reproductive } \\
\text { Units }\end{array}$ \\
\hline \multirow{2}{*}{ A1. Threatened species } & (a) CR or EN species & $\geq 0.5 \%$ & $\geq 1 \%$ \\
\cline { 2 - 4 } & (b) VU species & $\begin{array}{c}\text { Entire global } \\
\text { population size }\end{array}$ & $\geq 10$ \\
\cline { 2 - 4 } & (e) CR or EN species & $\%$ global pop. size/extent & $\begin{array}{c}\text { Reproductive } \\
\text { Units }\end{array}$ \\
\hline B. Geographically restricted biodiversity & Biodiversity element at site & $\geq 10 \%$ & $\geq 10$ \\
\hline B1: Individually geographically restricted species & Any species & $\%$ global pop. size/extent & $\geq 1 \%$ \\
\hline D. Biological processes & Biodiversity element at site & \\
\hline D1: Demographic aggregations & $\begin{array}{l}\text { (a) Species aggregation during one or more } \\
\text { key stages of its life cycle }\end{array}$ & $\begin{array}{l}\geq 10 \% \\
\end{array}$ \\
\hline D2: Ecological refugia & $\begin{array}{l}\text { Species aggregations during periods of past, } \\
\text { current or future environmental stress }\end{array}$ & \\
\hline
\end{tabular}

\begin{tabular}{|c|c|c|c|c|c|c|c|c|c|c|}
\hline KBA Name & Trigger species & Group & $\begin{array}{l}\text { Red List } \\
\text { Category }\end{array}$ & $\begin{array}{l}\text { Criterion } \\
\text { A1a }\end{array}$ & $\begin{array}{l}\text { Criterion } \\
\text { A1b }\end{array}$ & $\begin{array}{l}\text { Criterion } \\
\text { A1e (AZE) }\end{array}$ & $\begin{array}{l}\text { Criterion } \\
\text { B1 }\end{array}$ & $\begin{array}{l}\text { Criterion } \\
\text { D1a }\end{array}$ & $\begin{array}{l}\text { Criterion } \\
\text { D2 }\end{array}$ & $\begin{array}{l}\text { New/ } \\
\text { Adopted }\end{array}$ \\
\hline \multirow{5}{*}{$\begin{array}{l}\text { Amboaboa } \\
\text { Catchment }\end{array}$} & Paretroplus nourissati & Fishes & EN & yes & & & NA & & & \multirow[t]{5}{*}{ New KBA } \\
\hline & Ptychochromis insolitus & Fishes & $\mathrm{CR}$ & yes & & & NA & yes & yes & \\
\hline & Rheocles derhami & Fishes & CR & yes & & & $28.3 \%$ & yes & yes & \\
\hline & Sauvagella robusta & Fishes & EN & yes & & & NA & & & \\
\hline & $\begin{array}{l}\text { Paretroplus } \\
\text { gymnopreopercularis }\end{array}$ & Fishes & CR & & & yes & $100 \%$ & & yes & \\
\hline
\end{tabular}


Annex 9.1 cont'd KBA trigger species.

\begin{tabular}{|c|c|c|c|c|c|c|c|c|c|c|}
\hline KBA Name & Trigger species & Group & $\begin{array}{l}\text { Red List } \\
\text { Category }\end{array}$ & \begin{tabular}{|l|} 
Criterion \\
A1a
\end{tabular} & $\begin{array}{l}\text { Criterion } \\
\text { A1b }\end{array}$ & $\begin{array}{l}\text { Criterion } \\
\text { A1e (AZE) }\end{array}$ & \begin{tabular}{|l} 
Criterion \\
B1
\end{tabular} & \begin{tabular}{|l} 
Criterion \\
D1a
\end{tabular} & $\begin{array}{l}\text { Criterion } \\
\text { D2 }\end{array}$ & $\begin{array}{l}\text { New/ } \\
\text { Adopted }\end{array}$ \\
\hline \multirow{11}{*}{$\begin{array}{l}\text { Mahajanga } \\
\text { coastal zone }\end{array}$} & Paretroplus kieneri & Fishes & VU & & yes & & $N A$ & & & \multirow[t]{11}{*}{ New KBA } \\
\hline & Ammannia heterophylla & Plants & EN & yes & & & $11 \%$ & & & \\
\hline & $\begin{array}{l}\text { Ammannia } \\
\text { pauciramosa }\end{array}$ & Plants & EN & yes & & & $17.2 \%$ & & & \\
\hline & Cleome augustinensis & Plants & EN & yes & & & $16.2 \%$ & & & \\
\hline & Exacum gracile & Plants & EN & yes & & & NA & & & \\
\hline & Grangeopsis perrieri & Plants & EN & yes & & & $11.3 \%$ & & & \\
\hline & Klackenbergia stricta & Plants & EN & yes & & & $13.5 \%$ & & & \\
\hline & $\begin{array}{l}\text { Neostapfiella } \\
\text { chloridiantha }\end{array}$ & Plants & EN & yes & & & $24.5 \%$ & & & \\
\hline & Nymphoides elegans & Plants & EN & yes & & & NA & & & \\
\hline & $\begin{array}{l}\text { Pycreus } \\
\text { compressiformis }\end{array}$ & Plants & EN & yes & & & $18.6 \%$ & & & \\
\hline & $\begin{array}{l}\begin{array}{l}\text { Schoenoplectiella } \\
\text { perrieri }\end{array} \\
\end{array}$ & Plants & CR & yes & & yes & $100 \%$ & & & \\
\hline \multirow{8}{*}{$\begin{array}{l}\text { Nosivolo } \\
\text { River and } \\
\text { tributaries } \\
\text { (Ramsar } \\
\text { Site) }\end{array}$} & Gogo ornatus & Fishes & EN & yes & & & NA & & & \multirow[t]{8}{*}{ Adopted } \\
\hline & Katria katria & Fishes & EN & yes & & & NA & & & \\
\hline & Rheocles lateralis & Fishes & CR & yes & & yes & $100 \%$ & yes & & \\
\hline & Dicoryphe angustifolia & Plants & EN & yes & & & $59.6 \%$ & & & \\
\hline & Diospyros anosivolensis & Plants & $\mathrm{CR}$ & yes & & yes & $100 \%$ & & & \\
\hline & $\begin{array}{l}\text { Diospyros } \\
\text { dicorypheoides }\end{array}$ & Plants & EN & yes & & & $14 \%$ & & & \\
\hline & Hydrostachys laciniata & Plants & VU & & yes & & NA & & & \\
\hline & $\begin{array}{l}\text { Hydrostachys } \\
\text { verruculosa }\end{array}$ & Plants & VU & & yes & & NA & & & \\
\hline \multirow[t]{4}{*}{ Tolagnaro } & Aethiothemis modesta & Odonata & EN & yes & & & NA & & & \multirow[t]{4}{*}{ New KBA } \\
\hline & Aponogeton capuronii & Plants & EN & yes & & & $22.1 \%$ & & & \\
\hline & Xyris baronii & Plants & VU & & yes & & $16.3 \%$ & & & \\
\hline & Acisoma ascalaphoides & Odonata & EN & yes & & & NA & & & \\
\hline \multirow{3}{*}{$\begin{array}{l}\text { Faraony } \\
\text { Headwaters }\end{array}$} & Astacoides crosnieri & Crayfish & VU & & yes & & $17.2 \%$ & & & \multirow[t]{3}{*}{ New KBA } \\
\hline & Bedotia tricolor & Fishes & CR & & & yes & $100 \%$ & & & \\
\hline & Hydrostachys perrieri & Plants & CR & & & yes & $100 \%$ & & & \\
\hline \multirow{2}{*}{$\begin{array}{l}\text { Isalo } \\
\text { National } \\
\text { Park }\end{array}$} & Lanistes grasseti & Molluscs & VU & & yes & & NA & & & \multirow[t]{2}{*}{ Adopted } \\
\hline & Thelethylax isalensis & Plants & CR & & & yes & $100 \%$ & & & \\
\hline \multirow{6}{*}{$\begin{array}{l}\text { South } \\
\text { Manambato }\end{array}$} & Kuhlia sauvagii & Fishes & VU & & yes & & & & & \multirow[t]{6}{*}{ New KBA } \\
\hline & Aethiothemis modesta & Odonata & EN & yes & & & $17.6 \%$ & & & \\
\hline & Aponogeton capuronii & Plants & EN & yes & & & $43.3 \%$ & & & \\
\hline & Benthamia calceolata & Plants & EN & yes & & & $17.1 \%$ & & & \\
\hline & Dypsis aquatilis & Plants & $\mathrm{CR}$ & yes & & yes & $100 \%$ & & & \\
\hline & Xyris baronii & Plants & VU & & yes & & $32 \%$ & & & \\
\hline \multirow{6}{*}{$\begin{array}{l}\text { Mahavavy } \\
\text { Delta }\end{array}$} & Paratilapia polleni & Fishes & VU & & yes & & & & & \multirow[t]{6}{*}{ New KBA } \\
\hline & $\begin{array}{l}\text { Ptychochromis } \\
\text { oligacanthus }\end{array}$ & Fishes & EN & yes & & & & & & \\
\hline & Teramulus waterloti & Fishes & EN & yes & & & & & & \\
\hline & \begin{tabular}{|l|} 
Madagasikara \\
madagascarensis \\
\end{tabular} & Molluscs & EN & yes & & & $15.2 \%$ & & & \\
\hline & Paretroplus damii & Fishes & VU & & yes & & $12.9 \%$ & & & \\
\hline & Trachypteris drakeana & Plants & VU & & yes & & & & & \\
\hline
\end{tabular}


Annex 9.1 cont'd KBA trigger species.

\begin{tabular}{|c|c|c|c|c|c|c|c|c|c|c|}
\hline KBA Name & Trigger species & Group & $\begin{array}{l}\text { Red List } \\
\text { Category } \\
\end{array}$ & $\begin{array}{l}\text { Criterion } \\
\text { A1a } \\
\end{array}$ & $\begin{array}{l}\text { Griterion } \\
\text { A1b } \\
\end{array}$ & $\begin{array}{l}\text { Criterion } \\
\text { A1e (AZE) }\end{array}$ & $\begin{array}{l}\text { Criterion } \\
\text { B1 } \\
\end{array}$ & $\begin{array}{l}\text { Criterion } \\
\text { D1a } \\
\end{array}$ & $\begin{array}{l}\text { Criterion } \\
\text { D2 } \\
\end{array}$ & $\begin{array}{l}\text { New/ } \\
\text { Adopted } \\
\end{array}$ \\
\hline \multirow[t]{3}{*}{ Ikopa Lakes } & Paretroplus kieneri & Fishes & VU & & yes & & & yes & & \multirow[t]{3}{*}{ New KBA } \\
\hline & Paretroplus maculatus & Fishes & CR & yes & & & $29.1 \%$ & yes & & \\
\hline & $\begin{array}{l}\text { Grangea } \\
\text { madagascariensis }\end{array}$ & Plants & EN & yes & & & & & & \\
\hline \multirow{5}{*}{$\begin{array}{l}\text { Lower } \\
\text { Ankofia }\end{array}$} & Arius uncinatus & Fishes & CR & yes & & yes & $100 \%$ & yes & & \multirow[t]{5}{*}{ New KBA } \\
\hline & $\begin{array}{l}\text { Pachypanchax } \\
\text { sparksorum }\end{array}$ & Fishes & EN & yes & & & $15 \%$ & yes & & \\
\hline & \begin{tabular}{|l|} 
Paretroplus \\
maromandia
\end{tabular} & Fishes & EN & yes & & & & yes & & \\
\hline & $\begin{array}{l}\text { Ptychochromis } \\
\text { inornatus }\end{array}$ & Fishes & EN & yes & & & & yes & & \\
\hline & Teramulus waterloti & Fishes & EN & yes & & & & & & \\
\hline \multirow[t]{6}{*}{ Andasibe } & $\begin{array}{l}\text { Astacoides } \\
\text { betsileoensis }\end{array}$ & Crayfish & VU & & Yes & & $11.2 \%$ & & & \multirow[t]{6}{*}{ New KBA } \\
\hline & Astacoides caldwelli & Crayfish & VU & & Yes & & NA & & & \\
\hline & Bedotia leucopteron & Fishes & EN & Yes & & & NA & & & \\
\hline & $\begin{array}{l}\text { Madagasikara } \\
\text { vazimba }\end{array}$ & Molluscs & EN & & & Yes & $100 \%$ & & & \\
\hline & Helichrysum flagellare & Plants & VU & & yes & & $10 \%$ & & & \\
\hline & Zygophlebia subpinnata & Plants & NA & & & & $21.3 \%$ & & & \\
\hline \multirow[t]{16}{*}{ Antsiranana } & Boreathelphusa uglowi & Crabs & EN & Yes & & & $81.7 \%$ & & & \multirow[t]{16}{*}{ New KBA } \\
\hline & Foza ambohitra & Crabs & NA & & & & $61.3 \%$ & & & \\
\hline & Foza manonae & Crabs & NA & & & yes & $99.9 \%$ & & & \\
\hline & $\begin{array}{l}\text { Madagapotamon } \\
\text { humberti }\end{array}$ & Crabs & NA & & & & $57.5 \%$ & & & \\
\hline & Skelosophusa eumeces & Crabs & NA & & & & $34.6 \%$ & & & \\
\hline & Skelosophusa gollardi & Crabs & NA & & & & $83.6 \%$ & & & \\
\hline & Skelosophusa prolixa & Crabs & NA & & & & $75.2 \%$ & & & \\
\hline & $\begin{array}{l}\text { Glossogobius } \\
\text { ankaranensis }\end{array}$ & Fishes & NA & & & & $49.8 \%$ & & & \\
\hline & $\begin{array}{l}\text { Pachypanchax } \\
\text { sakaramyi }\end{array}$ & Fishes & EN & Yes & & & $78 \%$ & & & \\
\hline & Eupera degorteri & Molluscs & EN & Yes & & & $23.5 \%$ & & & \\
\hline & \begin{tabular}{|l|} 
Madagasikara \\
madagascarensis
\end{tabular} & Molluscs & EN & Yes & & & $72.2 \%$ & & & \\
\hline & Aponogeton ulvaceus & Plants & NA & & & & $25.7 \%$ & & & \\
\hline & Aponogeton viridis & Plants & EN & Yes & & & $75.8 \%$ & & & \\
\hline & Ixora ripicola & Plants & NA & & & & $26.1 \%$ & & & \\
\hline & $\begin{array}{l}\text { Pneumatopteris } \\
\text { humbertii }\end{array}$ & Plants & VU & & Yes & & $52.1 \%$ & & & \\
\hline & Trachypteris drakeana & Plants & VU & & Yes & & $40 \%$ & & & \\
\hline \multirow{5}{*}{$\begin{array}{l}\text { Lake Tseny } \\
\text { Catchment }\end{array}$} & Paretroplus lamenabe & Fishes & EN & Yes & & & NA & & & \multirow[t]{5}{*}{ New KBA } \\
\hline & Sauvagella robusta & Fishes & EN & Yes & & & NA & & & \\
\hline & Hydrostachys maxima & Plants & VU & & Yes & & NA & & & \\
\hline & Arius festinus & Fishes & CR & & & Yes & $100 \%$ & & & \\
\hline & $\begin{array}{l}\text { Paretroplus } \\
\text { menarambo }\end{array}$ & Fishes & CR & & & Yes & $100 \%$ & & & \\
\hline \multirow{2}{*}{$\begin{array}{l}\text { Lower Anove } \\
\text { River }\end{array}$} & Bedotia Iongianalis & Fishes & EN & Yes & & & NA & & & \multirow[t]{2}{*}{ New KBA } \\
\hline & Aponogeton eggersii & Plants & EN & Yes & & & $23 \%$ & & & \\
\hline
\end{tabular}


Annex 9.1 cont'd KBA trigger species.

\begin{tabular}{|c|c|c|c|c|c|c|c|c|c|c|}
\hline KBA Name & Trigger species & Group & $\begin{array}{l}\text { Red List } \\
\text { Category }\end{array}$ & $\begin{array}{l}\text { Criterion } \\
\text { A1a }\end{array}$ & $\begin{array}{l}\text { Criterion } \\
\text { A1b }\end{array}$ & \begin{tabular}{|l} 
Criterion \\
A1e (AZE)
\end{tabular} & \begin{tabular}{|l} 
Criterion \\
B1
\end{tabular} & \begin{tabular}{|l} 
Criterion \\
D1a
\end{tabular} & $\begin{array}{l}\text { Criterion } \\
\text { D2 }\end{array}$ & $\begin{array}{l}\text { New/ } \\
\text { Adopted }\end{array}$ \\
\hline \begin{tabular}{|l|} 
Mahajilo \\
River
\end{tabular} & Ptychochromoides itasy & Fishes & CR & yes & & & $16.1 \%$ & & & \\
\hline \multirow{2}{*}{$\begin{array}{l}\text { Upper } \\
\text { Mananara } \\
\text { River }\end{array}$} & Bedotia albomarginata & Fishes & EN & Yes & & & $19.6 \%$ & & & \multirow{2}{*}{ New KBA } \\
\hline & $\begin{array}{l}\text { Ptychochromoides } \\
\text { vondrozo }\end{array}$ & Fishes & EN & Yes & & & $13.8 \%$ & & & \\
\hline \multirow{8}{*}{$\begin{array}{l}\text { Manongarivo } \\
\text { Catchment }\end{array}$} & Paretroplus damii & Fishes & VU & & yes & & $10.6 \%$ & & & \multirow[t]{8}{*}{ New KBA } \\
\hline & $\begin{array}{l}\text { Paretroplus } \\
\text { maromandia }\end{array}$ & Fishes & EN & yes & & & NA & & & \\
\hline & $\begin{array}{l}\text { Ptychochromis } \\
\text { inornatus }\end{array}$ & Fishes & EN & yes & & & NA & & & \\
\hline & $\begin{array}{l}\text { Aponogeton } \\
\text { Iongiplumulosus }\end{array}$ & Plants & EN & yes & & & $34.3 \%$ & & & \\
\hline & $\begin{array}{l}\text { Endocaulos } \\
\text { mangorense }\end{array}$ & Plants & EN & yes & & & $12.9 \%$ & & & \\
\hline & Ixora sambiranensis & Plants & EN & yes & & & $17.9 \%$ & & & \\
\hline & Nymphoides bosseri & Plants & EN & yes & & & NA & & & \\
\hline & $\begin{array}{l}\text { Pneumatopteris } \\
\text { humbertii }\end{array}$ & Plants & VU & & yes & & NA & & & \\
\hline \multirow{4}{*}{$\begin{array}{l}\text { Marojejy } \\
\text { National } \\
\text { Park }\end{array}$} & Marojejy longimerus & Crabs & NA & & & & $11.7 \%$ & & & \multirow[t]{4}{*}{ Adopted } \\
\hline & Bedotia marojejy & Fishes & EN & Yes & & & $13.4 \%$ & & & \\
\hline & Deparia marojejyensis & Plants & VU & & Yes & & $11.7 \%$ & & & \\
\hline & $\begin{array}{l}\text { Pneumatopteris } \\
\text { humbertii }\end{array}$ & Plants & VU & & yes & & NA & & & \\
\hline \multirow{2}{*}{$\begin{array}{l}\text { Mikea } \\
\text { National } \\
\text { Park }\end{array}$} & Typhleotris pauliani & Fishes & CR & yes & & & $80.1 \%$ & & & \multirow[t]{2}{*}{ Adopted } \\
\hline & Pluchea grevei & Plants & NA & & & & $29.3 \%$ & & & \\
\hline \multirow{5}{*}{$\begin{array}{l}\text { Nosy Be } \\
\text { Island Group }\end{array}$} & Boreathelphusa uglowi & Crabs & EN & Yes & & & NA & & & \multirow[t]{5}{*}{ New KBA } \\
\hline & Paratilapia polleni & Fishes & VU & & Yes & & NA & & & \\
\hline & $\begin{array}{l}\text { Pachypanchax } \\
\text { omalonotus }\end{array}$ & Fishes & EN & Yes & & & NA & & & \\
\hline & $\begin{array}{l}\text { Ptychochromis } \\
\text { oligacanthus }\end{array}$ & Fishes & EN & Yes & & & NA & & & \\
\hline & $\begin{array}{l}\text { Madagasikara } \\
\text { madagascarensis }\end{array}$ & Molluscs & EN & Yes & & & NA & & & \\
\hline $\begin{array}{l}\text { Southern } \\
\text { Upper } \\
\text { Lokoho River }\end{array}$ & Rheocles vatosoa & Fishes & EN & yes & & & $15.6 \%$ & & & New KBA \\
\hline \multirow{4}{*}{$\begin{array}{l}\text { Upper } \\
\text { Kitsamby } \\
\text { River }\end{array}$} & Astacoides caldwelli & Crayfish & VU & & Yes & & NA & & & \multirow[t]{4}{*}{ New KBA } \\
\hline & $\begin{array}{l}\text { Africanogyrus } \\
\text { starmuehlneri }\end{array}$ & Molluscs & EN & Yes & & & NA & & & \\
\hline & Hydrostachys fimbriata & Plants & EN & Yes & & & NA & & & \\
\hline & Rorippa millefolia & Plants & EN & Yes & & & NA & & & \\
\hline $\begin{array}{l}\text { Kinkony } \\
\text { Lake } \\
\text { (Ramsar } \\
\text { Site) } \\
\end{array}$ & Paretroplus dambabe & Fishes & CR & & & yes & $100 \%$ & yes & & Adopted \\
\hline
\end{tabular}


Annex 9.2 Site Champions - Madagascar.

\begin{tabular}{|c|c|}
\hline KBA Name & Site Champion \\
\hline Marojejy National Park & $\begin{array}{l}\text { Maorejy National Park Authority } \\
\text { Système des Aires Protégées de Madagascar (SAPM) }\end{array}$ \\
\hline Nosivolo River and tributaries (Ramsar Site) & $\begin{array}{l}\text { Durrell Wildlife Conservation Trust Madagascar Programme } \\
\text { Direction Régionale de l'Environnement et des Forêts (DREF) de la région Antsinanana et les } \\
\text { Cantonnements de l'Environnement, des Eaux et Forêts du District de Marolambo et de Mahanoro } \\
\text { (Management Authority) } \\
\text { Ramsar National Focal Point }\end{array}$ \\
\hline Isalo National Park & $\begin{array}{l}\text { Isalo National Park Authority } \\
\text { Système des Aires Protégées de Madagascar (SAPM) }\end{array}$ \\
\hline Mikea National Park & $\begin{array}{l}\text { Mikea National Park Authority } \\
\text { Système des Aires Protégées de Madagascar (SAPM) } \\
\text { ASITY-Ligue Malgache pour la protection des oiseaux } \\
\text { Blueventures }\end{array}$ \\
\hline Faraony Headwaters & Conservation International \\
\hline Andasibe & $\begin{array}{l}\text { Système des Aires Protégées de Madagascar (SAPM) } \\
\text { Ramsar National Focal Point } \\
\text { Conservation International } \\
\text { Groupe d'étude et de recherche sur les primates de Madagascar (GERP) } \\
\text { Ambatovy (Nikel mining company) } \\
\text { Association Mitsinjo } \\
\end{array}$ \\
\hline Antsiranana & $\begin{array}{l}\text { Système des Aires Protégées de Madagascar (SAPM) } \\
\text { Conservation International } \\
\text { Missouri Botanical Garden } \\
\text { MBP-Madagascar Biodiversity Partnership } \\
\end{array}$ \\
\hline Bavara River & $\begin{array}{l}\text { University of Soavinandriana } \\
\text { SAHA (local NGO) } \\
\text { APPA (captive breeding) }\end{array}$ \\
\hline Lower Ikopa Catchment & BirdLife International \\
\hline Kinkony Lake & BirdLife International \\
\hline Lake Tseny Catchment & $\begin{array}{l}\text { Association Bongolava Maintso - working close by on the Bungolava KBA } \\
\text { Kew Gardens - interested in Bongolava } \\
\text { Madagasikara voakajy (MAVOA) - Working in Lac Tseny; APPA - fish breeding specialists } \\
\text { working on ex-situ breeding of fishes from the lake }\end{array}$ \\
\hline Amboaboa catchment & Madagascar Voakajy (Local NG0) \\
\hline Lower Ankofia & $\begin{array}{l}\text { Wildlife Conservation Socierty (WCS) } \\
\text { RBG Kew }\end{array}$ \\
\hline Lower Anove River & $\begin{array}{l}\text { Madagascar National Parks } \\
\text { GRET (French NGO working on village level management - especially water resource use) }\end{array}$ \\
\hline Mahajanga coastal zone & \begin{tabular}{|l} 
Komanga \\
Biopage
\end{tabular} \\
\hline Mahavavy Delta & $\begin{array}{l}\text { WWF } \\
\text { BirdLife International }\end{array}$ \\
\hline Manongarivo Catchment & $\begin{array}{l}\text { National Parks for the northern part of the KBA } \\
\text { Sahamalaza NP management in the SW }\end{array}$ \\
\hline Nosy Be Island Group & $\begin{array}{l}\text { L'Homme et environnement (MATE) } \\
\text { AVOTRA } \\
\text { TSARARIVOTRA } \\
\end{array}$ \\
\hline South Manambato & $\begin{array}{l}\text { ASITY } \\
\text { QMM }\end{array}$ \\
\hline \begin{tabular}{|l|} 
Southern Upper Lokoho River \\
\end{tabular} & \begin{tabular}{|l|} 
Local villages \\
Marojejy NP Authority \\
APPA-NGO - fish farming \\
WWF- office in Andapa \\
\end{tabular} \\
\hline Tolagnaro & $\begin{array}{l}\text { QMM; } \\
\text { ASITY }\end{array}$ \\
\hline Upper Kitsamby River & University of Soavinandriana - Institute of Technology; Village management \\
\hline Upper Mananara River & $\begin{array}{l}\text { Conservation International } \\
\text { Ramsar National Focal Point }\end{array}$ \\
\hline
\end{tabular}


Annex 9.3 Summary of the KBA Criteria and Thresholds (IUCN 2016).

\begin{tabular}{|c|c|c|c|}
\hline A. Threatened Biodiversity & Biodiversity element at site & \% global pop. size/extent & $\boldsymbol{R} \boldsymbol{U}^{\prime}$ \\
\hline \multirow[t]{4}{*}{ A1: Threatened species } & (a) CR or EN species & $\geq 0.5 \%$ & $\geq 5$ \\
\hline & (b) VU species & $\geq 1 \%$ & $\geq 1 \%$ \\
\hline & $\begin{array}{l}\text { (c) CR or EN species Threatened only due to } \\
\text { population size reduction in the past or present }\end{array}$ & $\geq 0.1 \%$ & $\geq 5$ \\
\hline & (e) CR or EN species & Entire global population size & \\
\hline \multirow[t]{2}{*}{\begin{tabular}{|l} 
A2: Threatened ecosystem types \\
\end{tabular}} & (a) CR or EN ecosystem type & $\geq 5 \%$ & \\
\hline & (b) VU ecosystem type & $\geq 10 \%$ & \\
\hline
\end{tabular}

\begin{tabular}{|c|c|c|c|}
\hline $\begin{array}{l}\text { B. Geographically restricted } \\
\text { biodiversity }\end{array}$ & Biodiversity element at site & \% global pop. size/extent & $\boldsymbol{R U}$ \\
\hline $\begin{array}{l}\text { B1: Individually geographically } \\
\text { restricted species }\end{array}$ & Any species & $\geq 10 \%$ & $\geq 10$ \\
\hline $\begin{array}{l}\text { B2: Co-occurring geographically } \\
\text { restricted species }\end{array}$ & $\begin{array}{l}\text { Restricted-range species: } \geq 2 \text { species OR } \\
0.02 \% \text { of total number of species in taxonomic group, } \\
\text { whichever is larger }\end{array}$ & $\geq 1 \%$ & \\
\hline \multirow[t]{3}{*}{$\begin{array}{l}\text { B3: Geographically } \\
\text { restricted assemblages }\end{array}$} & $\begin{array}{l}\text { (a) } \geq 5 \text { ecoregion-restricted species }{ }^{2} \text { OR } 10 \% \text { of the } \\
\text { species restricted to the ecoregion, whichever } \\
\text { is larger }\end{array}$ & \multirow[t]{3}{*}{$\geq 0.5 \%$} & \\
\hline & $\begin{array}{l}\text { (b) } \geq 5 \text { bioregion-restricted species }{ }^{2} \text { OR } 30 \% \text { of the } \\
\text { bioregion-restricted species known from the } \\
\text { country, whichever is larger }\end{array}$ & & \\
\hline & $\begin{array}{l}\text { (c) Part of the globally most important } 5 \% \text { of } \\
\text { occupied habitat of each of } \geq 5 \text { species within a } \\
\text { taxonomic group }\end{array}$ & & \\
\hline $\begin{array}{l}\text { B4: Geographically restricted } \\
\text { ecosystem types }\end{array}$ & Any ecosystem type & $\geq 20 \%$ & \\
\hline
\end{tabular}

\begin{tabular}{|l|l|l|l|}
\hline C. Ecological integrity & Biodiversity element at site & & \\
\hline & Wholly intact ecological communities & $\leq 2$ sites per ecoregion \\
\hline
\end{tabular}

\begin{tabular}{|c|c|c|}
\hline D. Biological processes & Biodiversity element at site & \% global pop. size \\
\hline \multirow[t]{2}{*}{ D1: Demographic aggregations } & $\begin{array}{l}\text { (a) Species aggregation during one or } \\
\text { more key stages of its life cycle }\end{array}$ & \multirow[t]{2}{*}{$\geq 1 \%$} \\
\hline & $\begin{array}{l}\text { (b) Among the largest } 10 \text { aggregations } \\
\text { known for the species }\end{array}$ & \\
\hline D2: Ecological refugia & $\begin{array}{l}\text { Species aggregations during periods of past, current } \\
\text { or future environmental stress }\end{array}$ & $\geq 10 \%$ \\
\hline D3: Recruitment sources & $\begin{array}{l}\text { Propagules, larvae or juveniles maintaining high } \\
\text { proportion of global population size }\end{array}$ & $\geq 10 \%^{3}$ \\
\hline
\end{tabular}

\begin{tabular}{|c|c|c|c|}
\hline $\begin{array}{l}\text { E: Irreplaceability through } \\
\text { quantitative analysis }\end{array}$ & Biodiversity element at site & Irrepl. score & $\boldsymbol{R U}$ \\
\hline & $\begin{array}{l}\text { Site has high irreplaceability measured } \\
\text { by quantitative spatial analysis }\end{array}$ & $\begin{array}{l}\geq 0.90 \text { on } \\
0-1 \text { scale }\end{array}$ & $\begin{array}{l}\geq 10 \text { (or } \\
\geq 5 \text { for EN/ } \\
\text { CR sp) }\end{array}$ \\
\hline
\end{tabular}

${ }^{1} \mathrm{RU}=$ reproductive units; ${ }^{2}$ within a taxonomic group; ${ }^{3}$ refers to global population size rather than immature individuals produced. 


\title{
Chapter 10
}

\section{A critical sites network for freshwater biodiversity in Madagascar}

\author{
Catherine Sayer ${ }^{1}$, William Darwall ${ }^{1}$

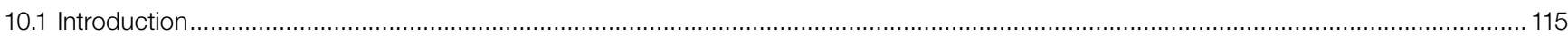

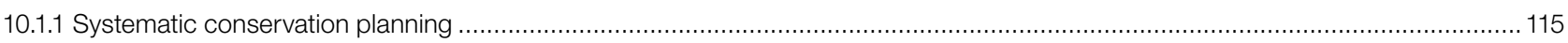

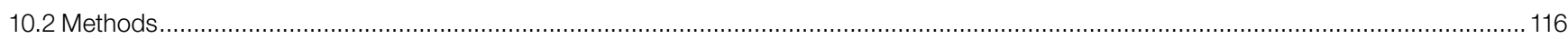 \\ 10.2.1 Marxan …

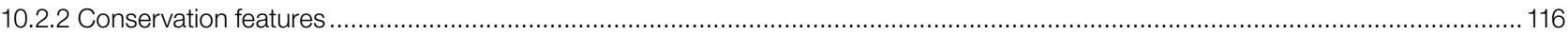

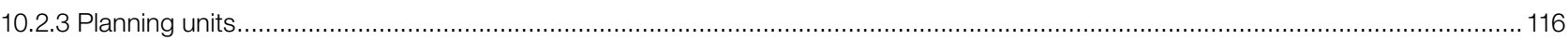

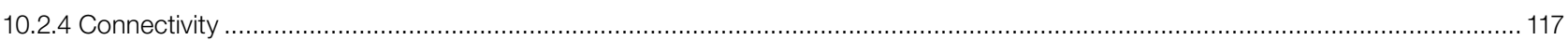

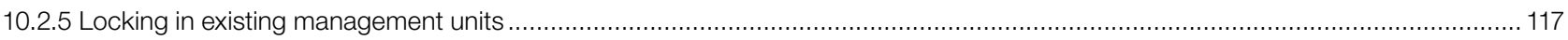

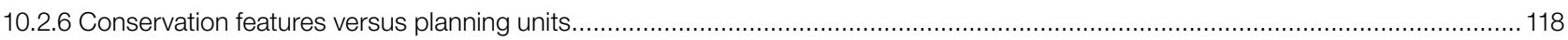

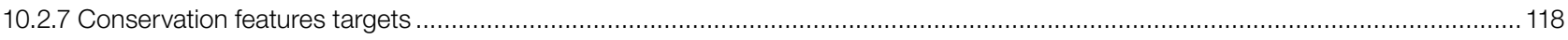

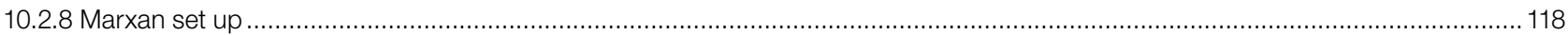

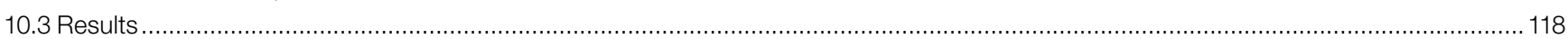

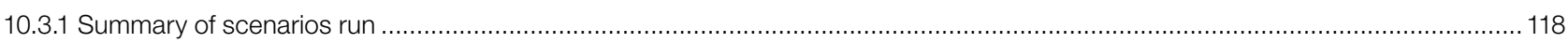 \\ 10.3.2 Scenario C - Optimal network considering current land use and potential management .....................................................122

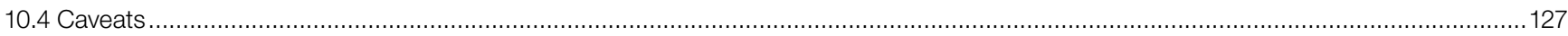

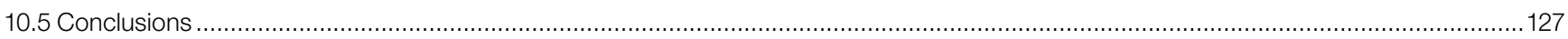

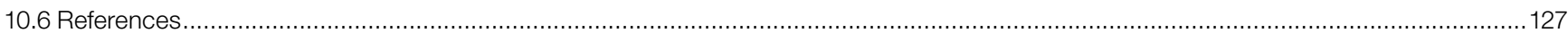

\subsection{Introduction}

\subsubsection{Systematic conservation planning}

Since conservation normally competes with other human interests (Margules et al. 2002) and as funds for conservation are limited, it is not feasible to conserve all areas that contribute towards biodiversity. Spatial prioritisation can be used to identify areas where it is best to allocate these limited resources to receive the greatest conservation benefits (Knight et al. 2007), for example through designation of reserves. The two objectives of reserve design are: i) Representativeness - the adequate representation of the target conservation features (e.g. species, habitat types) and; ii) Persistence - the longterm survival of these conservation features through maintenance of natural processes and viable populations, and the exclusion or management of threats (Margules \& Pressey 2000). Historically, the selection of areas for reserves was not systematic, often with areas which were remote or unproductive, and therefore not deemed to be of commercial importance, being designated as reserves regardless of their biodiversity value. This often led to reserves that did not meet the objectives stated above
(Hermoso et al. 2011) and systematic conservation planning was developed in response (Margules \& Pressey 2000).

Systematic conservation planning aims to identify an optimum network of areas in which explicit targets for conservation features are met, taking the cost of inclusion of areas and other aspects of reserve design (e.g. individual reserve size, fragmentation) into consideration. Systematic conservation planning methods now generally use complementarity-based algorithms, where complementarity is the increase in representativeness of the network when a new area is added (Possingham et al. 2000). This approach has been shown to result in networks that are more efficient in terms of both cost and the representation of conservation features than alternative methods, such as ad hoc, scoring or ranking strategies (Margules et al. 2002; Pressey \& Nicholls 1989; Pressey \& Tully 1994).

Although systematic conservation planning has been used extensively in the terrestrial realm, it has only more recently emerged in freshwater systems, with some alterations to consider the unique characteristics, such as hydrological connectivity, of these systems (Beger et al. 2010; Dunn 2003; Hermoso et al. 2011). 
We used systematic conservation planning software to identify networks of sites within Madagascar for the conservation of threatened freshwater biodiversity, using the newly delineated Key Biodiversity Areas (KBAs), existing KBAs and protected areas (PAs) as a base. We highlight sites outside of the current network and provide details of sites on which to build site-level management strategies, as a scientific basis for the development and expansion of the existing network.

\subsection{Methods}

\subsubsection{Marxan}

We used the conservation planning software Marxan (Ball et al. 2009) to identify networks meeting different targets for the conservation of freshwater biodiversity. Marxan uses simulated annealing (a heuristic algorithm) to identify a near-optimal network of sites that meets user-defined biodiversity targets at the lowest cost. Marxan compares potential networks of sites using the objective function, with a lower objective function value indicating a better network. The general Marxan objective function (Equation 1) contains terms representing costs and penalties. The first term is the sum of the costs of each planning unit (site) in the network. The second term is the sum of the boundary lengths of each planning unit, multiplied by a modifier through which the degree of fragmentation of the network can be controlled. The third term is the penalty applied if conservation features are not represented at their target levels. The final term penalises the network if it passes a cost threshold. The first and third terms are required, whereas the second and fourth are optional (Game \& Grantham 2008).

$$
\begin{aligned}
& \text { objective function } \\
& =\sum_{\substack{\text { Planning } \\
\text { Units }}}^{\text {planning unit costs }+B L M \sum_{\begin{array}{c}
\text { Planning } \\
\text { Units }
\end{array}} \text { boundary length }} \\
& +\sum_{\substack{\text { Conservation } \\
\text { features }}}(S P F \times \text { representation penalty })+\text { cost threshold } \\
& \text { penalty }
\end{aligned}
$$

\section{Equation 1 Marxan objective function equation.}

Where $B L M=$ boundary length modifier;

$S P F=$ species penalty factor

For this analysis, we adapted the objective function to be more appropriate for use in freshwater systems (Equation 2). Parameters related to the boundary length of the network were replaced by those related to the hydrological connectivity of the network. Additionally, we did not apply a cost threshold penalty.

$$
\begin{aligned}
& \text { objective function } \\
& =\sum_{\substack{\text { Planning } \\
\text { Units }}}^{\text {planning unit cost }+C S M \sum_{\substack{\text { Planning } \\
\text { Units }}} \text { connectivity penalty }} \\
& +\sum_{\text {Species }}(S P F \times \text { representation penalty) }
\end{aligned}
$$

Equation 2 Marxan objective function equation as used in this analysis.

Where CSM = connectivity strength modifier;

$S P F=$ species penalty factor

\subsubsection{Conservation features}

Conservation features are the elements of biodiversity that are the focus of the network. The conservation features for this analysis were threatened freshwater species (those assessed as Critically Endangered (CR), Endangered (EN) or Vulnerable (VU)) with spatial data in our priority taxonomic groups: freshwater crabs, crayfish, fishes, molluscs, Odonata, plants, and shrimps. Investigation of the Red List categories of the species in these taxonomic groups revealed that no freshwater shrimp species were classed as threatened and, therefore, freshwater shrimps were excluded from the analysis. This left 207 species to include as conservation features: one crab, four crayfish, 46 fishes, 12 molluscs, three odonates and 141 plants (but see section Conservation Features versus Planning Units below).

\subsubsection{Planning units}

\section{Type}

We split Madagascar into 981 planning units, which represent potential sites from which to form a network, using level 8 HydroBASINS. HydroBASINS is a global dataset of hierarchically nested catchments, with attributes that allow hydrologically connected upstream and downstream catchments to be identified (Lehner \& Grill 2013). Each level 8 HydroBASIN (sub-catchment) represents a planning unit. Level 8 HydroBASINS were chosen as this is the default resolution for mapping of freshwater species distributions on the IUCN Red List, our primary source of data on conservation features. Additionally, level 8 HydroBASINS represent manageable units in terms of their average area.

\section{Cost}

When running Marxan, a cost needs to be specified for each planning unit, which is the value added to the objective function when the planning unit is included in a 
network. Estimates of the financial cost of each planning unit were not available for this study. Instead, we used the area and the degree of anthropogenic impact of planning units and developed two cost indices as proxies for financial cost.

The first index (cost $A$ ) is based only on area of the planning unit (Equation 3), with larger planning units having a higher cost value (Figure 10.1 in Supplementary Material). Use of cost A causes Marxan to try to find a network of the smallest area that meets all conservation feature targets.

$$
\operatorname{cost} A=\text { area of planning unit }\left(\mathrm{km}^{2}\right)
$$

\section{Equation 3 Equation for cost of planning units following method $A$.}

The second index is based on the area and degree of anthropogenic impact on planning units. The Global Human Influence Index (HII) is a global dataset of $1 \mathrm{~km}$ grid cells, created from global data layers of human population pressure, human land use, infrastructure and human access (Wildlife Conservation Society-WCS and Center For International Earth Science Information NetworkCIESIN-Columbia University, 2005). The mean HII value was calculated per planning unit.

The HII value relative to the maximum $\mathrm{HII}$ value in the Madagascar was then calculated per planning unit (Figure 10.1). Following Linke and Hermoso (2012), this was used together with planning unit area to calculate the second cost index (cost B; Equation 4, Figure 10.2). Use of cost $B$ shifts the focus to finding a network with low levels of anthropogenic impact and a small area.

$$
\begin{aligned}
& \text { cost } B=\text { area of planning unit }\left(\mathrm{km}^{2}\right) \\
& \text { * relative Human Influence Index (HII) score }
\end{aligned}
$$

\section{Equation 4 Equation for cost of planning units following method $B$.}

The two indices were used in separate scenarios in order to compare results between a 'blank slate' network (cost A) and those under current land use conditions (cost B).

\subsubsection{Connectivity}

We incorporated hydrological connectivity into the prioritisation to account for the potential propagation of threats and movement of riverine species along river systems. A better connected site network will facilitate management efforts to allow free movement of species between sites and to reduce the spread of threats throughout the system.
Following Hermoso et al. (2011) and Linke \& Hermoso (2012), we included the asymmetric longitudinal connectivity rule which applies a penalty when the planning units upstream of a selected planning unit are not included in the network.

First, the individual river systems in Madagascar and the planning units that these systems occur in were identified. The HydroBASINS attributes were then used to calculate the distance between each planning unit and all upstream basins. The connectivity penalty was then calculated and weighted by the distance between planning units (Equation 5). This weighting means that closer upstream planning units receive a higher penalty than distant upstream

\begin{tabular}{|c|c|}
\hline & 1 \\
\hline necttvity pe & $\begin{array}{c}\text { distance between } \\
\text { planning units }(\mathrm{km})\end{array}$ \\
\hline
\end{tabular}
planning units if not included, and means that the penalty does not lead to the selection of entire river systems.

\section{Equation 5 Equation for connectivity penalty.}

\subsubsection{Locking in existing management units}

When using Marxan it is possible to lock particular planning units in or out of the final network, meaning that the planning units are fixed into or excluded from, respectively, the final network. In some scenarios we chose to lock in planning units representing different combinations of existing management units, again in order to compare results between a 'blank slate' network (i.e. no locked in planning units), a network including areas currently identified as important for freshwater biodiversity (i.e. locked in freshwater KBAs) and a network including areas currently identified as important for other biodiversity (i.e. locked in existing KBAs and PAs). This also allowed us to identify any additional planning units required to meet targets. These additional planning units represent gaps in the current network for the conservation of threatened freshwater biodiversity.

As discussed above, level 8 HydroBASINS (subcatchments) were used as planning units in this analysis. However, in general KBAs and PAs are not delineated to HydroBASINS and, therefore, we were required to select planning units that represent these management units when there is not a one-to-one match. Note that freshwater KBAs are delineated to HydroBASINS but generally at a higher resolution (e.g. level 10 or level 12 HydroBASINS) in order to focus actions on site based priorities.

We classed a planning unit as being an existing management unit if over $50 \%$ of the area of the planning unit was covered 
by an existing management unit. This classification was done separately for:

- Freshwater KBAs - 42 planning units were selected covering $23,046 \mathrm{~km}^{2}$ or $3.9 \%$ of Madagascar (Figure 2 in Supplementary Material).

- Existing KBAs - 143 planning units were selected covering $64,574 \mathrm{~km}^{2}$ or $10.9 \%$ of Madagascar.

- A subset of PAs (international designations of Ramsar Sites, World Heritage Sites and UNESCO-MAB Biosphere Reserves, and those in IUCN Categories I-VI) - 74 planning units were selected covering $28,360 \mathrm{~km}^{2}$ or $4.8 \%$ of Madagascar.

- All management unit types (all of the above) - 198 planning units were selected covering $93,690 \mathrm{~km}^{2}$ or $15.9 \%$ of Madagascar (Figure 10.3).

Please note that these total areas are calculated from the areas of the planning units chosen to represent the management units, and not the areas of the management units themselves (i.e. the areas of the solid green polygons in Figure 10.3, as opposed to the area of the hashed green polygons).

Due to the $50 \%$ threshold, many of the smaller existing management units (e.g. Forest Reserves) do not have corresponding planning units (Figure 10.3). However, this threshold was found to be the best trade-off between including existing management units and not locking in planning units of which only a small area was covered by management units.

\subsubsection{Conservation features versus planning units}

We used the spatial data produced through the Red List assessment process (see Chapters 3 to 8 ) to map freshwater species distributions to planning units. Spatial data coded as Presence 5 (Extinct) or Presence 4 (Possibly Extinct) were excluded from the analysis, and only Origin 1 (Native) or Origin 2 (Reintroduced) were included in the analysis. This left 205 species to include as conservation features: one crab, four crayfish, 45 fishes, 11 molluscs, three odonates and 141 plants (Appendix 1).

All planning units where species occur were given a value (abundance) of one for that species. It was not possible to estimate the abundance of each species in each planning unit as the data available (the IUCN Red List spatial data) are essentially presence/absence classifications.

\subsubsection{Conservation features targets}

We set the representation target as presence of each threatened freshwater species within two planning units (where possible, as some species were endemic to single planning units).

\subsubsection{Marxan set up}

\section{General settings}

As recommended in Game \& Grantham (2008), we ran Marxan using simulated annealing followed by two-step iterative improvement, with the main parameters of the algorithm set at their default values. We ran each scenario 1,000 times and used the selection frequency of each planning unit as a measure of its irreplaceability in the network. Planning units that were selected in over 990 runs (over 99\%) were considered irreplaceable, as their inclusion was required for the targets to be met at a low cost.

\section{Species Penalty Factor (SPF)}

The Species Penalty Factor (SPF) influences how high a penalty is applied to the network if conservation feature targets are not met. The SPF was set at the high value of $1,000,000$ to ensure that conservation feature targets were always met.

\section{Connectivity Strength Modifier (CSM)}

The Connectivity Strength Modifier (CSM) is used to control how hydrologically connected the network is. To find an efficient value for the CSM, we followed the method used by Stewart and Possingham (2005) for identifying an appropriate Boundary Length Modifier (BLM). Each scenario was run keeping all other parameters the same but changing the CSM between six values $(0 ; 1 ; 10 ; 100 ; 1,000 ; 10,000)$. We then plotted the total network area against the connectivity value for each CSM and found that a CSM of 1,000 was most efficient, as it occurred at the point where the greatest increase in connectivity for the smallest increase in area was achieved. This CSM value was then used for all scenarios.

\subsection{Results}

\subsubsection{Summary of scenarios run}

We used Marxan to find optimal networks to meet set targets for the conservation of threatened freshwater species. We used three different sets of input parameters to represent three different land use and management scenarios:

a. 'Blank slate' network - using cost A (Figure 1 in Supplementary Material) and with no locked in planning units. This scenario assumes Madagascar is a blank slate in terms of land uses, both positive and negative, and represents the network of planning units with the smallest total area that still represents the species at their target levels. 
Figure 10.1 Mean Human Influence Index (HII) value per planning unit. Value displayed relative to the maximum mean HII value in Madagascar.

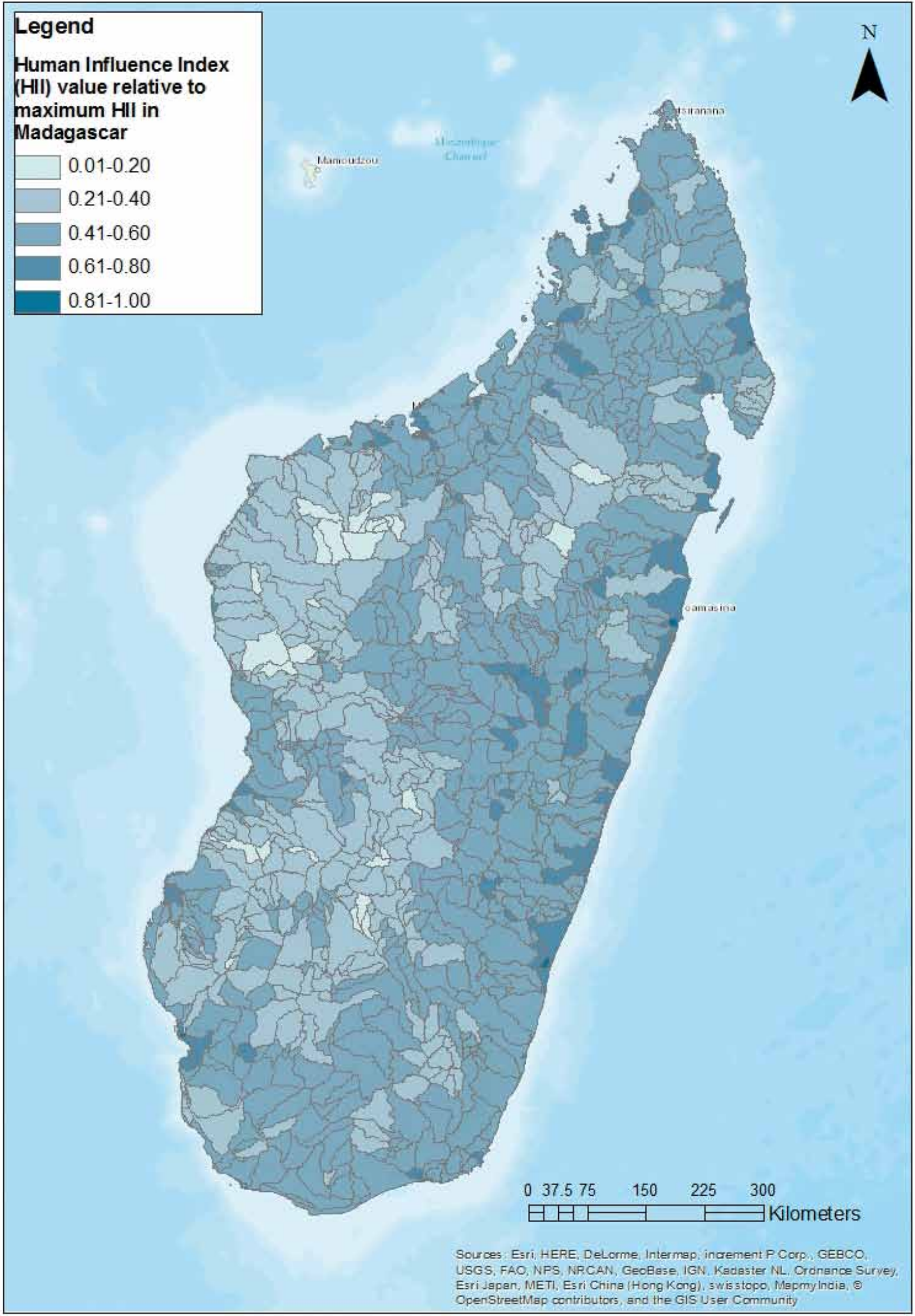


Figure 10.2 Cost of planning units (PUs) following method B. Value displayed relative to the maximum cost PU in Madagascar.

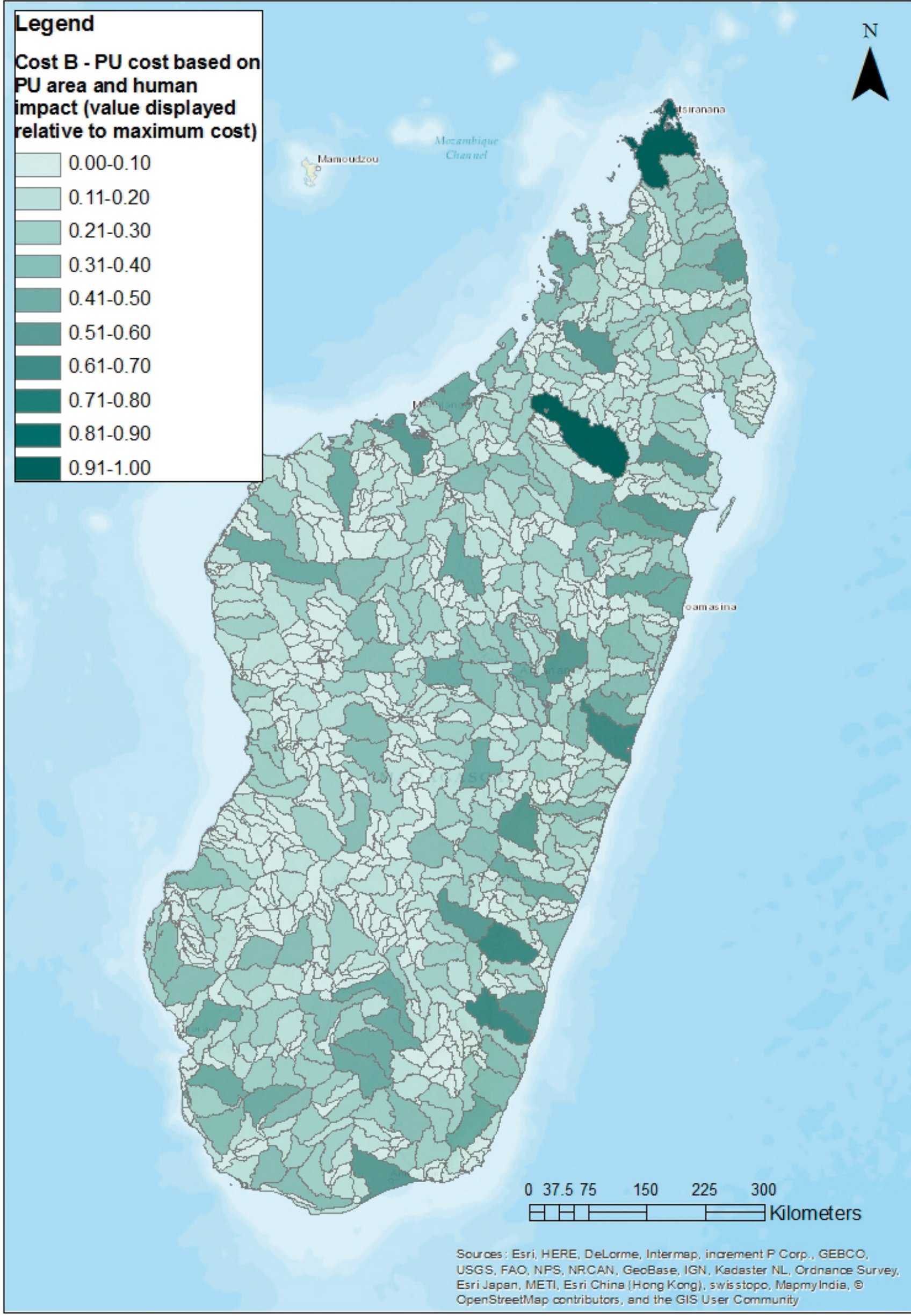


Figure 10.3 All management unit types (Freshwater Key Biodiversity Areas (KBAs), existing KBAs and selected protected areas (PAs) and their corresponding planning units (PUs) in Madagascar.

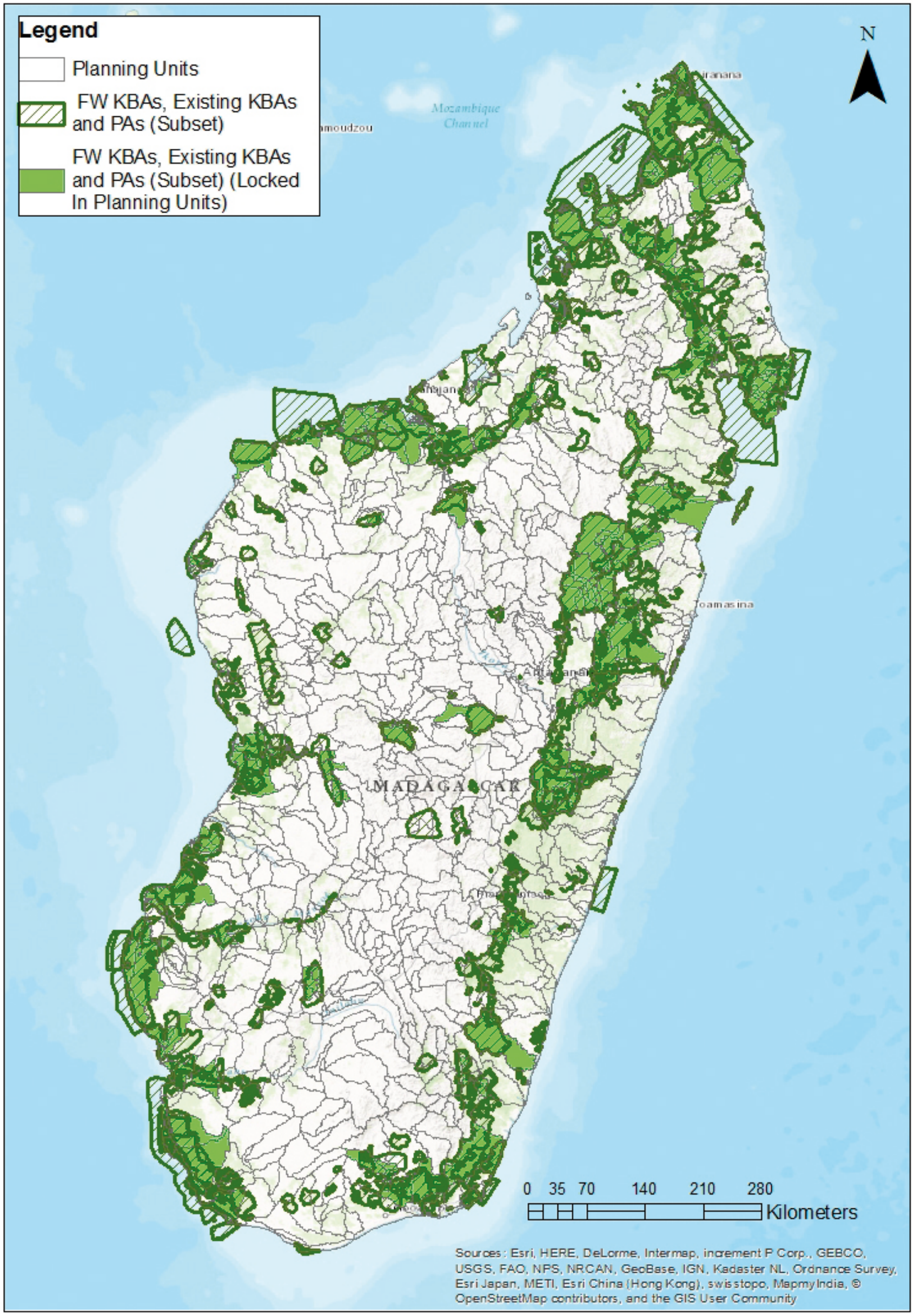


b. Network considering current land use and management - using cost $B$ (Figure 10.2) with planning units representing freshwater KBAs (Figure 2 in Supplementary Material) locked in. This scenario considers the area and present degree of human impact to each planning unit, and areas identified as important for freshwater biodiversity.

\section{c. Network considering current land use and potential} management (Figure 10.4, Figure 10.5) - using cost B (Figure 10.2) with planning units representing freshwater KBAs, existing KBAs and a subset of PAs (Figure 10.3) locked in. This scenario considers the area and present degree of human impact to each planning unit, and areas identified as important for biodiversity, which could potentially adopt management strategies specific to freshwater.

For each scenario, maps displaying the optimal network (the run leading to a site network with the lowest objective function value) and the irreplaceability of planning units were produced.

Only the network produced by scenario $\mathrm{C}$ is discussed in detail in this chapter. This scenario is presented as it is the best representation of the current situation in Madagascar and is therefore the best starting point for development and expansion of the PA network. For the detailed results for scenarios A and B see the Supplementary Material. Representation targets for threatened freshwater species were met in all scenarios.

\subsubsection{Scenario C - Optimal network considering current land use and potential management}

\section{Optimal network}

Scenario $C$ considers the distribution of threatened freshwater species, the present degree of human impact in planning units, and all areas currently identified as important for biodiversity. The resulting network is the one we would propose assuming all pre-existing areas currently identified and managed for biodiversity (KBAs and PAs) adopt management strategies targeted at freshwater biodiversity as appropriate. This network includes 298 planning units covering $169,190 \mathrm{~km}^{2}$ or $28.6 \%$ of the area of Madagascar (Figure 10.4, Table 10.1).

Appendix 2 provides details of each planning unit required within the scenario $\mathrm{C}$ optimal network including the threatened freshwater species present in each planning unit, as well as the area of the planning unit and degree of human impact (the mean Human Influence Index (HII) value in the planning unit relative to the maximum mean $\mathrm{HII}$ for a planning unit in Madagascar).

In addition to meeting or exceeding the targets for representation of all threatened freshwater species, the network also captures much of the total complement of other freshwater biodiversity. It includes occurrences of 503 freshwater species, representing $95.8 \%$ of the total number of freshwater species for which we have spatial data in Madagascar (Table 10.1).

Twenty-two percent (66) of planning units included in the network do not contain any target species and these planning units are included for one of two reasons. Fiftytwo of these planning units are within locked in pre-existing management units (FW KBAs, existing KBAs and PAs) and therefore, had to be included based on the input parameters. The other 14 of these planning units were included due to their upstream proximity to other planning units already included in the network, either as locked in pre-existing sites of biological importance or as sites with threatened species present. These sites need to be included in the network because activities within them could have a large influence on nearby downstream planning units that contain target species.

Table 10.1 Summary table for the optimal networks for scenarios A ('blank slate' network for conservation of threatened freshwater species); B (network for conservation of threatened freshwater species considering current land use and management); and $\mathrm{C}$ (network for conservation of threatened freshwater species considering current land use and potential management). PU=Planning Unit.

\begin{tabular}{|c|c|c|c|c|c|c|c|}
\hline \multirow[b]{2}{*}{ Scenario } & \multirow[b]{2}{*}{ Cost Type } & \multirow[b]{2}{*}{$\begin{array}{l}\text { Locked in } \\
\text { PUs }\end{array}$} & \multicolumn{5}{|c|}{ Values for the optimal network (site network with lowest objective function value) } \\
\hline & & & $\begin{array}{c}\text { Number of } \\
\text { PUs }\end{array}$ & $\begin{array}{c}\text { Total area / } \\
\mathbf{k m}^{2}\end{array}$ & $\begin{array}{l}\text { Percentage of } \\
\text { total area of } \\
\text { Madagascar }\end{array}$ & $\begin{array}{c}\text { Number of } \\
\text { freshwater species } \\
\text { (incl. non-target } \\
\text { species) }\end{array}$ & $\begin{array}{l}\text { Percentage of total } \\
\text { number of } \\
\text { freshwater species }\end{array}$ \\
\hline A & A & None & 121 & 97,580 & $16.5 \%$ & 488 & $93.0 \%$ \\
\hline B & B & FW KBAs & 156 & 110,744 & $18.7 \%$ & 489 & $93.1 \%$ \\
\hline C & B & $\begin{array}{l}\text { FW KBAs, } \\
\text { existing } \\
\text { KBAs and } \\
\text { PAs } \\
\end{array}$ & 298 & 169,190 & $\mathbf{2 8 . 6 \%}$ & 503 & $95.8 \%$ \\
\hline
\end{tabular}


On average, the selected planning units have a relative $\mathrm{HII}$ value of 0.47 , which is comparable with the mean relative $\mathrm{HII}$ value for Madagascar overall (0.46) and for the management units (KBAs and PAs) network (0.48). Planning units with low HII values (representing low anthropogenic impact) would predicate protective actions and those with high HII values (representing high anthropogenic impact) would predicate restorative actions. The most heavily impacted planning units in the network are either coastal or close to Antananarivo (mean relative HII values over 0.70 ). The least heavily impacted planning units in the network are in the Betsiboka region in western Madagascar (mean relative HII values of under 0.13 ).

\section{Irreplaceability}

Fifty-four planning units outside the pre-existing network of management units (KBAs and PAs, which were locked into each run) were considered irreplaceable as they were required to meet the targets in over $99 \%$ of the runs (Figure 10.5). Forty-five of the target species are restricted to a single planning unit and 13 are only known from two planning units. As the representation target set was for occurrence of each species in at least two planning units (where possible), some of the 54 irreplaceable planning units were considered as such because they had to be included in order for the network to meet the representation targets for these 58 restricted species (those occurring in only one or two planning units). Examples include: planning unit 114 (Appendix 2) covering the upper part of the Mahavavy River in central west Madagascar, which is the only known site for the mollusc Madagasikara zazavavindrano; planning unit 132 (Appendix 2) covering Plateau d'Ankara also in central west Madagascar, which is the only known site for the plant Ammannia alternifolia; and the neighbouring planning units 268 and 275 (Appendix 2) covering Andringitra which are the two sites where the plant Orthosiphon discolor occurs. Other planning units were considered irreplaceable due to the large number of threatened freshwater species present within them. For example, planning units 82 and 136 (Appendix 2) south-west and south of Antananarivo contain 26 and 21 target species, respectively. One irreplaceable planning unit contains no target species: planning unit 154 (Appendix 2 ), west of Mandritsara in north-eastern Madagascar. This is a small planning unit $\left(21.5 \mathrm{~km}^{2}\right)$ of medium human impact (mean HII of 0.43 ) and is upstream of five planning units of the Mananara River (in north-eastern Madagascar), which also occurs in the optimal network. The small cost of including this planning unit in the network is lower than the connectivity penalty applied if it is not included. It is therefore included in the network on account of its connectivity to other planning units in the network. This planning unit should be managed to facilitate movement of species to the five downstream planning units in the network, and to minimise spread of threats to these sites.

\section{Gaps in the current network}

The planning units included in the optimal site network under scenario $\mathrm{C}$ can be split into types based on their current level of recognition and degree of management, with regards to whether they represent: existing management units (existing KBAs and PAs); new management units (new freshwater KBAs that do not adopt the boundaries of existing management units); or gaps in the current network (planning units outside of the KBA and PA network) (Figure 10.6, Table 10.2).

One hundred and seventy-eight planning units with a combined area of $79,513 \mathrm{~km}^{2}$ are already within the boundaries of pre-existing KBAs and PAs (Figure 10.6, Table 10.2). The presence and importance of any freshwater species known to occur at these sites should now be communicated to the site managers, and management strategies aimed at freshwater biodiversity should be developed and implemented.

Twenty planning units (with an area of $14,177 \mathrm{~km}^{2}$ ) in this network are newly delineated freshwater KBAs that do not adopt the boundaries of existing management units (Figure 10.6, Table 10.2). These are new management units and it is important that management of these sites for freshwater biodiversity is taken up on the ground.

The remaining 100 planning units (with a combined area of $75,500 \mathrm{~km}^{2}$ ) are outside of the KBA (both existing and new freshwater) and PA networks (Figure 10.6, Table 10.2), and these sites represent the most important gaps, with respect to the conservation of threatened freshwater species, in the

Table 10.2 Planning Unit (PU) types in the optimal network of scenario C (network for conservation of threatened freshwater species considering current land use and potential management).

\begin{tabular}{|l|c|c|c|}
\hline PU Type in optimal network for scenario C & Number of PUs & Total area $/ \mathbf{k m}^{2}$ & Percentage of total area of Madagascar \\
\hline Existing management units (existing KBAs and PAs) & 178 & 79,513 & $13.5 \%$ \\
\hline $\begin{array}{l}\text { New management units (new freshwater KBAs that do } \\
\text { not adopt boundaries of existing management units) }\end{array}$ & 20 & 14,177 & $2.4 \%$ \\
\hline $\begin{array}{l}\text { Gaps in the current network (PUs outside of the KBA and } \\
\text { PA network) }\end{array}$ & 100 & 75,500 & $12.8 \%$ \\
\hline Total & $\mathbf{2 9 8}$ & $\mathbf{1 6 9 , 1 9 0}$ & $\mathbf{2 8 . 6 \%}$ \\
\hline
\end{tabular}


Figure 10.4 Optimal network (best run) of scenario $C$ (network for conservation of threatened freshwater species considering current land use and potential management) overlaid on the locked in planning units (PUs) representing all pre-existing management unit types (Freshwater Key Biodiversity Areas (KBAs), existing KBAs and select protected areas (PAs)).

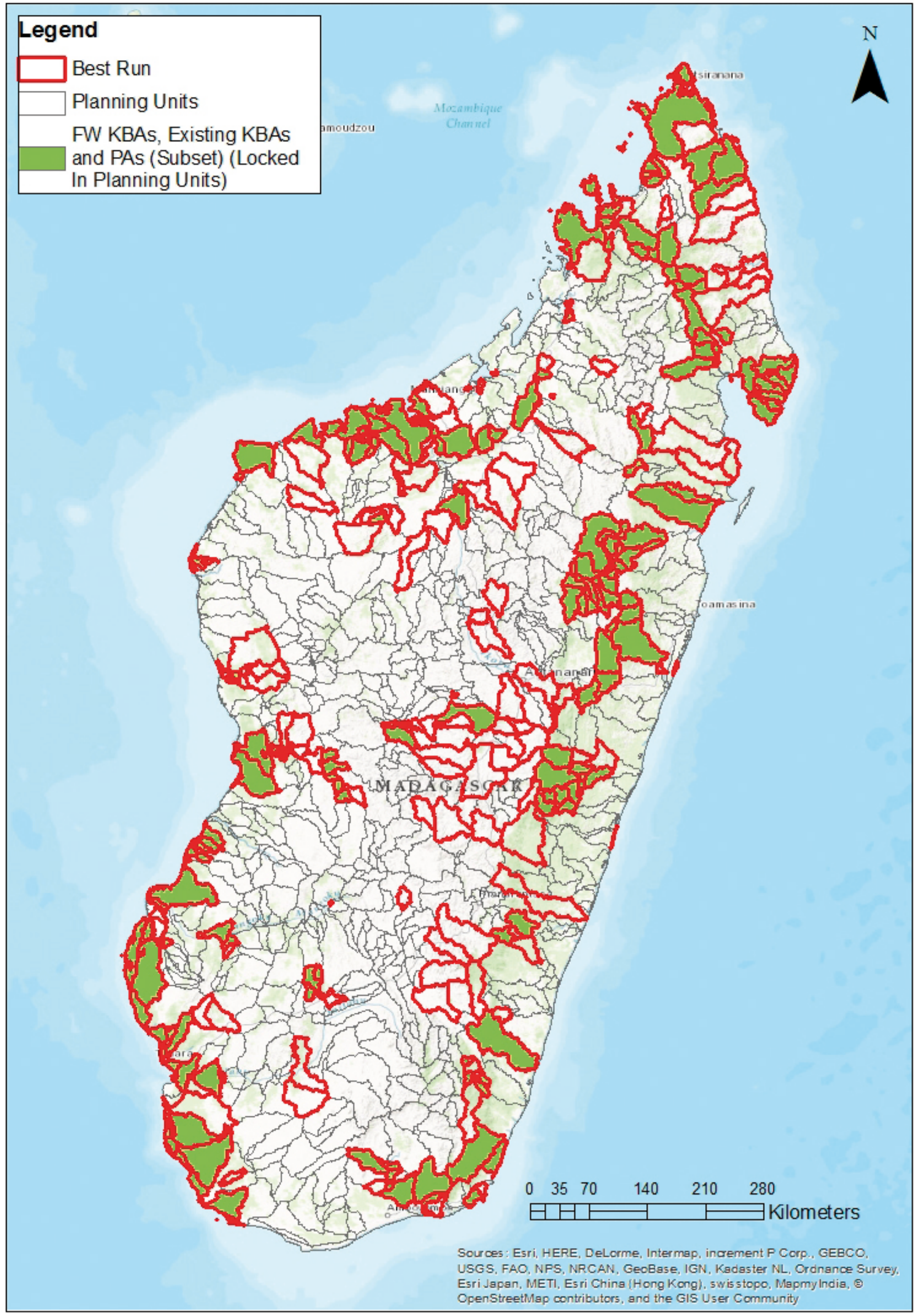


Figure 10.5 Frequency of selection of planning units (PUs) in scenario $C$ (network for conservation of threatened freshwater species considering current land use and potential management) as chosen by Marxan in 1,000 runs. PUs selected in over 990 runs $(99 \%)$ are considered irreplaceable in the network, being required to meet the set targets in most cases. The locked in planning units (PUs) representing all management unit types (Freshwater Key Biodiversity Areas (KBAs), existing KBAs and select protected areas (PAs)) are overlaid.

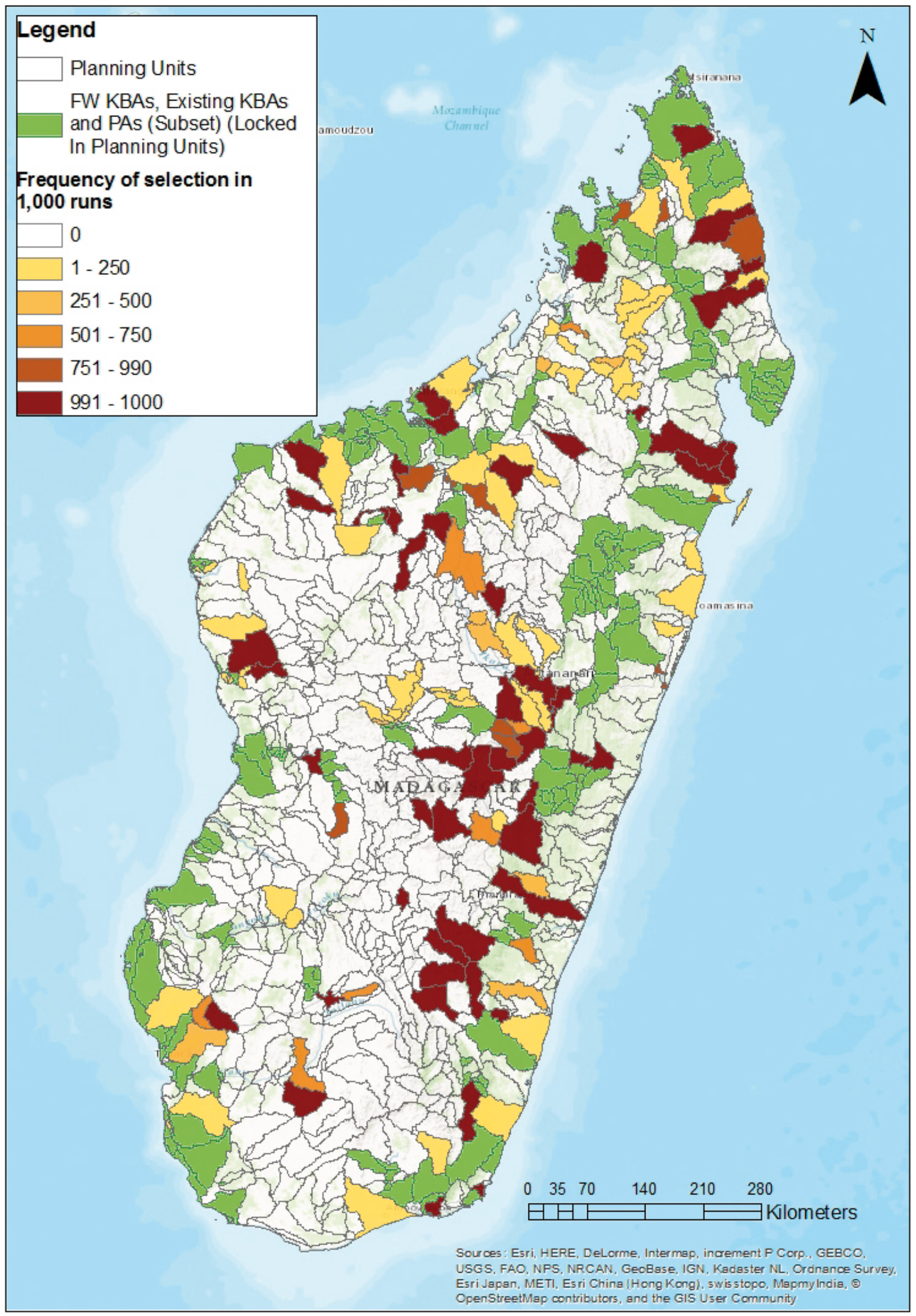


Figure 10.6 Planning unit (PU) types in the optimal network of scenario $C$ (network for conservation of threatened freshwater species considering current land use and potential management). Gaps in the current network are highlighted in red.

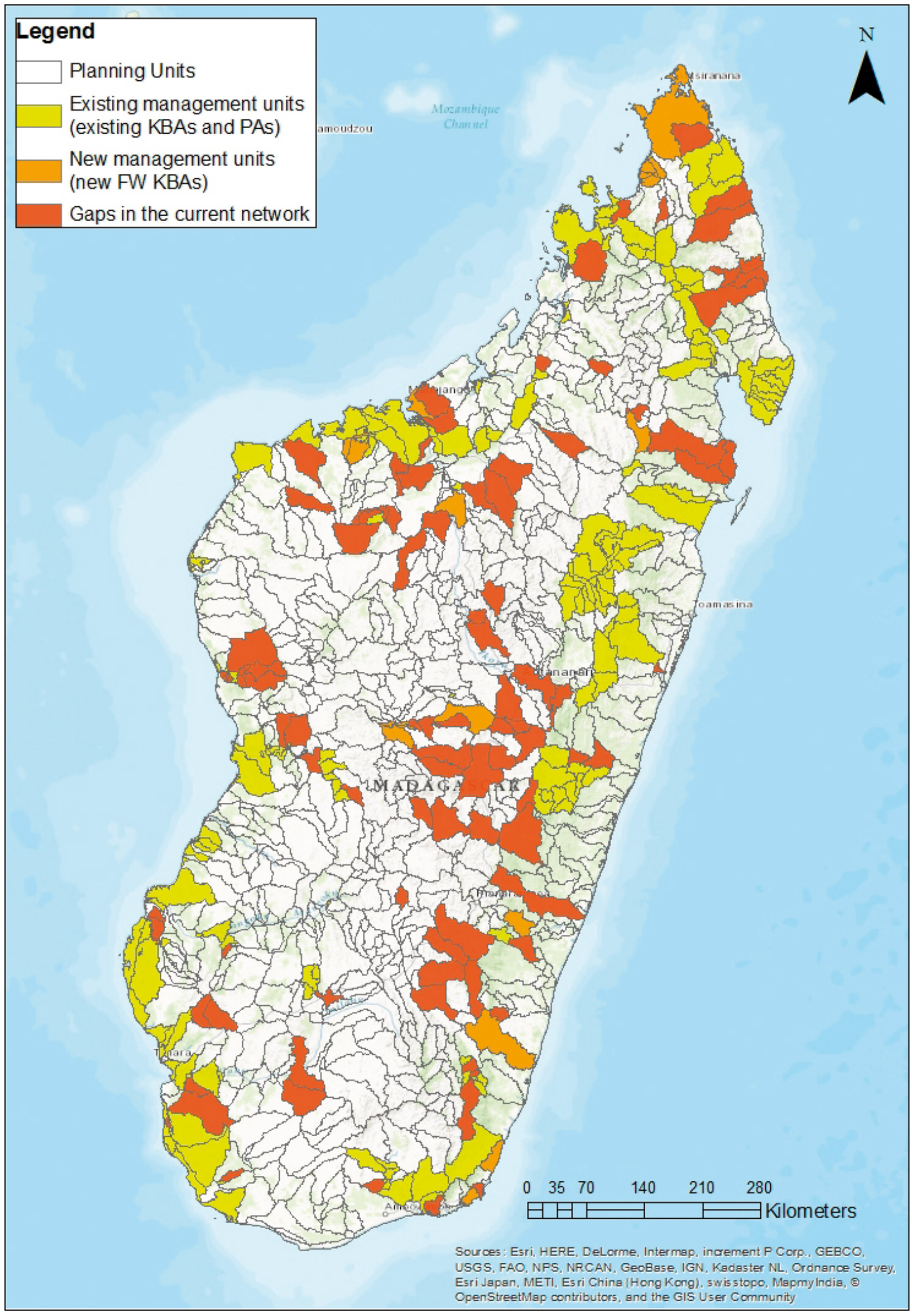


current network of sites. We advise that this network of gap sites is used as a scientific basis for the development and expansion of the existing KBA and PA network in order to ensure that freshwater biodiversity is better represented and protected. The information provided in Appendix 2 should be used by site managers to guide appropriate management action.

Appendix 2 provides details of each planning unit found in the optimal network of scenario $\mathrm{C}$, including the threatened freshwater species present in each planning unit, the area of each planning unit, and the degree of human impact (the mean Human Influence Index (HII) value in the planning unit relative to the maximum mean $\mathrm{HII}$ for a planning unit in Madagascar). It should be noted that the species lists presented are not complete inventories of freshwater species for the sites, and only include target species considered in the Marxan analyses (threatened freshwater species in the focal taxonomic groups of this study, see Chapters 3-8). The area and degree of human impact in the planning unit can be used to guide the type of management actions that are appropriate within that site - planning units with high degrees of human impact would require restorative actions, whereas those with lower degrees of human impact would require protective conservation actions. For recommended conservation actions at the species level, please see the published IUCN Red List assessments available online at www.iucnredlist.org. It should be noted that the boundaries of these planning units are entirely defined by HydroBASINS and may need to be refined following consultation with the relevant stakeholders. As such we only present the planning units with no current recommendations for boundary modifications.

\subsection{Caveats}

In this analysis, species were considered equally abundant across all planning units where indicated to be present, although this is probably an incorrect assumption based on the species-area relationship. This assumption was followed because the IUCN Red List spatial data used to inform whether species were present in planning units only indicate presence and not the abundance at which the species occurs. Population abundance data are lacking for the majority of freshwater species and this is an area requiring further research, not just restricted to Madagascar.

\subsection{Conclusions}

Through this analysis, we identified a network of sites for the conservation of threatened freshwater biodiversity within Madagascar, building on the existing KBA and PA network. We identified 100 sites representing gaps in the current network and provided summaries of the threatened freshwater species present, as well as the area and degree of human impact of the planning units, upon which general site-level management recommendations can be made. We hope this network and these recommendations will be used as a basis for the development and expansion of the existing network to best represent freshwater biodiversity.

\subsection{References}

Ball, I.R., Possingham, H.P. and Watts, M., 2009. Marxan and relatives: Software for spatial conservation prioritisation. In: Moilanen, A., K.A. Wilson, and H.P. Possingham (eds.). Spatial Conservation Prioritisation: Quantitative Methods and Computational Tools. Oxford University Press, Oxford, UK. pp 185-195.

Beger, M., Linke, S., Watts, M., Game, E., Treml, E., Ball, I. and Possingham, H.P. 2010. Incorporating asymmetric connectivity into spatial decision making for conservation: Asymmetric connectivity in conservation planning. Conserv. Lett. 3: 359-368. https://doi.org/10.1111/j.1755263X.2010.00123.x

Dunn, H. 2003. Can Conservation Assessment Criteria Developed for Terrestrial Systems be Applied to Riverine Systems? Aquat. Ecosyst. Health Manag. 6: 81-95. https:// doi.org/10.1080/14634980301478

Game, E.T. and Grantham, H.S., 2008. Marxan User Manual: For Marxan version 1.8.10. University of Queensland, St Lucia, Queensland, Australia, and Pacific Marine Analysis and Research Association, Vancouver, British Columbia, Canada.

Hermoso, V., Linke, S., Prenda, J. and Possingham, H.P. 2011. Addressing longitudinal connectivity in the systematic conservation planning of fresh waters: Connectivity in freshwater conservation planning. Freshw. Biol. 56: 57-70. https://doi.org/10.1111/j.1365-2427.2009.02390.x

Knight, A.T., Smith, R.J., Cowling, R.M., Desmet, P.G., Faith, D.P., Ferrier, S., Gelderblom, C.M., Grantham, H., Lombard, A.T., Maze, K., Nel, J.L., Parrish, J.D., Pence, G.Q.K., Possingham, H.P., Reyers, B., Rouget, M., Roux, D. and Wilson, K.A. 2007. Improving the Key Biodiversity Areas Approach for Effective Conservation Planning. BioScience 57: 256. https://doi.org/10.1641/B570309

Lehner, B. and Grill, G. 2013. Global river hydrography and network routing: baseline data and new approaches to study the world's large river systems. Hydrol. Process. 27: 2171-2186. https://doi.org/10.1002/hyp.9740

Linke, S. and Hermoso, V. 2012. Preliminary results of a freshwater biodiversity Marxan analysis for the Democratic Republic of Congo (Technical Report), Program to Reinforce the Protected Area Network (PARAP). ICCN and WWF. 
Margules, C.R. and Pressey, R.L. 2000. Systematic conservation planning. Nature 405: 243-253. https://doi. org/10.1038/35012251

Margules, C.R., Pressey, R.L. and Williams, P.H. 2002. Representing biodiversity: Data and procedures for identifying priority areas for conservation. J. Biosci. 27: 309-326. https://doi.org/10.1007/BF02704962

Possingham, H., Ball, I. and Andelman, S. 2000. Mathematical Methods for Identifying Representative Reserve Networks, In: Ferson, S., Burgman, M. (eds.). Quantitative Methods for Conservation Biology. Springer New York, New York, NY, pp. 291-306. https://doi.org/10.1007/0-387-22648-6_17

Pressey, R.L. and Nicholls, A.O., 1989. Efficiency in conservation evaluation: Scoring versus iterative approaches. Biol. Conserv. 50: 199-218. https://doi.org/10.1016/00063207(89)90010-4
Pressey, R.L. and Tully, S.L. 1994. The cost of ad hoc reservation: A case study in western New South Wales. Austral Ecol. 19: 375-384. https://doi.org/10.1111/j.1442-9993.1994. tb00503.x

Stewart, R.R. and Possingham, H.P. 2005. Efficiency, costs and trade-offs in marine reserve system design. Environ. Model. Assess. 10: 203-213. https://doi.org/10.1007/ s10666-005-9001-y

Wildlife Conservation Society-WCS, Center For International Earth Science Information Network-CIESIN-Columbia University, 2005. Last of the Wild Project, Version 2, 2005 (LWP-2): Global Human Influence Index (HII) Dataset (Geographic). https://doi.org/10.7927/H4BP00QC 



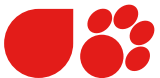 \\ ( $)$ REDT}

THE IUCN RED LIS OF THREATENED SPECIES ${ }^{w}$

IUCN

Rue Mauverney 28

$\mathrm{CH}-1196$ Gland

Switzerland

Tel: + 41229990000

Fax: + 41229990015

www.iucn.org/redlist

www.iucnredlist.org 